
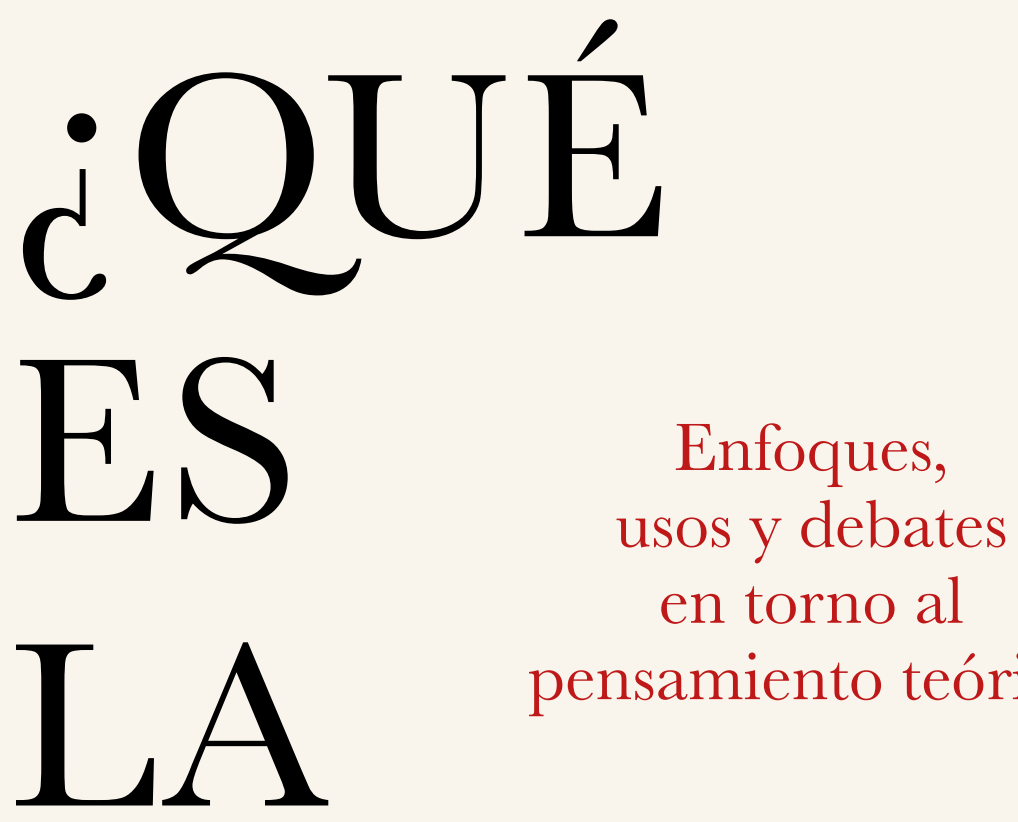

pensamiento teórico

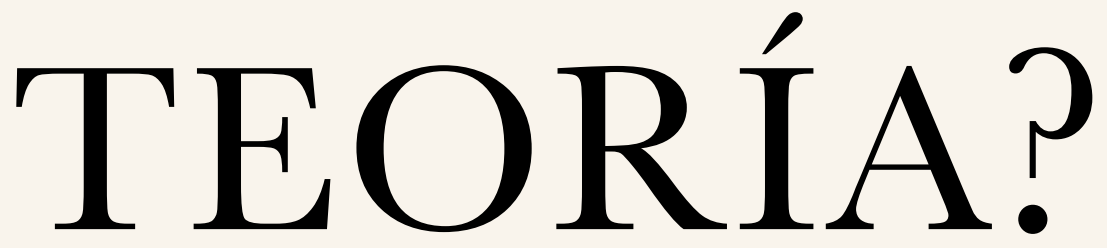

\author{
JOSÉ ENRIQUE JUNCOSA BLASCO \\ LUIS FERNANDO GARCÉS VELÁSQUEZ
}




\title{
¿Qué es la Teoría? Enfoques, usos y debates en torno al pensamiento teórico
}

\author{
José Enrique Juncosa Blasco \\ Luis Fernando Garcés Velásquez
}

\section{SciELO Books / SciELO Livros / SciELO Libros}

JUNCOSA BLASCO, J. E., and GARCÉS VELÁSQUEZ, L. F. In: ¿Qué es la teoría? Enfoques, usos y debates en torno al pensamiento teórico [online]. Quito: Editorial Abya-Yala, 2020, 266 p. ISBN: 978-9978-10-543-6. http://doi.org/10.7476/9789978105788.

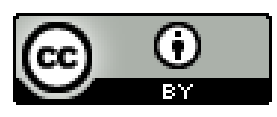

All the contents of this work, except where otherwise noted, is licensed under a Creative Commons Attribution 4.0 International license.

Todo o conteúdo deste trabalho, exceto quando houver ressalva, é publicado sob a licença Creative Commons Atribição 4.0.

Todo el contenido de esta obra, excepto donde se indique lo contrario, está bajo licencia de la licencia Creative Commons Reconocimento 4.0. 


\section{¿QUÉ ES LA TEORÍA?}

Enfoques, usos y debates en torno al pensamiento teórico 

José Enrique Juncosa y Luis Fernando Garcés

\section{¿QUÉ ES LA TEORÍA?}

Enfoques, usos y debates en torno al pensamiento teórico

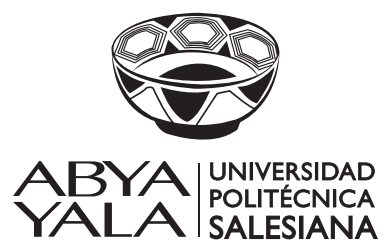

2020 


\section{¿QUÉ ES LA TEORÍA?}

Enfoques, usos y debates en torno al pensamiento teórico

(C) José Enrique Juncosa y Luis Fernando Garcés

1. a edición: Universidad Politécnica Salesiana

Av. Turuhuayco 3-69 y Calle Vieja

Cuenca-Ecuador

Casilla: 2074

P.B.X. $(+593$ 7) 2050000

Fax: (+593 7) 4088958

e-mail: rpublicas@ups.edu.ec

www.ups.edu.ec

CARRERA DE ANTROPOLOGÍA

Grupo de Investigación Estudios de la Cultura

ISBN:

978-9978-10-476-7

Edición, diseño,

Editorial Universitaria Abya-Yala

diagramación

Quito-Ecuador

e impresión

Tiraje:

300 ejemplares

Impreso en Quito-Ecuador, octubre de 2020

Publicación arbitrada de la Universidad Politécnica Salesiana 


\section{Capitulo I \\ LA TEORÍA DESDE EL POSITIVISMO LÓGICO, EL PENSAMIENTO CRÍTICO Y EL PENSAMIENTO COMPLEJO}

Introducción

Conocimiento y metateoría

según el racionalismo crítico de Karl Popper

Compromisos ontológicos, éticos y políticos ................................... 31

La metateoría popperiana ................................................................... 33

Las teorías: objetos y realidades del Mundo 3........................... 34

Las teorías: dispositivos de un mecanismo adaptativo ............ 38

Las teorías: redes e instrumentos para la solución

de problemas. El método deductivo de contrastar..................... $\quad 40$

Comentarios e implicaciones epistémicas, éticas y políticas ......... 47

Aspectos epistémicos .................................................................... 47

La dinámica teórica autorregulada. Ciencia, poder, naturaleza y mercado ............................................................. 52

Teoría y praxis. El pensamiento crítico de la escuela de Frankfurt ..... 58

La teoría crítica de Max Horkheimer.............................................. $\quad 60$

La escuela de Frankfurt de segunda generación. Jürgen Habermas: teoría crítica e intereses del conocimiento......................................... 66

Los intereses del conocimiento................................................... 67

La metateoría habermasiana .................................................... 71

Conocimiento teórico y conocimiento preteorético .................... 72

Teoría analítica y teoría dialéctica............................................. 76

Comentarios e implicaciones ............................................................ 77 
El paradigma del pensamiento complejo de Edgar Morin:

la teoría como sistema abierto de ideas

Compromisos ontológicos, éticos y políticos

del pensamiento complejo

La metateoría del pensamiento complejo

Las teorías: entidades logomorfas de la noosfera

El Reino de las ideas y sus diversos sistemas:

organización interna y tipología

Las polimáquinas de las teorías: el lenguaje y la lógica............ 96

El gobierno oculto de las teorías: los paradigmas...................... 100

La articulación manifiesta entre las teorías:

inter, multi, poli y transdisciplinariedad

Comentarios e implicaciones

Capitulo II

LA TEORÍA DESDE LOS ENFOQUES AXIOMÁTICO,

ESTRUCTURAL Y SEMÁNTICO. DISTINCIONES, ELEMENTOS Y ARTICULACIONES

Introducción

Distinciones básicas: teoría y sentido común. Teoría y ley científica...

Elementos de la teoría según la concepción axiomática

La metateoría estructuralista

La estructura sincrónica de una teoría

Componentes de la parte formal de una teoría:

el núcleo $K=(M p, M, G C, t)$

Componentes de la parte aplicativa de las teorías:

las aplicaciones intencionales

Las aserciones empiricas.

Las redes teóricas

Relaciones diacrónicas de las teorías

Relaciones interteóricas

Los elementos teóricos según las concepciones semánticas.

Teoría y modelo. Distinciones y relaciones

Semántica, ontología y epistemología de los modelos.

Su relación con las teorías. 
La articulación de las teorías según las corrientes historicistas ............ 154

El paradigma o matriz disciplinar de Kuhn ................................. 157

Los programas de investigación de Lakatos....................................... 161

Larry Laudan: la teoría, herramienta para la solución de problemas

empíricos y conceptuales. Las tradiciones de investigación ........... 165

Comentario e implicaciones .................................................................... 173

\section{Capítulo III \\ LA TEORÍA: APROXIMACIONES PEDAGÓGICAS Y SOCIOCULTURALES}

Introducción

Gilbert Ryle: teorizar y teoría como actuaciones discursivas

La práctica eficiente precede a la teoría

En contra del dualismo cartesiano y la leyenda intelectualista...

Teorizar y teoría desde la distinción "saber hacer" y "saber que..."

La teoría y sus formas discursivas

Comentarios y repercusiones pedagógicas

La producción de teorías científicas

y los paisajes mentales de Magoroh Maruyama

Modelos de causalidad y paisajes mentales.

Comentarios finales

206

Kieran Egan y la teoría como instrumento de conocimiento

de la forma de comprensión filosófica

La historia de la cultura y las bases pedagógicas

para el cultivo de la imaginación

Formas de comprensión e instrumentos intelectuales. La teoría:

instrumento de conocimiento de la comprensión filosófica

Implicaciones pedagógicas

\section{Capítulo IV \\ TEORÍAS DE LA EMANCIPACIÓN \\ Y PRÁCTICA TEÓRICA. DEBATES CONTEMPORÁNEOS}

Sobre la necesidad de una teoría emancipatoria 
¿Quién teoriza, sobre qué y para qué?

Lenguaje y teoría

¿Es posible interculturalizar la teoría?....................................................... 238

Teorizar sobre / desde / con los no humanos....................................... 240

El giro decolonial de los estudios culturales

latinoamericanos y la práctica teórica

Del "pensar para conocer" al "pensar para vivir".

La experiencia colonial como certeza colectiva del pensar.

"La teoría nunca será suficiente". Stuart Hall

y la práctica teórica como proyecto político

BIBLIOGRAFÍA ……............................................................... 257 


\section{Introducción}

En la mente de Dios, el pensar y el hacer son una y la misma cosa. Giambattista Vico (1725), Ciencia nueva.

La teoría ha llegado a formar parte del sentido común académico, activándose de muchas maneras en la cátedra universitaria: a la hora de entender o de construir el marco de comprensión de un problema de investigación; cuando reseñamos y describimos teorías; cuando cultivamos la capacidad de redactar marcos teóricos o estados de la cuestión, ofreciendo aproximaciones críticas respecto a ellas. Fluimos a tal punto inmersos en la atmósfera de esas realidades y artefactos abstractos que denominamos nociones, conceptos o teorías, que damos por sentada su realidad sin cuestionarla, sin reparar que se trata de instrumentos envueltos en prácticas sobre las cuales no existe unanimidad.

Tal como nos lo recuerda Ryle (2005, p. 209), el teorizar "es un tipo de trabajo" sujeto a reglas del juego que implica la capacidad de poseer, construir, exponer, explicar, reivindicar, aplicar, cuestionar o entender teorías (pp. 308-309). Pero aun cuando el trabajo teórico nos empeña en tales actuaciones, la mirada se refracta hacia otras direcciones preservando casi intacta la intimidad y estructuras internas de las teorías. De hecho, nos desempeñamos en medio de la teoría sin ser del todo conscientes de sus reglas del juego. La percepción que recorre los claustros consiste en asumir la actividad teórica como una categoría más o menos estable y portadora de consensos que no admiten mayor discusión. Sabemos, en cambio, que las discusiones en torno al ejercicio teórico son cada vez más frecuentes en 
los ámbitos de la epistemología, la filosofía de la ciencia y los estudios culturales, al punto de mostrar debates, multiplicidad de posturas, así como disputas muy profundas. Es así como este libro apunta a cuestionar la teoría como realidad dada y homogénea, problematizar su uso y dar cuenta de algunos de los debates contemporáneos.

En primera instancia, las preguntas generadoras ¿qué es la teoría?, ¿qué es teorizar? se inscriben en el campo de la metateoría (las teorías sobre la teoría y el teorizar) propio de la filosofía de la ciencia, pero admiten abordajes más amplios desde la epistemología y la reflexión sobre los saberes en general. La trayectoria de nuestra indagación se desarrolla por ambos senderos asumiendo la epistemología de tal modo que abraza la consideración de las condiciones de producción y legitimidad de todas las formas de saber, una de las cuales es el conocimiento científico. De la misma manera, plegamos a la postura del diálogo de saberes que supone la multiplicidad de formas de conocer. En consecuencia, no es el carácter científico de la teoría el que nos enrola en la epistemología, sino la actitud de fondo que la sitúa en el escenario compartido con otras formas de conocimiento con las cuales interactúa en un juego de inclusiones y exclusiones marcado por las relaciones de poder o que coloca la práctica teórica en el devenir de las transformaciones sociales. $\mathrm{Al}$ asumir que la teoría es una realidad fluida, discutible y sujeta a constantes redefiniciones, la obra expresa la opción por el movimiento intelectual que se articula en torno al cultivo de la reflexividad, actitud epistémica basada en la necesidad de conocer con mayor claridad la manera en que conocemos lo que conocemos ${ }^{1}$, que implica - por lo menos- el uso consciente de la teoría, acompañado de la problematización de

1 Para el antropólogo Clifford Geertz, como para muchos otros, el conocer la manera cómo conocemos lo que conocemos forma parte de una de las líneas maestras del pensamiento contemporáneo. (Cfr. Geertz 1997, p. 27). 
su carácter de realidad dada, no única, y que convive con otras formas de comprensión.

El texto que ofrecemos refleja aquel sentimiento de necesaria y saludable inseguridad e inestabilidad que los interrogantes pendientes nos provocan aun hoy. En sus páginas conviven modalidades descriptivas que responden al impulso exploratorio de quienes quieren saber qué es una teoría, ofreciendo descripciones, extractos y citas extensas. También incluye formas discursivas de carácter crítico y propositivo, orientadas a la valoración de los aportes y a establecer pautas para el buen pensar con la teoría. El texto definitivo se conforma, por un lado, de apuntes y escritos previos inéditos relacionados con la cátedra y formación docente, debidamente actualizados; por otro, se alimenta de la producción reciente que retoman las preguntas. El resultado propone al lector itinerarios que salen al encuentro de varias corrientes y tradiciones de pensamiento escogidas porque percibieron la teoría de manera problemática y problematizable, a la vez que ofrecen un acercamiento explícito respecto a la teoría y al teorizar. De esa forma, nos hemos propuesto sortear en cuanto sea posible la homologación del pensamiento teórico con el pensamiento científico para descartar las aproximaciones que tratan ambos términos como realidades intercambiables y decidimos prestar atención a los aportes que dan cuenta de la especificidad de la teoría como instrumento del conocimiento y explican sus dinámicas internas, relaciones y articulaciones.

Los resultados de la búsqueda se despliegan en cuatro capítulos. El primero describe la producción metateórica de diversas escuelas que han dejado sentir su influencia a lo largo del siglo XX y en el presente: a) el positivismo lógico de Karl Popper; b) la teoría crítica de la escuela de Frankfurt; c) y el pensamiento complejo de Edgard Morin. De ellos describimos los respectivos compromisos ontológi- 
cos e implicaciones éticas y políticas que orientan de un modo u otro la actividad teórica. La línea conductora del capítulo es cuestionar algunos de los rasgos del positivismo lógico, convertido en el sentido común de la práctica científica normal que asume sin cuestionamiento algunas de sus consecuencias, entre ellas, la autosuficiencia del teórico que - a nombre de la necesaria libertad de la cienciano debe comparecer ante la sociedad por las consecuencias de su saber. En el contexto de una universidad intercultural que opta por la transformación social en un marco de relaciones solidarias con los movimientos sociales, es necesario cuestionar cualquier enfoque que considere los rasgos subjetivos, compromisos ético-políticos y opciones existenciales como lastres de los cuales deshacerse.

El segundo capítulo, el más lejano a nuestra zona de confort, sistematiza los alcances de la filosofía de la ciencia y desarrolla la dimensión simbólica, instrumental y operativa de la teoría, al mismo tiempo que describe las relaciones diacrónicas y sincrónicas de los elementos proposicionales que la constituyen. Además de establecer distinciones entre teoría, ley científica y sentido común, profundizamos las implicaciones del carácter modélico de la teoría, es decir, en tanto sustitución simbólica simplificada (y altamente formalizada) de la realidad, a fin de comprenderla y actuar en ella. Pensamos que el carácter modélico de la teoría es uno de los aspectos más relevante para las ciencias de la vida y las tecnologías. El capítulo concluye con las visiones historicistas en torno al cambio científico y el rol de la teoría tal como lo conciben Imre Lakatos, Thomas Kuhn y Larry Laudan, este último especialmente relevante por su epistemología del problema científico en un contexto universitario de alta valoración del enfoque de solución de problemas aplicado a la gestión y al desarrollo.

El tercer capítulo despliega una serie de aproximaciones no fáciles de articular en un recorrido secuencial. La primera de ellas re- 
15

toma el aporte del antropólogo Magoroh Maruyama, quien explica la diversidad constitutiva del pensamiento teórico en la academia e instituciones que producen conocimiento como producto de la lógica profunda de una serie de paisajes mentales que predefinen la teoría en direcciones y estilos diferentes. Los otros dos autores, en cambio, son portadores de una potencialidad pedagógica muy consistente y relevante. El primero es Gilbert Ryle, para quien la teoría y el teorizar son capacidades sujetas al aprendizaje por ser formas públicas de actuación constituidas por reglas del juego y formas discursivas específicas. Su principio de oro consiste en que "la práctica eficiente precede la teoría”. Por ello, la capacidad de teorizar se aprende en el hacer, en un "hacer" público y manifiesto, destruyendo, así, el mito de que primero comprendemos y luego actuamos (primero la teoría y luego la práctica). El tercer aporte es el del pedagogo Kieran Egan, quien propone un programa de cultivo de la imaginación y desarrollo del pensamiento basado en múltiples formas de comprensión por las que ha pasado la cultura occidental. La teoría es apenas el instrumento de conocimiento de una de las formas de comprensión posibles: el pensamiento teórico, del cual describe su horizonte histórico, formas discursivas y concepción de la realidad.

El cuarto capítulo discute las posibilidades de teorizar desde las teorías de la emancipación y la práctica teórica. Para ello se parte de la pregunta sobre la necesidad contemporánea de existencia de una teoría de la emancipación para concluir que el cambio de paradigma interpretativo, basado en el valor de la diversidad y la crítica a los metarrelatos, desde los debates posmodernos y poscoloniales, parecería afirmar la necesidad de tal teorización. Ubicada en las posibilidades de un proyecto transmoderno (más allá de los límites de la modernidad), antes que antimoderno, en el complejo mundo poscolonial que habitamos, las teorías de la emancipación nos invitan a posicionarnos en los espacios entremedios, a fin de cambiar no solo 
los temas de discusión sino los términos mismos del discurso. Para ello será necesario no solo mirar reflexivamente quién es el sujeto de enunciación y cuál es su lugar social, político y cultural, sino en qué lenguaje se produce el discurso de emancipación. El capítulo se pregunta no solo por las posibilidades de interculturalización o transculturalización de la teoría, sino también por las posibilidades de teorizar desde-con los no humanos, tal como varios teóricos contemporáneos discuten al debatir críticamente la separación clásica entre naturaleza y cultura que instauró la modernidad. Finalmente, el capítulo cierra con un diálogo crítico entre posturas y autores revisados a lo largo de la obra con el proyecto del giro decolonial de los estudios culturales latinoamericanos, especialmente, con las implicaciones de aquello que Stuart Hall concibe como práctica teórica enmarcada en un proyecto político.

Si bien en esta obra exploramos preponderantemente las múltiples y diversas acepciones de la teoría y sus usos en los escenarios de la ciencia, sabemos que la teoría tiene vida más allá de ella. No se trata tan solo de una constatación, sino de la expresión de la expectativa deseable, según la cual el pensamiento teórico no debe quedar aprisionado como un factor de las ecuaciones que componen el método científico. Sabemos que por su misma composición etimológica la teoría desborda la ciencia y su raíz remite a la dramaturgia griega, donde teoría deviene de una voz compuesta por los términos theos ('espectador de teatro') y oreo ('mirar')2. Así, theoros es el espectador de teatro; theoria, el espectáculo observado; y theorein, la acción de observar el espectáculo teatral. Lo interesante de este rastro etimológico consiste en que también el observador, el theoros, formaba par-

2 Ver la voz 'teoría' en José Ferrater Mora (2009), tomo IV. 
te de un montaje mayor, el de una obra teatral, y su observación lo implicaba activamente en la escena, cuestionando la connotación actual que suele tener el "teorizar" como aquella forma de observar sin ser ni tomar parte en lo que ocurre. De este primer núcleo semántico se derivó luego al verbo griego theorein: 'pensar'; y el término theoria: 'lo pensado', lo producido por el pensamiento, definido desde la mirada y desde una forma de mirar (o conocer) particular y privilegiada sin conexión alguna con la dramaturgia.

El filósofo alemán Hans-Georg Gadamer (1900-2002), en su conocido artículo "Elogio de la teoría" (1983, pp. 23-42), nos recuerda, además de la connotación semántica señalada, que el pensamiento teórico no se agota en los usos que la práctica científica le atribuye, y traza un recuento histórico para identificar diversas maneras de articular la teoría y la praxis más allá de los límites del conocimiento científico. Su revisión arranca con Platón para quien el sophon era el tipo de sabiduría o pensamiento verdadero requerido para organizar la vida pública a partir de principios generales que trascienden los intereses particulares, superan las presiones del lenguaje beligerante de los sofistas y miran más allá de la inmediatez política y económica. Para Platón ${ }^{3}$ la teoría alimentó dos prácticas

3 Según Cornford (2007, pp. 22 ss. y 335 ss.) la epistemología de Platón se condensa en el mito de la caverna de tal modo que el mundo de las formas, el lugar de las teorías, es la verdadera realidad pues precede la experiencia y la percepción. Las formas (las ideas) son la esencia de la realidad sensible. De carácter estable e inmutable, las ideas son más reales que las cosas y no tienen una mera existencia mental: poseen una existencia exterior a la mente y, como entidades inteligibles, constituyen los verdaderos objetos de conocimiento. Aunque las ideas yacen en el olvido, debido al destierro de las almas en la realidad sensible, la acción de conocer consiste en una estrategia cognitiva basada en su recuerdo y actualización (ananmesis) pues el alma ha visto y experimentado ya las esencias. En este contexto debemos entender la acción de teorizar como la comprensión de la realidad a la luz de las esencias inmutables que le da forma y sentido. 
sociales distintas: un tipo de educación —educación teórica- dirigida a niños y jóvenes para familiarizarlos con los conceptos antes de emprender su vida activa como ciudadanos; y luego, el cultivo del "ideal de vida teórico" de quien, una vez liberado de las ataduras de la praxis, podía ahondar en la búsqueda y el recuerdo de los principios que la norman. A pesar de la separación metodológica entre teoría y praxis, el vínculo entre ambas es innegable pues la teoría pretendía alumbrar las deliberaciones de la ciudad griega a costa y condición de la "ineptitud práctica” del teórico (p. 26), a fin de mirar más lejos y con mejor perspectiva, vale decir, desde los principios.

Para Aristóteles la teoría pura llegó a ser el ideal de felicidad y responde a la necesidad de saber ${ }^{4}$. El conocimiento teórico es un saber, entre otros, que ilumina la vida práctica al interrogarse por el bien desde el horizonte de la ética y la política. Como nos recuerda Gadamer, para Aristóteles "el hombre en el sentido más profundo es una 'esencia teórica"” (p. 28). A la recapitulación de Gadamer nos permitimos añadir que, para Aristóteles, la theoria es un género superior de conocimiento (episteme) propio del conocimiento verdadero (la sabiduría); no es accesible a todos ni connatural a otras formas de conocer de me-

4 Para Aristóteles la theoria es una entidad mental producida por una actividad humana: el teorizar (theorein). A diferencia de la concepción platónica, la teoría es un concepto abstracto, resultado final de la percepción, real solo en tanto imagen mental, pero traído desde la realidad sensible, no anterior a ella como hubiera querido Platón. Los conceptos — y la teoría es una articulación de conceptosno se identifican con la esencia de las cosas ni constituyen una suprarrealidad separada y fundante; más bien las expresan abstractamente como resultado de la reelaboración sucesiva de la experiencia sensible. Además, Aristóteles vincula la teoría con un lenguaje peculiar pues esta se expresa verbalmente en forma de juicios, formas proposicionales que expresan los conceptos en categorías que permiten afirman algo sobre algo y que se articulan según leyes propias de un órganon o sistema lógico. Ver la explicación de la filosofía aristotélica en Hirschberger (1964), pp. 47-70. 
nor alcance, como la opinión o el sentido común (doxa). Teorizar se diferencia de otras acciones del conocimiento que tienen finalidades diversas, como la techné, orientada hacia la obtención de los medios adecuados para obtener un fin y cuyo producto es el conocimiento técnico; y la praxis, que persigue la realización de lo moral o políticamente deseable, y cuyo producto es el conocimiento práctico.

Tanto Aristóteles como Platón coinciden, entonces, en proponer la teoría como manera de pensar que no solo exige reglas diferentes respecto a otras formas de conocimiento, sino que promete un tipo de conocimiento mejor y más profundo de la realidad y de los principios que rigen la acción humana. En relación con la praxis, debemos recordar que la actividad teórica se afirmó en Grecia en el contexto del surgimiento y consolidación de la democracia urbana de Atenas, cuyas exigencias requerían del lenguaje apropiado para expresar abstractamente objetivos e ideales que debían ser comunes y unánimes (el bien, la verdad y la belleza), entendidos y aplicables a todos. La teoría hizo posible ese salto epistemológico que implicó pasar de una sociedad articulada desde los intereses de familias ampliadas (configurada según el ideal heroico) a la democracia ciudadana de la República, como nos recuerda MacIntyre (2001, p. 167). Al parecer, sin la teoría — sin el lenguaje adecuado para expresar ideales comunes_-, la democracia griega no hubiera sido posible, al menos de esa manera.

Con el advenimiento del cristianismo —continúa Gadamer- el ideal teórico se resignifica en contemplación y especulación (verse en el "espejo" de la divinidad), que implica rescatar el deseo de saber de la curiosidad, actitud epistémica propia de los gnósticos atada a las cosas, a lo contingente y variable. En la Edad Media, la vida monacal — si bien cultivó saberes organizativos y productivos potentes - circunscribió la teoría al cuidado de la letra (la transcrip- 
ción fue su principal oficio) y al servicio de la contemplación devota de la divinidad.

Hasta aquí, el trayecto reafirma que la teoría se despliega en ámbitos más allá del método científico pero la práctica teórica sufre un cambio de rumbo drástico en el siglo XVII, a partir de Galileo, quien fractura para siempre la imagen geocéntrica y teocéntrica del universo. Desde entonces, y con los aportes de Newton, deviene la "matematización del conocimiento" que provee un método desde el cual indagar y comprender las leyes mecánicas de la naturaleza y el cosmos. Ocurre, ahora sí, una transformación que nos es familiar y, como afirma Gadamer, transforma no solo el sentimiento del mundo, sino también el "ideal de vida teórica; la ciencia se convierte en investigación" (p. 30). El "ideal teórico" supone el abandono de toda doctrina y está condicionado por la práctica metódica, vale decir, por la lógica de la investigación. La opción por el camino de investigación metódica, en tanto marco de "autoaseguramiento de la razón", produce dos consecuencias: la emergencia de la figura del investigador, quien contribuye con otros a enriquecer los resultados de las investigaciones en un ciclo de constante y acumulativa renovación; y la conversión de la ciencia en una empresa colectiva dirigida a conocer lo desconocido.

Desde entonces, la praxis de la teoría se circunscribe a la praxis metodológica de la ciencia a pesar de esfuerzos posteriores para rescatarla de ese encierro, ya sea estableciendo la superioridad de la teoría sobre la praxis, ya buscando rearticular la teoría y la ciencia a la filosofía. El intento más grandioso ha sido el del romanticismo idealista de Hegel para quien la teoría es sinónimo de conciencia filosófica y autoconciencia del propio saber de Occidente. Pero las urgencias de la industrialización y de los saberes económicos y productivos emergentes replegarán nuevamente la teoría en el método, 
impulsando formas de investigación orientadas a fines pragmáticos y específicos de tal forma que la teoría definirá, incluso, las zonas de "lo investigable metódicamente" frente a las cuales se constituirán otras zonas de saberes difusos (p. 33). La recapitulación de Gadamer concluye con la siguiente propuesta: el conocimiento se despliega en zonas irreductibles al tipo de praxis teoría/metodología, y una de esas zonas es la de la intersubjetividad, donde la certeza proviene no del método, sino de la inmediatez del cuerpo y de la autoconciencia que revelan puntos de apertura (confianza) respecto a otras subjetividades. Estas presencias que se imponen no pueden ser reducidas a objetos y constituyen la raíz de un tipo de ejercicio teórico distinto que observa desde la inmediatez, "estando ahî" (pp. 37-39).

Otro filósofo, el lituano Emmanuel Levinas (1906-1995), en su obra La teoría fenomenológica de la intuición (2004), proporciona un marco hermenéutico paralelo al de Gadamer, apoyándose en un punto de vista ontológico desde el cual redimensionar los alcances de la conciencia teórica: el ser posee múltiples regiones y demanda múltiples formas de ser conocidas que la teoría no puede abarcar. En efecto, la teoría se despliega de acuerdo a las características de una sola de esas regiones: la que suponen las ciencias naturales cuya lógica explicativa acapara e impregna toda la ciencia; así, sus procedimientos se generalizan sin más para el conocimiento de otras regiones del ser. Por lo tanto, en el decir del "conocimiento científico" lo que en realidad tiene lugar es el conocimiento propio de la región del ser de las ciencias naturales. Al igual que Gadamer, Levinas establece que el saber es inacabado e incompleto. La epistemología no lo es todo, pues el ser se muestra en lo vivido y posee modalidades de existencia que la teoría — tan solo una forma de conciencia entre otras - no puede captar (pp. 73 ss.). Si Gadamer reivindica la expansión de la teoría más allá de los muros de la praxis metodológica de la ciencia, Levinas aboga, en cambio, por su 
redimensión en el marco del reconocimiento de otras formas de conciencia y de conocimiento propias de la multiplicidad del ser y de lo vivido.

Como veremos en el capítulo IV, a las razones invocadas por Gadamer (la relación de la teoría con la praxis social) y a las planteadas por Levinas (la fenomenología del ser), añadimos otra de carácter existencial: la opción de aquellos colectivos que demandan existencias diferenciadas de las cuales emergen saberes y pedagogías que agencian, a su modo, el pensamiento teórico. De una u otra manera, el pensamiento teórico está atravesado por constantes búsquedas, por la conciencia reiterada de sus límites, por tensiones y disputas que esta obra no busca resolver ni acallar, pero no deja de registrarlas para establecer posicionamientos. Debemos reconocer que la praxis metodológica de la teoría se ha vuelto hegemónica y es una herramienta que determina y moldea, a nivel global, la vida de sociedades enteras, sustituyendo conocimientos diversos y sus respectivos sistemas de toma de decisiones. Por ello, se requiere una aproximación más amplia y matizada desde la cual responder a esta pretensión asumida de plano por el conocimiento de los expertos cuya voz, muchas veces o casi siempre, acalla la de la gente desde la fuerza de la teoría.

Este libro se presta para desarrollar cursos alternativos de epistemología, cuyo auditorio imaginado está conformado por docentes y estudiantes empeñados en la elaboración de investigaciones y que requieren comprender mejor el lugar, alcance e implicaciones de la teoría en el proceso investigativo. Nuestras reflexiones serán de utilidad también para docentes-investigadores, pues la reflexión en torno a la teoría y su ejercicio detonará derivaciones e implicaciones 
pedagógicas inevitables respecto a cómo los docentes ponemos en escena el acumulado teórico de las disciplinas y a la manera en que los acompañamos en la construcción de objetos de conocimiento y problemas de investigación.

No quisimos elaborar un manual, tampoco ofrecer recetas. Procuramos alimentar la imaginación con recursos conceptuales que contribuyan a superar algunas formas de automatismo o usos que distorsionan o minimizan el alcance de las teorías, frecuentes en el aprendizaje y ejercicio de la investigación, tales como pretender explicar una vasta y compleja red de fenómenos con tan solo muy pocas de ellas; perder de vista que la teoría no sustituye la realidad sino que es parte de un lenguaje que pretende explicarla para ubicarse en ella; y la escasa integración de las teorías en el proceso de investigación, reduciéndolas muchas veces a un simple glosario de conceptos clave o categorías explicativas. Hemos procurado abrir la investigación más allá de nuestros confines disciplinares de tal modo que los hallazgos resulten relevantes para la cátedra universitaria en general y sean de interés para investigadores de todas las áreas del conocimiento. Por ello, la investigación se alimenta de los debates y conversaciones con colegas de las ciencias administrativas, de las ciencias de la vida, de las ciencias técnicas, de las ciencias sociales, humanas y pedagógicas y aspiramos que resulten relevantes para sus usos teóricos. De la misma manera, impulsó nuestra búsqueda la relación con tantos actores del desarrollo y académicos de diversos movimientos sociales para los cuales la práctica teórica es vital para sus militancias, y reconocen la teoría como un recurso para disputar marcos de comprensión de la realidad.

Deseamos que las páginas que siguen contribuyan a que los actores reconozcan sus prácticas teóricas y sean capaces de nombrarlas y situarlas en medio de otras posibles, vinculando de mejor ma- 


\section{4}

nera las opciones existenciales, aquello por lo cual pensamos y conocemos - los vivires en colectivo-, con las opciones epistémicas que de verdad las hagan posible.

José Enrique Juncosa Blasco Luis Fernando Garcés V. 


\section{Capítulo I \\ LA TEORÍA DESDE EL POSITIVISMO LÓGICO, EL PENSAMIENTO CRÍTICO Y EL PENSAMIENTO COMPLEJO 5}

\section{Introducción}

Los autores escogidos en este capítulo son representantes y fundadores de tendencias y enfoques que comparten el escenario histórico de la Europa del siglo XX, atravesada por la crisis cultural y del pensamiento propiciada no solo por los horrores de las dos guerras mundiales y la violencia desplegada por los regímenes totalitarios, sino también por los efectos deshumanizantes de la industrialización y el consumo. Estos enfoques, además de coincidir en su intencionalidad crítica, asumen en común dos agendas básicas: la primera de las cuales apunta a desmontar el programa epistémico del positivismo y sus rasgos esenciales: el empirismo (conocemos a partir de los hechos) y la pretensión de un conocimiento objetivo (lo que conocemos a partir de los hechos es totalmente verdadero e inobjetable). El segundo punto de la agenda convergente es la denuncia frontal de los diversos totali-

5 Este capítulo retoma, amplía y profundiza el apartado "Los paradigmas lógicos, críticos y eco-antropológico", del marco teórico de Juncosa, José Enrique. (2006). Teorías del conocimiento en experiencias universitarias con movimientos sociales. Un aporte para la carrera de Antropología Aplicada de la Universidad Politécnica Salesiana. (Tesis de maestría inédita en Desarrollo de la Inteligencia y Educación). Universidad Técnica Particular de Loja, Pontificia Universidad Católica del Ecuador, Ibarra, pp. 31-60. 


\section{6}

tarismos a los que sus autores clave se enfrentaron - el nazismo y el estalinismo, principalmente- mediante un discurso epistemológico que deslegitima cualquier forma o estructura cerrada de pensamiento como la ideología, el dogma o el lenguaje religioso.

El punto de partida de los autores convocados consiste en proponer los compromisos metafísicos, éticos o políticos para luego definir el marco epistemológico a partir del cual, finalmente, establecer las pautas del ejercicio teórico. Tal coincidencia en el itinerario metodológico no quita que los respectivos supuestos y concepciones resulten no solo diversos sino, inclusive, opuestos y polémicos entre sí. Estos autores, escogidos por su potencial y orientación crítica, por la visibilidad de sus huellas en el pensamiento contemporáneo latinoamericano y por su importancia para diversos proyectos políticos actualmente vigentes, son los siguientes:

a. Karl Popper (Viena, 1902-1994) fue el fundador del racionalismo crítico. Aunque algunos lo definen como positivista lógico, debido a la importancia de la empiría a la hora de falsar una teoría, Popper define el conocimiento y las teorías en el contexto del pensamiento deductivo orientado a la solución de problemas teóricos y prácticos. Popper representa muy bien la tendencia contemporánea dominante de la ciencia: el enfoque hipotético-deductivo. El fundamento epistemológico del ejercicio teórico es la negación de cualquier tipo de determinación del pensamiento (histórica, social, política o identitaria) y el correlato sociológico resultante es una sociedad abierta según las expectativas de la concepción liberal, sin dogmas ni sistemas cerrados de pensamiento y, por lo tanto, sin apuestas políticas utópicas o reduccionistas ni sujetas a la hegemonía de sujetos sociales determinados. El escenario de operación y control de la teoría es la lógica de la falsación. 
b. La escuela de Frankfurt, mediante dos de sus representantes: Max Horkheimer (Stuttgart, 1895-1973) y Jürgen Habermas (Düsseldorf, 1929), proporciona una lectura de la teoría a la luz del pensamiento crítico y dialéctico. Basados en la herencia dialéctica marxista, a la que también superan y resignifican, proponen una herramienta de análisis crítico del conocimiento, de la ciencia, de las artes y de las prácticas productivas según su capacidad de transformar las estructuras y el potencial de humanización que comportan. El paradigma crítico está presente en gran parte del ejercicio actual de las ciencias sociales y de la reflexión de los movimientos sociales. En este caso la sociología es el escenario de operación y control del conocimiento y la teoría.

c. Edgar Morin (París, 1921) es el promotor del paradigma del pensamiento complejo. Sobre la base del modelo ecoantropológico, Morin imagina la teoría como un organismo vivo capaz de autoorganización y retroalimentación con su entorno y con otras formas de conocimiento. El pensamiento teórico es un sistema abierto de ideas atravesado por la incertidumbre, que no mutila la totalidad y relaciona dinámicamente los términos excluidos. El escenario de control es el sentido, concebido como un metapunto de vista (ubicado más allá de la teoría) que trasciende la lógica y el lenguaje. Este paradigma es muy vigente y alimenta no pocas apuestas pedagógicas de diversos movimientos sociales e iniciativas de desarrollo que valoran la propuesta de inter y transdisciplinariedad aparejada a la epistemología de Morin.

El presente capítulo sistematiza la lectura y análisis de las obras más relevantes de los autores señalados desde el eje temático de la "teoría” y según las siguientes variables: base paradigmática (compromisos ontológicos y principios fundamentales), rasgos del conocimiento derivados, metateoría, procesos teóricos fundamentales, perfil del teórico, escenario de acción de la teoría y, por último, escenarios de control 
de la teoría. Finalmente, concluimos con la propuesta de algunas y muy breves implicaciones para la investigación. La Tabla 1 proporciona una visión comparativa de las características distintivas de cada uno de los enfoques que serán descritos a continuación.

\author{
Tabla 1 \\ La teoría según el positivismo lógico, \\ el pensamiento crítico-dialéctico y el pensamiento complejo
}

\begin{tabular}{|c|c|c|c|}
\hline \multirow{3}{*}{$\begin{array}{l}\text { Variables } \\
\text { de análisis }\end{array}$} & \multicolumn{3}{|c|}{ ENFOQUES METATEÓRICOS BÁSICOS } \\
\hline & Positivismo lógico & $\begin{array}{c}\text { Pensamiento } \\
\text { crítico-dialéctico }\end{array}$ & Pensamiento complejo \\
\hline & $\begin{array}{l}\text { Karl Popper } \\
(1902-1994)\end{array}$ & $\begin{array}{c}\text { Max Horkheimer } \\
(1895-1973) \\
\text { Jürgen Habermas (1926) }\end{array}$ & Edgar Morin (1921) \\
\hline $\begin{array}{l}\text { Compromisos } \\
\text { ontológicos } \\
\text { o base } \\
\text { paradigmática }\end{array}$ & $\begin{array}{l}\text { Carácter abierto del } \\
\text { tiempo. Historia sin } \\
\text { finalidad y sin utopías. } \\
\text { La realidad es indeter- } \\
\text { minada y cognoscible. }\end{array}$ & $\begin{array}{l}\text { La realidad no es dada } \\
\text { sino construida por las } \\
\text { relaciones. } \\
\text { La historia tiene un fin: } \\
\text { la humanización o la } \\
\text { emancipación. }\end{array}$ & $\begin{array}{l}\text { Carácter complejo de la } \\
\text { vida: autoorganización, } \\
\text { retroalimentación y } \\
\text { retroacción. } \\
\text { El sentido no está en la } \\
\text { historia. Es añadido por } \\
\text { los humanos. }\end{array}$ \\
\hline $\begin{array}{l}\text { Rasgos del } \\
\text { conocimiento }\end{array}$ & $\begin{array}{l}\text { El conocimiento funcio- } \\
\text { na como el tiempo y la } \\
\text { historia: es abierto y sin } \\
\text { determinaciones. } \\
\text { Conocimiento sin } \\
\text { subjetividad. } \\
\text { Pensamiento para la } \\
\text { solución de problemas: } \\
\text { mejora la estructura. } \\
\text { Pensar es conjeturar. } \\
\text { Pensamiento abierto. }\end{array}$ & $\begin{array}{l}\text { El conocimiento funciona } \\
\text { como la sociedad. Es pro- } \\
\text { ducto de la praxis social; } \\
\text { expresa sus relaciones. } \\
\text { Monitorea la marcha de } \\
\text { la historia: compara el ser } \\
\text { con el deber ser. } \\
\text { Pensamiento dialéctico } \\
\text { que trasciende la solución } \\
\text { de problemas y el funcio- } \\
\text { namiento de la estructura. } \\
\text { Pensar es cuestionar lo dado. } \\
\text { Pensamiento crítico. }\end{array}$ & $\begin{array}{l}\text { El conocimiento fun- } \\
\text { ciona como los seres } \\
\text { vivos (isomorfismo } \\
\text { vida-pensamiento). } \\
\text { El conocimiento relaciona } \\
\text { las cosas más allá de la } \\
\text { lógica de oposición. }\end{array}$ \\
\hline $\begin{array}{l}\text { Concepción } \\
\text { metateórica }\end{array}$ & $\begin{array}{l}\text { La teoría es un mecanis- } \\
\text { mo adaptativo diverso al } \\
\text { genético y conductual. } \\
\text { Mecanismo abierto y } \\
\text { acumulativo de solución } \\
\text { de problemas. } \\
\text { Rasgos esenciales: falsa- } \\
\text { ble y refutable. }\end{array}$ & $\begin{array}{l}\text { Teoría como praxis social. } \\
\text { Teoría crítica: devela } \\
\text { la enajenación del pre- } \\
\text { sente. Al servicio de la } \\
\text { emancipación. } \\
\text { Versus teoría tradicional } \\
\text { que considera la realidad } \\
\text { como dada. }\end{array}$ & $\begin{array}{l}\text { La teoría es como un } \\
\text { organismo vivo, pero de la } \\
\text { noosfera. } \\
\text { Forma de idea abierta: } \\
\text { versus dogma e ideología. } \\
\text { Compleja: interrelaciona } \\
\text { lo diverso. }\end{array}$ \\
\hline
\end{tabular}




\begin{tabular}{|c|c|c|c|}
\hline \multirow{3}{*}{$\begin{array}{l}\text { Variables } \\
\text { de análisis }\end{array}$} & \multicolumn{3}{|c|}{ ENFOQUES METATEÓRICOS BÁSICOS } \\
\hline & Positivismo lógico & $\begin{array}{l}\text { Pensamiento } \\
\text { crítico-dialéctico }\end{array}$ & Pensamiento complejo \\
\hline & $\begin{array}{l}\text { Karl Popper } \\
(1902-1994)\end{array}$ & $\begin{array}{c}\text { Max Horkheimer } \\
(1895-1973) \\
\text { Jürgen Habermas (1926) }\end{array}$ & Edgar Morin (1921) \\
\hline Procesos teóricos & $\begin{array}{l}\text { Planteamiento del } \\
\text { problema, conjetura } \\
\text { (teoría), falsación y } \\
\text { refutación. }\end{array}$ & $\begin{array}{l}\text { Identificar el contexto so- } \\
\text { cial e histórico de la teoría. } \\
\text { Identificar la praxis social } \\
\text { subyacente. }\end{array}$ & $\begin{array}{l}\text { Núcleo y cinturón } \\
\text { protector. } \\
\text { Interdisciplinariedad, } \\
\text { transdisciplinariedad, } \\
\text { paradigmas. }\end{array}$ \\
\hline Perfil del teórico & $\begin{array}{l}\text { Apóstol de la sociedad } \\
\text { abierta. Combate dog- } \\
\text { mas y sistemas cerrados } \\
\text { de pensamiento. Solu- } \\
\text { ciona problemas prácti- } \\
\text { cos y aplicados. }\end{array}$ & $\begin{array}{l}\text { Vigilante anticipador de la } \\
\text { marcha de los movimien- } \\
\text { tos sociales hacia la eman- } \\
\text { cipación. Cuestionador } \\
\text { de sistemas de acción y } \\
\text { pensamiento deshumani- } \\
\text { zantes y hegemónicos. }\end{array}$ & $\begin{array}{l}\text { Articulador de las vertien- } \\
\text { tes humanista y técnica del } \\
\text { conocimiento. Identifica- } \\
\text { dor de paradigmas y for- } \\
\text { mas de pensar antes que de } \\
\text { contenidos. Relacionador } \\
\text { del conocimiento teórico } \\
\text { con otras formas (el mito, } \\
\text { las creencias, el arte). }\end{array}$ \\
\hline $\begin{array}{l}\text { Escenarios } \\
\text { de acción }\end{array}$ & $\begin{array}{l}\text { La ciencia y la academia. } \\
\text { Reingeniería social. }\end{array}$ & $\begin{array}{l}\text { La política y las luchas } \\
\text { sociales. }\end{array}$ & $\begin{array}{l}\text { La educación formal e } \\
\text { informal. }\end{array}$ \\
\hline $\begin{array}{l}\text { Escenarios } \\
\text { de control }\end{array}$ & $\begin{array}{l}\text { La lógica: procesos lógi- } \\
\text { cos de falsación; apli- } \\
\text { cación y capacidad de } \\
\text { solución de problemas. }\end{array}$ & $\begin{array}{l}\text { La sociología; las utopías } \\
\text { emancipatorias. }\end{array}$ & $\begin{array}{l}\text { Metapunto de vista } \\
\text { respecto a la lógica y el } \\
\text { lenguaje: el sentido. }\end{array}$ \\
\hline
\end{tabular}

Elaboración de los autores.

\section{Conocimiento y metateoría según el racionalismo crítico de Karl Popper}

Karl Popper (Viena, 1902 - Londres, 1994) fue profesor de la London School of Economics ${ }^{6}$. Formó parte de numerosas academias científicas y recibió varios doctorados honoris causa. Al haber

6 Nació en el seno de una familia judía conversa al protestantismo. En 1937, tras el ascenso del nazismo, abandonó Viena y se trasladó primero a Australia y luego a Inglaterra, donde ejerció la etapa más productiva de su vida intelectual. En 1982 recibió de la reina Isabel II de Inglaterra el título nobiliario de Sir. 
sido uno de los epistemólogos más prestigiosos e influyentes del siglo XX, es un referente obligado e inexcusable para profundizar los procedimientos y alcances de la teoría. Víctima del nazismo, cultivó un rechazo profundo a las formas cerradas del pensamiento. Como creyente, asumió la perspectiva del teólogo protestante Karl Barth (1886-1968) para dar forma a su idea de pensar sin determinismos, a partir de un universo abierto y un mundo sin historia a total disposición de la libertad humana.

La obra que condensa su propuesta epistemológica es Lógica de la investigación cientifica (1934, 1973 b para una de sus ediciones en español) cuya tesis esencial se expresa en la siguiente proposición: "pensar es conjeturar"; es decir, pensar consiste en la capacidad de plantear respuestas anticipadas a problemas prácticos o teóricos, respuestas no irrefutables sino falsables, abiertas y disponibles a que la realidad tarde o temprano las pueda deslegitimar. Esta idea madre fue desarrollada posteriormente en múltiples conferencias y artículos. Los presupuestos ontológicos y políticos implicados en la tesis se pueden encontrar, además, en obras como La miseria del historicismo (1973a), El universo abierto. Un argumento a favor del indeterminismo (1994), El mito del marco común. En defensa de la ciencia y la racionalidad (2005) y La sociedad abierta y sus enemigos (2006).

Su actitud polémica apuntó contra varios frentes a la vez, todos ellos caracterizados por plantear algún tipo de determinismo respecto al conocimiento: contra el neopositivismo lógico del denominado Círculo de Viena del que formó parte, por condicionar el pensamiento a los mecanismos de inferencia inductiva; contra Freud y los defensores del psicoanálisis, por el determinismo del inconsciente sobre el pensamiento; contra el pensamiento dialéctico de Hegel y de Marx, por el determinismo histórico que los fundamenta. Contra los miembros de la escuela de Frankfurt lo animó una agria dispu- 
ta pública, en especial con Jürgen Habermas. De esta escuela llegó a afirmar, incluso, que "tan solo genera quejas y oscuros gritos de Casandra acerca de los malos tiempos en que vivimos y acerca de la perversión de la cultura burguesa”.

\section{Compromisos ontológicos, éticos y políticos}

A diferencia de otras posiciones, Popper hace de la cosmología el fundamento y el punto de partida de su epistemología y metateoría: "Mi argumentación, pues será más en un plano cosmológico: hablaré del carácter de nuestro mundo en vez de hablar del significado de las palabras" (1994, p. 23); por lo tanto, ni la sociología ni los análisis filosóficos en torno al lenguaje pueden ser puntos de partida válidos desde los cuales establecer los parámetros y alcances del conocimiento. La primera afirmación básica sobre el mundo se refiere al tiempo y consiste en su carácter abierto e impredecible, imposible de ser capturado por el pensamiento, ya sea bajo la forma de algún sentido o finalidad de la historia o a partir de la capacidad de predicción causal que se atribuye a las leyes.

Respecto al sentido de la historia, nada autoriza a pensar en su existencia previa más allá de los significados que nosotros podamos construir en ella ${ }^{8}$ ( $c f r$. infra); pero, en rigor, la historia carece de sentido. Las leyes científicas pueden establecer sistemas de predicción causal según reglas propias del pensamiento, pero no están en condiciones de anticipar el devenir del mundo, de autorizar miradas

7 Conversación sostenida con Marcuse en un programa de radio de la $B B C$ de Londres. Citada en http://cibernous.com/autores/popper2/teoria/biografia.html

8 En este aspecto interpreta epistemológicamente el punto de vista del teólogo protestante Karl Barth, según el cual cualquier trama de la historia funciona como pretendido marco común que exime al individuo de tomar decisiones y lo enajena de la posibilidad de responder a la fe desde su libertad. Ver Popper (2005, pp. 163 y ss.). 
proféticas, emancipatorias o identificar alguna trama en la historia que se constituya en un marco común para todos. Si las leyes científicas son deterministas en sus procedimientos, no podemos afirmar lo mismo del mundo y la historia cuya impredecibilidad parece ser su carácter esencial.

La unicidad del mundo respecto al conocimiento es el segundo rasgo de su cosmología que explica la tensión que predispone a las teorías hacia nuevos y cada vez mejores niveles de aproximación a la verdad y universalidad. El mundo tiene una sola calidad respecto al conocimiento, ya que todo él es virtualmente cognoscible, aun a pesar de su indeterminismo y de la imposibilidad real de lograrlo: "en este sentido del conocimiento, todo nuestro conocimiento se refiere solo a este único mundo nuestro y a ningún otro" (1994, p. 71). En este punto, es oportuno destacar su deslinde de la dualidad kantiana del mundo respecto al conocimiento expresada en las categorías de fenómeno (lo que puedo conocer) y noúmeno (lo que no puedo conocer).

La consecuencia para la conducta, la política y el pensamiento de los rasgos cosmológicos esenciales señalados, la impredecibilidad y unicidad del mundo respecto al conocimiento, es obvia: no existe nada que determine el pensamiento ni la psique ni las realidades físicas ni la historia. El correlato político de tal concepción es el proyecto de una sociedad abierta: a un universo abierto corresponde una sociedad abierta y democrática fundada en dispositivos teóricos considerados mecanismos también abiertos. Tal proyecto tiene un protagonista fundamental: el intelectual, quien debe combatir cualquier forma de visión determinista porque toda determinación innecesaria del pensamiento clausura su apertura ( $c f r$. supra). Desde esta trinchera, la batalla más dura se libra contra el determinismo cientí- 
fico', el enemigo más difícil de vencer, aun más que los determinismos religiosos y metafísicos, porque sus argumentos no adolecen de la debilidad de estos.

En última instancia, el programa epistemológico de Popper reivindica un proyecto ético y político fundado en la libertad absoluta en el cual el ejercicio del pensamiento libre de ataduras es más importante que la reflexión explícita sobre la moral y la ética, ámbitos proclives a deslizarse por diversos determinismos. Si en un momento se distanció del dualismo kantiano porque considera inaceptable la existencia de diversas realidades, una que podemos conocer y otra imposible de ser conocida, recupera y restaura en cambio el proyecto kantiano de racionalidad iluminista porque lo considera una herramienta útil para superar formas cerradas y violentas de pensar. La racionalidad libre es el instrumento y el fundamento capaz de

evaluar razones o argumentos, en pro o en contra de enunciados de hecho, o teorías científicas [...] Si disfrutamos de este tipo de libertad, es posible que disfrutemos también de la libertad de crear, de razonar y de deducir en los aspectos morales, y de disfrutar de la responsabilidad que acompaña a la creación y a la elección. (1994, pp. 135-136)

\section{La metateoría popperiana}

A partir de la cosmología descrita, la reflexión metateórica de Popper consta de tres aspectos muy integrados que separamos para

9 Según Popper, el determinismo científico es "la doctrina que dice que el estado de cualquier sistema físico cerrado en cualquier instante futuro dado puede ser predicho, incluso desde dentro del sistema, con cualquiera que sea el grado estipulado de precisión, mediante la deducción de la predicción a partir de teorías, en conjunción con condiciones iniciales cuyo grado de precisión requerido puede calcularse siempre... si la tarea de predicción es dada" (1994, p. 59). 
facilitar su comprensión: 1. las teorías en el contexto de la concepción de los tres mundos; 2 . la teoría, dispositivo de un mecanismo adaptativo: el conocimiento científico; 3. la teoría considerada dispositivo conjetural que aspira a la verdad.

\section{Las teorías: objetos y realidades del Mundo 3}

La metafísica popperiana decanta en la teoría de los tres mundos, la cual, a su vez, se constituye en el fundamento cosmológico de su "filosofía pluralista" que se distancia de otras cosmologías y teorías del conocimiento monistas o dualistas, cabalmente porque estas últimas producen visiones deterministas de la sociedad y de la existencia.

Su punto de partida consiste en reinterpretar el mundo de las ideas de Platón y advertir que la tradición había englobado erróneamente en el mundo de las ideas tanto los actos mentales (aprehensión, comprensión) cuanto sus subproductos (conceptos, teorías, argumentos). De la mano de lógico y matemático alemán Gottlob Frege (1848-1925) establece una lectura creativa e innovadora de la epistemología platónica al distinguir y separar los actos mentales de las ideas producidas por esos mismos actos, entre las operaciones intelectuales y los instrumentos del conocimiento como objetos y habitantes de dos mundos diversos. Estructura así, la teoría de los tres mundos: el Mundo 1 (M1) o de la realidad física, el Mundo 2 (M2) o de los estados y las operaciones mentales, y el Mundo 3 (M3) o el de las realidades del lenguaje y de los contenidos o ideas; mundos irreductibles entre sí que gozan de una relativa autonomía, a la vez que se vinculan mutuamente según relaciones específicas. La Figura 1 sistematiza las características esenciales de los seres de cada uno de los tres mundos y sus relaciones. 


\section{5}

Figura 1

Los tres mundos según Karl Popper ${ }^{10}$

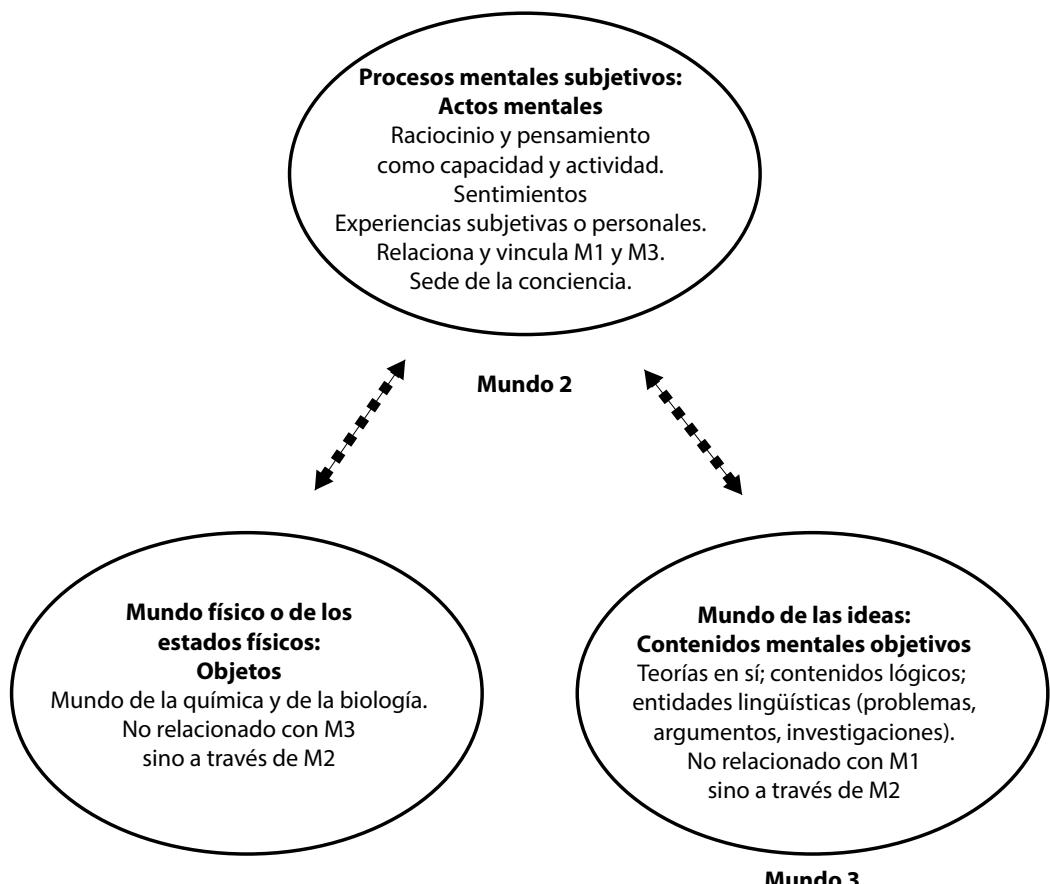

Mundo 1

Mundo 3

Elaboración de los autores.

10 Elaboración de los autores a partir de la versión ampliada de una de sus conferencias de 1968: "Una teoría objetiva de la comprensión histórica" ([1968] 1990, pp. 209 y ss.). También ver su "Post Scriptum a la lógica de la investigación científica”, en El Universo abierto. Un argumento a favor del indeterminismo, vol. II (Popper, 1994, pp. 64 y ss.) Algunas de las conferencias reunidas en La responsabilidad de vivir (1995) también son claves para determinar las relaciones entre los mundos popperianos y para comprender la conciencia como realidad del M2 al mismo tiempo que producto de la relación con M1 y M2. Para una caracterización del M3, ver "Epistemología sin sujeto cognoscente", ponencia dictada en 1967 (Estany, A., 2001). 


\section{6}

El M1 es el mundo de los estados físicos, de los objetos y realidades químicas y biológicas. El M3 es abstracto y es el más complejo de todos. Allí habitan los contenidos mentales objetivos. Es el mundo del conocimiento humano que posee una historia, que incluye al que ha sido formulado lingüísticamente como al que no ha sido formulado todavía. Como parte integrante del universo del discurso, las realidades del M3 poseen el carácter objetivo de verdad o falsedad en tanto que los estados de la conciencia (M2) podrán ser catalogados de subjetivamente sinceros o insinceros. Las obras de arte y los productos culturales (una ópera, una película) también integran el M3, del que también forman parte realidades híbridas, como los libros y las bibliotecas que son, al mismo tiempo y en tanto objetos físicos, parte del M1. El M2 es la sede de la conciencia, de la subjetividad y de los sentimientos, así como de las capacidades y operaciones intelectuales, no de los contenidos ni de los productos de estas (M3).

Las relaciones entre los mundos se caracterizan por la causalidad, la relativa autonomía y la mutua apertura. Como se observa en el esquema, el M2 es el único que se relaciona con los otros dos mundos; el M1 se relaciona con el M3 y viceversa, solo por medio del M2. El primer tipo de estas relaciones es causal, de tal modo que la apertura causal del Mundo 1 hacia el Mundo 2 y la mutua apertura causal entre el Mundo 2 y el Mundo 3 persigue también crear espacios para la libertad (Popper, 1994, p. 137). En efecto, es la irreductibilidad y mutua apertura de estos mundos la que previene contra cualquier reduccionismo que pretenda hacer de uno de ellos una realidad derivada de cualquiera de los otros dos o concebir el conocimiento como subproducto del mundo físico (M1), de la mente (M2) o del lenguaje (M3).

En tal sentido, el esquema solicita una serie de precisiones respecto al M3, la más importante de las cuales consiste en que, si bien 
es producido por el M2, sus objetos, en cambio, son productos no intencionados y no planificados del M2, es decir, autónomos, con una enorme capacidad de generar realidades en el M1, así como estados del $\mathrm{M}^{11}$. Por lo tanto, los objetos del M3 no son meros instrumentos sino realidades producidas y productoras, a la vez, de otras realidades. Así, las teorías, seres privilegiados del M3, no son simplemente constructos mentales o meros instrumentos ya que están doblemente orientadas hacia la realidad y hacia la objetividad lógica: "su verdad y falsedad dependen enteramente de su relación con el 'Mundo 1', una relación que... no podemos alterar. Su verdad o falsedad dependen de la estructura interna del 'Mundo 3' (especialmente el lenguaje) y del 'Mundo 1', el último de los cuales... es el patrón mismo de la realidad" (1994, p. 143). Debido a que la relación entre M3 y M1 es mediada, las teorías no tienen una relación directa con el mundo. Con ello, hecha por tierra el postulado positivista según el cual los conceptos, teorías y leyes científicas son abstracciones de hechos reales y constituyen algo así como copias del mundo, y anula su pretensión de que, efectivamente, las teorías copian o expresan la realidad. Los mundos se vinculan entre sí también mediante relaciones de carácter genético que configuran un itinerario evolutivo de humanización creciente que arranca con el M1 (el mundo físico), continúa con los sentimientos animales propios del M2 y culmina en el M3 con la aparición del lenguaje.

11 “Trataré de mostrar que tenemos que admitir la existencia de una parte autónoma del 'Mundo 3'; una parte que consiste en los contenidos de pensamiento objetivos que son independientes, y claramente diferenciables de los procesos de pensamiento subjetivos o personales por medio de los cuales son captados y en cuya captación influyen causalmente. Afirmo así que existen objetos autónomos del 'Mundo 3' que no han tomado aún una forma propia del 'Mundo 1' ni del 'Mundo 2', pero que, no obstante, interactúan con nuestros procesos de pensamiento. De hecho, influyen decisivamente en nuestros procesos de pensamiento" (Popper, 1994, p. 141). 
Vale la pena aquí adelantar la crítica a la teoría de los tres mundos respecto a la lectura despectiva del M2, al que Popper califica de "fango segundo mundano"12, percibido apenas como mediador, sumido en la subjetividad y la inconsistencia emocional. Si su propuesta de conocimiento y de ciencia se enraíza en la objetividad, atributo del M3, único lugar donde florece la "buena ciencia", la racionalidad popperiana excluiría toda forma de subjetividad, tanto en su expresión individual como colectiva (el "nosotros"). Por lo tanto, la teoría del M3 busca construir una epistemología "sin sujeto cognoscente" (Popper, 2001, pp. 138 y ss.) antagónica a las tesis psicologistas, a la sociología del conocimiento y a las actuales posturas que revindican y recuperan la subjetividad y las pertenencias identitarias en la práctica científica. Para la epistemología sin sujeto son irrelevantes las pertenencias de género, culturales o sociales, pues todos deben contribuir como obreros genéricos a acrecentar el conocimiento objetivo.

\section{Las teorías: dispositivos de un mecanismo adaptativo}

Desde un punto de vista biológico evolutivo ${ }^{13}$, Popper identifica tres mecanismos adaptativos de los organismos: el mecanismo genético, el conductual y el conocimiento científico; este último, una especialización muy desarrollada de los mecanismos biológicos. Los mecanismos genéticos se caracterizan por responder a un desequilibrio o problema mediante el despliegue de dispositivos de eliminación y selección natural según los cuales una transformación no programada

12 Tal expresión respecto al M2 consta en otro de sus ensayos que no hemos revisado: Conocimiento objetivo (1974, pp. 148 y ss., citado en Datri et al., 2004, p. 104).

13 Ver sus conferencias recopiladas en La responsabilidad de vivir. Escritos sobre politica, historia y conocimiento ([1972] 1995, pp. 17 y ss.) y El mito del marco común. En defensa de la ciencia y la racionalidad ([1975] 2005, pp. 17 y ss.). 
pero adaptada pervive en tanto que los individuos en el que aparece un cambio genético no adaptado desaparecen por no poder sobrevivir. De manera análoga, los mecanismos conductuales responden a los desequilibrios por criterios de ensayo y error no orientados, eliminando aleatoriamente las conductas no adaptadas e incorporando aquellas que de manera casual resultan eficaces. Las transformaciones genéticas o conductuales se incorporan a los organismos y forman parte de él, por transmisión genética en el primer caso o mediante procesos de transmisión cultural o imitación, en el segundo.

El conocimiento opera en todos los organismos (humanos y no humanos), merced al mismo procedimiento de ensayo y error común a los otros mecanismos adaptativos, según el siguiente esquema de tres fases: surgimiento de un problema, intentos de solución y eliminación (Popper, 1995, pp. 22 y ss.). La teoría es el dispositivo más importante del conocimiento y, a diferencia de los mecanismos genéticos y conductuales, no incorpora las transformaciones a los organismos ni al sistema genético, haciendo posible su fluida asimilación o eliminación. Por no estar incorporadas al organismo y contar con una existencia relativamente autónoma, la función eliminatoria de la teoría no es violenta porque es posible descartar, anular o subsumir una teoría en otra sin necesidad de eliminar a los individuos, lo que no ocurre con las transformaciones genéticas o conductuales cuyas funciones eliminatorias son violentas.

Actúa al son de un aparato racional en el que las transformaciones son evaluadas primero y asimiladas luego de ser sometidas a un aparato crítico. La teoría también produce adaptaciones porque busca solucionar problemas desde un punto de vista crítico, no casual (como el sistema genético) ni aleatorio (como el conductual). Además, este dispositivo es abierto ya que la solución de un problema implica la aparición de otros en un horizonte ilimitado y progre- 
sivo, a diferencia de las transformaciones genéticas y conductuales que son realidades orgánicas cerradas y clausuradas en sí mismas.

Las teorías son dispositivos que abrazan todo el pensamiento y, por lo tanto, no son sistemas especializados que se desarrollan exclusivamente en el escenario de la ciencia, sino también de la vida cotidiana, ya que comparten los principios que rigen el pensamiento ordinario. Las teorías actúan científicamente, en cambio, porque: a) Se ejercen en un marco de posibilidad en tanto que los mecanismos genético y conductual reaccionan solo ante cambios reales; b) A diferencia de como ocurre en el pensamiento ordinario, las teorías científicas son conjeturas, no certezas; a la vez, forman parte de marcos lógicos y críticos que permiten identificar nuevos problemas, teóricos y prácticos, en las conjeturas producidas.

Desde dicho enfoque, el carácter público de las teorías, es decir, el que deban formularse lingüísticamente y comunicarse públicamente es esencial para convertirse en objetos exteriores abiertos a la investigación y a la crítica. Si hay batallas que valen la pena, estas son las teóricas ya que al ser libradas en los foros académicos solo eliminan ideas y no personas.

\section{Las teorias: redes e instrumentos para la solución de problemas. El método deductivo de contrastar}

Hasta aquí, las teorías han sido consideradas realidades autónomas del M3; al mismo tiempo, han sido definidas como la expresión más evolucionada de un sistema adaptativo: el conocimiento. Sin embargo, el punto de vista más desarrollado es el funcional a partir del cual Popper desarrolla el proceso de conocimiento teórico y en cuyo contexto concibe las teorías no solo como instrumentos del conocimiento sino también como aproximaciones sucesivas en 
nuestra búsqueda de la verdad, "en nuestra búsqueda de soluciones cada vez mejores a problemas cada vez más profundos (donde 'cada vez mejores' significa... 'más próximos a la verdad')” (Popper, 2005, p. 192). En tanto aproximación perfectible, la universalidad de las teorías es un producto, un logro final y meta, nunca un punto de partida. Es el resultado de un proceso continuo de aproximaciones en el cual a mayor universalidad mayor aproximación.

Es en este punto donde la elocuente metáfora de la red abre nuevos significados para entender la teoría como punto inicial de un proceso de conocimiento enfocado a la solución de problemas:

Yo considero nuestras teorías científicas como invenciones humanas, redes creadas por nosotros para atrapar el mundo. Por supuesto, estas difieren de las invenciones de los poetas e incluso de las de los técnicos. Las teorías no son solo instrumentos. A lo que aspiramos es a la verdad: contrastamos nuestras teorías con la esperanza de eliminar las que no son verdad. De esta manera podemos conseguir nuestro propósito de perfeccionar nuestras teorías; incluso como instrumentos: haciendo redes que estén cada vez mejor adaptadas para capturar nuestro pescado, el mundo real. Sin embargo, nunca serán instrumentos perfectos para ese propósito. Son redes racionales hechas por nosotros mismos, y no deben confundirse con una representación completa del mundo real en todos sus aspectos, ni siquiera aunque tengan un gran éxito; ni siquiera aunque parezcan producir excelentes aproximaciones a la realidad. (Popper, 1994, p. 65)

¿Cómo funciona esta red? La teoría es una forma de representación de la realidad o del sistema por medio de un modelo simplificador (pp. 67 y ss.), cuya función es reducir al máximo la complejidad del mundo para iluminar (atrapar) solo lo pertinente de él, aquello que se quiere explicar y dar razón (predecir). En rigor las teorías no constituyen una representación completa del mundo sino una aproximación instrumental; por lo tanto, ni su simplicidad ni su 
complejidad ni su determinismo lógico son rasgos del mundo, sino de las teorías. Un modelo teórico, entonces, es una red que incluye, excluye y predice en un campo limitado de la realidad. Para ello, son preferibles las teorías simples porque cumplen mejor su tarea de red y, además, resultan mejor contrastables respecto a la realidad y las aplicaciones que las complejas.

Para definir el ciclo de operaciones y procedimientos asociados con la teoría Popper se desentiende de la perspectiva positivista basado en la inducción, proceso inferencial que procede de lo particular a lo universal, de la experiencia y la observación al concepto, y que hace de la teoría el resultado de la generalización de los datos. Su procedimiento se basa, en cambio, en la deducción, que procede de manera inversa; es decir, de lo general a lo particular (del concepto, teoría o hipótesis a la experiencia) como única forma de inferencia capaz de producir conocimiento (Popper, 1973, pp. 27-47) y explicar causalmente la realidad: "Dar una explicación causal de un evento significa el deducir un enunciado que lo describe, usando como premisas de la deducción una o más leyes universales, junto con ciertos enunciados singulares, las condiciones iniciales" (pp. 27-47).

Su crítica al rol y los alcances de la inducción cava una zanja que lo separa radicalmente de todas las formas de positivismo y, especialmente, del neopositivismo de la escuela de Viena, por dos razones fundamentales: la negación del rol esencial de la formulación del problema en la investigación y la negación de la carga teórica del dato. En efecto, el conocimiento teórico no nace de la observación tal como pretenden los positivistas, quienes mutilan la totalidad del proceso investigativo al excluir del ciclo el problema inicial y los interrogantes que condicionan la mirada de la realidad. Popper no desconoce el rol de la observación, pero la reubica en una fase posterior y la integra en un proceso más amplio de resolución de problemas. 
Además, el neopositivismo desconoce que "todas las observaciones están impregnadas de teoría. No hay observación pura, desinteresada, libre de teoría" (2005, p. 28). En este sentido, las teorías funcionan como órganos sensoriales y nuestros órganos sensibles, como teorías. Tal postura deja insubsistente, incluso, la concepción axiomática de la teoría que distingue en su interior dos tipos de afirmaciones o proposiciones: las teóricas (abstractas) y las observacionales (aplicadas a la realidad) (ver infra) ya que estas últimas también están cargadas de teoría.

La inducción, por tanto, no solo resulta superflua; además, enturbia el problema epistemológico y ni siquiera es fuente de probabilidad. A este método, el inductivo, Popper opone lo que él denomina el método deductivo de contrastar, mediante el cual una hipótesis o teoría puede contrastarse empíricamente después de que ha sido formulada. Los pasos del proceso de conocimiento deductivo, en un sentido más amplio, son los siguientes (2005, pp. 196 y ss.): 1. Seleccionamos un problema, quizá por haber tropezado con él; 2 . Tratamos de resolverlo proponiendo una teoría como solución tentativa; 3. Mediante la discusión crítica de nuestras teorías, nuestro conocimiento se desarrolla por medio de la eliminación de algunos errores, y de esta manera aprendemos a comprender nuestros problemas y nuestras teorías, así como la necesidad de obtener nuevas soluciones; 4. La discusión crítica incluso de nuestras mejores teorías siempre saca a luz nuevos problemas. En cuatro palabras, el proceso se resume así: problemas - teorías - crítica - problemas. Si bien todo conocimiento procede de esta forma, la característica del proceder científico es la eliminación de errores por medio de la crítica y discusión de las teorías.

En un plano más específico y detallado, las operaciones y productos mentales y proposicionales del método deductivo de contrastar son los siguientes: 
a. Identificación del problema teórico o práctico que emerge de la realidad o de las mismas teorías.

b. Creación de teorías e hipótesis (hipotizar). Son explicaciones anticipadas que surgen a partir de los problemas teóricos o prácticos identificados, o según procesos creativos intuitivos, de tal modo que no existen procedimientos lógicos que aseguren el modo adecuado de "inventarlas".

c. Extracción de las conclusiones de la teoría o hipótesis según procesos deductivos cuyo resultado son proposiciones que establecen conexiones de la teoría con aplicaciones prácticas o realidades experimentales.

d. Contrastación según cuatro procedimientos. 1. Comparación lógica de una conclusión con otra (coherencia interna del sistema); 2. Estudio de la forma lógica de la teoría o hipótesis para determinar si la teoría es empírica o tautológica; 3. Comparación de la teoría con otra(s) teoría(s) para determinar si se trata de un avance científico; 4. Contrastación empírica de las conclusiones o enunciados singulares que se deducen de la teoría, en relación con la práctica, a la realidad experimental o a las posibles aplicaciones. Si las conclusiones han sido verificadas por la práctica, han sido verificadas por esta ocasión y no las desechamos (por ahora). Si las conclusiones han sido desmentidas por la práctica, esto es, que han sido falsadas, se deduce que la teoría que les ha dado origen también es falsa.

Los principios del conocimiento científico son comunes a todas las ciencias y se alinean en un sistema autopropulsor (2005, p. 177) basado en el mecanismo de la hipótesis y la conjetura (P1-TT-DC-P2), en el que P1 (problema inicial, teórico o aplicado), TT (teoría tentativa), DC (discusiones críticas), P2 (resultados formulados como nuevos problemas) se vinculan 
circularmente de uno a otro en un movimiento sin fin. Este mecanismo instaura una ley de movimiento según la cual es posible iniciar por cualquiera de los términos del ciclo conjetural y no necesariamente por el problema, pero Popper propone la actitud socrática del ciclo abierto que inicia con un problema y culmina con otro (2005, p. 177) para dar cuenta de la fecundidad irrefrenable de la ciencia. Por tanto, se parte de problemas, se acude luego a la teoría y al análisis crítico para iluminar respuestas anticipadas y las conclusiones obtenidas son (o deberían ser) falsables y dispuestas a ser desbancadas por futuras y mejores conclusiones.

La Figura 2 resume las diferencias entre el procedimiento inductivo, que coloca la observación en primer lugar y luego la teoría como resultado final de la generalización de los datos, y el deductivo propuesto por Popper, cuyo proceso investigativo inicia con el planteamiento del problema y la teoría, implícita en la hipótesis que lo ilumina.

Figura 2

Proceso inductivo y deductivo y lugar de la teoría
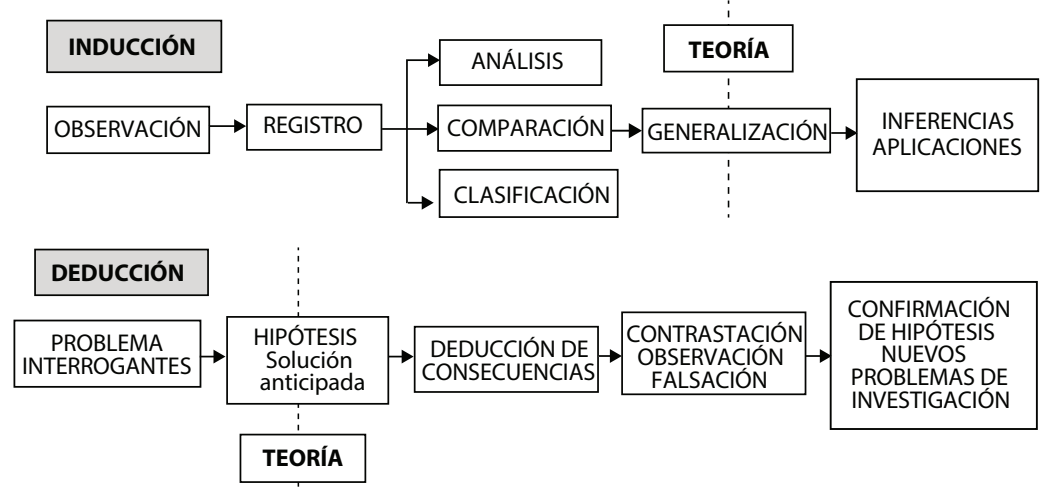

Elaboración de los autores a partir de Pardo (1998, p. 74). 
La hipótesis y la falsación son criterios metodológicos de demarcación que, por un lado, homologan todos los tipos de conocimiento científico a pesar de referirse a distintos ámbitos de la realidad; por otro, esos criterios distinguen la ciencia de otros tipos de conocimiento. Popper propone la unidad de las ciencias porque todas responden al mismo paradigma hipotético, trasfondo común para todas las ciencias, superando así el paradigma que separa drásticamente la historia (las humanidades) de las ciencias naturales, tal como propusieran en su momento Wilhelm Dilthey (1833-1911) y Robin G. Collingwood (1889-1943) para construir un estatuto jerárquicamente diferenciado para uno de los dos ámbitos o para la historia, o para las ciencias naturales (Popper, 2005, p. 174).

Además, Popper cuestiona la distinción jerarquizada que opera en la academia en torno a la primacía de las ciencias aplicadas respecto a las ciencias sociales y humanistas. Así, los saberes no se distinguen según el ámbito de la realidad al que se refieren ni al tipo de saber requerido por cada uno de esos ámbitos; no es verdad que operaciones del tipo "comprender" se reservan a la historia; y "explicar", a las ciencias naturales. En rigor, todas las ciencias comparten los mismos principios y no tienen sentido las distinciones basadas en lógicas diferentes que nacen de ámbitos de la realidad también diferentes.

Pero el principio de falsación genera también el criterio de demarcación o el lindero que separa la ciencia del sentido común y otros tipos de conocimiento teóricos, aunque todos participen de las mismas dinámicas de solución de problemas. El sentido común considera irrefutable la producción teórica; en tanto que la ciencia considera toda teoría como potencialmente falsable; es decir, toda teoría posee una naturaleza transitoria y provisoria; sobre cada una, sin excepción alguna, pende la amenaza permanente de una posible falsación. En este sentido, lo único que cabe hacer con un nuevo conocimiento es 
falsarlo o refutarlo. No existen marcos teóricos estables ni fijos, sino esquemas abiertos y disponibles a que la realidad misma o los desfases de la aplicación sean los que los deslegitimen. El principio de que una teoría es válida solo si es falsable cuestiona otros criterios de demarcación como, por ejemplo, el propuesto por Thomas Kuhn (19221997) y los historicistas, para quienes la validez depende del carácter significativo de la teoría respecto a las comunidades interpretativas que las originan y les atribuyen sentido y pertinencia.

El dispositivo teórico propuesto por Popper funciona a la manera de esquema tentativo y abierto de resolución de problemas que asegura la producción de teorías generadoras, a su vez, de otros tantos problemas no intencionados que reclaman sucesivamente otras tantas teorías. Así, resulta idealmente imposible sistematizar y axiomatizar las teorías.

\section{Comentarios e implicaciones epistémicas, éticas y políticas}

\section{Aspectos epistémicos}

Popper construye su agenda crítica desde la lógica hipotética deductiva y la reubicación de la teoría en la construcción de los datos, al menos en dos direcciones. La primera apunta contra el positivismo; la segunda, contra toda forma de ideología y sistema cerrado de ideas. Respecto a la primera, cuestiona el principio epistémico heredado de Francis Bacon (1561-1626), uno de los padres del empirismo científico, según el cual conocemos sin marcos teóricos previos — desprovistos de hipótesis o conjeturas - proyectando sobre él la crítica al positivismo del siglo XX cuyo fundamento es conocer con certeza a partir de la experimentación y no de la teoría ${ }^{14}$. A la vez

14 Para una crítica de Popper, según la cual el proceso de falsación no logra trascender el positivismo por remitirse en última instancia a la experiencia, ver 
que reconoce el potencial de Bacon para depurar la ciencia de prejuicios inútiles, ataca y con razón su pretensión de purgar la mente de teorías pues "una mente purgada de esa manera no solo sería una mente pura: sería también una mente vacía” (2005, p. 114).

El segundo punto de su agenda consiste en restaurar aquella porción de la Ilustración desde la cual desmontar la estructura cerrada de las ideologías, las doctrinas y sus correlatos de acción y pensamiento (recordemos que Popper vivió en medio de totalitarismos). Desde esa agenda, en contrapartida, Popper revaloriza la confianza de Francis Bacon en la razón y destaca su influencia en varios aspectos que determinarán el desarrollo futuro de la ciencia (2005, pp. 244 y ss.): la conexión de la ciencia con la utopía del bienestar por medio de la actitud pragmático-tecnológica; la visión acumulativa del conocimiento y, por lo tanto, la concepción del trabajo científico como una empresa cooperativa y organizada; la visión de la naturaleza como libro ilimitadamente abierto y la primacía de la actitud de dominio sobre la naturaleza. Es crítico respecto a cada uno de estos aportes, pero señala que, si bien la inducción no refleja la lógica del entendimiento humano, tuvo el mérito de hacer pensar al ser humano por sí mismo y haber instaurado la autoconfianza y la esperanza en un conocimiento sin límites y libre de las ataduras de los prejuicios religiosos.

La epistemología popperiana influyó decisivamente en el historicismo de Imre Lakatos (1923-1974) y coincide parcial y casualmente (porque ninguno conoció la obra del otro) con la propuesta

Datri et al. (2004, pp. 104 y ss.) y también Hollis, M. (1998, pp. 79 y ss.). Vale aclarar que Popper reconoce explícitamente la construcción teórica del dato y que la falsación no se remite a la experiencia bruta, como si se tratara de un laboratorio, sino a la realidad concebida como campo experimental, de aplicación y de práctica de la teoría. El que la teoría exprese una relación necesaria con la realidad no autoriza a clasificar de positivista a Popper. 
hipotética del filósofo estadounidense Charles Sanders Pierce (18391914). Si bien sus desarrollos son diferentes, ambos conceden un lugar central a la conjetura, valoran la productividad práctica de la teoría (resuelve y abre problemas, a la vez) y reconocen a la comunicación de resultados un rol crucial en la investigación.

Entre los aspectos epistémicos problemáticos de su metateoría, señalamos los siguientes: la exclusión de la práctica científica de toda forma de subjetividad, individual o colectiva; la pretendida unidad metódica de las ciencias en general y de las ciencias sociales en particular y, por último, la idealización de la teoría como la forma ideal y mejor de conocimiento. Revisemos cada uno de estos puntos.

Tal como plantea la teoría de los tres mundos, algunos consideran que Popper constituye el puntal ideológico de una forma de racionalidad liberal que deshistoriza e ignora las agencias y los sujetos de la historia (Datri, 2004, p. 105) y hace del ideal de objetividad procedimental el dispositivo que expulsa del conocimiento toda forma de subjetividad individual o colectiva. Hoy, su pretensión de fundar una objetividad que requiere de una mente totalmente imparcial alejada de las miradas y componentes subjetivos, capaz de neutralizar las emociones, nos resulta indigerible y es quizás el aspecto más polémico para la actual sensibilidad epistémica que, en cambio, revaloriza la subjetividad del investigador, su carga emotiva, sus pertenencias y lazos identitarios, su corporalidad y todas las formas de diversidad posibles, recuperándolas como aspectos pertinentes y significativos del conocer y de la investigación. La aserción respecto a que "la subjetividad (individual o colectiva) es la mejor herramienta de investigación", tan central para la actitud intelectual contemporánea, resultaría, en cambio, inadmisible para Popper.

Otro de los aspectos difíciles de aceptar es su terminante refutación de los esquemas dialécticos de pensamiento, especialmente 
los de Hegel, Marx y Freud, a quienes Popper considera los enemigos más formidables de la sociedad abierta no porque no se los deba cuestionar, sino por el argumento de fondo que sustenta su crítica. Reconocer que "el futuro está abierto de par en par" (1995, p. 203) y que, por tanto, es necesario rechazar cualquier teoría "según la cual hay una trama en la historia" (2005, p. 164) resulta problemático pues convierte a Popper en aliado de las vertientes posmodernas radicales que, al negar la historia, terminan por deslegitimar y desconocer las subjetividades sociales que reclaman formas diversas de pensar y de situarse en la sociedad. ${ }^{15}$

El programa epistemológico de Popper anula las diferencias radicales entre las ciencias (a la unicidad del mundo respecto al conocimiento le corresponde la unicidad de la ciencia), especialmente entre las físicas, naturales y sociales, ya que todas ellas despliegan dispositivos teórico-metodológicos similares basados en el único método deductivo de contrastar. La explicación, la predicción y la experimentación no son enfoques capaces de establecer rupturas estructurales o radicales entre las disciplinas o áreas de conocimiento, sino

15 Sin duda, la obra del epistemólogo argentino Mario Bunge (1919), un filósofo radicado en Canadá y autor de numerosas obras sobre epistemología y metodología científica, muy citada y tomada en cuenta en Latinoamérica, es la prolongación del enfoque popperiano, especialmente en lo que concierne a la negación de la subjetividad y la pretensión de neutralidad de las ciencias. En efecto, Bunge retoma el espíritu de las refutaciones de Popper cuando identifica y descalifica otras aproximaciones como las ciencias sociales inspiradas en el enfoque interpretativo (la interpretación es, al fin y al cabo, un asunto eminentemente subjetivo), el marxismo y el feminismo —entre otras expresiones- por tratarse de ideologías ajenas a los hechos y a los principios de la ciencia objetiva y, sobre todas las cosas, negar uno de sus requisitos fundamentales: el de ejercer la ciencia a partir de actitudes políticamente neutrales. Ver, por ejemplo, una de las últimas producciones de Bunge (1999), en la que plantea su posición respecto a los alcances de las ciencias sociales contemporáneas como la antropología, la sociología y la historia, entre otras. 
tan solo énfasis diversos según el tipo de problemas convocados. En consecuencia, todas las ciencias son iguales porque comparten necesariamente el mismo método. Las ciencias sociales, por otro lado, son comprendidas como parte de los mecanismos adaptativos de la sociedad y, consecuentemente, las teorías resultantes se conciben en términos de reingeniería social.

En efecto, al desplegar en el escenario que le corresponde el método de solución de problemas y acoplarse a los procedimientos de falsación mediante el ensayo y error, su misión es la de rectificar errores o postular por adelantado soluciones posibles y tentativas; o bien, establecer falsaciones en torno a las decisiones que la práctica deslegitima. Sin embargo, las actuales tendencias de las ciencias sociales plantean reparos tanto a la pretendida unicidad metódica de las ciencias, porque reclaman su especificidad también con respecto al enfoque, al método y a los objetivos, como al carácter de reingeniería social y de saber adaptativo en la que se las pretende encasillar porque se las margina del horizonte de sentidos y transformaciones profundas al que aspiran.

Como los cambios y transformaciones teóricas son producto de la lógica autopropulsada de las teorías y del talento creativo del investigador, Popper construye una suerte de epistemología carente de sociología que rechaza y minimiza los factores externos, sociales e históricos que inciden en los cambios teóricos, oscureciendo la relación de las teorías con las comunidades interpretativas y con los contextos que les dan significado. Además, desconoce, en el fondo, el potencial cognitivo de la relación del conocimiento teórico con otras formas de saberes con lo cual refuerza el teoricismo y promueve la idealización de la figura del teórico-investigador, protagonista único de la clave de comprensión de los problemas y de la transformación progresiva de la realidad. 


\section{2}

\section{La dinámica teórica autorregulada.}

\section{Ciencia, poder, naturaleza y mercado}

La perspectiva ética y política de Popper tiene mucho que ver con su visión del carácter progresivo de la ciencia y la técnica, basado en el esquema de adición acumulativa de mejoras que trasunta la confianza en su ilimitada capacidad para resolver problemas; en el fondo, se trata de una lectura epistemológica de la ideología del progreso. En esta visión, el futuro popperiano se inscribe en la prognosis de gloria constituida por los logros potenciales que la ciencia es capaz de construir; el futuro es el resultado de la acumulación sucesiva de éxitos presentes producidos por el movimiento perpetuo de los mecanismos del pensamiento científico autopropulsado que procede de avance en avance, indefinida e ininterrumpidamente. El futuro es abierto e incierto, pero por ningún motivo inquietante. $\mathrm{Y}$ ello pese a su plena conciencia del clima cultural adverso y cuestionamientos a la ciencia provocados por hechos como, por ejemplo, la bomba de Hiroshima. La siguiente cita es sumamente elocuente al respecto si tomamos en cuenta que fue pronunciada en 1989, en una conferencia en el ocaso de su vida y en un punto muy alto de la relativización y crítica radical a la ciencia y la técnica por sus amenazantes consecuencias:

Pero tan pronto como se había creado el estado de bienestar y todo marchaba bien en Occidente, comenzaron los grandes gritos e improperios de los intelectuales acerca de nuestra mala época, de nuestra sociedad, de nuestra civilización, de nuestro medio ambiente. Comenzaron las tremendas exageraciones sobre las destrucciones y las contaminaciones, que presuntamente habíamos causado por nuestra codicia, para aniquilar lo más pronto posible las ruinas de un mundo que una vez fue tan hermoso. Es cierto que toda vida está siempre amenazada. Todos nosotros, supongo, vamos ciertamente a morir; tarde o temprano. Peligro ha habido siempre, siempre, desde el origen de la vida, también para el medio ambien- 
te. Gracias a la ciencia natural y a la tecnología y a la industria, por primera vez desde la creación de nuestro sistema solar estamos en situación de hacer algo por el medio ambiente, y todos los científicos naturales y técnicos se esfuerzan por ello. Sin embargo, se les culpa de destruir la naturaleza. Entretanto, hace ya tiempo que fueron puestos a salvo, con toda tranquilidad, el hermosísimo lago Zürcher y también el enorme lago Michigan... (1995, p. 212)

El dispositivo de adición sucesiva de pequeñas pero continuas mejoras que provee la ciencia alimenta el horizonte de temporalidad corta que se desentiende del futuro y a partir del cual las consecuencias remotas o imprevistas del desarrollo tecnológico resultan inimputables precisamente porque el desempeño científico está necesariamente atravesado por limitaciones inherentes que obstaculizan la capacidad de control, en gran medida, debido a la inconmensurabilidad de los procesos naturales y al carácter impredecible e involuntario de los descubrimientos científicos y tecnológicos que generan un marco de inevitable y necesaria incertidumbre (1995, p. 221).

La traducción del futuro abierto en el contexto de la ciencia y la técnica y su relación con la naturaleza resulta en la noción de azar que significa la imposibilidad de anticipar y someter a control social —ex ante - las consecuencias de ese conocimiento y de las intervenciones tecnológicas. Así, Popper coloca el sustrato epistémico que niega a la ciencia y la tecnología un ámbito social y político de control y previsión de tal modo que los desastres naturales y sociales solo recibirán el trato de consecuencias indeseables e involuntarias, de daños colaterales o "no buscadas consecuencias del desarrollo del conocimiento científico y la tecnología” (2005, p. 240), conocimientos autopropulsados desde su propia lógica que no deben estar sujetos, por principio, a controles externos.

Así, la imprevisibilidad de las consecuencias de los conocimientos o aplicaciones tecnológicas es una debilidad constitutiva e inheren- 
te al saber científico, y es un lugar desde el cual cuestiona la pretensión baconiana de que el saber es poder, por la única razón de que la dinamia de la ciencia va del no saber (un problema irresuelto) al no saber (otro problema irresuelto). La imprevisibilidad azarosa es parte de la impotencia del saber y la incapacidad para anticipar sus propias consecuencias y dominar el futuro es una consecuencia lógica de tal manera de concebir el conocimiento (2005, p. 113). De esa manera, sustrae la ciencia de cualquier mecanismo político de control social.

Vemos que Popper construye el sustrato epistémico de aquella actitud generalizada que posterga indefinidamente las evaluaciones anticipadas de los posibles impactos y consecuencias de la ciencia y la tecnología por no contar con un marco seguro de conocimiento. Vemos también que destruye toda posibilidad de imaginación anticipada y control de las consecuencias, como el principio de precaución, pues se requiere alejar la ciencia de las injerencias inoportunas de la política (como ha sucedido en los totalitarismos). Al sustentar la epistemología en una visión del mundo y de la historia como realidades abiertas e imprevisibles, la ciencia no posee la capacidad de anticipar y proyectar el futuro: debe jugar en un marco de impredecibilidad constitutiva y necesaria, de lo contrario, estará sujeta a los determinismos de los marcos comunes. No obstante, la ciencia no se desentiende del poder, lo reasume de otra manera en el sentido de que la ciencia no debe estar sujeta a controles; pero es poder en el sentido de que se trata de un saber de dominio sobre la naturaleza no exento de riesgos, aunque Popper nunca aportó a profundizar las consecuencias de este dominio no deseado de la ciencia sobre la naturaleza, pero de todas maneras inscrito en su dinámica porque se trata de daños potenciales inintencionales, como se verá más adelante. Comentando sobre Bacon en torno a esta idea, afirma lo siguiente:

Tuvo la visión de una nueva época, de una era industrial que también sería la era de la ciencia. En referencia al descubrimiento 
accidental de la pólvora y de la seda, habló de la posibilidad de una investigación científica sistemática en vista a otras substancias y materiales, y de una nueva sociedad en la cual los hombres, a través de la ciencia, encontraran la salvación de la miseria y de la pobreza. De esta suerte, la nueva religión de la ciencia sostuvo una nueva promesa del cielo en la tierra, de un mundo mejor que, con ayuda del nuevo conocimiento, los hombres crearían por sí mismos. Saber es poder — dijo Bacon—, y esta idea, esta peligrosa idea del dominio del hombre sobre la naturaleza, de los hombres como dioses, ha sido una de las ideas más influyentes a través de las cuales la religión de la ciencia ha transformado nuestro mundo. (2005, p. 113)

Al mismo tiempo, articula el poder político con la ciencia según el principio de que "al científico solo le interesa la verdad, no el poder. El político es quien se ocupa del poder", y establece una clara jerarquía a favor de la ciencia (de la verdad): "el conocimiento es mucho mejor que el poder” (2005, p. 240). Retoma así el lugar kantiano para fundar la ética: la racionalidad y sus fines. Pero la responsabilidad tecnológica es un asunto librado a la racionalidad del científico y a su rol de tutela; los poderes derivados del conocimiento deben ser controlados desde el conocimiento mismo y por las lógicas que le son inherentes.

Es la tutela del científico, en especial la del científico social, quien debe prevenir y anticipar el descontrol de la tecnología. Ahora bien, según Popper, el científico social está atravesado por la tensión de un doble rol: su rol prioritario consiste en identificar amenazas contra la libertad humana y luchar contra ellas, proveyendo de "contramedidas efectivas" (2005, p. 160) desde el horizonte de una ciencia independiente que asegure un futuro indeterminado "abierto de par en par" (p. 103). El segundo rol del científico social, subordinado al primero, consiste en alertar contra los peligros de la ciencia y la tecnología solo en tanto comparables a los peligros inherentes al 


\section{6}

totalitarismo y no como un atentado contra la misma naturaleza o a causa de una mínima duda acerca de la autosostenibilidad del mundo natural. Así, Popper encarna el principio de la ética según el cual lo social y lo natural no solo son órdenes separados sino también jerárquicamente ubicados (lo social tiene prioridad sobre la naturaleza); además, no constituyen escenarios intrínsecamente ligados y en los que se juega el futuro de la raza humana. En Popper calza muy bien la tensión antropocéntrica de la ética tradicional que invisibiliza la naturaleza, minimiza las consecuencias de la ciencia para la especie y confina la responsabilidad del científico al ámbito social e intersubjetivo como se recoge en la siguiente extensa cita:

Se podría cuestionar que corresponda verdaderamente al científico una responsabilidad distinta de la que corresponde a cualquier otro ciudadano o a cualquier otro ser humano. Pienso que la respuesta es que todo el mundo tiene una responsabilidad especial en el campo en que tiene un poder o un conocimiento especial. Así, en lo fundamental, solo los científicos pueden evaluar las implicaciones de sus descubrimientos. El profano y, por tanto, el político, no sabe lo suficiente. Esto vale tanto para los nuevos productos químicos para aumentar el rendimiento de la producción agrícola como para las nuevas armas. De la misma manera que, en otra época [...] es el acceso potencial al conocimiento lo que crea la obligación. Solo los científicos pueden prever los peligros, por ejemplo, del aumento de la población, o de los aumentos en el consumo de productos derivados de petróleo, o los peligros inherentes a los desechos atómicos, incluso en tiempos de paz. Pero ¿saben ellos lo suficiente sobre todo esto? ¿Son conscientes de sus responsabilidades? Algunos lo son, pero me parece que muchos no lo son. Algunos quizás, están demasiado ocupados. Otros, tal vez, son demasiado irreflexivos. De una u otra manera, las repercusiones no intencionales de nuestro incauto progreso tecnológico no parecen ser responsabilidad de nadie. Las posibilidades de aplicación parecen intoxicantes. Aunque mucha gente se haya preguntado hasta qué punto el progreso tecnológico 
nos hace más felices, pocos han sentido como su responsabilidad el descubrir cuánto sufrimiento evitable es consecuencia inevitable, aunque no intencional, del progreso tecnológico.

El problema de las consecuencias no intencionales de nuestras acciones, consecuencias que no solo no son intencionales, sino que a menudo son muy difíciles de prever, es el problema fundamental del científico social.

Puesto que el científico natural se ha implicado inextricablemente en la aplicación de la ciencia, también él debería considerar como una de sus responsabilidades especiales el prever, en la medida de lo posible, las consecuencias no intencionales de su trabajo y llamar la atención, desde el primer momento, sobre todo aquellos que deberíamos esforzarnos por evitar. (2005, pp. 161-162)

Respecto a la política, en cierto punto, Popper (1995, pp. 220 y ss.) relaciona explícitamente los principios del mercado con los posibles marcos de control social y político de la ciencia y la tecnología. Propone sustituir la ideología del mercado libre por el principio de limitar la libertad solo allí donde sea necesario por motivos únicamente urgentes, sin la seguridad de encontrar los límites de lo necesario debido a la indeterminación y complejidad propia de los problemas ambientales. Por ello, no se puede postular sin más que las regulaciones ambientales atentan contra la libertad pues toda sociedad libre, garantizada desde el Estado, presupone regulaciones, limitaciones y restricciones que benefician la libertad general del ciudadano. Tampoco es posible responder con demasiada anticipación a tales problemas. Establecer tales restricciones será siempre problemático y "una cuestión de la experiencia”, es decir, un procedimiento ex post, no anticipable:

... evidentemente, la legislación tiene que prohibir la emisión de gases venenosos en el proceso de producción, y evidentemente, la 


\section{8}

frontera entre gases venenosos y formas más benignas de contaminación, como los que producen los automóviles, es indeterminada o problemática: depende entre otras cosas de la densidad del tráfico. (1995, p. 221)

En lo tocante a la idoneidad de los tribunales científicos y expertos como instancias naturales de control, constatamos que Popper no toma nota de las transformaciones producidas por la forma dominante de producción de conocimientos, la cual ya no gira en torno a una comunidad científica como sujeto ideal y abstracto que procesa las discusiones y asume la responsabilidad de control y evaluación de la ciencia, sino a fuerzas corporativas y "contextos institucionales de alta tecnología directamente relacionados con aplicaciones tecnológicas tanto comerciales como militares" (Lander, 1994, p. 75).

\section{Teoría y praxis. El pensamiento crítico de la escuela de Frankfurt}

La escuela que más ha aportado para develar la relación de diversas formas de teoría con la comprensión del presente en relación con la emancipación social y a la humanización de la existencia - la praxis - es la escuela de Frankfurt, que ha condicionado en gran medida el pensamiento y el tono de la teoría social latinoamericana. Estuvo constituida por el conjunto de investigadores alemanes que compartieron el enfoque crítico y progresista del pensamiento social cuyos nombres más conocidos son Theodor Adorno (19031969), Max Horkheimer (1895-1973), Herbert Marcuse (18981979), Erich Fromm (1900-1980) y Walter Benjamin (1892-1940), todos ellos integrantes del Instituto de Investigación Social fundado en Frankfurt en 1924, con el objetivo de investigar y comprender el marxismo. En 1933 el instituto fue prohibido por el nazismo y Max Horkheimer, entonces director, junto con otros miembros —algu- 
nos de ellos judíos - debieron exiliarse y se radicaron en la Universidad de Columbia (Nueva York), donde permanecieron hasta 1943.

Allí, en contacto con una sociedad capitalista avanzada y altamente industrializada, centraron su reflexión en las consecuencias deshumanizantes de la racionalidad y el progreso técnico. La teoría crítica, herencia del marxismo, constituye una arremetida contra los totalitarismos políticos, el positivismo y el industrialismo, a los que consideran "filosofías y ciencias que sacrifican lo individual y particular a la Totalidad de un sistema mitificado (Hegel), al Ser (Heidegger), a la ciencia objetiva (los positivistas como Karl Popper y Hans Albert), o bien al proceso histórico (Marx y Engels). Estas teorías bastante heterogéneas tienen en común subordinar el sujeto al objeto, lo particular a lo general" (Zima, 1973, p. 24).

Los diversos miembros de esta escuela, basados en la relectura de filósofos como Hegel, Marx, Freud y Nietzsche, desarrollan una concepción de teoría (una teoría crítica) cuya función esencial es develar los diversos mecanismos de enajenación del presente y proponer prácticas emancipatorias y humanizantes. Dicho enfoque, que privilegia la actitud política del sujeto investigador, pretende desenmascarar la pretensión de neutralidad objetiva del positivismo, neutralidad a la que acusan de ingenua y servicial respecto al orden existente, así como superar el horizonte meramente instrumental del conocimiento y, por lo tanto, de la teoría.

Hemos escogido dos autores paradigmáticos de esta orientación: Max Horkheimer, miembro de la primera hora de la escuela y uno de sus principales orientadores, y Jürgen Habermas (1929), el último en incorporarse a ella en 1956, en medio de las críticas radicales a la orientación excesivamente especulativa que culminarían con su cierre. Ambos sociólogos y filósofos alemanes compartieron su preo- 
cupación por la teoría y su significado político y social, y desarrollaron sobre bases comunes los conceptos de "teoría crítica” y "teoría dialéctica”, respectivamente, los cuales serán analizados a continuación.

\section{La teoría crítica de Max Horkheimer}

El pensamiento de Horkheimer, no obstante su clara filiación marxista, combina otros aportes como los de Nietzsche y Freud en un contexto histórico caracterizado por el ascenso del nazismo en Alemania y del estalinismo en la Unión Soviética, los cuales no solo frustraron la inminente transformación revolucionaria, sino que pusieron de manifiesto su tendencia a la totalización a la que es necesario enfrentar con la reflexión filosófica y sociológica. Por lo tanto, el aporte de Horkheimer no solo cuestiona al capitalismo sino también - y con crudeza - la concreción estalinista del marxismo, a la vez que construye una de las críticas más profundas de la razón abstracta y del fetichismo del dato que caracteriza al cientifismo positivista.

Para comprender los mecanismos de la dominación Horkheimer consideró necesario profundizar fenómenos como la ideología y la falsa conciencia que se interiorizan en la estructura psíquica de los individuos, así como en el ejercicio de la ciencia como factores determinantes del éxito o fracaso de los procesos emancipatorios. $\mathrm{Su}$ propuesta se desarrolla en uno de los ensayos más conocidos y que más profunda huella ha dejado en las ciencias sociales latinoamericanas, a pesar de ser publicado en 1937, Teoría tradicional y teoría crítica ([1937] 2003), considerado el acta fundacional del pensamiento crítico. Su telón de fondo es el cuestionamiento al positivismo y las prácticas científicas de subordinación que generan hostilidad indiscriminada y sospecha ante cualquier esfuerzo crítico. Así, la ciencia es un territorio donde se juega la emancipación, ya que lo que afecta a la teoría afecta también a la praxis liberadora y, si la teoría no se 
continúa, “... no queda lugar para la esperanza de mejorar fundamentalmente la existencia humana” (2003, p. 263).

Horkheimer resume y da forma a la doctrina oficial de la escuela sobre la teoría, conjuntamente con el aporte de Theodor Adorno. Su punto de partida es la filosofía marxista y la tesis central consiste en que "la acción conjunta de los hombres en la sociedad es la forma de existencia de su razón” (2003, p. 237), es decir, los hombres piensan tal como actúan en sociedad, colectivamente. Por lo tanto, la ciencia no es un mecanismo lógico autosuficiente y su pertinencia y productividad no dependen únicamente de sus elementos formales e internos (como pretendería Popper); antes bien, la transformación de las estructuras científicas (las teorías, los métodos, los temas) deriva de factores sociales en un sentido muy estricto: el modo de producción teórica responde al modo de producción histórico, de tal manera que las preferencias teórico-metodológicas derivan de y convergen en la praxis social (pp. 228-231).

Una forma de teoría, a la que denomina "tradicional", acepta la realidad y la acción como algo dado o suma de facticidades y fuerzas naturales inmutables que deben ser aceptadas; tal actitud teórica es incapaz de percatarse de que el mundo percibido y fáctico es producto de la praxis y que, por tanto, el conocimiento y la percepción derivan de ella; le pasa por alto que la realidad "no está ahî" y que "lo fáctico está mediado por la praxis social como totalidad" (p. 236). El concepto de teoría tradicional se asume y se entroniza como forma independizada, "como si se lo pudiera fundamentar a partir de la ciencia íntima del conocimiento... o de alguna otra manera ahistórica, se transforma en una categoría cosificada, ideológica” (pp. 228-229).

Es necesario superar la teoría tradicional por medio de la conciencia de su relación con los procesos sociales y con la convicción de 


\section{2}

que se trata de un producto determinado por el trabajo del científico. Este punto de vista separa al autor de otras corrientes que, si bien imbrican las teorías con el aparato social, las conciben como realidades autosuficientes determinadas "cabe si"; al negar que tales teorías son producto de la división social del trabajo, son incapaces tanto de determinar su función respecto a la autoconservación del orden establecido como de tomar conciencia del ocultamiento que propician con respecto a las relaciones y determinaciones de las realidades sociales.

Surge así la necesidad de un nuevo concepto teórico para superar la falsa conciencia que envuelve la teoría tradicional: la teoría crítica, concebida como un comportamiento crítico y emancipatorio, una forma de pensar que es, al mismo tiempo, una forma de actuar sobre la sociedad que trasciende finalidades como la solución de problemas o un mejor funcionamiento de la estructura para proyectarse hacia la emancipación. El rasgo distintivo de la teoría crítica no radica en el objeto (qué se comprende) sino en el sujeto de conocimiento. Él no es el lugar en el que confluyen el conocimiento y su objeto; el sujeto de conocimiento, más bien, es el individuo cruzado por relaciones reales con otros individuos y grupos, con una clase y con la naturaleza (p. 243), inmerso en un proceso histórico concreto. Por último, la única instancia de juicio de la teoría crítica, o su criterio de demarcación respecto a la teoría tradicional, es su interés por la supresión de la injusticia social.

Todas las teorías responden a uno u otro esquema y estos agotan todas las posibilidades de ejercicio teórico, tanto los propios de la matemática, la física como de las ciencias sociales. Si bien ambas formas de producción teóricas son antagónicas, es posible establecer interacciones ya que la teoría crítica integra, requiere y recupera aspectos de la teoría tradicional, pues no se trata de desechar la ciencia tradicional como totalidad, sino de integrarla en la perspectiva de la transformación social emancipatoria. La Tabla 2, un tanto extensa y detallada, sistematiza los 
rasgos contrastados de ambas formas de producción teórica, así como la base paradigmática y supuestos metateóricos que las constituyen.

\author{
Tabla 2
}

Teoría tradicional y teoría crítica según Horkheimer

\begin{tabular}{|c|c|}
\hline \multicolumn{2}{|c|}{ Formas de producción teórica según Horkheimer (1937) } \\
\hline Teoría tradicional & Teoría crítica \\
\hline \multicolumn{2}{|c|}{ Concepciones sobre la realidad (sociedad, naturaleza y hombre) } \\
\hline $\begin{array}{l}\text { La realidad es previa y sin contradic- } \\
\text { ciones, susceptible de ser comprendida } \\
\text { conceptualmente. }\end{array}$ & $\begin{array}{l}\text { - La realidad es un todo determinado por rela- } \\
\text { ciones y contradicciones sociales. }\end{array}$ \\
\hline $\begin{array}{l}\text { - La naturaleza es exterior en cuanto reali- } \\
\text { dad suprahistórica. }\end{array}$ & $\begin{array}{l}\text { - La naturaleza es exterior en cuanto suma de } \\
\text { factores aún no dominados por la actividad hu- } \\
\text { mana (no es suprahistórica). }\end{array}$ \\
\hline $\begin{array}{l}\text { La realidad social es escindida y com- } \\
\text { partimentada: segmenta la realidad en } \\
\text { ciencias especializadas, separa teoría y } \\
\text { praxis, pensamiento y acción, individuo } \\
\text { y sociedad. }\end{array}$ & $\begin{array}{l}\text { La compartimentación de la realidad social } \\
\text { cobra el carácter de contradicción conscien- } \\
\text { te. Relativiza la separación entre individuo y } \\
\text { sociedad. Las distinciones y separaciones son } \\
\text { funciones surgidas del obrar humano con } \\
\text { arreglos afines y son reflejo de las relaciones } \\
\text { sociales y de producción. La realidad y el cono- } \\
\text { cimiento son producidos por la praxis social. }\end{array}$ \\
\hline $\begin{array}{l}\text { La sociedad (la cultura, la economía) es } \\
\text { exterior al sujeto; se trata de procesos } \\
\text { extrahumanos y naturales que se expli- } \\
\text { can a partir de mecanismos y funciones } \\
\text { mecánicas. }\end{array}$ & $\begin{array}{l}\text { - La sociedad (la cultura y la economía) es un } \\
\text { producto del obrar humano y son formas } \\
\text { históricas. Constata el carácter inhumano de } \\
\text { la sociedad actual y pone el pensamiento al } \\
\text { servicio de su transformación. }\end{array}$ \\
\hline $\begin{array}{l}\text { Los individuos y los grupos se comprenden } \\
\text { de manera aislada a partir de conceptos } \\
\text { puros y simples. Las relaciones se limitan a } \\
\text { combinar las situaciones espirituales (ideas) } \\
\text { con las situaciones sociales (contextos). }\end{array}$ & $\begin{array}{l}\text { - Parte de una concepción del hombre que se } \\
\text { opone a sí mismo hasta no producir la identi- } \\
\text { dad. Los conceptos develan determinaciones } \\
\text { y contradicciones. }\end{array}$ \\
\hline $\begin{array}{l}\text { Construye un ego que se asume autónomo, } \\
\text { abstracto y origen del mundo. Construye } \\
\text { un nosotros retórico (la raza, la nación). }\end{array}$ & - Se opone al ego aislado y al nosotros retórico. \\
\hline
\end{tabular}




\begin{tabular}{|c|c|}
\hline \multicolumn{2}{|c|}{ Formas de producción teórica según Horkheimer (1937) } \\
\hline Teoría tradicional & Teoría crítica \\
\hline $\begin{array}{l}\text { - Se enfoca en el objeto de conocimiento. } \\
\text { En el sujeto pensante confluyen conoci- } \\
\text { miento y objeto. }\end{array}$ & $\begin{array}{l}\text { - Se construye a partir del sujeto de conoci- } \\
\text { miento: consciente de las relaciones con otros } \\
\text { individuos y grupos, clases y con la naturaleza. }\end{array}$ \\
\hline \multicolumn{2}{|c|}{ Estructura y elementos de las teorías } \\
\hline $\begin{array}{l}\text { - Supone la invariabilidad esencial de la re- } \\
\text { lación entre sujeto, teoría y objeto. }\end{array}$ & $\begin{array}{l}\text { - Supone una lógica dialéctica: el conocimiento } \\
\text { transforma la estructura social en su totalidad, } \\
\text { transforma el sujeto y el rol del pensamiento. }\end{array}$ \\
\hline $\begin{array}{l}\text { Valida el presente. Al servicio de una to- } \\
\text { talidad que se renueva a sí misma: con- } \\
\text { formismo y quietismo. }\end{array}$ & $\begin{array}{l}\text { - Expresa el secreto del presente y traza una lí- } \\
\text { nea de lucha contra lo establecido. }\end{array}$ \\
\hline $\begin{array}{l}\text { - Se organiza según lógica formal y en fun- } \\
\text { ción del dominio de la naturaleza. }\end{array}$ & $\begin{array}{l}\text { - Teoría como momento de una praxis orientada } \\
\text { hacia formas sociales nuevas. El criterio de eva- } \\
\text { luación es su capacidad de transformación social. }\end{array}$ \\
\hline $\begin{array}{l}\text { - Necesidad lógica según paradigma de } \\
\text { ciencias biológicas. }\end{array}$ & $\begin{array}{l}\text { - Necesidad concreta, propia del acontecer } \\
\text { práctico. La necesidad descansa en los acon- } \\
\text { tecimientos que se pueden determinar e in- } \\
\text { fluir racionalmente. }\end{array}$ \\
\hline $\begin{array}{l}\text { - Los conceptos de causa, condición o fun- } \\
\text { ción son los productos clave. }\end{array}$ & $\begin{array}{l}\text { - Las fuerzas, contrafuerzas y contradicciones } \\
\text { son los conceptos clave. }\end{array}$ \\
\hline $\begin{array}{l}\text { - Jerarquización; los hechos son casos ais- } \\
\text { lados, ejemplares o materializaciones de } \\
\text { los géneros por deducción. Atemporali- } \\
\text { dad que esconde las diferencias tempora- } \\
\text { les entre los sistemas. }\end{array}$ & $\begin{array}{l}\text { - El cambio domina la realidad social, se supe- } \\
\text { ra la deducción al identificar los antagonis- } \\
\text { mos sociales y su agudización. }\end{array}$ \\
\hline $\begin{array}{l}\text { Hipotética: resuelve problemas. Productiva } \\
\text { en dos sentidos: crea valores (aplicaciones) } \\
\text { y posibilita la reproducción de un sistema. }\end{array}$ & $\begin{array}{l}\text { - Comportamiento crítico: no busca subsanar } \\
\text { inconvenientes ni optimizar el funciona- } \\
\text { miento de la estructura. }\end{array}$ \\
\hline $\begin{array}{l}\text { - Se funda en juicios categóricos: afirmacio- } \\
\text { nes sobre la realidad que la describen y } \\
\text { explican, pero no la transforman. }\end{array}$ & $\begin{array}{l}\text { - Se funda en juicios de existencia: concede im- } \\
\text { portancia relativa a los juicios de existencia y } \\
\text { se centra en el juicio que denuncia procesos } \\
\text { de alienación que deben ser superados. }\end{array}$ \\
\hline $\begin{array}{l}\text { - Tiende a conformar marcos generalmen- } \\
\text { te aceptados. }\end{array}$ & $\begin{array}{l}\text { - Se refiere a la totalidad, pero no es general- } \\
\text { mente reconocida. Es minoritaria e incómoda. }\end{array}$ \\
\hline
\end{tabular}




\section{5}

\begin{tabular}{|c|c|}
\hline \multicolumn{2}{|c|}{ Formas de producción teórica según Horkheimer (1937) } \\
\hline Teoría tradicional & Teoría crítica \\
\hline $\begin{array}{l}\text { - Considera la teoría crítica como parcial, } \\
\text { injusta e improductiva. }\end{array}$ & $\begin{array}{l}\text { - Sospecha de categorías como mejor, útil, ade- } \\
\text { cuado, productivo, valioso... }\end{array}$ \\
\hline $\begin{array}{l}\text { - La praxis es exterior al sistema. Separación } \\
\text { entre valor e investigación, conocimiento } \\
\text { y acción, teoría y praxis pues preserva al } \\
\text { investigador de las contradicciones y le } \\
\text { otorga un marco fijo a su actividad. }\end{array}$ & $\begin{array}{l}\text { - La praxis constituye el sistema. El científico } \\
\text { ejerce su praxis en el ejercicio teórico crítico. }\end{array}$ \\
\hline $\begin{array}{l}\text { - Pensar cabe sí mismo. La razón es la fuente } \\
\text { de la crítica de sí misma, sin ser ni emanci- } \\
\text { patoria ni pragmática. Es estéril. Ordena y } \\
\text { extrae de sí los fines de tal ordenamiento. }\end{array}$ & $\begin{array}{l}\text { - Pensar referenciado por relaciones y activi- } \\
\text { dad humana. Conocimiento del hacer en la } \\
\text { historia y comprensión de las contradiccio- } \\
\text { nes contenidas en la propia existencia. }\end{array}$ \\
\hline \multicolumn{2}{|c|}{ Relación con la temporalidad } \\
\hline $\begin{array}{l}\text { - Valora el presente: funda utopías abs- } \\
\text { tractas que parten de la idealización del } \\
\text { estado actual de las fuerzas productivas. }\end{array}$ & $\begin{array}{l}\text { El presente debe ser superado dialécticamente. } \\
\text { La realización futura define los aspectos recu- } \\
\text { perables de la teoría. El futuro constituye un } \\
\text { pensamiento a modo de fantasía: la imagen del } \\
\text { futuro que surge de la comprensión del presen- } \\
\text { te determina los pensamientos y las acciones. }\end{array}$ \\
\hline $\begin{array}{l}\text { El investigador es un diagnosticador so- } \\
\text { ciológico sin conciencia de los intereses } \\
\text { políticos: previene con verosimilitud he- } \\
\text { chos de diversa naturaleza sin conexión } \\
\text { necesaria con los anhelos. }\end{array}$ & $\begin{array}{l}\text { El investigador se concentra en un anhelo } \\
\text { no realizado. Prefigura acontecimientos que } \\
\text { pueden lograr la emancipación. }\end{array}$ \\
\hline $\begin{array}{l}\text { - Los juicios categóricos cambian según su } \\
\text { contenido intrínseco. }\end{array}$ & $\begin{array}{l}\text { - Los juicios de existencia se transforman en la } \\
\text { medida que cambian las relaciones sociales. } \\
\text { Una teoría permanece a pesar de los cambios } \\
\text { si las relaciones de producción que la hacen } \\
\text { posible no se han transformado. }\end{array}$ \\
\hline $\begin{array}{l}\text { - Conforma un corpus tradicional acu- } \\
\text { mulativo, traspasable de una generación } \\
\text { a otra. }\end{array}$ & $\begin{array}{l}\text { - No tiene carácter aditivo: los nuevos con- } \\
\text { tenidos no se añaden a otros ya dados pues } \\
\text { constituyen un todo unitario con la sociedad. }\end{array}$ \\
\hline $\begin{array}{l}\text { - Se reproduce y transmite merced a la le- } \\
\text { galidad orgánica o sociológica. }\end{array}$ & $\begin{array}{l}\text { - El enfoque crítico vive de la voluntad de } \\
\text { transformación. }\end{array}$ \\
\hline
\end{tabular}

Elaboración de los autores a partir del estudio Teoría tradicional y teoría crítica de Horkheimer (2003, pp. 223-271). 


\section{6}

El aporte de Horkheimer es sumamente fecundo para comprender el carácter ambivalente de la ideología y la cultura —y de las teorías - como mecanismos poderosos que interiorizan psicológicamente la necesidad de reproducir el sistema. El poder de la teoría tradicional para perpetuar el orden establecido va de la mano con su impotencia y se expresa en los consecutivos fracasos para transformar la realidad, intentos que culminan siempre en formalismos vacíos o reformas epidérmicas e inútiles. Por lo tanto, adolecen de fisuras a partir de las cuales es posible posicionar el enfoque crítico.

\section{La escuela de Frankfurt de segunda generación. Jürgen Habermas: teoría crítica e intereses del conocimiento}

Jürgen Habermas (1929) es miembro de segunda generación de la escuela, junto con otros discípulos suyos como Claus Offe (1940), Oskar Negt (1934), Albrecht Wellmer (1933-2018) ${ }^{16}$ y Alfred Schmidt (1940), este último discípulo de Horkheimer. Uno de sus méritos ha consistido en prolongar el programa de sus antecesores al relacionar la epistemología con otras dimensiones de la vida social: la política, los movimientos sociales, la comunicación y la cultura (Muñoz, 2005, pp. 250 y ss.).

Jürgen Habermas desarrolla y profundiza la crítica heredada de Horkheimer y Theodor Adorno (1903-1969) sobre la razón instrumental, y determina, de inicio, que la primacía de la racionalidad instrumental (la que ajusta la relación entre medios y fines) sobre la racionalidad objetiva (la que determina los fines) es el rasgo distintivo del pensamiento contemporáneo. Si bien en este sentido se adhiere a la crítica antipositivista de Popper, en el marco de un programa que busca culminar una modernidad inacabada, se distancia

16 Albrecht Wellmer se graduó de doctor en Filosofía (1966) con la tesis Metodología como teoría del conocimiento. La ciencia en Karl Popper. 
de él por la inspiración dialéctica y hermenéutica de su pensamiento ya que, al retomar la praxis como determinante fundamental del conocimiento, supera el encierro de la reflexión epistemológica en los estrechos linderos de las condiciones y procesos de los procedimientos lógicos que caracteriza la propuesta de Popper.

Por lo tanto, y por las polémicas entre ambos, Habermas puede ser considerado como la antítesis de Popper. Según Habermas, el territorio epistémico desde donde se encumbra la racionalidad instrumental es el positivismo al cual se propone desmontar sobre la base de una concepción amplia del conocimiento como saber y de la inclusión del interés como uno de sus elementos constitutivos; solo así es posible deslegitimar la pretensión de objetividad de la ciencia e integrar, desde este nuevo enfoque, la teoría y la praxis.

\section{Los intereses del conocimiento}

El primer aspecto básico de su teoría es concebir el conocimiento como el conjunto de saberes que hacen posible la acción humana. Desde allí, redimensiona, mediante reducción, el lugar de la ciencia y, por ampliación, el alcance de la epistemología: la ciencia no agota el conocimiento ya que solo es una de sus modalidades posibles; por tanto, la epistemología no se puede reducir al conocimiento científico y debe considerar otras formas de producción teórica; tampoco es posible que el problema del conocimiento se deba reducir al método, tal como pretende el positivismo, pues ello desplaza al sujeto que conoce del proceso de conocimiento y opaca el hecho de que el sujeto que conoce forma parte también del objeto de conocimiento. Al incluir la ciencia en el telón de fondo de otras formas de saber, al expandir la epistemología hacia otros saberes y liberar el conocimiento de su encierro en el método, pone las bases de una crítica de la teoría instrumental cuya intención final es relacio- 
nar el conocimiento con el proceso de autoconstitución del hombre y de la sociedad. A diferencia de Popper que ancla su teoría del conocimiento en la metafísica o la cosmología, Habermas considera que tanto la teoría de la sociedad como la del conocimiento se necesitan mutuamente al punto de que toda teoría del conocimiento es al mismo tiempo una teoría de la sociedad (Laso, 2004, p. 15).

El segundo aspecto de su teoría retoma la mutua implicación entre conocimiento y sociedad, y relaciona el conocimiento con las formas de desarrollo histórico de la sociedad. El producto de tal relación es el concepto clave de intereses del conocimiento 17. Habermas describe a la sociedad como constituida por dos dimensiones en torno a las cuales la humanidad se transforma a sí misma a lo largo de la historia: la dimensión técnica, construida sobre las relaciones con la naturaleza centradas en el trabajo productivo y reproductivo, y la dimensión social, construida a partir de las relaciones entre los hombres centradas en la cultura y las normas sociales.

Es evidente que en la sociedad contemporánea la dimensión técnica domina sobre la social y el establecimiento de una relación más equilibrada entre ellas es posible al elucidar los intereses de conocimiento que las atraviesan, entendidos como las orientaciones básicas de la sociedad humana respecto al proceso de reproducción y autoconstitución del género humano. El interés técnico es la orientación básica de la dimensión técnica y de su respectiva forma de conocimiento, encaminada al dominio de la naturaleza mediante las ciencias naturales. El interés práctico es la orientación básica de la dimensión social y de su respectiva forma de conocimiento orientada al desarrollo de las relaciones entre los hombres y su entendimiento mutuo mediante las ciencias hermenéuticas.

17 Este concepto se describe en el estudio de Habermas (1986b, pp. 164 y ss.). También cfr. Ureña, E. M. (1998, pp. 95 y ss.). En este aspecto sigo la sistematización de Laso, S. I. (2004, pp. 13 y ss.). 
La crítica al positivismo es obvia. En primer lugar, porque ninguna investigación - y su respectiva construcción del objeto de conocimiento - es neutral y desinteresada respecto a los intereses; más bien el interés es un elemento constitutivo del conocimiento y se produce según las orientaciones de autoconstitución del género humano. Por lo tanto, no se trata de captar un objeto para comprenderlo tal cual es, como tampoco es posible considerar el conocimiento una copia de la realidad. En segundo lugar, los intereses no solo condicionan la investigación y su objeto; también determinarán la experiencia del objeto, el lenguaje de esa experiencia y el ámbito en que se aplicará la acción derivada de ese conocimiento.

El tercer elemento consiste en expandir los intereses a un tercero: el interés emancipatorio, entendido como una nueva orientación básica que no corresponde a una tercera forma de desarrollo histórico al surgir del proceso mismo de autoconstitución de la sociedad humana. Su interés primario es librarse de la opresión causada por la naturaleza externa no dominada y por la naturaleza interna deficientemente socializada; el interés emancipatorio constituye la base y el punto de relación entre los intereses técnicos y prácticos, y se expresa en un tercer tipo de ciencias: las críticas. Estas atraviesan las ciencias naturales y prácticas porque constituyen una instancia de autorreflexión y de vinculación derivativa respecto al proceso de humanización. En definitiva, los intereses son racionales en cuanto no responden a necesidades empíricas, sino "que esas necesidades y esa relación dependen de la interpretación que de ellas hagan los hombres. Como toda interpretación pertenece a la dimensión comunicativa, la dimensión técnica... está empotrada en esta última. De allí la centralidad que Habermas otorga a la acción comunicativa" (Laso, 2004, p. 16); esta última categoría extiende y enriquece el concepto de intereses del conocimiento y permite relacionar de manera más profunda la teoría con la praxis. 
Las consecuencias de la concepción del interés emancipatorio como fuente y criterio de evaluación de los otros son profundas: entre las principales, se destaca el restablecer la relación entre ciencia y filosofía, esta última considerada ya no como reina, pero sí con un rol fundamental al interno de las ciencias. Las ciencias requieren de la filosofía para liberar el pensamiento de los estrechos márgenes del positivismo y desenmascarar la insuficiencia normativa del interés técnico respecto al proceso de autoconstitución humana.

La teoría de la acción comunicativa es otro de los puntales de la teoría habermasiana del conocimiento respecto a la cual establece una serie de distinciones explicitadas en la Tabla 3.

Tabla 3

Acciones comunicativas según Habermas

\begin{tabular}{|l|l|}
\hline \multicolumn{1}{|c|}{ Acciones } & \multicolumn{1}{c|}{ Relaciones con el mundo } \\
\hline Acción teleológica & $\begin{array}{l}\text { Concibe un solo mundo objetivo con el cual el actor puede establecer } \\
\text { dos relaciones: conocer estados de cosas existentes y traer a la exis- } \\
\text { tencia estados de cosas deseados. }\end{array}$ \\
\hline Acción estratégica & $\begin{array}{l}\text { Concibe un solo mundo, pero en interacción con otros agentes. Uso } \\
\text { del lenguaje como medio orientado al éxito y no al entendimiento. }\end{array}$ \\
\hline normas & $\begin{array}{l}\text { Concibe dos mundos: un mundo objetivo de cosas y un mundo so- } \\
\text { cial que consiste en normas institucionales que fijan reglas, roles y } \\
\text { valores. El actor se concibe como miembro de un grupo social al } \\
\text { que necesita para satisfacer sus necesidades. El individuo se disuelve } \\
\text { en la sociedad. }\end{array}$ \\
\hline Acción dramatúrgica & $\begin{array}{l}\text { Concibe tres mundos: además del mundo de las cosas y del mundo } \\
\text { social, incluye un mundo subjetivo al que solo el actor tiene acceso. } \\
\text { El actor interactúa y se comunica con otros actores para posicionar } \\
\text { su rol y su imagen. La sociedad se disuelve en el individuo. }\end{array}$ \\
\hline Acción comunicativa & $\begin{array}{l}\text { Concibe cuatro mundos: al mundo objetivo, social y subjetivo, agre- } \\
\text { ga el mundo del lenguaje mediante el cual los actores llegan a un } \\
\text { acuerdo en una acción orientada al entendimiento. }\end{array}$ \\
\hline
\end{tabular}

Elaboración de los autores a partir de Laso (2004, p. 17). 
Las acciones así concebidas se articulan en una doble dimensión: la dimensión instrumental, que comprende lo teleológico-estratégico; y la dimensión comunicativa, basada en la interacción por procesos cooperativos de interpretación de significados y valoraciones que requieren un cierto grado de comunidad en el mundo de la vida (Laso, 2004, p. 20). La acción comunicativa es la más importante de todas por ser constitutiva de la sociedad humana; la considera el fundamento de su filosofía de la racionalidad y ayuda a comprender la razón como una trama discursiva que articula las acciones de los individuos. A la vez, es un concepto crítico ya que denuncia "el carácter mutilado de la comunicación vigente en la sociedad contemporánea” (p. 21), así como otros aspectos característicos de la deshumanización como la instrumentalización del conocimiento y de las relaciones entre los individuos y el dominio suicida respecto al medioambiente. Denuncia, en suma, la hegemonía del interés instrumental sobre el interés práctico (comunicativo) y emancipatorio. La Tabla 4 expresa las relaciones entre las dimensiones, intereses y formas de conocimiento y acciones, según Habermas.

\section{La metateoría habermasiana}

La metateoría habermasiana se juega en dos escenarios. El primero profundiza antes que las diferencias las relaciones del conocimiento teórico con otras formas de conocimiento denominadas preteoréticas, vale decir, el sentido común o conocimiento no científico. El segundo prolonga y retoma la reflexión de Horkheimer para desarrollar la teoría dialéctica en contraposición con la teoría analítica. Veamos los puntos fundamentales de ambos desarrollos. 


\section{2}

Tabla 4

Dimensiones del desarrollo histórico de la sociedad según Habermas

\begin{tabular}{|c|c|}
\hline \multicolumn{2}{|c|}{ Dimensiones } \\
\hline Dimensión técnica & Dimensión social \\
\hline $\begin{array}{l}\text { Relaciones hombre-naturaleza. } \\
\text { Trabajo productivo y reproductivo. } \\
\text { Orientación básica: interés técnico (dominio } \\
\text { sobre la naturaleza). }\end{array}$ & $\begin{array}{l}\text { Relaciones entre los hombres. } \\
\text { Cultura y normas sociales. } \\
\text { Orientación básica: interés práctico (relacio- } \\
\text { nes y entendimiento entre los hombres). }\end{array}$ \\
\hline \multicolumn{2}{|c|}{ Aspectos cognitivos } \\
\hline $\begin{array}{l}\text { Interés técnico: ciencias empírico-analíticas. } \\
\text { Objeto de conocimiento técnico (manipula- } \\
\text { ción instrumental de la naturaleza). } \\
\text { Lenguaje fisicalista. } \\
\text { Ciencias naturales. }\end{array}$ & $\begin{array}{l}\text { Interés práctico: ciencias } \\
\text { histórico-hermenéuticas. } \\
\text { Objeto de conocimiento práctico (comuni- } \\
\text { cación entre individuos). } \\
\text { Lenguaje intencional. } \\
\text { Ciencias hermenéuticas. }\end{array}$ \\
\hline $\begin{array}{l}\text { Acciones instrumentales: acciones teleológi- } \\
\text { cas y estratégicas (medios y fines) enroladas } \\
\text { en la orientación técnica. }\end{array}$ & $\begin{array}{l}\text { Acciones orientadas por normas y roles } \\
\text { insertadas en la orientación práctica. }\end{array}$ \\
\hline \multicolumn{2}{|c|}{$\begin{array}{c}\text { Interés emancipatorio (o interés crítico) como orientación básica de la sociedad: } \\
\text { ciencias sociales críticamente orientadas. } \\
\text { Se identifica con el proceso de autoconstitución humana. } \\
\text { Base y fuerza derivativa de los intereses técnicos y prácticos. } \\
\text { Acciones orientadas al entendimiento, argumentación } \\
\text { y reconocimiento de validez de los actos de habla. } \\
\text { Guiadas por el interés crítico. }\end{array}$} \\
\hline
\end{tabular}

Elaboración de los autores a partir de Laso (2004, p. 14).

\section{Conocimiento teórico y conocimiento preteorético}

Habermas, a lo largo de un ensayo escrito en 1977 (1996, pp. 453 y ss.), establece que el sentido, entendido como el significado que los actores atribuyen a sus acciones, es una condición ontológica de la sociedad humana en cuanto producida y reproducida por sus miembros que hace posible las acciones y la intersubjetividad. La 
realidad social, como mundo social de la vida, está simbólicamente preestructurada; es preteorética y, en rigor, no necesita de la teoría para acceder al sentido. Además, es una realidad que habla y se comunica. Esta ontología conecta el conocimiento con la producción y las relaciones sociales, y entiende las ciencias sociales como acceso comprensivo - hermenéutico - a su ámbito de objetos "porque encuentra en él procesos de entendimiento a través de los cuales y en los cuales ese ámbito objetual se ha constituido previamente, es decir, con anterioridad a toda intervención teorética" (1996, p. 457). Por tanto, no son las teorías las que estructuran al mundo o logran entenderlo sobre el supuesto de que existe un vacío de significados. El mundo ya está estructurado por el significado que le atribuyen sus actores.

En este contexto, toda teoría se entiende como materialización o expresión simbólica de la realidad, una metáfora que interpreta la realidad de tal manera que, en rigor, todas las ciencias son hermenéuticas, incluso las naturales. Por tanto, cualquier teoría debe ser interrogada a partir del sentido, el referente teorético básico, pues todas las teorías son interpretaciones de la realidad. No obstante, en las ciencias sociales tiene lugar una doble hermenéutica, pues el investigador interpreta los enunciados del actor social (el mundo social habla) y a paso seguido los compara con los suyos mediante una relación compleja entre teoría, realidad y lenguaje. En cambio, en las ciencias naturales ocurre un tipo de hermenéutica diversa, de una sola vía, ya que se trata de un mundo sin enunciados, que no habla. Habla el investigador e interpreta lo que él dice del mundo.

La pertenencia del investigador a un mundo de la vida trae consigo presupuestos del lenguaje y de la acción de tal manera que la teoría del investigador también es anterior a la realidad social y, además, la realidad social está constituida con anterioridad a la teo- 
ría, es decir, es precientífica. El científico se topa con una realidad construida por los actores, por los sentidos que ellos han generado; a la vez, todo científico participa de un proceso de entendimiento inmerso en una situación comunicativa que lo vuelve interlocutor participante de su objeto.

Habermas asume innovadoramente la distinción entre teoría y sentido común. Comienza afirmando que ambas poseen estructuras similares, pero considera que solo la relación entre ellos produce el saber de la realidad sociocultural según un método que relaciona los saberes preteoréticos y los teóricos, de tal manera que los segundos logren traducir e interpretar los primeros. Así, el científico, al ser parte del mundo social de la vida, participa tanto del conocimiento teórico como preteórico, a la vez que forma parte de la sociedad, del objeto que constituye su investigación; con ello, trasciende también la dualidad sujeto-objeto de conocimiento propia del positivismo. El científico "tiene en cierto modo que pertenecer al mundo social de la vida cuyos ingredientes trata de describir. Pues para describirlos tiene que entenderlos; para entenderlos, tiene en principio que poder participar en su generación; y la generación presupone pertenencia" (Habermas, 1996, p. 468).

Las consecuencias metodológicas de esta manera de ejercer la teoría son muy profundas y las resumimos en tres ideas fundamentales e interconectadas entre sí:

En primer lugar, las teorías tratan de conocer manifestaciones simbólicas, tanto si se trata de las teorías del investigador cuanto de las preteorías del campo, tanto de las acciones sociales cuanto de sus relaciones.

En segundo lugar, el conocimiento teórico de la realidad social accede a las manifestaciones simbólicas mediante la participación del 
investigador en el mundo social que busca comprender. Por lo tanto, la investigación social es una experiencia comunicativa que implica diálogos para interrogar el sentido y supone participación en un proceso de entendimiento. No se trata de empatía, sino de participación. La investigación es una actitud realizativa (performativa) de un participante en la comunicación cuyo logro a alcanzar consiste en iluminar desde dentro los significados de las producciones humanas, revelando la posición del actor. Si el investigador no participa — real o virtualmente - del grupo que quiere conocer, no puede comprender. La realidad simbólicamente preestructurada le resulta impermeable e ininteligible al observador ya que la observación, como proceso autorreferenciado y controlable, no es suficiente para comprender las realidades sociales y del espíritu, las cuales están simbólicamente predeterminadas. Es válida si va acompañada por una comprensión del sentido en el contexto de una experiencia dialogal y comunicativa (p. 460).

En tercer lugar, también el científico social hace uso de un saber del que intuitivamente dispone como lego cuando incorpora sus teorías del mismo modo que la gente posee el sentido común, al incorporarlas en su mundo preteorético. Mientras no identifique su saber preteórico y no establezca qué papel desempeña en la investigación, no puede controlar las consecuencias de su participación en el grupo cuyas acciones quiere comprender. Por tanto, debe realizar el tremendo esfuerzo de clarificarse a sí mismo qué supuestos teóricos no consentidos o no conscientes interfieren en su investigación. Habermas incorpora el sentido común, o conocimiento preteórico, como elemento esencial del método y lo incluye, además, en el lado del investigador y en confrontación con sus teorías. Las teorías también pueden actuar como sentido común e imponer sus reglas del juego, sin que el investigador sea consciente de ello. 


\section{6}

\section{Teoría analítica y teoría dialéctica}

En otro ensayo (Habermas [1963] 1996, pp. 21 y ss.) también referido a la comprensión de la vida social, construye la distinción entre teoría analítica y teoría dialéctica para esbozar los rasgos adicionales de su metateoría. En el contexto de la comprensión de la realidad social, define las teorías como "esquemas de ordenación que construimos a voluntad en un marco sintácticamente vinculante. Tales esquemas resultan útiles para un ámbito especial de objetos cuando la diversidad de lo real se ajusta efectivamente a ellos" (p. 22). Así, todo saber es mediatizado por categorías del entendimiento de tal modo que las teorías no constituyen copias de lo real como pretende el positivismo, sino instrumentos de interpretación de la realidad; ni siquiera podemos suponer que las teorías se correspondan ontológicamente con la realidad. En el sentido de que las teorías no expresan la realidad, se acerca a Popper, no obstante lo cual, se distancia de él en el punto de establecer que el saber no es mera opinión.

El segundo aspecto de la metateoría habermasiana retoma la tradición proveniente de Horkheimer basada en una doble distinción: la teoría analítica, encaminada al dominio sobre la naturaleza, y la teoría dialéctica cuyo fin es comprender el sentido de las acciones humanas. La diferencia entre ambas modalidades se aprecia en la Tabla 5.

La teoría dialéctica, signada por la comprensión, es la alternativa al programa positivista y, por lo tanto, más cercana a la hermenéutica y a la interpretación, rasgo característico de las ciencias sociales y de la educación. A partir de tal apreciación de las ciencias sociales, se distancia definitivamente de Popper cuya propuesta se basa en una cierta homogeneidad metodológica entre ciencias naturales y sociales, pues ambas invocan el mismo rigor lógico que establece leyes y modelos, no interpretaciones (Popper, 2005, pp. 201 y ss.). 


\section{7}

Tabla 5

Contrastación entre teoría analítica y teoría dialéctica según Habermas

\begin{tabular}{|l|l|}
\hline \multicolumn{1}{|c|}{ Teoría analítica } & \multicolumn{1}{c|}{ Teoría dialéctica } \\
\hline $\begin{array}{l}\text { Su modelo son las ciencias naturales } \\
\text { basadas en operaciones hipotéticas } \\
\text { deductivas. }\end{array}$ & $\begin{array}{l}\text { Explica la sociedad y las acciones humanas según } \\
\text { la explicación hermenéutica de sentido. } \\
\text { Las categorías se determinan progresivamente. }\end{array}$ \\
\hline Se basa en la observación controlada. & Parte de la conciencia de los sujetos. \\
\hline $\begin{array}{l}\text { Plantea leyes restrictivas que pretenden } \\
\text { validez universal. }\end{array}$ & $\begin{array}{l}\text { Plantea leyes de validez comprehensiva sin validez } \\
\text { general pero que aprenden una situación histórica } \\
\text { en su conjunto. }\end{array}$ \\
\hline $\begin{array}{l}\text { El valor de conocimiento se materializa } \\
\text { en las leyes empíricamente contrasta- } \\
\text { das con capacidad de proponer técni- } \\
\text { cas aplicadas a la práctica para con- } \\
\text { trolar procesos sociales como si fueran } \\
\text { naturales. }\end{array}$ & $\begin{array}{l}\text { Se deja interpelar por el objeto de conocimiento } \\
\text { para plantear sus problemas a partir del objeto } \\
\text { Une la reflexión teórica con la práctica social; la } \\
\text { dimensión instrumental con la dimensión crítica. }\end{array}$ \\
\hline $\begin{array}{l}\text { Cosifica la vida social y objetiva su reali- } \\
\text { dad enajenando su conocimiento de los } \\
\text { intereses del investigador. }\end{array}$ & Los intereses son constitutivos del acto de conocer. \\
\hline
\end{tabular}

Elaboración de los autores a partir de Habermas (1996).

\section{Comentarios e implicaciones}

La propuesta de Horkheimer pone en escena la centralidad del sujeto intelectual, que hace de sus opciones y voluntad de transformación el punto de arranque para construir la teoría crítica sobre otras condiciones del pensamiento tales como la delimitación de un objeto o la determinación de las condiciones del conocimiento. El rol del sujeto intelectual en relación con los movimientos emancipatorios, además, es un tema clave respecto al cual Horkheimer favorece la imagen de un teórico de vanguardia no solo independiente de los partidos y movimientos, sino en permanente pugna con ellos, de 


\section{8}

cierta manera un personaje solitario y en minoría también respecto a los teóricos tradicionales.

El rol del crítico no se limita a expresar y describir el pensamiento de una clase ni tampoco su función es avalarlo, ya que las diversas formas de autoconciencia no expresan necesariamente la verdad sobre esa clase ni implican de por sí emancipación; cualquiera de dichas tareas es legítima solo en razón de su eficacia transformadora. Por ello, la relación del intelectual con las clases sociales será siempre conflictiva, y la teoría, cuya intencionalidad es apurar las formas sociales nuevas, debería ser ejercida, incluso, como "crítica agresiva" nada contemplativa ni condescendiente (p. 247).

Como el proletariado no genera espontáneamente teoría, el conflicto surge también de la visión de conjunto más amplia que puede aportar el teórico al leer la realidad y determinar medios y fines para asegurar la "coherencia interna" de los procesos. Surge así el peligro de que el intelectual crítico se constituya en intelligentsia, forma de ejercicio teórico que, aunque situada en el escenario de las luchas sociales, no deja de ser abstracta y formal, autónoma y desligada de la praxis, cuya tendencia natural es imponer sus convicciones a la conciencia general. Por ello, "la vanguardia necesita la perspicacia en la lucha política, no la información académica acerca de su pretendida posición" (p. 253).

El pensamiento de Horkheimer ha sido tan discutido como ampliado y desarrollado. Uno de sus puntos débiles radica en la pretensión de criticar una totalidad desde otra, como si fuera posible reducir la diversidad de ejercicios teóricos y de saberes a cualquiera de las dos posibilidades en un momento en que resulta obvio el carácter multiforme del pensamiento. Asimismo, tanto a él como a Adorno se les reprocha que su influencia en América Latina ha sido tan poderosa 
que ha impedido pensar "todo lo que de nuestra realidad y cultura no cabía ni en su sistematización ni en su dialéctica” (Barbero, 1998, p. 69); sin embargo, no dudamos de su utilidad para advertir, en primer lugar, que toda teoría es producto de relaciones — no exclusivamente de producción — y del trabajo, y que inevitablemente está unida a una praxis; en definitiva, el conocimiento mismo es una práctica social históricamente determinada. Finalmente, a partir de que todo pensamiento contiene al mismo tiempo el secreto y la protesta del presente (lo real no es racional, pero debe serlo), es posible comprender que, antes que la objetividad, la razón emancipatoria es el alimento de la teoría. Por lo tanto, ninguna teoría es neutral y la razón instrumental no puede constituirse en el horizonte final de su ejercicio.

Si evaluáramos a Popper según las categorías analíticas de Horkheimer, no tardaríamos en advertir que su propuesta es la antítesis perfecta por su negación de la historia y de las utopías. Popper, sin duda, ejemplifica a la perfección la teoría tradicional porque postula un sujeto abstracto basado en la relación invariable respecto a la realidad histórica y social y a su objeto; ya porque se fundamenta en un procedimiento autorreferenciado según las leyes de falsación, o porque su enfoque en la solución de problemas perpetúa la estructura social y hace de la ciencia un generador de valores de utilidad y no de transformación. No obstante, debemos recordar que la crítica de Horkheimer no deslegitima ni anula el ejercicio de la ciencia tradicional, sino su pretensión de erigirse en criterio absoluto y autónomo respecto a la transformación social y la humanización.

Si bien Habermas ha sido blanco de cuestionamiento y críticas porque supuestamente representa la ideología de la democracia liberal que idealiza el consenso y la acción comunicativa por encima de las determinaciones y exclusiones reales del poder; y porque los movimientos sociales consideran que el conocimiento interpretativo 
no cubre las expectativas de la emancipación (Walsh, 2007). No obstante, el aporte de Habermas diseña un método claro para superar la distinción dual sujeto-objeto, raíz de todas las formas de pensar que constituyen la base de relaciones hegemónicas y excluyentes del tipo hombre-mujer, hombre-naturaleza, civilizado-salvaje, etc., según denuncian los ideólogos de los movimientos sociales.

Las aplicaciones para el ejercicio teórico se relacionan con la teoría dialéctica, cuya idea central consiste en que los datos y las categorías con las que pretendemos acercarnos a la comprensión de la realidad social "vienen estructurados por el plexo de la totalidad social" (Habermas, 1996, p. 23); por lo tanto, el sujeto de conocimiento, la teoría y el trabajo científico no son puntos de partida, sino parte integrante del objeto de conocimiento, de la totalidad social que es necesario conocer. Al estar inmersos el investigador y sus teorías en el objeto que se busca conocer, ninguna de las categorías que usa le deben "permanecer externas" (p. 23) y en ningún momento deben actuar desde el sentido común, sin sentir la necesidad de controlar sus alcances y restricciones.

Tal afirmación fundamental conlleva profundas consecuencias para nuestra actitud cognoscitiva respecto a la realidad social: no se trata de acercarse a ella para observar y registrar regularidades empíricas o solucionar problemas (como pretende Popper), pues tales esquemas no pueden penetrar la estructura social y, de cierta manera, la falsifica; además, la teoría se torna irrelevante porque es invalidada por el objeto (p. 23).

La teoría dialéctica debe ser entendida también como una actitud epistémica profunda que supera la lógica de exclusión de los opuestos para vincularlos complementaria y relacionalmente. Así, la actitud dialéctica no enfrenta el saber teórico con los saberes preteo- 
réticos para anularlos e invalidarlos; los incorpora en una relación generadora de conocimientos de la misma manera que no contrapone y relaciona los factores subjetivos de la investigación (el género y el mundo emotivo del investigador) con los objetivos.

En relación con la naturaleza y la trama de la vida amenazada en el planeta, el pensamiento crítico es relevante porque denuncia la racionalidad instrumental de la ciencia y la técnica condicionadas al sometimiento de la naturaleza y la aniquilación de la vida. Hans Jonas (1903-1993) asume la tarea de traducir para la ética el contraste entre teoría tradicional y teoría crítica, y postula la ética de la responsabilidad (1995) basada en evidenciar los principios de la ética tradicional y de la ética crítica (Juncosa, 2013, pp. 239-244). La ética crítica parte de una serie de transformaciones respecto a la noción de naturaleza y la manera de entender lo humano como parte de lo viviente, a la vez que evidencia los siguientes supuestos de la ética tradicional que alimentan relaciones de dominio respecto a lo viviente:

1) neutralidad ética de la actividad humana respecto a la naturaleza; 2) carácter antropocéntrico de la ética tradicional que desconoce las relaciones con la naturaleza y lo viviente; 3) concepción de la naturaleza como realidad dada, incompleta o imperfecta sin la intervención humana y, por lo tanto, objeto necesario de su acción. Así, la visión tecnológica se instaura desde una visión optimista de sus propias posibilidades sobre un trasfondo pesimista respecto a la naturaleza, considerada como algo dado sin valor y disponible a cualquier apuesta de mejoría. (Lander, 1994, pp. 138 y 143) (Juncosa, 2013, 240-241)

La ética crítica concibe la naturaleza como totalidad de lo viviente, y es una realidad autónoma y completa en sí misma que no requiere de la acción humana para perfeccionarse; está habitada por finalidad e intencionalidad propia, por valores y motivaciones. A su 
vez, el hombre es un organismo que integra lo viviente y lo orgánico constituye su subjetividad. Las consecuencias de tales puntos de partida apuntan a desbloquear la ética de las relaciones interpersonales para hacer de la naturaleza "el polo obligado de la acción ética" (p. 241), acción que busca asegurar no solo la supervivencia humana, sino también el sostenimiento de la vida en todas sus formas. Por lo tanto, no existen acciones éticamente neutrales respecto al sostenimiento de la vida. Entre las consecuencias epistémicas de concebir al hombre como organismo viviente consta "la superación de toda forma de dualismo (noúmeno-fenómeno, mente-cuerpo, sociedadnaturaleza, reino de la necesidad-reino de la libertad, etc.) porque enajena y escinde del ser" (p. 241).

\section{El paradigma del pensamiento complejo de Edgar Morin: la teoría como sistema abierto de ideas}

En la vida de Edgar Morin (París, 1921) confluyen, de manera tan temprana como intensa, la militancia política y la producción académica. A los 15 años fue miembro de los anarquistas catalanes y en 1941 se unió al Partido Comunista Francés, en su condición de judío, para integrarse a la resistencia contra la invasión nazi. Luego de ser expulsado del partido en 1951, por sus críticas a los sistemas que conformaban el socialismo real (el estalinismo, el régimen de Tito y de China), formó parte de los Comités de Intelectuales por la Paz contra la Remilitarización de Alemania y la guerra en Argelia (1954) y se involucró desde las aulas de la Universidad de Nanterre en las revueltas estudiantiles de Mayo del 68. Este recorrido da cuenta de su militancia reflexiva pero también de su aversión hacia los sistemas cerrados de ideas como las ideologías y los dogmas.

Entre los contactos importantes con otros filósofos y sociólogos, cabe destacar la relación, en los años 60, con Roland Barthes 
(1915-1980) y Cornelius Castoriadis (1922-1997), quienes influirán decisivamente en su forma de concebir el sujeto, el pensamiento y la comunicación. Su huella está presente en la convicción de que es posible entender mejor problemas contemporáneos como el cine, la literatura, la muerte y la subjetividad mediante la integración de múltiples perspectivas integradas que confluyen en la mirada humanista. Las experiencias decisivas que contribuirán a consolidar su epistemología ocurrirán por esos mismos años, durante los cuales incursionará en el territorio de las ciencias "duras", en especial, en las ciencias del cosmos, la física y la ecología.

Para ello resultó clave su paso por el Instituto Jonas Salk de Estudios Biológicos (California), a instancias del biólogo francés y Premio Nobel Jacques Monod (1910-1976), donde profundizó las implicaciones de la revolución biológica en las ciencias sociales y humanas. Inmediatamente, a partir de los aportes del zoólogo británico Gregory Bateson (1904-1980), integró los principios de la teoría general de sistemas, de la cibernética y de la teoría de la información, al mismo tiempo que asimiló, entre otros, la propuesta del físico de origen soviético Ilya Prigogine (1917-2003) de una ciencia abierta al caos y a la incertidumbre, así como las del matemático John von Neumann (1903-1957) y del cibernetista Heinz von Foerster (1911-2002), relacionadas con el "azar organizador" y la "autoorganización”.

Finalmente, durante su estadía en la Universidad de Berkeley, se abrió al paradigma del nuevo pensamiento ecológico y sus implicaciones para una nueva epistemología. Semejante itinerario consolida la orientación inter y transdisciplinaria, y hace posible la identificación de los dos principios fundamentales que regirán su propuesta denominada pensamiento complejo: la globalidad y la reorganización, surgidos de la interacción de las humanidades con las ciencias naturales y cibernéticas. 
La obra de Morin es extensa pero la de mayor relevancia epistemológica para la metateoría es, sin duda, El método, que consta de seis tomos. El cuarto, Las ideas. Su hábitat, su vida, sus costumbres, su organización (1992), expone los fundamentos de su metateoría y constituye la principal fuente de este apartado. Los supuestos ontológicos y políticos del pensamiento complejo, en cambio, los hemos tomado fundamentalmente de su obra La mente bien ordenada (2001), que desarrolla muy claramente la visión de la realidad y del individuo, así como sus implicaciones para el conocimiento.

\section{Compromisos ontológicos, éticos y políticos del pensamiento complejo}

La visión de la realidad asumida por Morin se basa en el isomorfismo (del griego iso: 'igual'; morfé: 'forma') o correspondencia compleja entre universo, vida y pensamiento, según la visión emergente de la segunda revolución científica, operada a partir de los años 60 por la ecología, las ciencias de la tierra, la cosmología y la cibernética. Estas no conciben su objeto como un sector o parcela de la realidad; su objeto es el sistema, entendido como un todo organizador. En consecuencia, la visión de la realidad que contribuyen a modelar corresponde a la de una entidad compleja que se autoorganiza y cuyos elementos establecen relaciones de diverso tipo como las interacciones, las retroacciones y la interretroacciones a partir de las cuales "el todo y las partes se entreproducen y se entreorganizan" (2001, p. 33). En consecuencia, es posible comprender diversos fenómenos económicos, sociales, políticos o psicológicos —incluido el pensamiento - considerados sistemas o totalidades a partir de la dinámica de los organismos biológicos: la bio-lógica.

La noción de sujeto se construye sobre la misma base (2007, pp. 170 y ss.), una de cuyas coordenadas lo define como ser autóno- 
mo, autonomía que no es absoluta sino relativa a y en interacción con su entorno biológico, cultural y social. La segunda interrelaciona complementariamente el carácter de individuo (la consistencia del ser biológicamente único) con el de sujeto (las tensiones con la especie que representa, los aspectos universales). Así, la dimensión cognitiva es esencial para la vida del sujeto, pues todo proceso de intercambio con el entorno, en el fondo, se puede traducir en términos de intercambio de información. En el sujeto el conocimiento es un acto de cómputo, sí, pero con relación a sí mismo y, por lo tanto, es un acto de cómputo irreductible, no maquinal.

La noción de sentido es otro de los aspectos relevantes (2007, pp. 18 y ss.) para la epistemología de Morin y puede ser entendida de dos maneras: en tanto teleología, o la orientación histórica general impresa en la realidad y atribuida a una instancia providencialista, externa y anterior; y en tanto telenomía, o necesidad inherente al ser mismo de atribuirse finalidades y asumir la subjetividad. Con respecto a la primera, coincide parcialmente con Popper en cuanto a la imposibilidad de reconocer la existencia de cursos de la historia de tipo providencialista que actúan como marcos totales. Desde este punto de vista, el sentido no reina en las cosas; de hecho, tanto en la macro como en la microfísica reina la arbitrariedad y la deflagración en mayor medida que el orden y la armonía; asimismo, tal como lo demuestra la evolución, la vida también procede según itinerarios multidireccionales e inesperados en los que la conciencia no parece ser más que un resultado aleatorio y casual antes que un desemboque esperado.

La telenomía, en cambio, es un rasgo ontológico del ser humano cargado de consecuencias para la existencia y el pensamiento, la más importante de las cuales consiste en que el sentido, al mismo tiempo que frágil, es una emergencia y una construcción; no es un 


\section{6}

hecho dado y anterior, sino producido por el conocimiento y la subjetividad sobre el trasfondo del no-sentido teleológico. La emergencia de los sentidos en un marco de no-sentido implica consecuencias epistemológicas profundas, entre las más importantes está la legitimidad de la hermenéutica y la necesaria apertura del pensamiento a la incertidumbre, a lo inconcebible e ininteligible, donde toda comprensión o propuesta de sentido, en el fondo, es una apuesta abierta (2007, p. 165).

Un último aspecto de la visión sobre la historia que refuerza la relación orden-desorden es la teoría de la acción (ecología de la acción) expresada en dos principios fundamentales (2001, p. 117): 1. Toda acción, una vez lanzada, entra en un juego de interacciones y retroacciones que pueden ocasionar resultados desviados de los fines o inesperados; 2. Las consecuencias últimas de la acción son impredecibles. La incertidumbre y la impredecibilidad son, por lo tanto, condiciones normales de la vida y del conocimiento.

Además, la mirada histórica de Morin atribuye al presente el carácter de crisis profunda y global que es resultado de una manera de pensar. Por ello, Morin propone una nueva forma de pensar que se encarna en su programa de reforma del pensamiento, reforma "no programática, sino paradigmática, que concierne a nuestra aptitud para organizar el conocimiento" (2001, p. 22). Precisamente será la bio-lógica, o lógica de lo viviente, la fuente de los principios-guías para pensar bien que encauzarán su reforma del pensamiento y sentarán las bases del pensamiento complejo (complexus: lo que está tejido con), y cuya potencialidad consiste en permitir captar las partes por el todo $y$, viceversa, reconocer y tratar realidades solidarias a la vez que conflictivas, comprender los fenómenos según las múltiples dimensiones que los constituyen, y por último, respetar lo diverso y reconocer lo único. Los siete principios son los siguientes (pp. 123 y ss.): 
1. El principio sistémico u organizativo que consiste en relacionar el conocimiento de las partes con el conocimiento del todo, recuperando el principio de la lanzadera de Pascal. ${ }^{18} \mathrm{El}$ todo confiere a las partes el carácter de emergencias y las dota de cualidades que serían inexistentes si se las considera individualmente.

2. El principio hologramático según el cual no solo la parte se encuentra en el todo, sino donde el todo está inscrito en la parte, tal como la totalidad del patrimonio genético está presente en la célula individual o la sociedad (sus normas, lenguaje y cultura) está presente en el individuo.

3. El principio del bucle retroactivo (feedback) es el conjunto de retroacciones autorreguladoras de un organismo que permite su homeostasis o adaptación a las presiones y demás del sistema. Al reelaborar las transformaciones del entorno, el feedback se contrapone a la causalidad lineal porque da lugar a nuevas direcciones y opciones imprevistas que hacen posible la persistencia del organismo. En su forma negativa, el principio del bucle retroactivo reduce las desviaciones; en su forma positiva, es un mecanismo amplificador.

4. El principio del bucle recursivo que supera la noción de regulación por la de autoproducción y autoorganización. Se trata de un bucle generador, según el cual los productos y efectos son a la vez productores y causantes de lo que los produce. Así, es cierto que los individuos son producto de la cultura, pero, a la vez, la producen y transforman con su práctica.

5. El principio de autonomía-dependencia (auto-eco-organización), según el cual los seres vivos son seres autoorganizadores e incluyen interacciones con el medio para mantener su autonomía mediante intercambios de energía. Para los seres vivos

18 "Considero imposible conocer las partes sin conocer el todo, y tampoco conocer el todo sin conocer particularmente las partes". Citado en Morin (2001, p. 123). 
en general esos intercambios ocurren con el entorno geoecológico; para los humanos, con la cultura. Los intercambios energéticos implican la dualidad muerte-vida en la constitución misma de los procesos de regeneración.

6. El principio dialógico permite asumir racionalmente la inseparabilidad de nociones contradictorias y unir dos principios o nociones que deben excluirse mutuamente, pero que son indisociables en una misma realidad. Así, el cosmos integra dialógicamente la secuencia orden-desorden-organización, integración propia también del mundo biológico como humano. El pensamiento, por ejemplo, integra tantos procesos objetivos como subjetivos, reorganizándolos permanentemente.

7. El principio de la reintroducción del conocedor en todo conocimiento, según el cual todo conocimiento es una reconstrucción-traducción por un espíritu-cerebro en una cultura y un tiempo dado.

\section{La metateoría del pensamiento complejo}

Lo medular de la metateoría de Morin se desarrolla a lo largo del tomo IV de El método. Las ideas. Su hábitat, su vida, sus costumbres, su organización, en el cual describe el mundo de las ideas como si se tratara de un mundo biológico, donde las ideas son seres dotados de vida que se reproducen en una atmósfera propia y poseen sus propias reglas de evolución. El presente apartado describirá el "ecotipo" del mundo de las ideas (la noosfera), la estructura interna de las teorías y su relación con seres de otro tipo que habitan el mismo mundo. Luego, establecerá el lugar del lenguaje y la lógica, a los que considera polimáquinas de la teoría; finalmente, concluirá con el análisis de las posibilidades de articulación teórica explícitas (las disciplinas) o subyacentes (los paradigmas). 


\section{Las teorías: entidades logomorfas de la noosfera}

Tal como sucede con los seres biológicos, las ideas tienen su propio ser y existencia; son medios (instrumentos) al mismo tiempo que elementos constitutivos de un mundo llamado noosfera, o tercer mundo, análogo al mundo de las ideas de Popper, en el que habitan las cosas del espíritu, productos culturales, nociones, teorías, conocimientos científicos, etc. Las ideas, aunque son producidas y dependientes, adquieren "una realidad y una autonomía objetivas" (Morin, 1992, p. 112), de tal manera que "hay que considerar la vida de las ideas, no ya en el sentido metafórico y vago del término 'vida', sino enraizando este sentido en la teoría de la auto-eco-organización de lo viviente" (p. 114). La Figura 3 muestra el lugar y las relaciones de la noosfera con el resto de estratos de la antroposfera (p. 126).

Figura 3

Ubicación de la noosfera en el contexto de los estratos de la antroposfera

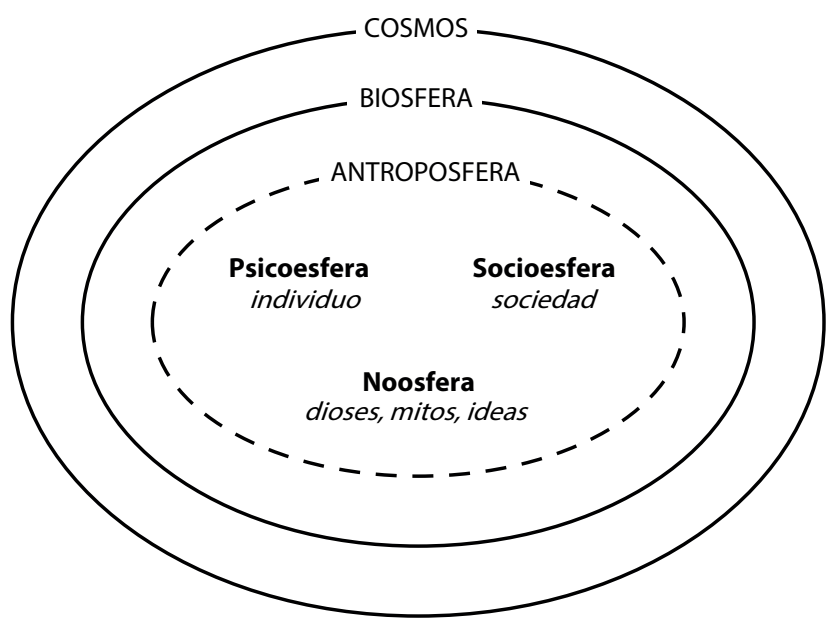

Tomado de Morin (1992, p. 126). 
Estos estratos, una trinidad inmersa articulada simbióticamente y englobada por la naturaleza (biosfera) y el cosmos, son la psicoesfera, la socioesfera y la noosfera. La psicoesfera es el mundo de los espíritus-cerebros individuales, fuente de las representaciones y causa de su consistencia. La socioesfera hace posible la concretización de las representaciones y que estas tengan vida por medio de la cultura, producida por las interacciones entre espíritus-cerebros y continente del lenguaje, el saber, las reglas lógicas y paradigmáticas. La noosfera, o tercer reino, es un constituyente objetivo de la realidad humana cuya demografía consiste de "seres materialmente enraizados, pero de naturaleza espiritual” (Morin, 1992, p. 118), cuyo soporte físico son las inscripciones cerebrales y los intercambios energéticos. Los tres mundos son simbióticos, ya que cada uno vive y requiere del otro y que cada instancia es medio y fin para el otro. Las simbiosis entre los mundos no siempre son sanas y emancipatorias: a veces, el mundo de las ideas impone sus reglas al resto, como en el caso de la técnica o de la ideología.

Los entes de la noosfera, al mismo tiempo que viven en la psicoesfera y la socioesfera, son necesarios para la regeneración de cada uno de ellos. A partir de una de las tipologías propuestas por el autor, los entes noológicos son de dos clases: seres gaseosos, que se disipan con la misma facilidad con que emergen (sueños); y seres sólidos, de carácter estable, los cuales incluyen las entidades cosmo-bio-antropomorfas (mitos, religiones, genios, espíritus, dioses), y las entidades logomorfas (doctrinas, teorías, filosofías, sistemas de ideas). Entre las entidades cosmo-bio-antropomorfas y las logomorfas existe una ruptura ontológica. Todas estas entidades conforman tres reinos fundamentales: los dioses (seres religiosos), los productos culturales (seres estéticos) y las ideas (teorías, ideologías, creencias). 
Según la metáfora biológica, los seres del espíritu, como todo ser vivo, se organizan, garantizan su existencia, crean su medio y reproducen desdoblándose "a través de mil redes de comunicación humana, a través del discurso, la educación, el adoctrinamiento, la palabra, el escrito, la imagen" (p. 129). Asimismo, se regeneran sin cesar según sus propias reglas de evolución al pasar por diversas fases: de los mitos arcaicos a las grandes religiones de la Antigüedad y de los tiempos modernos; de la proliferación de ideologías y las ideas abstractas hasta el saber técnico y el universo imaginario de los productos culturales (literatura, novela, cine y televisión).

La noología es la ciencia que hace posible comprender las cosas del espíritu como entidades objetivas, así como sus principios de organización; asume que sus entes poseen una existencia propia, diversa a lo concreto, sin que ello implique reducir su grado de realidad a reverberaciones de la psique (psicologismo) o de la sociedad (sociologismo); estos entes son autónomos (eventualmente soberanos) y enraizados en la psique y la sociedad. Para comprender los entes noológicos es necesario integrar tres ángulos: el noológico, el psicológico y el sociológico de tal manera que sea posible no solo concebirlos como productos o constructos, sino también como productores de sentido, ya que las religiones, los productos culturales y las ideas son a la vez autónomos y dependientes. Por lo tanto, no constituyen solo instrumentos al servicio de la interpretación de la realidad, también poseen sus patologías pues tienen el poder de poseer y de constituirse en soberanos como ocurre cuando los seres humanos se someten a las ideologías o cuando los entes mitológicos pretenden sustituir la realidad al oscurecer su dimensión de instrumentos.

Lo importante de la propuesta de Morin es que, al concebir las ideas y, por ende, las teorías, como entes con vida propia, trasciende su carácter de instrumentos del conocimiento. Las ideas no solo pue- 


\section{2}

den ser usadas y producidas, también poseen el poder de imponer a los espíritus individuales y a la cultura sus propias reglas y, más a menudo de lo que creemos, se apoderan de ellos. Por ello, la dialéctica producto-productor es inherente a las teorías. La Figura 4 da cuenta de los seres de la noosfera y de la ubicación del Reino de las ideas en el que se desarrollan los seres logomorfos que denominamos teorías.

Figura 4

Seres de la noosfera

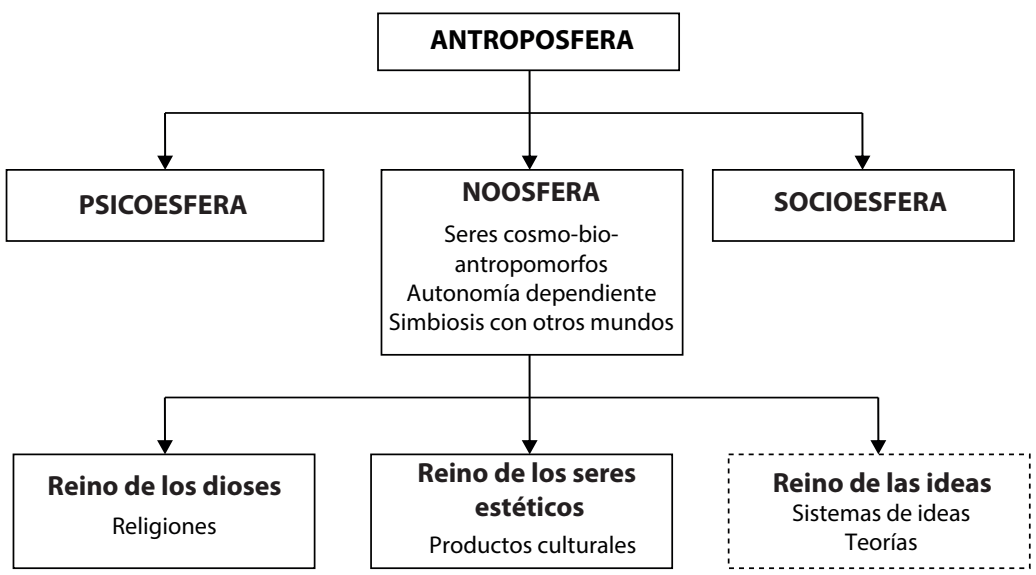

Elaboración de los autores a partir de Morin (1992).

\section{El Reino de las ideas y sus diversos sistemas: organización interna y tipología}

Son dos los niveles fundamentales de organización al interno de un sistema de ideas. Según el primero, todo sistema de ideas está constituido "por una constelación de conceptos asociados de forma solidaria y cuya disposición es establecida por los vínculos lógicos... en virtud de axiomas, postulados y principios de organización subyacentes... un sistema tal produce en su campo de competencia enun- 
ciados que tienen valor de verdad $y$, eventualmente, predicciones sobre todos los eventos que en él deben manifestarse" (Morin, 1992, p. 132). En un segundo nivel Morin afirma - siguiendo el aporte de Lakatos - que todo sistema de organización de ideas comporta dos dispositivos: uno de autoorganización (abierto) y otro de autodefensa (cerrado). El dispositivo de autoorganización está constituido por un núcleo polinuclear merced al cual se produce y reproduce a sí mismo. El núcleo duro, conformado por postulados indemostrables y principios ocultos (paradigmas), es una suerte de zona ciega que tiende a ser refractaria a la autocrítica respecto a sus fundamentos. El núcleo determina principios y reglas de organización de las ideas, los criterios de legitimación de la verdad del sistema a la vez que activa mecanismos de selección de los datos relevantes y de apoyo o de ignorancia en relación con lo irrelevante. El dispositivo de autodefensa activa funciones inmunológicas de protección y autodefensa que eliminan todo aquello que tiende a perturbar y desajustar el sistema. Según esta concepción, todo sistema de ideas se protege y defiende de las degradaciones procedentes del exterior al mismo tiempo que se alimenta de ellas. Todo sistema de ideas

posee cierto número de caracteres auto-eco-organizadores que aseguran su integridad, su identidad, su autonomía, su perpetuación; le permiten metabolizar, transformar y asimilar los datos empíricos que dependen de su competencia; se reproduce a través de los espíritus/ cerebros en las condiciones socioculturales que le resultan favorables. Puede tomar la suficiente consistencia y potencia como para retroactuar sobre los espíritus humanos y sojuzgarlos. (1992, p. 141)

En este marco la racionalización es un tipo de respuesta defensiva que resiste a las críticas y refutaciones externas, opuesta a la racionalidad. Si bien ambos procedimientos buscan la coherencia, la racionalidad es abierta a lo real y la racionalización integra lo real a su propia lógica. El autoritarismo y la agresividad "ortodoxa”, junto 
con la racionalización, es otro de los peligros inminentes de todo sistema de ideas, merced a la ceguera cognitiva que lo constituye.

Según el criterio de cierre y apertura, los sistemas de ideas a cuya forma de organización es posible reducir todas las demás son de dos tipos: las teorías (privilegian la apertura) y las doctrinas (privilegian el cierre). Ambos no constituyen realidades del todo separadas; más bien, los límites son difusos y porosos, al punto de que toda teoría tiende a convertirse en doctrina (el dogma es la intención del pensamiento); si bien estos sistemas tienden a cerrarse sobre sí, en la teoría esta tendencia no es irreductible. La Figura 5 muestra la primera clasificación del mundo de las ideas basada en las dinámicas de cierre y apertura porque, luego, Morin propondrá otra más histórica y compleja:

Figura 5

Sistemas del Reino de las ideas

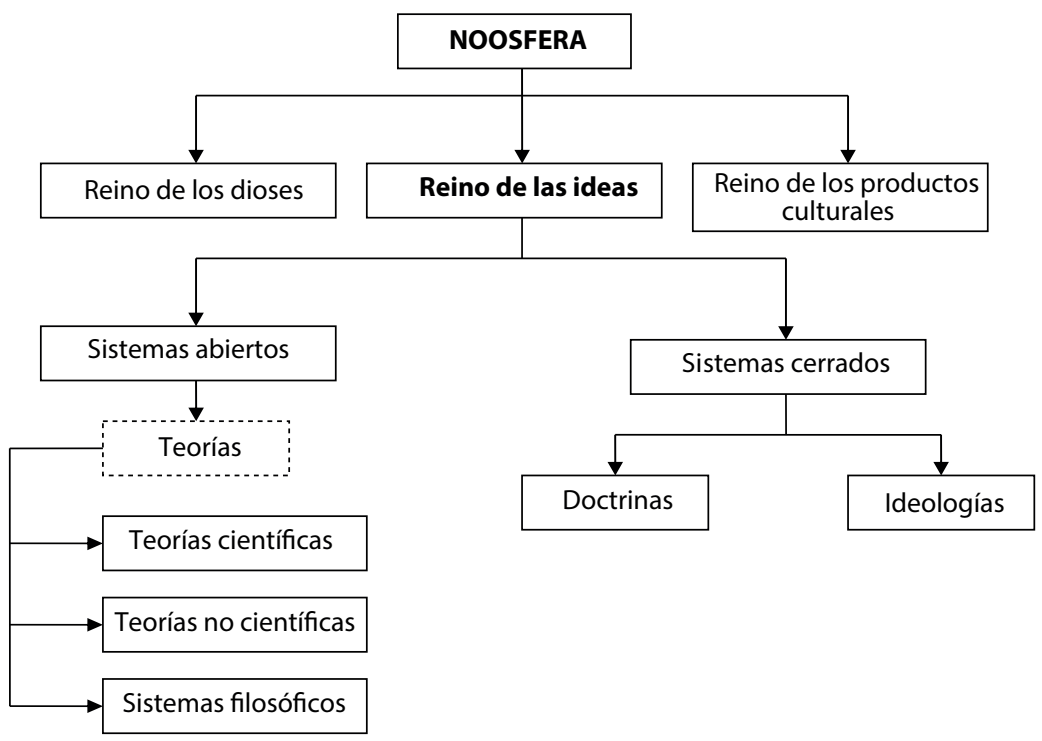

Elaboración de los autores a partir de Morin (1992). 
La segunda tipología se origina en el territorio de una visión histórica de la cultura europea como laboratorio noológico de la razón. Así, el desarrollo concreto de la noosfera filosófica europea evidencia, sobre la distinción básica arriba descrita, tres tipos diferentes de sistemas de ideas (Morin, 1992, pp. 141 y ss.): a) las teorías científicas, cuyo campo de pertinencia se limita al conocimiento; b) los sistemas normativos que unen hechos y valores; y c) los sistemas explicativos universales, con una evidente vocación a conformar marcos explicativos globales.

Las doctrinas, los sistemas filosóficos y las ideologías son sistemas normativos; las grandes doctrinas, los grandes sistemas filosóficos y las grandes ideologías forman parte de los sistemas explicativos universales, siendo el de Hegel el más grandioso de todos. De alguna manera los sistemas filosóficos y, por extensión, los grandes sistemas filosóficos, pueden considerarse teorías en tanto que las ideologías son formas doctrinarias de pensamiento. La Figura 6 da cuenta de esta nueva tipología, atenta al desarrollo histórico del Mundo de las ideas.

Figura 6

Las teorías y su relación con los sistemas normativos y explicativos

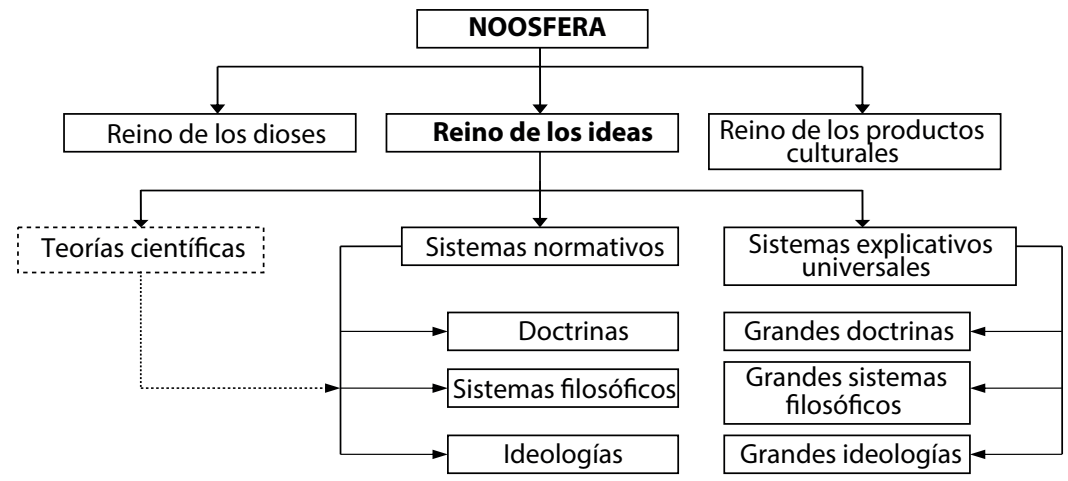

Elaboración de los autores a partir de Morin (1992). 


\section{6}

\section{Las polimáquinas de las teorías: el lenguaje y la lógica}

La relación del lenguaje y la lógica con la teoría han sido temas clave de la epistemología, pues algunas escuelas y orientaciones han reducido el pensamiento teórico a una realidad sobredeterminada por uno u otro elemento. Morin retoma este problema clásico y redimensiona la lógica y el lenguaje, asignándoles la función de polimáquinas de la teoría; vale decir que les confiere el rol de dimensiones esenciales, sin las cuales las teorías no podrían comunicarse ni articularse, a la vez que preserva su relativa autonomía y su carácter de realidades mutuamente irreductibles.

El lenguaje: es imposible concebir las teorías sin los textos ni los discursos que las expresan. Sin embargo, la consideración del lenguaje es crucial no solo como modalidad expresiva de los sistemas de ideas; también el que lo concibamos de una u otra manera nos posiciona respecto a sus alcances y límites con relación al conocimiento. Según la propuesta del pensamiento complejo (Morin, 1992, pp. 149 y ss.), el lenguaje forma parte de la realidad noológica y es esencial para la vida de la noosfera ya que de él depende la organización de los seres del espíritu, entre ellos, las teorías. La vida del lenguaje es un dato evidente, pues se autoconstruye, cambia, se transforma. Como sucede con otros sistemas, es una realidad autoeco-organizada, autónoma y dependiente a la vez, al punto de que puede ser considerado un instrumento o bien una realidad humana clave. El lenguaje es un organismo complejo, polivalente y polifuncional, con fines tanto descriptivos como performativos. Morin (pp. 167 y ss.) lo define como polimáquina, e identifica tres maquinarias o subsistemas articulados a otras máquinas y sistemas: a) máquina de doble articulación (sonidos y sentidos); b) máquina asociada a la maquinaria cerebral (lógica y analógica); y c) máquina engranada a la máquina cultural. 
La tesis esencial se resume en que el conocimiento no se reduce al lenguaje; por lo tanto, es ilegítimo trascendentalizarlo y dotarlo de una realidad hegemónica a tal extremo que resulte posible subsumir el problema del pensamiento en el del lenguaje. Los argumentos se despliegan en dos direcciones: la primera consiste en la referencialidad del lenguaje; la segunda, en el carácter contextual del sentido. En efecto, debido a que implica una referencia necesaria a algo diverso de él mismo y que "la autonomía-centralidad del lenguaje no excluye ni el espíritu/cerebro humano que lo produce, ni el sujeto que es locutor, ni las interacciones culturales y sociales en las que adquiere consistencia y ser" (1992, p. 166), es necesario situarlo sin disolverlo ni reificarlo, incorporándolo en una red de interdependencias y relaciones productivas.

Con respecto al sentido, Morin establece su importancia como resultante de la relación entre significado y significante, al mismo tiempo que en virtud de condición y finalidad del lenguaje; no obstante, advierte que no es posible concebirlo de manera tal que nos lo imaginemos atrapado o encapsulado en los elementos lingüísticos; más bien, el sentido implica y llama a relacionar el lenguaje con una realidad mucho más amplia que él mismo y considerar una imbricación de elementos diversos como el contexto, la situación y el marco conceptual en juego. Por añadidura, el sentido también hace referencia y dice interdependencia a una cadena de otros sentidos en los que se inscribe. Por lo tanto, no es posible disolver el pensamiento en la interrogación por el sentido circunscrito al discurso ni en la semántica del lenguaje.

Por último, el autor relaciona conocimiento y lenguaje para traer a colación el conocido hecho del desdén y desprecio de los académicos respecto al lenguaje común y ordinario como expresión no solo de la necesidad que nace del rigor terminológico inscrito en 
el método científico; se trata, además, de un hecho de poder, de la "voluntad de reservar para los iniciados, expertos o especialistas las competencias fundamentales para tratar todos los problemas" y de la tendencia a "privar a los ciudadanos del derecho al conocimiento" (Morin, 1992, p. 176).

La lógica: es la segunda maquinaria — la "maquinaria cognitiva formal" - conformada por dos sistemas: la realidad compútica (el aspecto formal y las normas) y la realidad noológica, asociada pero no reducida al lenguaje. En tanto tal, es la armadura formal de un sistema de ideas. Morin (pp. 177 y ss.) aplica a la lógica la misma advertencia que al lenguaje: en tanto realidad noológica, a la vez autónoma y dependiente, es capaz de servir como instrumento de los diversos sistemas de ideas o apoderarse hegemónicamente del mundo de las ideas. La lógica no puede constituirse en un juez supremo ni autónomo del conocimiento. La lógica, cuyo correlato es la certeza racional, es un tipo especial de racionalidad fuertemente condicionada por la obediencia controlada a principios, axiomas y operaciones lógicas; en este sentido, constituye el carácter fundamental de las teorías. En tanto que sistemas lógicos, los rasgos fundamentales de las teorías racionales son dos: a) coherencia: por un lado, los elementos están estrechamente unidos entre sí, según los procedimientos lógicos de deducción-inducción; por otro, los enunciados obedecen al principio de no contradicción; b) relación verificable y no arbitraria respecto al mundo objetivo al que se aplican.

El lugar de la lógica se define a partir del análisis crítico de dos de sus desarrollos históricos: la lógica identitaria (basada en el $O r$ ganon de Aristóteles) y la de quienes la absolutizan, como Ludwig Wittgenstein (1889-1951), Rudolf Carnap (1891-1970) y el Círculo de Viena (al que perteneció Popper). Los términos de su propuesta final incluyen no el desconocimiento, pero sí una opción que 
aboga por el debilitamiento de la lógica. En contraste a las posiciones arriba descritas, el pensamiento complejo aboga por una lógica que no se baste a sí misma, que deba ser considerada tan solo como un sistema formal, no autosuficiente, necesitado de un contexto no formal y de rango superior para determinar sus principios. Son dos las condiciones de la nueva lógica: la necesidad de incorporar la contradicción como método y la constitución de un metapunto de vista que se instaure como criterio. Veamos ambos aspectos.

A partir de los descubrimientos físicos del siglo XX, como la indeterminabilidad cuántica, el principio de incertidumbre, la noción contradictoria de partícula y del quantum, Morin concluye que estos no solo afectan los principios básicos de la lógica clásica, sino que han dado lugar a la denominada Revolución epistémica de Bohr, según la cual dos proposiciones contrarias pueden ser también complementarias. Así, se fortalece una visión aporética del ser al punto de que toda contradicción es indicio y anuncio de lo verdadero y, por lo tanto, sin contradicción no hay progresión en el conocimiento. La contradicción es valorada como la norma de oro del pensar: "Pensar con/contra la contradicción es la tarea del pensamiento complejo" (Morin, 1992, p. 202). Por lo tanto, toda limitación debe ser apreciada como un camino al conocimiento y toda teoría debe valorar las contradicciones fuertes sobre las débiles; es decir, aquellas que tengan valor heurístico, las que abren horizontes de preguntas sobre las que los cierran; las que poseen el potencial de cuestionar constructos y contradicciones que se juegan sobre la doble montura de lo lógico y lo real sobre las que son unidimensionalmente lógicas.

Inspirado en el filósofo y matemático Bertrand Russell (18721970), el pensamiento complejo valora como principio el metapunto de vista, según el cual todo sistema conceptual no es autosuficiente e incluye cuestiones a las que únicamente puede responder desde el 
exterior mismo de su sistema. Así, lo que organiza una teoría no es la lógica, sino una metalógica que reivindica el lugar del sujeto sin que este se diluya en ella. Toda teoría solicita un punto de observación sobre sí misma ubicado más allá de sí misma, desde donde es capaz de examinar sus propias condiciones de emergencia y de ejercicio, sus condiciones lógicas y noológicas, así como las condiciones históricosocio-culturales en las que se desarrolla (Morin, 1992, p. 209). El metapunto de vista obra en virtud de un procedimiento sin fin, basado en las operaciones sucesivas de problematización y reproblematización. Lo plausible, valor epistémico que prima sobre lo certero, se instaura como mecanismo de discernimiento y asume una actitud de relatividad (no de relativismo) entendida como apertura y reconocimiento de la complejidad: "la complejidad puede ser descompuesta, pero no siguiendo los axiomas que excluyen la contradicción” (p. 209).

Finalmente, de la mano del isomorfismo y correspondencia compleja entre pensamiento, vida y universo anteriormente señalados, Morin asume que "si lo real es complejo, la lógica es incompleta" y tanto la teoría como la realidad son abiertas. En consecuencia, "la existencia viviente es alógica, sublógica, metalógica” (p. 209). A partir de la dialógica (lógica debilitada), la propuesta de Morin establece, para el proceso de construcción de teorías y su análisis, criterios de juicio basados en una serie de reivindicaciones: la circularidad yo-tú-sociedad-cultura, el primado del sujeto, la referencialidad con la realidad y el sentido, la relación sujeto-objeto. Así, toda teoría es un sistema ideacional abierto, falible y complejo.

\section{El gobierno oculto de las teorías: los paradigmas}

Como hemos visto, la teoría admite varios niveles de articulación intra e interteóricos para cuya comprensión Morin reelabora puntos de vista complementarios provenientes de varias tradiciones. 
En primer lugar, recupera muy genéricamente y casi sin entrar en detalles la postura axiomática para dar cuenta de los aspectos más visibles y superficiales de la articulación intrateórica, entendida como la constelación de conceptos asociados de forma solidaria según una disposición lógica que concatena axiomas, postulados y principios de organización subyacentes. En segundo lugar, asume con mayor desarrollo la visión historicista de Lakatos para describir el segundo nivel, más profundo, en el que todo sistema de organización de ideas integra dos dispositivos: el núcleo duro o de autoorganización (abierto) y el cinturón protector o de autodefensa (cerrado) cuyas dinámicas combinadas explican las continuidades y resistencias, así como las transformaciones teóricas. Finalmente, incorpora ampliamente la explicación historicista de Kuhn para explicar el tercer nivel, el más profundo y decisivo de todos, en el cual las teorías se articulan entre sí según esquemas subyacentes denominados paradigmas o principios de conocimiento que las gobiernan de manera oculta e implícita y condicionan su desarrollo.

Veamos ahora los detalles y alcances de la articulación paradigmática entre teorías, aspecto al cual Morin le confiere particular interés (1992, pp. 216 y ss.) y en el que recupera de la manera más radical una propuesta que el mismo Kuhn no se sentía ya capaz de sostener, vencido por las críticas contra la vaguedad e imprecisión del término. Morin no recupera al concepto de paradigma a pesar $d e$, sino precisamente por su vaguedad e imprecisión, rasgos que dan perfecta cuenta del tipo de poder propio de una instancia que gobierna de manera subyacente y oculta todo sistema de ideas incluida la teoría en su calidad de fundamento primero, fundador y nuclear. Su definición de paradigma es el siguiente:

Un paradigma contiene, para cualquier discurso que se efectúe bajo su imperio, los conceptos fundamentales o las categorías rectoras de 
inteligibilidad al mismo tiempo que el tipo de relaciones lógicas de atracción/repulsión (conjunción, disyunción, implicación u otras) entre estos conceptos o categorías. (1992, p. 218)

Esta definición implica un triple carácter: semántico, ideológico y lógico. El carácter semántico consiste en determinar la inteligibilidad y otorgar sentido a los sistemas de ideas; ideológicamente, impone los tipos de asociación, eliminación y la selección de la organización de las ideas; lógicamente, determina las operaciones lógicas rectoras (p. 218).

Para Morin la noción de paradigma incluye y especifica otras como la de episteme de Michel Foucault (1926-1984) ${ }^{19}$, y los tipos epistemológicos de Magoroh Maruyama. La noción de episteme es más profunda y amplia por referirse a los fundamentos del saber en general y recubrir la totalidad del campo cognitivo de la cultura. No obstante, y a diferencia del paradigma, la relación episteme-cultura planteada por Foucault es simple ya que cada cultura articula su saber en torno a una sola de ellas. Los tipos epistemológicos, según Maruyama, son formas de pensamiento que condicionan de manera diversa la percepción, la causalidad y la lógica, y cada uno determina su propio paisaje mental que organiza y confiere visibilidad a lo que debe ser pensado, que presenta aquello que puede estar al "alcance de la mente".

El interés de la propuesta de Maruyama ${ }^{20}$ radica — igual que la episteme - en su generalidad pues se aplica no solo al conocimiento,

19 Foucault desarrolla el concepto de episteme (2005) y la trata como una formación discursiva con efectos de poder. Otra de las categorías importantes de Foucault en relación con la episteme es la de orden del discurso que profundiza la intencionalidad de los discursos también en función del poder.

20 Maruyama desarrolla su propuesta de los paisajes mentales en el artículo Mindscapes and Science Theories (1980), del cual ofreceremos una descripción detallada en el capítulo III. 
sino también a la ética, la estética y la religión. Ambas propuestas se refieren, por lo tanto, a grandes paradigmas que controlan el campo cognitivo en su totalidad y a toda la cultura; si bien la noción estricta de paradigma es más acotada, se inscribe en toda forma posible de conocimiento y se aplica a todos los sistemas noológicos en general. La operativa y el funcionamiento del paradigma se expresa en sus caracteres esenciales, reagrupados temáticamente (Morin, 1992, pp. 222 y ss.), según su rol en los procesos de conocimiento teórico, en la configuración de la realidad, y las relaciones entre los paradigmas.

En relación con los procesos de conocimiento y los sistemas de ideas, el paradigma no es falsable y está fuera del alcance de cualquier proceso de validación o verificación; son falsables, en cambio, las teorías que emanan de él. Si bien el paradigma confiere autoridad a los axiomas, estos a su vez lo legitiman. El paradigma es un criterio de reconocimiento de problemas y establece las exclusiones o inclusiones de los datos y preguntas que está dispuesto a reconocer según criterios de simplificación, reducción, disyunción o complejidad. Es el organizador invisible del núcleo organizacional visible de la teoría y crea la evidencia ocultándose a sí mismo, de tal manera que genera la ilusión de obedecer a los hechos o a la lógica. Si bien la invisibilidad lo hace invulnerable, todo paradigma está sujeto a cambios y a transformaciones, y las grietas paradigmáticas se evidencian primero por su lado visible y aspectos secundarios: las teorías y los sistemas de ideas.

Con respecto a la realidad, así como el paradigma niega carácter real a lo que excluye, genera la sensación de realidad a lo que incluye en su enfoque. Además, determina la mentalidad o visión del mundo, en términos de los mindscapes (paisajes mentales), de tal forma que un cambio de paradigma se ramifica en sucesivas transformaciones de la producción artística, la política, la moral o la religión. Finalmente, en lo que a la relación entre paradigmas respecta, 


\section{4}

es posible la coexistencia de varios paradigmas en el seno de una cultura, pero siempre habrá incomunicabilidad y antinomia entre ellos, así como entre las teorías y los sistemas que controlan.

Los paradigmas se inscriben en la organización cognitiva, en la organización noológica, en los procesos lingüísticos y lógicos, en la cultura y en la sociedad. Estas últimas instancias son determinadas por estos del mismo modo que aquellas determinan los paradigmas (Morin, 1992, p. 235). Así como pueden convivir varios paradigmas a la vez en el seno de un ambiente cultural o civilización de manera pacífica o violenta, muchas veces, ideas en apariencia contrarias o irreductibles pueden obedecer a un mismo paradigma. Morin aporta un muy buen ejemplo de ello a partir de las teorías que relacionan cultura y naturaleza; así, algunas postulan que la naturaleza es una instancia por entero reductible a la cultura en el sentido de que la naturaleza no puede ser entendida sino por ser intervenida y habitada por la cultura; otras, en cambio, aducen que la cultura es producto de la naturaleza y un reflejo de los constreñimientos que el medio proyecta sobre la sociedad. Ambas posibilidades que en la superficie son rivales y responden a paradigmas diversos en lo profundo son la expresión de un mismo paradigma: de aquel que excluye y opone ambas instancias para convertir a cada una en un producto de la otra en lugar de relacionarlas según vínculos de mutua implicación.

Por lo tanto, y partir del ejemplo mencionado, podemos entender que un paradigma no se traduce ni expresa tanto en una serie de contenidos o aserciones cuanto en una manera de articularlas y relacionarlas entre sí, ya sea de manera excluyente o disyuntiva, relacional, dual o tripartita, entre otras posibilidades. Se trata más bien de un modo de pensar, de una lógica que condiciona en lo profundo las posibilidades de relación. Los grandes paradigmas que Morin describe (1992, pp. 226 y ss.) son fundamentalmente dos: el gran 
paradigma de Occidente y el paradigma emergente. Veamos muy resumidamente los aspectos esenciales de cada uno.

El gran paradigma de Occidente se consolida con la concepción cartesiana de la realidad, la cual separa y secciona los órdenes de lo real en dos mitades irreductibles y separadas: sujeto-objeto, alma-cuerpo, espíritu-materia, cualidad-cantidad, sentimiento-razón, etc., al punto que entre tales dualidades se instaura una relación disyuntiva, de mutua exclusión, que se expresa en todos los ámbitos de una cultura esquizofrénica y desintegrada. Podemos entender así la separación entre las humanidades y la práctica científica, así como la relación de dominio del hombre respecto a la naturaleza como expresión del mismo paradigma. La vida cotidiana también se ve afectada por la partición del universo en dos cuando la religiosidad, el arte y la literatura y la esfera de la vida privada y de los sentimientos en general funcionan como contrapeso no integrado o desahogo del yugo de la objetividad a la que nos somete la ciencia o los procesos económicos, productivos o burocráticos:

el gran paradigma está presente [...] no solo en la sociedad (disyunción entre la organización tecno-buro-econocrática y la vida cotidiana), en la cultura (disyunción entre cultura de las humanidades y cultura científica), sino también en los psiquismos y en las vidas, suscitando los pasos, como saltos cuasi cuánticos, del mundo de los sentimientos, pasiones, poesía, literatura, música, al mundo de la razón, el cálculo, la técnica. (Morin, 1992, p. 234)

El gran paradigma de Occidente da vida a la ciencia clásica cuya expresión cumbre ha sido el positivismo lógico debido a su ilusión de sustentarse en dos ejes incuestionables: por un lado, la lógica; por otro, la realidad. En la ciencia clásica el principio de disyunción separó las ciencias entre sí y, en su interior, unas disciplinas de otras "fragmentando su objeto en el tejido solidario de lo real" (1992, p. 
231). El principio de exclusión va asociado a otros principios subsidiarios que han regido la ciencia clásica: el primero de ellos es la visión mecanicista de la realidad que la reduce a un orden determinista simple; el segundo es el principio de reducción, el cual da lugar a una visión atomista de la realidad "que conmina a desintegrar las entidades globales y sus organizaciones complejas en provecho de las unidades elementales que la constituyen, y que se convierte en fuente y fundamento de toda inteligibilidad" (p. 231).

En este punto, Morin retoma la visión kuhniana de las revoluciones científicas y las entiende como transformaciones paradigmáticas que ocurren a nivel de la manera de pensar y concebir la relación entre los varios aspectos de la realidad, de tal modo que tales transformaciones obligan a reorganizar las teorías y reconsiderar los fenómenos en función del nuevo paradigma.

Finalmente, Morin diagnostica fisuras y agrietamientos en el gran paradigma de Occidente — el cual todavía continúa muy operativo - habida cuenta de los siguientes síntomas: a) cada vez más se mira hacia los sistemas, la totalidad y la complejidad, poniendo las cosas en relación con su entorno; b) el sujeto se introduce en el objeto en lugar de excluirse y separarse de él, es decir, los investigadores se cuestionan sus teorías y métodos e incluye su propia subjetividad; c) cuestionamiento a la lógica deductiva-identitaria. No obstante, y a pesar de los crujidos y de los cuestionamientos no se da paso todavía a una nueva lógica ni se establecen ligazones reales entre los diversos órdenes de la realidad, a pesar de los deseos de interdisciplinariedad. Se vive una crisis, eso sí; pero para instaurar el nuevo paradigma hace falta una reforma en cadena del entendimiento. De momento, vivimos en la incertidumbre y tan solo balbuceamos el nuevo paradigma en medio de una batalla conformada por una sucesión de 
múltiples e imprevistos combates planteada no entre ideas sino entre nuevas formas de organizarlas (Morin, 1992, pp. 240 y ss.).

\section{La articulación manifiesta entre las teorías:} inter, multi, poli $y$ transdisciplinariedad

Para la epistemología de la ciencia, la cuestión de la inter o la transdisciplinariedad remite, en el fondo, a establecer cómo se organizan e integran las teorías entre diversos marcos disciplinarios, en la cual, la disciplina constituye - a diferencia del paradigma - la forma visible y manifiesta de articulación interteórica. Con respecto a la articulación entre teorías que pertenecen a espacios disciplinarios diversos, el aporte de Morin es sumamente relevante y dotado de un potencial crítico notable; la tesis que le sirve de fundamento es la siguiente: la superación de los límites de la disciplina es la condición indispensable para el desarrollo del conocimiento teórico; tal superación se alcanza mediante el desarrollo de distintas formas de relación entre los diversos dominios disciplinarios o mediante la articulación creativa en un sistema teórico común.

Entendemos como disciplina el conjunto de teorías que se refieren a un ámbito de la realidad. Las teorías no agotan las disciplinas y estas están constituidas por varias de ellas según relaciones de diverso tipo: complementariedad, rivalidad total o parcial, hegemonía y de presuposición (Gianella, 2003, pp. 50 y ss.). Con respecto a la articulación entre teorías que pertenecen a espacios disciplinarios diversos, el aporte de Morin es sumamente relevante y dotado de un potencial crítico notable. La tesis esencial consiste en que el conocimiento teórico es posible solo si se superan los límites de la disciplina, ya sea para desarrollar distintas formas de relación entre los dominios disciplinarios, ya para articularlos en un sistema teórico común. Por lo tanto, el encierro disciplinario no solo es una 
patología cognitiva: es la negación del conocimiento que nace de la mutilación de la realidad en parcelas. Por ello, toda disciplina está atravesada por relaciones ecológicas con otras disciplinas, y admite múltiples maneras de interacción y retroacción. No se niega la disciplina, pero sobre la base de su interdependencia y apertura a la globalidad, emanadas de la complejidad constitutiva del dominio que cada una se propone conocer.

Veamos cómo Morin da cuenta de las relaciones que trascienden el encierro disciplinario. En primer lugar (2001, pp. 148 y ss.), evidencia las dinámicas de la disciplina, su tendencia a la autonomía y a generar fronteras, fundadas en la tradición universitaria decimonónica y enraizadas en la manera en que la sociedad en su conjunto concibió el trabajo y la productividad según el criterio de hiperespecialización propio de la era industrial. Tal modelo produce una estrategia crucial para la institucionalización del saber: la disciplina, la cual, si bien comporta ventajas como la capacidad de determinar un objeto de conocimiento no trivial y sus dominios, así como las competencias, el lenguaje y los conceptos que conformarán el marco de abordaje, también implica riesgos: la hiperespecialización del investigador y la cosificación del objeto de conocimiento como realidad autosuficiente y aislada, sin conexiones ni solidaridades teóricas, metodológicas o terminológicas con otras realidades. De esa manera, "el espíritu hiperdisciplinario va a convertirse en un espíritu de propietario que prohíbe cualquier incursión ajena en su parcela de saber" (p. 148). La superación de la hiperespecialización disciplinaria forma parte del desafío científico constitutivo, a su vez, de un proyecto cognitivo más amplio que incluye otros desafíos, como el cultural y el cívico (pp. 18 y ss.), desafíos que trasladan a sus respectivos escenarios la necesidad de superar diversos niveles de partición de la realidad y del conocimiento. 
El desafio cientifico, por tanto, busca superar el encasillamiento, la partición y la hiperespecialización del saber y de las disciplinas por medio del pensamiento contextual y complejo, más atento a las interrelaciones y abierto a la incertidumbre. El desafio cultural persigue superar la bipartición de la cultura alimentada por el saber humanista y el saber científico. El uno genérico, integrador y amplio; el otro, aplicado a escenarios separados y ámbitos específicos pero incapaz de pensarse a sí mismo y de incluir el destino humano en su horizonte. Esta partición los nutre de mutuas suspicacias y amenaza la consistencia y vigencia de ambas formas de mirar al mundo.

Por último, el desafío cívico apunta a superar el debilitamiento de la responsabilidad y de la solidaridad que surge de la renuncia a la globalidad y de la invisibilidad de los lazos orgánicos que ligan al individuo con su ciudad y conciudadanos. El déficit democrático lesiona también el derecho al conocimiento ocasionado por su apropiación en pocas mentes y por los mecanismos de accesibilidad condicionada, según el cual se vuelven inaccesibles los conocimientos globales y accesibles los compartimentados. Por ello, el programa cívico de Morin se cristaliza en la democracia cognitiva.

La historia de la ciencia (2001, pp. 149 y ss.) proporciona algunos ejemplos de contravención del espíritu hiperdisciplinario como la visión extradisciplinaria y las intromisiones y migraciones interdisciplinarias. La visión extradisciplinaria es propia de los iluminados que no se aferran a los límites inhibidores de la disciplina que profesan para mirar los datos de nuevas maneras. Es el caso de Wegener, meteorólogo, quien, al interpretar los mapas continentales a partir de las coincidencias entre sus contornos, elaboró la teoría de la deriva de los continentes. Las intromisiones y migraciones interdisciplinarias explican la circulación de las nociones y teorías por campos disciplinarios que no son propios a los cuales fecundan y potencian 
como, por ejemplo, la traslación de la noción de información, propia de la realidad social, al campo de la biología donde conformó el concepto de código genético. Asimismo, se transfieren no solo conceptos sino también esquemas cognitivos enteros como, por ejemplo, los presupuestos semióticos de Jacobson en la antropología estructural de Claude Levi-Strauss.

Otras formas de relación planteadas en términos de actitudes epistémicas programáticas son la inter, la multi, la poli y la transdisciplinariedad. La interdisciplinariedad es la forma elemental de asociación entre las ciencias y consiste en enfrentar un problema de investigación desde varias perspectivas disciplinarias a la vez, sin interacciones entre sus teorías y métodos, sino mediante la suma de aportes independientes como sucede, por ejemplo, cuando se busca comprender el alcoholismo desde la psicología profunda, la genética y la antropología.

La multidisciplinariedad es más compleja y consiste en el proceso mediante el cual, en razón del tipo de proyectos y objetos de conocimiento multicompetentes, así como de la complejidad inherente a ciertos campos de investigación, algunas disciplinas deben, forzosamente, superar sus límites disciplinarios y complejizar las competencias del investigador. Es el caso de la historia, la ciencia multidisciplinaria por excelencia, y del perfil multidisciplinario del historiador que integra la antropología, la literatura, la estética, las ciencias políticas o la urbanística, entre otras disciplinas.

La polidisciplinariedad es una forma de asociación de disciplinas en función de un objeto de estudio que les es común y que todas contribuyen a delimitar. También se da cuando las disciplinas construyen solidariamente nuevos marcos metodológicos en función de tal objeto. 
La transdisciplinariedad, por último, es actuada por esquemas cognitivos que al mismo tiempo que trascienden las disciplinas las pueden atravesar, generando rupturas disciplinarias y articulaciones imprevistas para unir ámbitos en apariencia disjuntos. El ejemplo es la biología molecular respecto a la astrofísica: ambas se han transdisciplinarizado a partir de la inclusión del interrogante de la vida en el universo, y generaron nuevas hipótesis y esquemas cognitivos que las trascendieron y determinaron nuevas maneras de concebir el problema.

\section{Comentarios e implicaciones}

La influencia de Morin ha sido muy profunda en varios escenarios de la reflexión latinoamericana debido a su rol como titular de la Cátedra Itinerante "Edgar Morin” sobre Pensamiento Complejo, creada por la Unesco en 1999 y a numerosos cursos dictados en universidades de Bolivia, Perú, México y Brasil, así como en varias sedes de la Facultad Latinoamericana de Ciencias Sociales (Flacso). En Ecuador, su aporte es seguido muy de cerca por no pocas experiencias educativas relacionadas con educación formal y popular en contextos de desarrollo y, de manera particular, por las nuevas universidades indígenas, pues su refutación de la lógica disyuntiva basada en oposiciones va muy de la mano de la autocomprensión que los indígenas tienen de su propio conocimiento, orientado a integrar las contradicciones e incorporar la ritualidad y el mito.

Morin nos enseña que para acceder a lo real y dialogar con el mundo son necesarias las ideas y es imposible prescindir de ellas, pues son mediadoras de nuestra relación con lo real. De hecho, estamos poseídas por ellas, pero también podemos intentar poseerlas, a fin de superar las ideologías, las doctrinas y las teorías reductoras y mutilantes. Las teorías científicas de alguna manera pueden civilizar el mundo de las ideas, pero a condición de que sean abiertas 
y acepten el principio de biodegradabilidad, reconociendo también sus carencias, en especial la incapacidad para mirar reflexivamente su núcleo paradigmático, la tendencia a disociar hecho y valor $\mathrm{y}$, por último, la ineptitud de pensarse a sí mismas que surge del ocultar y rechazar los problemas filosóficos (1992, p. 254). Se requiere, en suma, "una nueva generación de teorías abiertas, racionales, críticas, reflexivas, autocríticas, aptas para auto-reformarse, auto-revolucionarse incluso" (p. 256).

La salida para recuperar y reencauzar el ejercicio de las teorías científicas es establecer un campo de comunicación y de mutua apertura con las teorías epistemológicas, filosóficas y éticas. Así como no podemos prescindir de la esfera científica, tampoco podemos prescindir de la filosofía ni del mito, el arte o la novela, estrategias cognitivas que conviven y se interrelacionan necesariamente.

Sobre la base de la incertidumbre Morin identifica tres tareas adicionales del conocimiento (1988, pp. 169 y ss.). La primera consiste en establecer un diálogo con lo irracionalizado y lo irracionalizable, es decir, con aquello que no entra en los cánones de la lógica aristotélica. La segunda tarea se refiere a la investigación, respecto a la cual el conocimiento ejerce un patrullaje por medio de los conos de sombra y de lo que escapa a la comprensión, invocando otras formas de entendimiento como, por ejemplo, las metáforas y la poesía. Por último, la tercera tarea es evidenciar la ignorancia, los agujeros negros que constituyen el pensamiento. El conocimiento, así entendido, se previene de toda pretensión de saber absoluto, definitivo o irrefutable: esa es la tarea de la epistemología compleja.

A la hora de identificar posibles aplicaciones a los procesos investigativos, se debe tomar en cuenta que se trata de una propuesta con muy poco desarrollo metodológico todavía, tal como reconoce 
el mismo Morin; por lo tanto, aunque no existen pistas claras de cómo poner en uso aspectos como el principio de incertidumbre o la transdisciplinariedad, es posible ensayar algunos lineamientos generales. La primera pista consiste en la capacidad de integrar las teorías filosóficas, epistemológicas, éticas y científicas, una tarea muy urgente para la universidad actual, ya que esta se ha convertido en el preciso lugar donde ellas se divorcian y distancian.

Es muy frecuente en las ciencias humanas y sociales la actitud de permanente crítica hacia las ciencias duras o aplicadas respecto a sus carencias epistemológicas o filosóficas, porque en verdad suelen mirar con desdén tales interrogantes, sin conceder la posibilidad de beneficiarse del movimiento inverso que las obligaría a cuestionar sus propios logros desde las ciencias aplicadas en términos de mayor precisión, exactitud o pertinencia. Los ejercicios de inter o transdisciplinariedad implican no solo saltar los límites entre disciplinas emparentadas entre sí; también es necesario suturar linderos y fronteras más profundas como las que pueden existir entre la visión humanista y las ciencias. Se me ocurre, por ejemplo, que, al pretender investigar desde la botánica y la biología los principios activos de una planta y sus aplicaciones médicas, el cometido quedaría trunco, si no se incorpora la tradición oral y la mitología mediante las cuales las poblaciones locales codifican los conocimientos, significados y los usos en torno a dichos recursos. Sin duda alguna, investigaciones de este tipo implican trabajo en equipo y amplitud en la tarea de diseñar investigaciones.

En segundo lugar, el pensamiento complejo nos invita a no seccionar los objetos de conocimiento y mirarlos en su totalidad, tomando en cuenta los contextos que los soportan. Los problemas de investigación - cualquiera que ellos sean- se insertan en una situación, en un marco más amplio y forman parte de una totalidad que 
debe ser respetada y no mutilada por el enfoque investigativo, de tal modo que, si es necesario especificar y acotar el rango del estudio, siempre se debe partir del reconocimiento y respeto por la totalidad.

En tercer lugar, la apuesta de Morin nos invita a no idealizar, absolutizar o reificar las teorías, primero porque se trata de una entre tantas estrategias cognitivas; y luego, porque - como todo ser vivo- se degradan. Ello no es una invitación al relativismo indiscriminado y escéptico: su apuesta nos prohíbe vivir solo de la teoría y nos impele a considerarlas como sistemas abiertos y en constante transformación y a relacionarlas (en este sentido toda teoría es eminentemente relativa) con otras formas de conocimiento.

A la hora de la enseñanza o comprensión del patrimonio teórico de las ciencias, el pensamiento complejo propone la difícil tarea de no mirar tanto a los cúmulos conceptuales sino de penetrar en el núcleo paradigmático y en la lógica subyacente a cada propuesta teórica; es decir, nos obliga a priorizar el ámbito de la racionalidad antes que el de la racionalización. No se trata tanto de saber qué dijo tal o cual autor, ni de dedicar a la tarea exclusiva de develar los procedimientos lógicos de cada corriente cuanto de comprender cómo tal o cual autor pensó tal o cual problema, en términos de paradigmas o supuestos profundos de pensamiento; es decir, de penetrar no solamente los contenidos sino, y sobre todo, las maneras de pensar.

A pesar de los aportes señalados, planteamos dos posibles reparos a la propuesta de Morin que señaláramos en un artículo sobre el Buen Vivir, la relacionalidad y la disciplina en la educación superior (Juncosa, 2014, pp. 29-31). El primer reparo nace de la advertencia de Wallerstein respecto al resultado real de los esfuerzos para implementar la inter- y la transdisciplinariedad en las instituciones de conocimiento. Tales esfuerzos han cumplido la función de poner al día 
el ejercicio teórico de cara a las transformaciones científicas, fortaleciendo los aparatos organizativos en vez de abrir posibilidades para un mayor cuestionamiento de la razón de ser de las mismas disciplinas. En lugar de ello, se detonó el efecto contrario que sancionó la necesidad de la presencia de las disciplinas en el ámbito de otras en lugar de cuestionar su razón de ser. La disciplina, finalmente, llegó a ser tan importante que sin su aporte las demás no podrán sobrevivir, punto de vista de la actitud disciplinar identificado también por el filósofo afrocaribeño Lewis Gordon (2013). En palabras de Wallerstein,

[1]a alabanza de los méritos del trabajo interdisciplinario no ha minado hasta ahora significativamente la fuerza de los aparatos organizativos que amparan la separación existente entre las disciplinas. De hecho, casi se podría decir lo contrario: lo que ha acentuado la pretensión de cada disciplina de representar un ámbito coherente de análisis independiente vinculado a una metodología propia es la aseveración constante [...] de que cada una tiene algo que aprender de las otras [...] que este "otro" conocimiento es pertinente e importante para resolver los problemas intelectuales en los que cada una de esas disciplinas trabaja. El trabajo interdisciplinar no es en absoluto una crítica intelectual per se a la compartimentación actual de las ciencias sociales y en todo caso carece de influencia política para modificar las estructuras institucionales existentes. (Wallerstein, 2004, p. 136, citado en Juncosa, 2014, p. 30)

El segundo reparo al pensamiento complejo nace desde la opción por la interculturalidad crítica y consiste en el peligro de encerrar los "metapuntos de vista" en un circuito de autoobservación y acción autorreferida en el marco de conocimientos homogéneos propios de la ciencia. Así, para el pensamiento complejo el trabajo teórico corre el peligro de clausurarse en un ciclo de procesos cerrados que busca componer 


\section{6}

"teorías abiertas, racionales, críticas, reflexivas, autocríticas, aptas para auto-reformarse, auto-revolucionarse incluso" (Morin, 1998, p. 256), sin que requiera su conexión con los resurgimientos y la autoafirmación de los pueblos. En tanto proyecto que busca instaurar "una mejor manera de conocer" no por ello garantiza que las instituciones educativas, especialmente la universidad, se confronten a sí mismas respecto a los continuos posicionamientos de los pueblos indígenas y negros. No obstante, el pensamiento complejo admite una posibilidad si logra resignificar la transdisciplinariedad como articulación del pensamiento con los conocimientos otros, subalternizados y exteriorizados, para convertirlos en "metapuntos de vista" ineludibles capaces de confrontar la producción teórica con su carácter moderno colonial. (Juncosa, 2014, p. 30) 


\section{Capítulo II LA TEORÍA DESDE LOS ENFOQUES AXIOMÁTICO, ESTRUCTURAL Y SEMÁNTICO. DISTINCIONES, ELEMENTOS Y ARTICULACIONES ${ }^{21}$}

\section{Introducción}

La revisión de las propuestas de Popper, Horkheimer, Habermas y Morin nos ha permitido acceder a las características fundamentales de la teoría desde un punto de vista crítico respecto a otras funciones adaptativas (los mecanismos genéticos), las capacidades aprendidas, los sistemas mentales (la ideología y la doctrina), la racionalidad instrumental. Otras aproximaciones, propias de la filosofía de la ciencia, identifican con mayor precisión los elementos sincrónicos que constituyen las teorías y sus respectivas relaciones.

El itinerario de este apartado inicia con la consideración de las distinciones básicas e indispensables de la teoría respecto al sentido común y la ley científica, y continúa con la identificación de los

21 Este capítulo retoma, amplía y profundiza el apartado "Las teorías como instrumentos complejos de conocimiento", del marco teórico de Juncosa, José Enrique. (2006). Teorias del conocimiento en experiencias universitarias con movimientos sociales. Un aporte para la carrera de Antropología Aplicada de la Universidad Politécnica Salesiana. (Tesis de maestría inédita en Desarrollo de la Inteligencia y Educación). Universidad Técnica Particular de Loja, Pontificia Universidad Católica del Ecuador. Ibarra, pp. 61-77. 
elementos que componen la arquitectura de la teoría según varias perspectivas: la axiomática, la historicista, la semántica y, finalmente, una prolongación de esta última corriente: la estructuralista ${ }^{22}$; todas ellas ofrecen diversas posibilidades para identificar los elementos constitutivos de las teorías y definir sus relaciones. La concepción axiomática asume que las teorías son reductibles a formulaciones lógicas y sus elementos básicos equivalen a los términos. El valor de validez o invalidez se relaciona con la coherencia lógica y formal y, por lo tanto, su escenario de control es la lógica. La concepción historicista, en cambio, enfoca la teoría desde el punto de vista del cambio; es decir, estableciendo elementos perdurables y constantes y otros menos estables que giran alrededor de ellos. El historicismo se basa en el carácter de pertinencia histórica como criterio de validez o invalidez de una teoría y su escenario de control es la sociología de la ciencia, pues, en definitiva, o es la comunidad científica la que establece la validez de una teoría o es la sociedad en su conjunto la que la ratifica al considerarla útil y pertinente. Finalmente, la propuesta semántica considera que toda teoría es una forma de representación del conocimiento sobre la realidad y enfatiza el hecho de que las teorías se comportan como modelos para interpretar y solucionar problemas. Los criterios de validez o invalidez se relacionan, entonces, con la capacidad modélica que posee un caso real o un esquema lógica para lograr la comprensión de otros casos.

22 Las diferencias entre teoría, sentido común y ley científica se basan en el criterio ampliamente difundido de Ernest Nagel (1991). La descripción de las corrientes metateóricas de la filosofía de la ciencia se basa en los aportes del mismo Nagel y otros autores como Carl G. Hempel (2005), Van Fraassen (1996), así como en las sistematizaciones de Díez y Moulines (1997) y Lorenzano (2002). 


\section{Distinciones básicas: teoría y sentido común. Teoría y ley cientifica}

Por lo general, los manuales de filosofía de la ciencia abordan la distinción entre teoría y sentido común como realidades opuestas e irreductibles entre sí, sin tomar en cuenta que son continuas y se relacionan entre sí. A continuación, contrastaremos ambos saberes con fines didácticos y con la precaución de considerar ambas como instancias en permanente interacción en la generación de conocimientos. En la mayoría de casos, las teorías corren el riesgo de constituirse en sentido común cuando el investigador las incorpora como realidades dadas de su acerbo cognitivo, cuando ya no son objeto de la crítica reflexiva y pierden, por ello, el carácter instrumental que las anima. Observamos, incluso, que en la cultura contemporánea la teoría ha llegado a ser un objeto de consumo de masas mediante la difusión de la ciencia en programas televisivos, artículos periodísticos y publicaciones, difusión que en muchos casos adquiere los tintes de banalización de la ciencia. Por tanto, también en este escenario la teoría ha infiltrado el sentido común colectivo para incorporarse en el lenguaje y las preocupaciones cotidianas de la sociedad.

El aporte del filósofo Thomas Nagel (1991, pp. 15-38) contribuye a entender las teorías, tanto desde el contexto de las ciencias formales cuanto de las naturales y sociales, a partir de la distinción entre dos formas fundamentales de conocimiento a las que el autor considera estrategias explicativas y predictivas diversas: el sentido común y la ciencia. Según el autor, esta última, en tanto arte institucionalizado de la investigación, permite obtener conocimientos teóricos generales respecto a las condiciones de aparición de sucesos y procesos, y hace posible emancipar la mente de supersticiones antiguas y creencias tradicionales. La segunda línea divisoria es aquella 
que distingue la teoría con respecto a la ley científica, dos elementos distintos pero que constituyen las expresiones elementales de la metateoría. La Figura 7 grafica, de manera muy general, las relaciones de subordinación e inclusión entre estos diversos sistemas explicativos y predictivos.

Figura 7

Ciencia y sentido común según Nagel

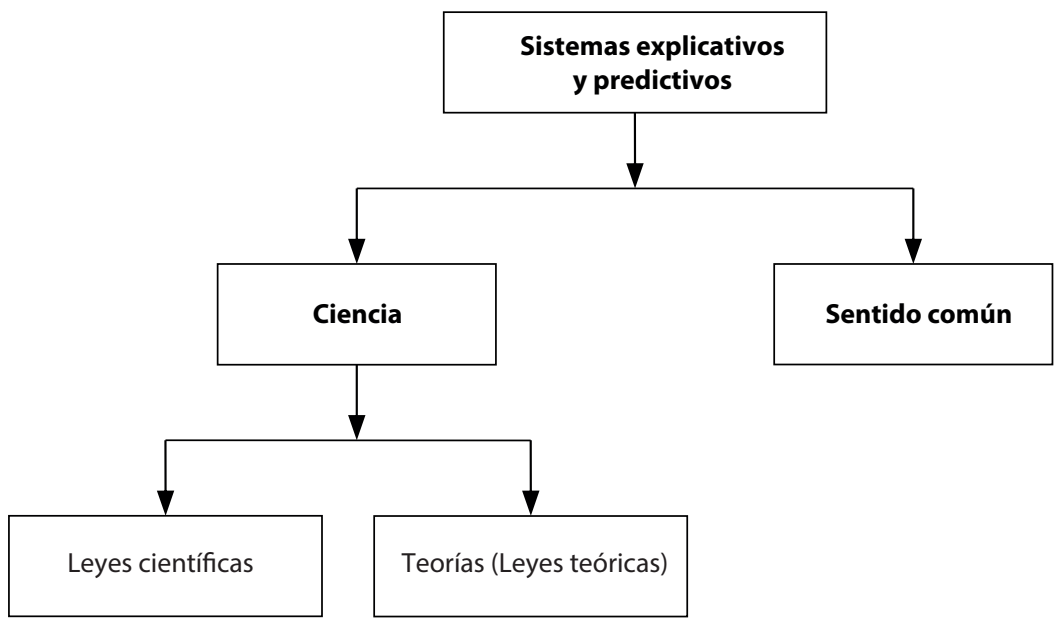

Elaboración de los autores a partir de Nagel (1991).

La Tabla 6, en cambio, sistematiza más o menos in extenso la caracterización contrastada de los principales sistemas explicativos: el sentido común y la ciencia, según las siguientes variables: explicación sistemática, restricción de la validez, antagonismos, lenguaje y orientación, y testabilidad. 
Tabla 6

Contrastación entre sentido común y ciencia

\begin{tabular}{|c|c|}
\hline \multicolumn{2}{|c|}{ Conocimiento (estrategias explicativas) } \\
\hline Sentido común (SC) & Ciencia $(C)$ \\
\hline \multicolumn{2}{|c|}{ Explicación sistemática } \\
\hline $\begin{array}{l}\text { Las conclusiones del sentido común tie- } \\
\text { nen continuidad con la ciencia. } \\
\text { La información adquirida en la expe- } \\
\text { riencia cotidiana es bastante exacta, pero } \\
\text { no está acompañada de una explicación } \\
\text { de por qué los hechos son como se pre- } \\
\text { sentan; cuando explica carece de pruebas } \\
\text { críticas de su vinculación con los hechos. }\end{array}$ & $\begin{array}{l}\text { Surge de las preocupaciones cotidianas: } \\
\text { - cuerpo de conocimiento organizado; } \\
\text { - clasificación de sus materiales en tipos o géneros } \\
\text { significativos. } \\
\text { Su origen es el deseo de hallar explicaciones sistemá- } \\
\text { ticas y controlables por elementos de juicio fáctico. } \\
\text { Su objetivo lo concreta sobre la base de principios } \\
\text { explicativos; descubre - para luego formular en } \\
\text { términos generales- condiciones de los fenóme- } \\
\text { nos; los enunciados de estos son las explicaciones; } \\
\text { este desarrollo se da aislando propiedades, diferen- } \\
\text { ciando esquemas de dependencia y encontrando } \\
\text { vinculaciones e interconexiones sistemáticas. }\end{array}$ \\
\hline \multicolumn{2}{|c|}{ Restricción de la validez } \\
\hline $\begin{array}{l}\text { Conocimiento incompleto y no erróneo, } \\
\text { por la falta de conciencia de los límites } \\
\text { dentro de los cuales sus creencias tienen } \\
\text { validez. } \\
\text { El conocimiento del SC se aplica supo- } \\
\text { niendo la permanencia de factores o per- } \\
\text { sistencia de condiciones; ello no quiere } \\
\text { decir que sus efectos sean erróneos ni sus- } \\
\text { ceptibles de cambio (a veces duran siglos). }\end{array}$ & $\begin{array}{l}\text { La ciencia sistemática completa el defecto del } \\
\text { conocimiento del SC: introduce agudeza en las } \\
\text { creencias al manifestar conexiones sistemáticas } \\
\text { de proposiciones del SC; muestra que las prác- } \\
\text { ticas comunes son explicables por principios que } \\
\text { formulan relaciones entre distintos puntos de } \\
\text { amplios ámbitos de hechos. }\end{array}$ \\
\hline \multicolumn{2}{|c|}{ Antagonismos } \\
\hline $\begin{array}{l}\text { Las contradicciones del SC se originan } \\
\text { en su contenido: es referido a efectos que } \\
\text { tienen las cosas corrientes sobre cuestio- } \\
\text { nes que los hombres valoran. } \\
\text { - } \mathrm{Ni} \text { se observan relaciones entre } \\
\text { fenómenos. } \\
\text { - Ni se explican sistemáticamente inde- } \\
\text { pendientemente de su impacto sobre las } \\
\text { preocupaciones humanas. }\end{array}$ & $\begin{array}{l}\text { Los juicios antagónicos son estímulos porque la } \\
\text { ciencia los combate con: } \\
\text { - explicaciones sistemáticas de hechos, discerni- } \\
\text { miento de condiciones y consecuencias de sucesos; } \\
\text { - evidencia de las relaciones lógicas entre } \\
\text { proposiciones. } \\
\text { Pese a que no existen garantías de ausencia de } \\
\text { contradicciones, cuando las hay, o son aparentes } \\
\text { o genuinas, pero transitorias. }\end{array}$ \\
\hline
\end{tabular}




\begin{tabular}{|c|c|}
\hline \multicolumn{2}{|c|}{ Conocimiento (estrategias explicativas) } \\
\hline Sentido común (SC) & Ciencia $(C)$ \\
\hline \multicolumn{2}{|c|}{ Características del lenguaje } \\
\hline $\begin{array}{l}\text { El lenguaje corriente presenta indeter- } \\
\text { minación (vaguedad e inespecificidad) y } \\
\text { ello dificulta el control experimental de } \\
\text { las creencias por la imposibilidad de es- } \\
\text { tablecer diferencias entre juicios confir- } \\
\text { matorios y contradictorios de aquellas. } \\
\text { Es esta indeterminación la que explica la } \\
\text { estabilidad de muchas creencias. }\end{array}$ & $\begin{array}{l}\text { Introduce modificaciones en el lenguaje para una } \\
\text { mayor determinación porque busca explicacio- } \\
\text { nes sistemáticas. Por su precisión, los enuncia- } \\
\text { dos se hacen más susceptibles de ser sometidos } \\
\text { a pruebas y críticas por medio de la experiencia } \\
\text { (enfrentan mayores riesgos de ser refutados por } \\
\text { los datos empíricos). } \\
\text { Por el incremento de la determinación de sus } \\
\text { enunciados y su incorporación a sistemas expli- } \\
\text { cativos lógicamente integrados, la C: } \\
\text { - agudiza su poder discriminatorio frente a las } \\
\text { pruebas; } \\
\text { - acrecienta la fuente de sus elementos de juicio } \\
\text { para sus conclusiones. }\end{array}$ \\
\hline \multicolumn{2}{|c|}{ Orientación; términos } \\
\hline $\begin{array}{l}\text { Limitada a la influencia de sucesos sobre } \\
\text { cuestiones que son objeto de valoracio- } \\
\text { nes por los hombres. } \\
\text { Conceptos abstractos. }\end{array}$ & $\begin{array}{l}\text { Ilimitada en sus preocupaciones; de ahí que los } \\
\text { enunciados científicos parezcan remotamente re- } \\
\text { lacionados con las cosas cotidianas. } \\
\text { Conceptos abstractos en relación no obvia con lo } \\
\text { cotidiano; presentan lejanía con lo ordinario por } \\
\text { su búsqueda de explicaciones de largo alcance (y } \\
\text { estas, siendo explicaciones de lo vario, se formu- } \\
\text { lan como propiedades estructurales sin referencia } \\
\text { a relaciones individualizantes de lo cotidiano). }\end{array}$ \\
\hline \multicolumn{2}{|c|}{ Testabilidad } \\
\hline $\begin{array}{l}\text { No sometidas a escrutinio sistemático } \\
\text { para determinar la exactitud y validez de } \\
\text { creencias. } \\
\text { Son aceptadas sin evaluación crítica. }\end{array}$ & $\begin{array}{l}\text { Sometida al desafío de datos observacionales crí- } \\
\text { ticamente probatorios. El que las hipótesis expli- } \\
\text { cativas sean testables significa que están abiertas } \\
\text { a la posibilidad de rechazo, según procedimientos } \\
\text { críticos. } \\
\text { La crítica se realiza con el fin de } \\
\text { - juzgar la confiabilidad de los procedimientos; } \\
\text { - evaluar la fuerza probatoria de los elementos de } \\
\text { juicio de las conclusiones. }\end{array}$ \\
\hline
\end{tabular}

Elaboración de los autores a partir de Fernández y Barbosa (1996, pp. 37-38). 
Otra de las distinciones clave de Nagel es la de ley experimental y ley teórica, a las que considera formas proposicionales o enunciados con forma gramatical propia que expresan distintos niveles de las categorías del conocimiento científico. Ambas desempeñan el papel de sistemas explicativos y predictivos, y funcionan como suposiciones; las leyes experimentales se refieren a fenómenos "observables" y las leyes teóricas, de carácter más vasto y abstracto, no se relacionan con fenómenos observables, aunque los incluyen en sus términos. Sin embargo, entre ambas categorías no existe una ruptura o división radical, sino que forman parte de un continuum. En la Tabla 7 apreciamos los caracteres esenciales de ambos tipos de categorías, según el mismo Nagel (1991, pp. 84 y ss.).

\section{Tabla 7}

Contrastación entre ley experimental y teoría

\begin{tabular}{|c|c|}
\hline \multicolumn{2}{|c|}{ Conocimiento teórico } \\
\hline Leyes experimentales & Leyes teóricas (teorías) \\
\hline $\begin{array}{l}\text { Enunciado que formula una relación en- } \\
\text { tre cosas o características de cosas que son } \\
\text { observables. } \\
\text { No significa que se deducen de experimentos } \\
\text { de laboratorio. } \\
\text { La ley puede ser convalidada con cierto } \\
\text { grado de probabilidad por la observación } \\
\text { controlada. }\end{array}$ & $\begin{array}{l}\text { Suposiciones no relacionadas con fenómenos } \\
\text { observables. } \\
\text { No significa que son puramente especulativas. } \\
\text { Sus términos se refieren a algo no manifies- } \\
\text { tamente observable ni confirmable mediante } \\
\text { experimentos u observaciones de las cosas a } \\
\text { los que se refieren. }\end{array}$ \\
\hline $\begin{array}{l}\text { Se expresan con términos abstractos, no solo } \\
\text { observacionales. }\end{array}$ & $\begin{array}{l}\text { Se expresan con términos abstractos, aunque } \\
\text { también incluyen fenómenos observacionales. }\end{array}$ \\
\hline $\begin{array}{l}\text { Contenido empírico determinado, contro- } \\
\text { lado por elementos observacionales según } \\
\text { procedimientos establecidos. }\end{array}$ & $\begin{array}{l}\text { Los términos de una teoría no se definen me- } \\
\text { diante procedimientos experimentales explí- } \\
\text { citos. Derivan de analogías generadoras. Una } \\
\text { teoría no puede ser sometida a una prueba } \\
\text { experimental directa. }\end{array}$ \\
\hline
\end{tabular}


124

\begin{tabular}{|l|l|}
\hline \multicolumn{2}{|c|}{ Conocimiento teórico } \\
\hline $\begin{array}{l}\text { Son generalizaciones inductivas basadas } \\
\text { en relaciones que se cumplen en los datos } \\
\text { observados. }\end{array}$ & $\begin{array}{l}\text { Una teoría no es una generalización a partir } \\
\text { de datos observacionales. Los datos sugieren } \\
\text { o apoyan teorías. } \\
\text { Su basa en elementos de juicio observacionales. } \\
\text { leyes empíricas. } \\
\text { La ley experimental tiene vida propia y puede } \\
\text { sobrevivir a la teoría, pero una ley es ininte- } \\
\text { ligible al margen de la teoría que la explica. } \\
\text { Lasendiones teóricas no pueden ser com- } \\
\text { prendidas separadamente de la teoría parti- } \\
\text { cular que las define. } \\
\text { Cuando se alteran los postulados básicos } \\
\text { cambia el significado de los términos básicos. } \\
\text { Una nueva teoría explica las leyes de la ante- } \\
\text { rior teoría más otras nuevas. }\end{array}$ \\
\hline $\begin{array}{l}\text { Sin excepción, una ley experimental se for- } \\
\text { mula por medio de un solo enunciado. }\end{array}$ & $\begin{array}{l}\text { Sistema de varios enunciados vinculados en- } \\
\text { tre sí. }\end{array}$ \\
$\begin{array}{l}\text { Las leyes explican hechos cualitativamente } \\
\text { similares y definidos: dominio estrecho de } \\
\text { explicación. }\end{array}$ & $\begin{array}{l}\text { Mayor generalidad y mayor poder explicativo. } \\
\text { Marcan dominios de hechos cualitativamen- } \\
\text { te dispares debido a su independencia de } \\
\text { la observación y el carácter simbólico de la } \\
\text { teoría. }\end{array}$ \\
$\begin{array}{l}\text { Dos funciones: a) Poner de manifiesto las co- } \\
\text { nexiones sistemáticas entre leyes experimenta- } \\
\text { les relacionadas con fenómenos de ámbito di- } \\
\text { verso; b) Suministra sugerencias para otras le- } \\
\text { yes experimentales y el método observacional. }\end{array}$ \\
\hline
\end{tabular}

Elaboración de los autores a partir de Nagel (1991, pp. 84 y ss.).

Como se puede observar en la Tabla 7, el aporte de Nagel menciona otros elementos como términos y nociones teóricas, elementos nucleares y constitutivos de la teoría que serán mejor explicados en el siguiente apartado referido a la concepción axiomática.

\section{Elementos de la teoría según la concepción axiomática}

La concepción axiomática es, sin duda, la postura más difundida que nutre muchas aproximaciones y aportes sobre filosofía de 
la ciencia. Concibe las teorías como cuerpos de conocimientos que articulan afirmaciones o enunciados organizados — proposicionesde distinto grado de abstracción según los principios de la gramática del lenguaje lógico. Las teorías son el conjunto previo de afirmaciones sobre determinados ámbitos de la realidad, de tal manera que "se analizan o reconstruyen como teniendo cierta estructura que expresa las relaciones que mantienen entre sí las diversas afirmaciones y los diversos términos o conceptos con los que se realizan tales afirmaciones" (Díez y Moulines, 1997, p. 268).

En el plano de sus componentes lógicos básicos, toda teoría (T) se expresa mediante un conjunto reducido de afirmaciones fundamentales y básicas que originan, mediante procesos de inferencia deductiva, a todas las demás. Los elementos básicos de una teoría son dos: a) Los axiomas o postulados $(A)$, proposiciones básicas, autónomas e independientes en el sentido de que no proceden ni se derivan de las restantes: son capaces de condensar lógicamente la teoría y poseen un carácter primitivo y originante; b) Los teoremas $(t)$ : son las proposiciones derivadas o deducidas de los axiomas, es decir, aquellas que los explicitan; por lo tanto, no contienen nueva información. Los axiomas y sus consecuencias lógicas son las instancias que definen realmente una teoría en tanto que los teoremas no añaden nueva información. Toda teoría, por lo tanto, puede ser expresada según la siguiente fórmula: $(T=A+t)$ y es susceptible de ser axiomatizada cuando se identifica el conjunto completo de sus afirmaciones o supuestos fundamentales que la constituyen.

Asimismo, una teoría admite axiomatizaciones alternativas y no necesariamente se atan a un solo esquema lógico. El proceso de axiomatización, por otra parte, no se funda en criterios de prioridad epistémica, es decir, no selecciona aquellas proposiciones "bien fundadas", sino que establece el orden en un cuerpo de afirmaciones 
previamente existentes que no requieren ser comprobados y funcionan como supuestos; así, el criterio de la axiomatización procede por medio de la identificación de contradicciones e implica tomar partido por ellas.

Las teorías incluyen otros elementos de carácter básico: los términos-conceptos o definiciones, los cuales son proposiciones diversas a los axiomas y teoremas cuya función es "capturar entidades de diverso tipo (objetos individuales, sus propiedades y relaciones) que conforman el ámbito de la realidad del que se ocupa la teoría” (Díez y Moulines, 1997, p. 269). Del mismo modo como los teoremas proceden de los axiomas, algunos términos tienen un valor previo y originante, de tal modo que de unos se deducen otros. Aquellos términos dotados de la capacidad de originar a otros se denominan términos primitivos. Las proposiciones definitorias se construyen de tres modos: como relatores (el término más la variable, propiedades o relaciones entre entidades), términos singulares (ser " 1 ”) y functores (funciones-operaciones entre individuos).

Si bien las definiciones son lógicamente eliminables y prescindibles ya "que no constituyen afirmaciones sustantivas de la teoría sino que expresan meras abreviaturas notacionales" (Díez y Moulines, 1997, p. 290), en la práctica una teoría resulta incomprensible sin ellas y son elementos de enorme valor en la economía intelectual para la comprensión teórica. La Figura 8 organiza visualmente los elementos de una teoría y sus relaciones.

Es posible entender mejor la articulación de los elementos que constituyen una teoría no solo a partir de la discriminación de sus elementos lógicos, sino también según el tipo de enunciados que los expresan (Gianella, 2003, p. 48). Así, toda teoría relaciona enunciados de distintos niveles conectados por relaciones de compatibilidad 
e implicación, y referidos a determinados dominios de la realidad. En las ciencias fácticas, las teorías admiten la concatenación de niveles diversos de enunciados de abstracción creciente (p. 48):

a. Los enunciados empiricos básicos que se refieren a descripciones, datos y observaciones directamente conectados con la base empírica de la teoría;

b. Las generalizaciones empiricas, indirectamente conectadas con la base empírica pues expresan universalizaciones absolutas, estadísticas o existenciales. Este nivel es todavía preteórico;

c. Los enunciados teóricos propiamente dichos que intentan dar cuenta totalmente en abstracto lo asumido por los otros dos niveles. Los enunciados teóricos son puros cuando la totalidad de sus términos son abstractos; o mixtos, cuando incluyen algún término observacional, es decir, referido a la realidad. Estos últimos se denominan reglas de correspondencia o principios puente porque conectan los términos abstractos con la realidad.

Figura 8

Elementos de la teoría según la concepción axiomática

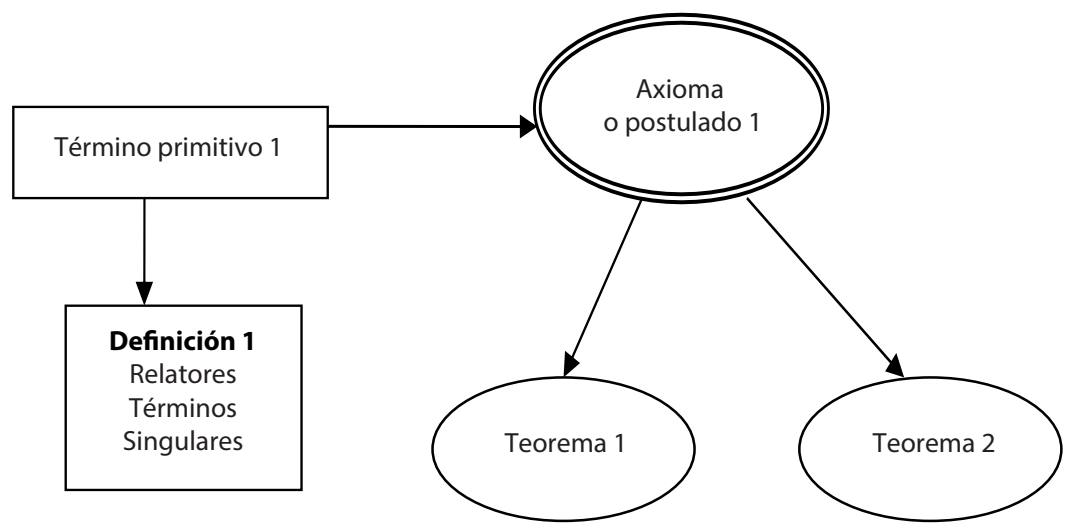

Elaboración de los autores a partir de Díez y Moulines (1997, pp. 268-290). 
La Figura 9 muestra la relación de los enunciados tal como los describe Gianella.

\section{Figura 9}

Elementos de los enunciados de los niveles preteórico y teórico

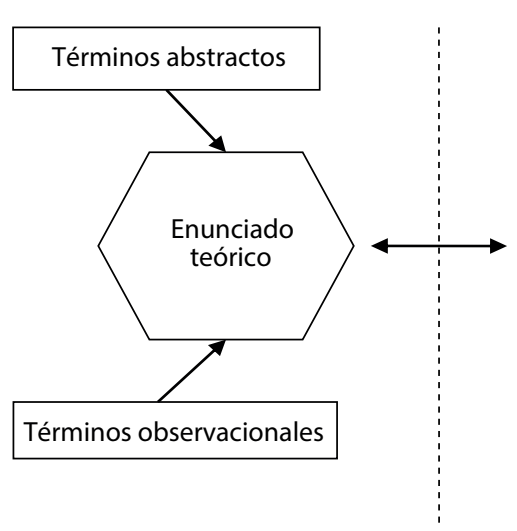

Nivel teórico

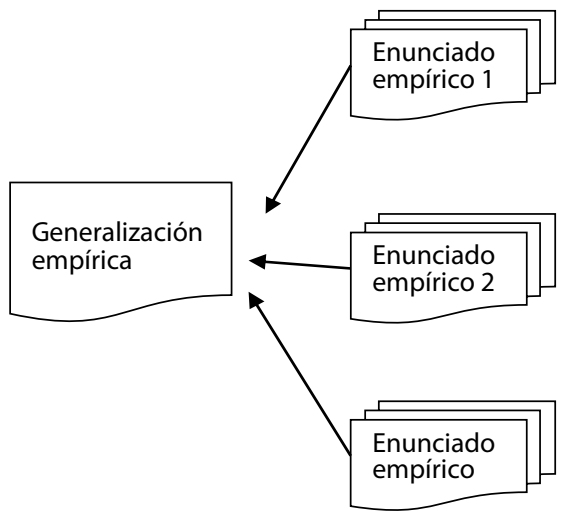

Nivel preteórico

Elaboración de los autores a partir de Gianella (2003, p. 48).

Entre los nudos más críticos de la propuesta, destacamos los siguientes: a) La problemática relación de continuidad entre el núcleo axiomático y la base empírica de la teoría (Díez y Moulines, 1997, pp. 297 y ss.), que consiste en la negación de la carga teórica del dato, un aspecto que ya hemos constatado gracias a Popper (su$p r a)$. Este aspecto es crucial porque la propuesta axiomática supone que la teoría es el resultado de sucesivas generalizaciones y, por lo tanto, esconde la pretensión de que los axiomas expresan la realidad. Sin embargo, todo dato u observación siempre están premoldeados por la teoría. b) Sustitución de la realidad y su sentido por los aspectos formales y lógicos de las teorías, según advierte y cuestiona Russell (Ribes, 1989, pp. 33 y ss.). c) La postura axiomática aspira a establecer un marco común universal de expresión y contenidos 
de conocimiento, en contravía con la diversidad y la novedad con el peligro de constituirse, según Feyerabend, en la expresión epistemológica de un orden político totalitario, no abierto a la diversidad.

No obstante, recalcamos aspectos a favor como el rigor lógico y la capacidad de identificar elementos estructurales y sus relaciones. En definitiva, aunque constituyen una dimensión importante de las teorías, los aspectos lógicos y formales no son los únicos que determinan una teoría ni pueden dar total cuenta de esta, como si se tratara de un cuerpo de conocimientos autorreferenciado, autosuficiente y encerrado en sus propias reglas. Existen, además, otros factores como, por ejemplo, los socio-históricos, pero para ello debemos revisar la siguiente corriente: la historicista, también denominada nueva filosofía de la ciencia.

\section{La metateoría estructuralista}

La concepción estructuralista ${ }^{23}$ de la teoría - también denominada sintáctica - es un desarrollo específico y muy reciente producido especialmente por J. Sneed, discípulo de P. Suppes. Según Díez y Lorenzano, el estructuralismo metateórico

es una de las principales escuelas actuales en filosofía de la ciencia y la que más atención ha dedicado al análisis y reconstrucción de teorías científicas particulares y la que mayores frutos ha dado en la clarificación de los problemas conceptuales y en la explicitación de los supuestos fundamentales de teorías científicas concretas. (2002, p. 55)

Esta concepción usa el término estructura según el significado puesto en juego por la lógica de conjuntos y no debe confundirse con el significado que diversas corrientes antropológicas y lingüísti-

23 Para este apartado nos basamos casi exclusivamente en Díez y Moulines (1997, pp. 351 y ss.) y Díez y Lorenzano (2002). 
cas le atribuyen. Sneed reconoce varias herencias que configuran la tradición metateórica estructuralista (2002, p. 58): de Carnap, recupera el rigor descriptivo y el uso de instrumentos formales de análisis; de los historicistas, especialmente de Lakatos, asume, en primer lugar, que la teoría no es un conjunto de axiomas y enunciados ya que se trata de una entidad estructuralmente compleja y dinámica compuesta de un núcleo inmutable y un cinturón en transformación; en segundo lugar, retoma la identificación de dos niveles de conceptualización: el teórico y el empírico. De Kuhn, asume que la identidad de la teoría está conformada por el paradigma expresado por medio de leyes o generalizaciones simbólicas y las aplicaciones (o ejemplares). De Suppes, recoge la tesis semanticista básica según la cual la teoría es un conjunto de modelos antes que un conjunto de proposiciones y afirmaciones. Por tanto, es la lógica de conjuntos el instrumento formal de análisis, resultando inadecuados los métodos proposicionales o sintácticos cuyo objeto de control son las proposiciones o afirmaciones.

Para el estructuralismo el modelo es "un sistema real que puede ser descrito mediante un cierto lenguaje formal; es decir, el modelo no sería lo que representa un sistema real, sino aquello-que-esrepresentado por un cierto conjunto de enunciados" (2002, p. 58), de tal manera que se trata de: 1 . un conjunto formado por una serie de conjuntos (dominios o entidades contenidas en la estructura); y 2. por una serie de relaciones (Zamora Bonilla, 2001, tema vii). Por lo tanto, no debemos atribuir al término un referente necesariamente real; se trata, para esta concepción, de modelos matematizables o altamente formalizables y expresados mediante fórmulas lógicas de exclusión, inclusión, equivalencia, etc.

Sneed distingue tres dimensiones básicas para describir las teorías que conforman los puntos fundamentales de nuestra siguiente 
explicación: 1. la sincrónica (los elementos intrateóricos), 2. las relaciones interteóricas y 3. la dimensión diacrónica (las transformaciones de la teoría a lo largo del tiempo); al mismo tiempo, el análisis integrado según estas tres dimensiones explica las rupturas de la concepción estructuralista con respecto a otras, en especial con aquellas centradas exclusivamente en los elementos sincrónicos y con las que restringen el análisis solo a los elementos susceptibles de análisis formal. A continuación, desarrollaremos la metateoría estructuralista según cada una de las dimensiones propuestas por Sneed, siguiendo paso a paso a Díez y Lorenzano (2002).

\section{La estructura sincrónica de una teoría}

El corte sincrónico de una teoría es la imagen congelada en un momento de su evolución (un fotograma), según la imagen de un entramado en red (red teórica) que articula elementos estratificados según diversos grados de especificidad (2002, p. 359). Los elementos teóricos son los constituyentes de la red teórica y se consideran la expresión mínima de una teoría, de tal manera que

la parte formal global de la teoría-red queda expresada por el conjunto de las partes formales de los elementos constituyentes; su parte aplicativa global por el conjunto de las partes aplicativas de sus constituyentes. A estos elementos constituyentes se les denomina elementos teóricos. La parte formal de los elementos teóricos se denomina núcleo y su parte aplicativa dominio de aplicaciones pretendidas (propuestas o intencionales). (pp. 59-60)

Por lo tanto, los elementos teóricos se componen de una parte formal o núcleo $(K)$ y otra parte aplicativa o de aplicaciones pretendidas $(I)$, de tal manera que el conjunto se expresa $\mathrm{T}=(\mathrm{K}, \mathrm{I})$. Veamos, entonces, cuáles son los constituyentes del núcleo y las aplicaciones. 
132

\section{Componentes de la parte formal de una teoría:}

el núcleo $K=(M p, M, G C, t)$

El núcleo $(K)$ es la parte formal de la teoría, es decir, las condiciones o leyes que, según la teoría, rigen la realidad a la que se refiere, pero expresadas no en términos lingüísticos (propio del modelo axiomático), sino según la lógica modelo-teórica de conjuntos.

a. Los modelos de la teoría. El núcleo $K$ incluye modelos potenciales $(M p)$, las estructuras o entidades que pueden ser modelos de la teoría (que pudieran satisfacer las leyes). El conjunto de estos modelos expresa el aparato conceptual de la teoría; y los modelos actuales $(M)$, restringidos a aquellos que en efecto son modelos de la teoría (que de hecho satisfacen las leyes).

Zamora Bonilla (2001, tema vii) define con precisión a $M p$ y $M$ de la siguiente manera:

1. $M$ se define por una serie de axiomas (condiciones que un modelo debe cumplir para pertenecer a dicha clase), entre los que se distinguen especialmente las "tipificaciones" (indicaciones del tipo lógico de cada concepto que intervienen en los modelos, especialmente las funciones), las "caracterizaciones" (indican la estructura matemática básica de esas funciones), las "leyes fundamentales" (condiciones que establecen una relación de dependencia entre todos los conceptos del modelo) y las "leyes especiales" (condiciones que son válidas solo en algunos conjuntos de modelos de la teoría, pero no en todos ellos)" (tema vii).

2. Mp es el conjunto de las estructuras que satisfacen la estructura formal básica de los modelos de una teoría (esto es, sus tipificaciones y caracterizaciones, pero no necesariamente su ley fundamental). 
b. Las condiciones de ligadura. El núcleo Kincluye, además, las condiciones de ligadura o constraints $(G C)$ o bien las condiciones para los modelos que no derivan necesariamente de las leyes, sino de un conjunto de modelos. Así, se determinará la característica de una partícula no solo por las leyes que rigen un solo modelo, sino por la suma de los modelos bajo los cuales la partícula en cuestión es analizada. Las características de la partícula serán definidas entonces por intersección o adición conjuntista de los modelos. Las ligaduras son de dos clases: de identidad o de aditividad.

c. La teoricidad. El último elemento del núcleo es la teoricidad $(t)$ o bien la relación de un término o un concepto con respecto a la teoría. Así, un concepto no es teórico de por sí, sino que su teoricidad es proporcionada por una teoría dada que lo constituye, de tal modo "que un concepto es T-teórico si es un concepto propio de la teoría T, introducido por ella, y es T-no teórico si es un concepto previamente disponible a T" (Díez y Lorenzano, 2002, p. 62). El carácter t-teórico es dependiente de la teoría; en tanto el t-no teórico es independiente de ella y no presupone la validez de las leyes de la teoría.

La formulación de si un concepto es teórico o no se establece por un procedimiento de determinación que depende de la teoría (determino la masa de un cuerpo a partir de la teoría de la gravedad) o es independiente de la teoría (determino la masa usando procedimientos ópticos o procedentes de otro entorno teórico como, por ejemplo, la cinemática).

\section{Componentes de la parte aplicativa de las teorías:} las aplicaciones intencionales

$$
\mathrm{I}=(M p p)
$$

Las aplicaciones intencionales son la dimensión o la base empírica de las teorías o el conjunto de sistemas reales a los que se quie- 
134

re aplicar la teoría o la red teórica, y su conjunto se expresa como $I$. En lenguaje kuhniano, se trataría de los ejemplares.

a. Las pretensiones (los sistemas reales) de una teoría se individualizan y describen mediante un vocabulario previo a $T$ ( $t$-no teórico) usando, por ejemplo, para el sistema del péndulo términos previos o externos a la mecánica clásica, como posición y tiempo (describen trayectorias no en términos de masa sino relativos a la cinemática). Todos los datos están cargados de teoría, pero no todos de la teoría para la que son datos, es decir, algunos datos devienen de teorías previas o antecedentes. Cada aplicación pretendida es, entonces, un modelo parcial $(M p p)$, distinto al modelo potencial $(M p)$ o actual $(M)$, que pretende satisfacer en su totalidad la teoría, en tanto que $M p p$ por ser una realidad empírica no estaría en condiciones de lograrlo. Con relación a $M$ y $M p, M p p$ resulta de suprimir las relaciones correspondientes a los conceptos teóricos. Si como afirma Moulines (2002, p. $101)$, $I$ es un subconjunto de $M p p$, entonces podemos definir a $K$ como la especificación de los tres conjuntos $M p p, M p$ y $M$.

b. La determinación de $I$ (las aplicaciones intencionales) está guiada, además, por elementos pragmáticos, es decir, que responden a la intencionalidad de los usuarios que pretenden que las leyes se cumplan en esos y otros sistemas de acuerdo a sus expectativas e intereses.

Si unimos estas dos dimensiones tenemos que Teoría (T) se expresa según la siguiente fórmula: $T=(K, I)$ o bien $T=[K(M p, M$, $G C, t)+I(M p p)]$. Una vez entendidos los elementos que conforman la teoría, recapitulamos que el elemento teórico es una teoría en sentido mínimo y, según hemos explicado,

está constituido por (1) una parte formal, que expresa los recursos conceptuales a diferentes niveles y las constricciones-leyes que 
según la teoría rigen su ámbito de estudio, y (2) una parte aplicativa, que especifica en términos no teóricos respecto de la teoría los sistemas empíricos a los que una teoría pretende aplicarse, de los que pretende que son regidos por sus constricciones-leyes. Así, un elemento teórico $\mathrm{T}$ se identifica con el par formado por el núcleo $\mathrm{K}$, la parte formal, y el dominio de aplicaciones I, la parte aplicativa: $\mathrm{T}$ $=(\mathrm{K}, \mathrm{I})$. (Díez y Lorenzano, 2002, p. 65)

\section{Las aserciones empíricas}

La aserción empírica es lo que la teoría afirma, es decir, que existe algún conjunto de modelos $\mathrm{X}$ que satisface todos los axiomas de la teoría, y tal que la restricción de $\mathrm{X}$ a los términos no teóricos es idéntica a I; o dicho de otra manera, la aserción empírica de la teoría consiste en decir que I es subsumible dentro de un conjunto de modelos que satisfacen los axiomas de la teoría. (Zamora Bonilla, 2001, tema vii)

Según Moulines (2002, p. 100), la aserción empírica central es un enunciado que pone a prueba la teoría en un dominio dado de la realidad y para toda teoría empírica viable tal aserción debería ser falsa en el sentido de que, si bien, "ninguna teoría logra nunca ser aplicada con toda exactitud a su dominio de aplicaciones propuestas" (p. 100), la aserción empírica posee un carácter aproximativo determinado por un conjunto de aproximaciones admisibles.

\section{Las redes teóricas}

El concepto de red teórica es el que expresa de manera más rica y compleja la estructura sincrónica o estática de las relaciones intrateóricas y traduce en lenguaje formal los paradigmas o matrices disciplinares de Kuhn y los programas de investigación de Lakatos en algún momento de su evolución. "Una red teórica es un conjunto 
de elementos teóricos conectados mediante la relación de especialización" (Díez y Lorenzano, 2002, p. 69), según diversos estratos o niveles de concreción o especificidad cada vez más restrictivos hasta conformar las "ramas" de la estructura arbórea conformadas por elementos que concretan o especifican la red-teoría.

Así,

un elemento teórico $\mathrm{T}$ es especialización de otro T’ si T impone constricciones adicionales a las de T'. Ello supone que: (1) los conjuntos de modelos parciales y potenciales de ambos coinciden, e. e. su aparato conceptual es el mismo; (2) los conjuntos de modelos actuales y condiciones de ligadura de $\mathrm{T}$ están incluidos en los de T', pues algunos modelos de T' no satisfarán las constricciones adicionales que añade $\mathrm{T}$; (3) el dominio de aplicaciones pretendidas de T está incluido en el de T’, esto es, el elemento más específico se pretende aplicar a algunas aplicaciones del más general. (pp. 68-69)

\section{Relaciones diacrónicas de las teorías}

La teoría no es una realidad estática y parte de su explicación consiste en desplegar las evoluciones teóricas que le son propias, pues el concepto de red teórica no basta para acceder a la estructura de la teoría en toda su complejidad. Es necesario, además, determinar la persistencia de las teorías a pesar de las versiones que la extienden en el tiempo, aspecto en el cual el estructuralismo asume las nociones de ciencia normal de Kuhn y programas de investigación de Lakatos, precisándolas con el lenguaje formal que lo caracteriza.

El concepto que abre tal dimensión es el de evolución teórica, aún más complejo que el de red teórica pues lo incluye: "la evolución teórica es una determinada sucesión de redes teóricas en las que se conservan determinados elementos constantes a lo largo de toda la sucesión" (Díez y Lorenzano, 2002, p. 69). Los elementos que in- 
tervienen para determinar las partes esenciales y accidentales de una teoría son de índole pragmática, principalmente la comunidad de científicos y los períodos históricos. Si la teoría-red es el fotograma, la evolución teórica es la película entera.

\section{Relaciones interteóricas}

Siguiendo la línea progresiva en procura de mayor amplitud y complejidad analíticas cada vez, no basta determinar las relaciones intrateóricas (los elementos sincrónicos) y su evolución en el tiempo (los aspectos diacrónicos). Es necesario precisar el entorno teórico, es decir, la relación de los elementos teóricos, de las teorías-red y de las evoluciones teóricas con otras teorías. Tales relaciones no se establecen a partir de los conjuntos de enunciados, sino del conjunto de modelos de teorías diferentes. Estas relaciones reciben el nombre de vínculos o links $(L)$ que constituyen el último elemento del núcleo $K$. La clase total de los vínculos se expresan con las siglas $G L$.

En este punto, el análisis interteórico recupera la teoricidad de los elementos no teóricos (prestados de otras teorías) de una teoría $T$, definidos por fuera de su aparato conceptual $(M p)$, al identificar sus vínculos con el aparato conceptual $(M p)$ de la teoría de la cual depende su teoricidad ( $T$ ). Es decir: se identifica la fuente teórica de los elementos teóricamente independientes (o no teóricos) de una teoría. Así, algunos elementos que no son teóricos para una teoría lo son para otra.

Las relaciones interteóricas son de dos tipos: de reducción y equivalencia, las cuales no serán explicadas aquí.

Los vínculos $(G L)$ completan el último elemento del núcleo $K$ de una teoría científica, de tal modo que la serie completa que articula sus constituyentes queda como sigue: $\mathrm{K}=(M p, M, M p p, G C, G L)$. 


\section{Los elementos teóricos según las concepciones semánticas}

La familia semántica reúne una serie de propuestas que irrumpieron en los años $70 \mathrm{y}$, sin lugar a dudas, constituye el aporte metateórico más rico y significativo por dos razones fundamentales. En primer lugar, porque supera tanto el extremo rigor lógico-sintáctico propio de la corriente axiomática cuanto la imprecisión lógica de las corrientes historicistas ${ }^{24} \mathrm{y}$ en segundo lugar, porque incluye la categoría de sentido y significado, irrelevante para la corriente axiomática, en el centro de su edificio argumental. Por tanto, las metateorías que emergen de las concepciones semánticas revisten especial importancia para las ciencias sociales.

Esta familia metateórica recibe el calificativo de semántica porque supone que toda teoría es un instrumento para interpretar o traducirsimbólicamente una realidad, un problema o un sistema por medio de modelos que los sustituyen, según algunos, en términos lógicos y conceptuales; según otros, también por medio de una realidad perceptible que posee la capacidad de explicar otras realidades y que, a la vez, incluye todas las relaciones lógicas de la teoría. Al concebir la teoría como sustitución simbólica de la realidad a fin de entenderla e interpretarla, el concepto clave y articulador de las corrientes semánticas es el de modelo, tomado en cuenta ya por la propuesta historicista de Kuhn (cfr. supra, los conceptos kuhnianos de modelo y ejemplar como elementos de la teoría) y anticipado de alguna manera por Popper al concebir las teorías como simplificaciones de la realidad.

A continuación, revisaremos los puntos fundamentales de esta corriente de la mano de sus principales autores pertenecientes, en su mayoría, a la Universidad de Stanford, como Patrick Suppes, Ernest

24 Para el desarrollo de este apartado nos basamos fundamentalmente en Díez y Moulines (1997, pp. 327 y ss.), además, en Van Fraassen (1980) y Pérez Ransanz (2000). 
Adams, Ronald Giere y Bas van Fraassen, entre otros que han dado vida a esta visión tan reciente de la mano de fuentes secundarias ${ }^{25}$, con excepción de van Fraassen (1996).

\section{Teoría y modelo. Distinciones y relaciones}

La visión semántica asume de manera muy particular la concepción modélica, lo cual implica que las teorías no constituyen, primariamente, clases de axiomas o clases de enunciados. Las teorías, aunque los incluye son realidades que no se reducen a sus elementos lingüísticos o lógicos. El cambio de perspectiva que propicia la concepción modélica consiste en que toda teoría es una clase o un conjunto de modelos (esquemas) que se aplican a ciertos dominios de la realidad (Díez y Moulines, 1997, p. 328). Al enfatizar el carácter modélico de la teoría sobre el entramado de axiomas y enunciados, la concepción semántica pone de manifiesto que el objetivo de la teoría es ofrecer esquemas para interpretar y apropiarse de la realidad. Por lo tanto, para esta corriente "una teoría consiste en un conjunto de modelos, caracterizados por una 'definición teórica', más una aserción empírica ('hipótesis teórica') acerca de la relación entre ciertos tipos de sistemas reales y los modelos de la teoría" (Pérez Ransanz, 2000, p. 112). La relación teoría-modelo da lugar a una serie de implicaciones fundamentales que exponemos a continuación:

a. Mediante el modelo (esquema que representa la realidad), la función de la teoría es identificar una clase de datos, fenómenos o experiencias en un determinado ámbito de la realidad. Así, para la corriente semántica, de acuerdo con Van Fraassen, la teoría es una estrategia de análisis y de investigación (2000,

25 Para el desarrollo de este apartado nos basamos fundamentalmente en Díez y Moulines (1997, pp. 327 y ss.) y Pérez Ransanz (2000). 
p. 109) cuyo criterio de evaluación consiste en la productividad descriptiva e informativa respecto a la realidad.

b. La noción de modelo asume que la teoría "se aplica bien" a la realidad, a los sistemas a explicar, que los sistemas empíricos se comportan de "ese modo". "Que las leyes definen una serie de modelos significa solo que las leyes determinan qué entidades son las que se comportan de acuerdo con las teorías" (Díez y Moulines, 1997, p. 331).

c. Tanto el modelo como los fenómenos a los que se refieren son los elementos esenciales de la teoría y la relación entre ambos se expresa mediante una proposición que constituye la aserción empírica de la teoría.

d. Las teorías, como conjuntos de modelos, no son ni verdaderas ni falsas. Son aplicables o no aplicables, adecuadas o inadecuadas, explicativas o poco explicativas, de tal manera que el carácter de verdad o falsedad se restringe a la adecuación o inadecuación empírica respecto a los hechos que caen bajo el dominio de la teoría, de tal modo que las aserciones empíricas derivadas sí podrán ser verdaderas o falsas. Las teorías no son falsables primariamente, pero sí derivativamente en el sentido de que, si la aserción (la supuesta adecuación empírica) es falsa, la teoría queda falsada. En tal sentido, esta posición contesta la pretendida infalsabilidad del núcleo teórico tal como pretende Lakatos, según el cual la falsación afecta solo el cinturón protector de hipótesis específicas. Los hechos que no caben en el modelo crean una incomodidad que obliga a expandir o cambiar la teoría.

e. La opción modélica pretende superar la sintaxis propia de la corriente axiomática a favor de la matemática conjuntista como procedimiento y regla para establecer la extensión de los predicados y el modo de relación entre teorías y sistemas. Según la matemática conjuntista, toda aserción da cuenta de 
una forma de relación, fuerte o débil, entre modelo y fenómeno: el sistema fenoménico puede representar un caso idéntico al modelo, aproximado o subsumido en él.

f. El punto de vista semántico es interesante también porque incluye la relación entre teorías, a partir de los conjuntos y en términos de inclusión y traducibilidad. Así, es posible afirmar que una teoría incluye otras, o que representa una de carácter más general o es más progresiva (Dalla Chiara, 2001, p. 241). Al postular que toda teoría interesante no es autosuficiente para explicar un dominio y que es menester acudir a otra para amplificar su potencia explicativa (p. 241), este enfoque supera la inconmensurabilidad entre teorías afirmada por Kuhn y encamina las preferencias en favor de la diversidad complementaria y la cohabitación de teorías, principio que expresa muy bien la práctica cotidiana de las ciencias sociales.

Figura 10

Relaciones del modelo con los elementos empíricos

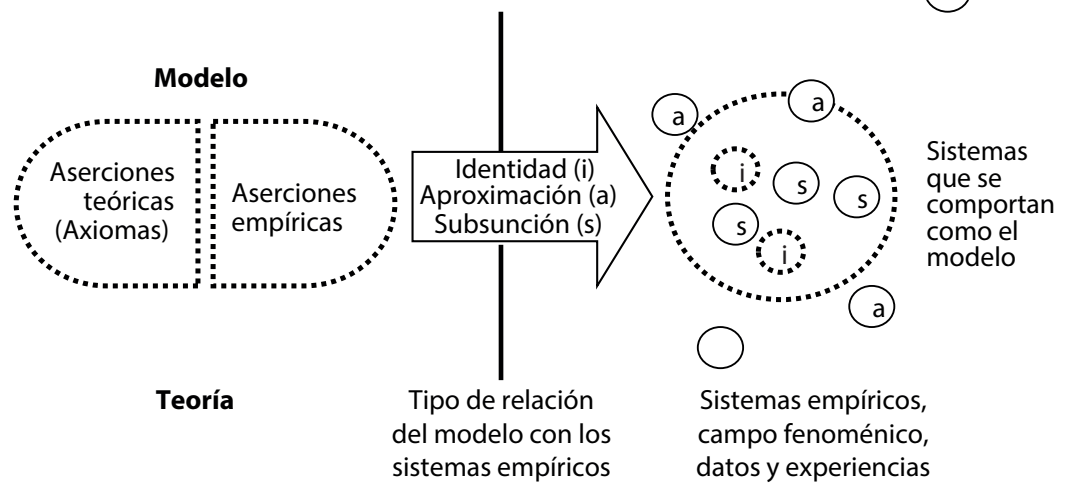

Elaboración de los autores a partir de Díez y Moulines (1997), Van Fraassen (1980) y Pérez Ransanz (2000). 
La Figura 10 permite apreciar los elementos de la teoría y sus relaciones según la concepción semántica modelística. Pero algunos autores de la corriente semántica proponen variantes al esquema básico del cuadro anterior. La primera es la de Ernest Adams (Díez y Moulines, 1997, pp. 340 y ss.), según la cual es posible considerar un número limitado de sistemas reales como modelos pretendidos para otras realidades; es decir, el modelo es un caso ejemplar de la realidad cuyas relaciones y características poseen el potencial para explicar otros casos reales por analogía. Así, los sistemas Tierra-Luna o Sol-planetas, por ejemplo, son sistemas reales que se constituyen en modelos pretendidos de la física newtoniana (de su teoría) para entender otros sistemas planeta-lunas, como el caso de Júpiter y sus lunas. Desde este punto de vista, toda teoría consta de un aspecto formal (los predicados conjuntistas y la extensión de dicho predicado a los sistemas que le corresponden) y un aspecto explicativo (el conjunto de modelos pretendidos que sirven para explicar otros sistemas). En la selección de los sistemas reales que corresponden al modelo ejemplar, juega un papel importante la comunidad de científicos y su producción científica.

Una segunda variante es la que proporciona Ronald Giere para quien el modelo teórico es "un mundo imaginado" (no un sistema real), a la manera de mapa de la realidad cuyo componente más importante es la estructura; es mediante esta que un mapa rinde su información y se relaciona con la realidad sin copiar lo que representa, sino que

representa reproduciendo, a una escala mucho menor, las relaciones estructurales existentes entre elementos del territorio. Las líneas de un mapa se relacionan estructuralmente entre sí de tal manera que representan las relaciones entre las partes del propio territorio. En ambos casos, la estructura de la representación casa con la estructura 
de aquello que representa. Podemos expresar esto diciendo que ambos son "estructuralmente isomórficos". (Lynch, 2005, p. 108)

Una realidad es susceptible de ser representada por medio de estructuras diferentes tal como ocurre, por ejemplo, con una misma canción grabada según formatos estructuralmente tan diversos como el LP, el CD o el MP3 (p. 108). Por último, la estructura mantiene una relación de realismo causal respecto a la realidad pues un "mapa no sería como es si el territorio no fuese como es" (p. 110). Según Giere, la hipótesis teórica es el tipo de aserción que corresponde a la teoría entendida como mapa de la realidad y se trata de una entidad lingüística de carácter proposicional que afirma cierto tipo de relación entre un modelo y un sistema real, relación plausible de ser verdadera o falsa. Resumimos en algunas proposiciones fundamentales las características de la hipótesis teórica (Díez y Moulines, 1997, p. 348):

a. En la hipótesis, la relación entre modelo y sistema no es de identidad sino de semejanza y similitud, caracteres que deben ser explicitados de tal manera que "tal sistema real identificable es similar al modelo designado en los aspectos y grados indicados". Al mismo tiempo, no todos los aspectos del sistema real se deben reflejar en el modelo.

b. Los enunciados que formulan la teoría no están en conexión directa con el mundo real, sino que se conectan indirectamente con el mundo por medio de los modelos.

En razón de ello, la concepción modélica de Giere provoca que las teorías científicas no sean entidades bien definidas. En tanto constructos sociales, la comunidad de científicos interviene para identificar los modelos y los sistemas de referencia pertinentes según un esquema flexible e incluyente que hace posible adoptar, como vimos, varios modelos para comprender un mismo sistema, de la mis- 
144

ma manera que podemos circular por Quito con dos mapas diferentes, pero nunca con un mapa de Guayaquil.

\section{Semántica, ontología y epistemología de los modelos. Su relación con las teorías}

La Enciclopedia de Stanford (2020) sistematiza el alcance actual sobre la concepción y uso los modelos ${ }^{26}$ y da cuenta de su creciente importancia en contextos científicos, tal como podemos corroborar en la práctica académica cuando oímos mencionar, cada vez con mayor frecuencia, términos como "modelar", "modelización", "construir" o "aplicar modelos". También se ha vuelto usual, sobre todo en las ciencias tecnológicas, la referencia a "modelos computacionales", "modelos explicativos", "modelos teóricos", "modelos exploratorios", "modelos matemáticos”, etc., hasta conformar la terminología de rigor. Hoy día, tales nociones forman parte del vocabulario normal de la ciencia, pero reclaman respuestas pendientes a preguntas de orden semántico (cómo representan los modelos), ontológico (qué tipo de cosas son los modelos), y epistémicos (de qué manera los modelos permiten conocer) que no son poseídas con la misma naturalidad que cabría suponer por el uso de los términos. El Cuadro 1 ofrece un extracto de las respuestas de la Enciclopedia a estos interrogantes, desarrollando con mayor pausa aquellos aspectos que convocan el eje de la metateoría.

26 Ver Models in Science (2006). 


\section{CUADRO 1: LOS MODELOS EN LA CIENCIA ${ }^{27}$}

\section{Aspectos semánticos de los modelos: ¿cómo representan la realidad?}

La dimensión semántica define los modelos como recursos simbólicos que representan de cierta manera un ámbito selectivo de la realidad (sustituyen la realidad), es decir, aquello que se quiere comprender. Este ámbito de la realidad que se quiere representar se denomina "sistema objetivo del modelo" o también "sistema de destino". La Enciclopedia, entre otros, proporciona el ejemplo del modelo de economía abierta de Mundell-Fleming o el modelo a escala de un puente (el más simple y fácil de entender). Tipos de modelos de representación son los que se describen a continuación y, aunque puedan compartir pertenencia con otras categorías, sus diferencias responden a formas específicas de representación.

Modelos a escala: son copias reducidas o ampliadas de sus sistemas de destino, como las maquetas de edificios a escala reducida para simular en laboratorio su sismorresistencia. El comportamiento de esta forma de representación nunca será igual al del sistema de destino y ello solicitará correcciones y tabulaciones que anticipan la relación no del todo lineal entre lo representado y el modelo.

Modelos analógicos: se basan, valga la redundancia, en la analogía, una figura literaria y un recurso lingüístico de gran valor heurístico que comprende una realidad sobre la similitud del comportamiento o con (entre) propiedades compartidas con otra realidad. Entre otros ejemplos, podemos citar el modelo hidráulico de un sistema económico o el modelo del agujero negro. El ejemplo epistémico más frecuente es

27 Para la síntesis de la Stanford Encyclopedia of Philosophy se obvian las numerosas y densas referencias al estado actual de la discusión y a los aportes críticos a cada uno de los temas. Asimismo, y por razones obvias, la síntesis no recoge la enorme riqueza de ejemplos. 
aquel que comprende analógicamente el pensamiento con la visión; y la comprensión, con la iluminación. No obstante, el uso de la analogía es más complejo y se expresa también en ecuaciones matemáticas compartidas.

Modelos idealizados: son aquellos que proceden vía simplificación o distorsión deliberadas y controladas del sistema de destino para afrontar la comprensión de sistemas demasiado complejos. Se conocen dos tipos de idealizaciones: las aristotélicas, que simplifican despojando el sistema de destino de propiedades no relevantes para el análisis y poder concentrarse en lo esencial; y las galileas, que distorsionan deliberadamente un sistema de destino como, por ejemplo, cuando se representa el movimiento de masas despojadas de fricción, o cuando se postula el movimiento perpetuo a partir de un péndulo despojado de la resistencia de sus elementos concretos. También cuando se explica la conducta económica a partir de un sujeto omnisciente y racional. Un concepto relacionado con la idealización es el de aproximación, que marca la relación de un modelo a otro por criterio de cercanía y no tanto (aunque no lo excluye) porque exista relación entre sus elementos.

Modelos de juguete: son modelos extremadamente simplificados y distorsionados de los sistemas objetivos, como si fueran caricaturas y representan una cantidad muy limitada de caracteres de los sistemas objetivos. El procedimiento es aislar un número determinado de características y distorsionarlas al extremo. La Enciclopedia cuestiona el valor predictivo de tales modelos debido a la sobresimplificación de la realidad ${ }^{28}$. Los modelos mínimos son representaciones muy simplificadas de los sistemas de destino y, por ello, están relacionados con los modelos de juguete. No necesariamente se trata de representaciones del sistema de destino.

28 En realidad, la lógica comercial obedece muchas veces a la toma de decisiones basada en la simplificación de atributos para establecer el precio de inventario de ciertos productos, aplicando un descuento anual de su valor regido por el criterio temporal respecto a su adquisición. Así, sin importar la demanda o el valor intrínseco de ciertos productos, la norma se aplica a todos por igual. 
Modelos fenomenológicos: representan propiedades observables de sus sistemas objetivos. A veces se los presenta independientemente de las teorías, sin que se deriven de ellas, aunque incorporen elementos teóricos, como leyes físicas que explican parcialmente el funcionamiento del sistema de destino. A este tipo de modelo pertenecen los modelos de un "fenómeno", entendiendo este último término como el conjunto de características relativamente estables y generales de un suceso particular de interés y al alcance de la observación de la ciencia como, por ejemplo, el comportamiento de los precios de vivienda y sus relaciones con determinadas características, el crecimiento de la población de cierto tipo de fauna y flora.

Modelos exploratorios: son de carácter dinámico y su función es la de aprender algo sobre un sistema objetivo específico o un fenómeno bajo experimento sin contar con un modelo acabado. El modelo inicial es un punto de partida para nuevas y sucesivas exploraciones, a lo largo de las cuales se modifica y refina el modelo. Por lo tanto, se debe distinguir entre modelos iniciales y modelos a medio término o término de la investigación. Este tipo de modelo es una herramienta útil para la analizar las características de una teoría.

Modelos de datos: requieren de herramientas estadísticas complejas y de una cada vez mayor capacidad de almacenamiento y procesamiento de datos obtenidos de la observación inmediata. Estos modelos se desarrollan por medio de la "reducción de datos", proceso de depuración de dos fases: a) eliminación de errores (debido a una observación defectuosa); y b) presentación ordenada de los datos. Estos modelos representan el sistema de destino a la manera de curvas delineadas por los puntos de los datos. Son importantes para la confirmación de teorías y el problema crucial consiste en la capacidad de determinar las técnicas de información adecuadas para comprender el sistema de destino. Entre otros ámbitos, se usa cada vez más en análisis de conductas de consumo, y para comprender y anticipar la expectativa de públicos de usuarios. 


\section{Aspectos ontológicos: ¿qué son los modelos?}

Los modelos deben ser entendidos como una gama heterogénea de cosas con capacidad de representar un sistema objetivo. Se trata de artefactos mentales o físicos, de objetos que representan la realidad y a la hora de describir aquellos que efectivamente usan los científicos incluyen los siguientes tipos: "objetos físicos, objetos ficticios, objetos abstractos, estructuras teóricas de conjuntos, descripciones, ecuaciones” o sus combinaciones. Cada uno representa y explica los sistemas de destino de manera diferente.

Objetos físicos: se denominan también "objetos materiales", como los modelos a escala, los que representan la estructura y secuencia del $\mathrm{ADN}$, las maquetas geofísicas.

Objetos de ficción y objetos abstractos: aunque los científicos se refieren a estos como si se tratara de objetos, estos modelos son ficticios porque existen en la mente de los investigadores, como el modelo de átomo de Bohr. Se usan objetos de ficción para imaginar realidades físicas, poblacionales o económicas ficticias, del tipo "imaginando que una población dada, en una situación dada... etc.”. El valor de estos modelos es proporcionar visiones imaginativas cargadas de valor eurístico (permiten pensar y suponer) pero plantean dificultades a la hora de establecer su conexión con la realidad y si es viable la pretensión de representar la realidad por medio de ficciones. Los objetos abstractos, a su vez, son entidades no físicas que representan un posible objeto concreto en tanto figuras del habla, del lenguaje, sin referencia en la realidad. No obstante, la discusión es vigente. Hoy, podemos comprender mejor la pandemia del coronavirus por medio de las ficciones cinematográficas que de alguna manera la anticiparon, que resultan útiles para abordar la comprensión de comportamientos colectivos ante la crisis y el aislamiento.

Estructuras teóricas: esta aproximación es propia de la visión semántica de las teorías que define los modelos como estructuras teóricas, fundamentalmente, de dos tipos: modelos interpretativos y modelos mediadores. La Enciclopedia cuestiona esta postura porque, en tanto 
estructuras teóricas, los modelos no pueden ser representativos de un sistema objetivo por las siguientes razones: muchos no se ajustan a una estructura; no es posible establecer su comportamiento ni el de sus elementos a lo largo de la investigación; su estructura no refleja relación de correspondencia con la estructura del sistema objetivo. Estos modelos se refieren, más bien, a la estructura de la teoría, no a la de un posible modelo representativo de un sistema objetivo.

Descripciones y ecuaciones: según esta forma de aproximación propia de la visión sintáctica de la teoría, "un modelo es una descripción estilizada de un sistema de destino". De esta forma confunde el modelo con la formulación particular de la teoría, con la configuración particular de sus elementos cuando, en realidad, se trata de enunciados descriptivos. El modelo, según esta vertiente, tendría un valor descriptivo pero no refleja un sistema objetivo, sino un sistema articulado de enunciados de diverso nivel sobre él. Asimismo, la descripción remite obligadamente a su forma literaria cuando el modelo se comporta de manera diversa: es un objeto que sustituye la realidad y de cuya representación objetual emanan descripciones.

La concepción del modelo como articulación de ecuaciones es otra versión que obedece a la misma lógica, tanto por su valor descriptivo cuanto porque son elementos sintácticos que describen una estructura matemática. Así, la ecuación no es un modelo porque este tiene propiedades representativas diferentes.

\section{Epistemología: funciones cognitivas de los modelos}

Los modelos son importantes en la ciencia, principalmente por su valor cognitivo porque permiten conocer y aprender mediante un "razonamiento subrogante", es decir, colocándose en lugar de la parte de la realidad o el fenómeno que se quiere comprender. De ese modo, "algunas partes importantes de la investigación científica se llevan a cabo en modelos en lugar de en la realidad misma”. 
Aprender acerca de los modelos: no hay fórmulas para aprender a construir o evaluar modelos a no ser la de aprender haciendo. En el uso y la manipulación concretas aprendemos de las propiedades y las capacidades de un modelo, no antes. Algunos tipos de modelos permiten, más que otros, aprendizajes sobre su funcionamiento y, por lo tanto, son más propensos a mejoras y rectificaciones tal como sucede con los modelos matemáticos y computacionales que ofrecen mayores posibilidades de simulación. Pero no siempre la comprensión de una realidad y la fortaleza de los modelos son directamente proporcionales a la capacidad de incorporar e interpretar datos. Es posible que se generen, de la mano de esas capacidades, distorsiones y limitaciones.

Aprender acerca de los sistemas de destino: es clave que los modelos reflejen adecuadamente los sistemas de destino según correspondencias consistentes. Los aprendizajes en tal contexto serán diversos según el tipo de representación modélica, ya que cada uno está cargado de posibilidades y límites distintos.

La explicación mediante modelos: cabe aquí preguntarse qué tipo de explicación ofrecen los modelos y las respuestas a esta pregunta están ligadas al criterio de verdad-validez de las explicaciones científicas. La pregunta básica es si lo modelos ofrecen o no acceso a explicaciones de carácter causal. En este sentido, algunos modelos ofrecen explicaciones más realistas que otros, de tal modo que el rango explicativo es muy bajo cuando se trata de modelos muy idealizados; en tanto que cuanto mayor es la correspondencia del modelo con el sistema objetivo tanto mejor su capacidad explicativa. Para otras posiciones el valor explicativo depende del carácter relevante de la explicación causal, no importa si se trata de modelos más cercanos o lejanos al sistema objetivo. Algunos, inclusive, otorgan valor explicativo a los modelos falsos que explican, aun, "debido a su falsedad".

La comprensión mediante modelos: la comprensión "es una forma particular de acceso epistémico que un científico posee para ofrecer una explicación”. Se trata de un conocimiento de carácter holístico que 
relaciona la investigación de un fenómeno con el contexto más amplio de una teoría y sus métodos o desde un modelo, poniendo en juego un ámbito de explicaciones y recursos más amplio. Los modelos juegan un papel crucial en la comprensión científica porque relacionan la tarea de explicar ese fenómeno desde la capacidad explicativa del modelo cuya capacidad comprensiva no culmina en lo que puede o no afirmar sobre su sistema objetivo, ya que abarca e incluye también el cuerpo de afirmaciones y métodos más amplio e integral que constituye ese modelo.

Síntesis de Stanford Encyclopedia of Philosophy (2006).

Con respecto a la relación entre las teorías y los modelos, la Enciclopedia plantea posiciones que van desde postular modelos como subpartes de las teorías hasta modelos independientes de las teorías, y también reconocer los modelos como mediadores entre las teorías y el mundo. Revisemos esa tipología.

Modelos como subpartes de la teoría: para entender las relaciones entre los modelos y las teorías es necesario recordar que una teoría es un conjunto de oraciones (proposiciones) expresadas en un lenguaje formal; en tanto que un modelo es una estructura que hace posible "que todas las proposiciones de una teoría sean verdaderas cuando sus símbolos se interpretan como referencia a objetos, relaciones o funciones de una estructura", de tal manera que "la estructura es un modelo de la teoría en el sentido de que es correctamente descrita por la teoría”. Otra distinción clave es la que existe en las nociones de modelo lógico y modelo representativo, de forma tal que los modelos teóricos indican que son interpretaciones de un sistema formal abstracto (modelos lógicos) y cuando leyes generales se aplican a un modelo en particular este resulta ser una interpretación (o realización) de la ley general. Por lo tanto, existen modelos lógicos que no son representativos y otros que son ambas cosas a la vez. 
Tanto para la visión sintáctica como para la visión semántica de las teorías, los modelos juegan un rol secundario respecto a las teorías. Para la visión sintáctica la teoría es un dispositivo lógico (conjunto de proposiciones articuladas en un sistema lógico axiomatizado) y hace del modelo una interpretación alternativa de un cálculo determinado que opera cálculos formales abstractos. La visión semántica, en cambio, prescinde de proposiciones organizadas según un sistema lógico axiomatizado e interpreta la teoría como familia de modelos ("un modelo es un cluster de teorías") como si se tratar de bloques de construcción de las teorías.

Modelos independientes de las teorías: ambas visiones, tanto la sintáctica como la semántica, consideran los modelos como instancias subordinadas a las teorías. No obstante, los modelos gozan de varias formas de libertad respecto a las teorías especificadas de la siguiente manera:

- Los modelos completamente independientes de la teoría: un ejemplo es el modelo Lotka-Volterra que describe la interacción entre una población de depredadores y otra de animales de presa. Ese modelo se desmarca de las teorías disponibles que explican el comportamiento de ambas poblaciones y establece suposiciones con base en ecuaciones diferenciales porque no resultaron atractivas. Cuando un modelo se construye sobre la inexistencia de una teoría relacionada con el fenómeno se llama "modelo sustituto" porque, en efecto, sustituye una teoría.

- Los modelos como medios para explorar teorías: ello ocurre cuando un modelo "es un modelo lógico de una teoría" y tiene la capacidad de desplegar sus proposiciones e inferencias. También modelos que no son lógicos son aptos para explorar teorías como aquellas que apelan a los principios del "caos". 
- Los modelos como complementos de teorías: se trata de modelos que proporcionan un referente concreto y de distinto signo a los de determinada teoría. Es el caso de una teoría cualitativa cuyo modelo le provee de medidas cuantitativas, porque la teoría está subdeterminada en determinados campos que el modelo complementa o porque existen procesos no especificados en la teoría, aunque relacionados con ella. Los modelos pueden ofrecer soluciones y aplicaciones que no derivan de las teorías per se.

- Los modelos como teorías preliminares: se trata de modelos de sondeo, de los cuales no se espera que cumplan a cabalidad su función de representación ("no instruyen más allá del propio modelo"). Se usan para probar nuevas y más complejas herramientas teóricas.

- Los modelos interpretativos: intervienen siempre que se aplica una teoría en su forma matemática general, como ocurre con las teorías físicas, de tal modo que el modelo interpreta cuando concreta los términos abstractos para describir el sistema objetivo al que representa. Ejemplo: en el contexto de la mecánica clásica, el concepto abstracto de fuerza se concreta en el concepto de gravedady, para obtener ecuaciones manejables, el modelo proporciona un escenario simplificado (planetas esféricos y homogéneos, espacio vacío), dejando a un lado la complejidad real. Así, es posible interpretar la aplicación de teorías matemáticas a objetos del mundo real.

Modelos como mediadores: los modelos constituyen instrumentos que median entre las teorías y el mundo. Las teorías no son máquinas expendedoras que proporcionan modelos y para ello es menester considerar los modelos como "agentes autónomos", tanto de las teorías cuanto de sus sistemas de destino. A veces se alimentan de teorías diferentes que trabajan colaborativamente, como sucede en el modelado climático, en el que el resultado no depende de una teoría, sino del trabajo en conjunto entre varias teorías que un modelo hace posible. 


\section{La articulación de las teorías según las corrientes historicistas}

Si el enfoque de las concepciones axiomáticas y estructurales privilegia la gramática del lenguaje lógico, las posturas generadas por la "revuelta historicista" hacen prevalecer, en cambio, los factores exógenos a las mismas teorías para explicar sus cambios, permanencia o evaluación, como la fuerza de la comunidad científica, las percepciones éticas, políticas u ontológicas de una sociedad, sus valoraciones sociales, entre otros factores que no se relacionan directamente con el despliegue de la lógica teórica. La tesis fundamental de los historicistas afirma que toda teoría consta de elementos históricos y sociales ineliminables, que son inaccesibles al análisis formal que intervienen en la evaluación de las teorías y en la preferencia de unas respecto a otras. A partir de análisis dúctiles y flexibles que privilegian los aspectos diacrónicos del ejercicio teórico, algunos filósofos de la ciencia explican el progreso científico de diversas maneras, a la vez que identifican algunos elementos de las teorías que conservan su identidad no obstante los cambios; y otros, en cambio, que cambian y se transforman en el curso del tiempo y resultan de carácter accidental y periférico.

A continuación, desarrollaremos brevemente la propuesta historicista de tres filósofos de la ciencia, casi contemporáneos y conocidos entre sí29: Thomas Kuhn (1922-1996) ${ }^{30}$, Imre Lakatos (1922-

29 Para este apartado nos basamos en el guion temático proporcionado por Díez y Moulines (1997, pp. 310 y ss.), profundizado por los siguientes textos capitales: La estructura de las revoluciones cientificas de Kuhn ([1962] 2006), La metodología de los programas de investigación cientifica de Lakatos ([1968] 1989) y El progreso y sus problemas. Hacia una teoría del crecimiento cientifico de Laudan ([1977] 1986).

30 Thomas Kuhn, estadounidense. Se graduó de físico en la Universidad de Harvard y fue un connotado filósofo e historiador de la ciencia. Ejerció la cátedra en las universidades de California (Berkeley) y de Princeton, así como en el Instituto Tecnológico de Massachusetts (MIT, por sus siglas en inglés). 
$1974)^{31}$ y Larry Laudan (1941)32. Ellos enriquecieron el vocabulario metateórico con términos como microteorías, teorías particulares o teorías rivales, postulando entre esas realidades formas de articulación más amplias expresadas en los términos macroteoría, familia teórica y redes teóricas. Ninguna de ellas se explica a sí misma sino en relación con marcos históricos más profundos e implícitos que explican no solo las relaciones sincrónicas y diacrónicas entre teorías, pues condicionan y otorgan, sobre todo, los atributos de credibilidad, legitimidad y consistencia al ejercicio de la ciencia.

Esos marcos que nuclean teorías o grupos de ellas y formas de hacer ciencia son los siguientes: paradigma (Kuhn), programas de investigación (Lakatos) y tradiciones de investigación (Laudan). En la Tabla 8 explicamos cada una de ellas anticipando similitudes y diferencias:

Tabla 8

Aspectos metateóricos de las corrientes historicistas

\begin{tabular}{|c|l|l|l|}
\hline \multirow{1}{*}{ Kuhn } & \multicolumn{3}{|c|}{ Corrientes historicistas } \\
\cline { 2 - 4 } & \multicolumn{1}{|c|}{ Lakatos } & \multicolumn{1}{|c|}{ Laudan } \\
\hline \multirow{5}{*}{ Concepto clave } & $\begin{array}{l}\text { Paradigma o matriz } \\
\text { disciplinar } \\
\text { Son excluyentes (no } \\
\text { coexisten). } \\
\text { Compromisos com- } \\
\text { partidos por la comu- } \\
\text { nidad de científicos. }\end{array}$ & $\begin{array}{l}\text { Programas de } \\
\text { investigación } \\
\text { Son coexistentes. } \\
\text { Componentes: heurís- } \\
\text { tica negativa (núcleo } \\
\text { sólido); heurística po- } \\
\text { sitiva (cómo cambiar a } \\
\text { nivel de microteorías); } \\
\text { teorías particulares. }\end{array}$ & $\begin{array}{l}\text { Tradiciones de } \\
\text { investigación } \\
\text { Pueden coexistir. } \\
\text { tidos, articulación } \\
\text { teórica, resolución de } \\
\text { problemas, desarrollo } \\
\text { histórico. }\end{array}$ \\
\hline
\end{tabular}

31 Imre Lakatos, húngaro de origen judío. Fue economista, filósofo y matemático; discípulo de Popper y catedrático de la London School of Economics.

32 Larry Laudan, estadounidense. Doctor en Filosofía por la Universidad de Princeton; catedrático de varias universidades, entre ellas, Pittsburgh e Illinois. Actualmente es investigador de la Universidad Nacional de México. 


\begin{tabular}{|c|c|c|c|}
\hline & \multicolumn{3}{|c|}{ Corrientes historicistas } \\
\hline & Kuhn & Lakatos & Laudan \\
\hline $\begin{array}{l}\text { Concepción } \\
\text { de ciencia }\end{array}$ & $\begin{array}{l}\text { Dos ciencias: ciencia } \\
\text { normal y ciencia } \\
\text { revolucionaria. } \\
\text { El paso de una a otra } \\
\text { se da por una crisis } \\
\text { paradigmática. }\end{array}$ & $\begin{array}{l}\text { Dos formas de ejerci- } \\
\text { cio: heurística positiva } \\
\text { (ajusta las teorías) y } \\
\text { heurística negativa } \\
\text { (lo que no se puede } \\
\text { cambiar). }\end{array}$ & $\begin{array}{l}\text { La ciencia es una sola } \\
\text { pero la rivalidad de las } \\
\text { teorías para solucio- } \\
\text { nar problemas empí- } \\
\text { ricos y conceptuales es } \\
\text { un rasgo permanente. }\end{array}$ \\
\hline $\begin{array}{l}\text { Factor explica- } \\
\text { tivo del cam- } \\
\text { bio teórico }\end{array}$ & $\begin{array}{l}\text { El cambio es siempre } \\
\text { paradigmático y se da } \\
\text { por razones externas } \\
\text { relacionadas con las } \\
\text { demandas de la co- } \\
\text { munidad científica. }\end{array}$ & $\begin{array}{l}\text { Cambio por contenido: } \\
\text { progresión empírica } \\
\text { (más importante): apa- } \\
\text { rece una teoría con ma- } \\
\text { yor potencial empírico } \\
\text { predictivo y explicativo } \\
\text { (más importante). } \\
\text { Progresión teórica } \\
\text { (menos importante): } \\
\text { la anterior se inserta } \\
\text { en la nueva. }\end{array}$ & $\begin{array}{l}\text { Cambio por grado de } \\
\text { eficacia para resolver } \\
\text { problemas empíricos } \\
\text { y conceptuales. } \\
\text { La resolución de } \\
\text { problemas concep- } \\
\text { tuales explican mejor } \\
\text { el crecimiento cien- } \\
\text { tífico y los cambios } \\
\text { teóricos. }\end{array}$ \\
\hline $\begin{array}{l}\text { Relación entre } \\
\text { paradigmas }\end{array}$ & $\begin{array}{l}\text { Inconmensurabilidad } \\
\text { entre uno y otro pa- } \\
\text { radigma; radicalidad } \\
\text { de los cambios. }\end{array}$ & $\begin{array}{l}\text { Los cambios equivalen } \\
\text { a progreso empírico. } \\
\text { Son progresivos y } \\
\text { acumulativos pero } \\
\text { en ocasiones son } \\
\text { cualitativos. }\end{array}$ & $\begin{array}{l}\text { Cambios progresivos } \\
\text { y acumulativos pero } \\
\text { no necesariamente li- } \\
\text { neales. Cohabitación } \\
\text { entre teorías rivales. }\end{array}$ \\
\hline $\begin{array}{l}\text { Elementos } \\
\text { de las teorías }\end{array}$ & $\begin{array}{l}\text { Generalizaciones } \\
\text { simbólicas, modelos, } \\
\text { valores y ejemplares. }\end{array}$ & $\begin{array}{l}\text { Dos tipos de teorías: } \\
\text { microteorías, serie de } \\
\text { teorías. }\end{array}$ & $\begin{array}{l}\text { Compromisos } \\
\text { metafísicos. } \\
\text { Normas epistémicas y } \\
\text { metodológicas. } \\
\text { Componentes de } \\
\text { la teoría: supuestos } \\
\text { axiomáticos, pre- } \\
\text { dicciones empíri- } \\
\text { cas, explicaciones } \\
\text { fenoménicas. } \\
\text { Microteorías y } \\
\text { macroteorías }\end{array}$ \\
\hline
\end{tabular}

Elaboración de los autores a partir de Díez y Moulines (1997, pp. 310 y ss.). 


\section{El paradigma o matriz disciplinar de Kuhn}

Thomas Kuhn, en su célebre ensayo La estructura de las revoluciones cientificas (1962), distingue dos modos fundamentales de hacer ciencia: la ciencia normal y la ciencia revolucionaria. En el primero, la ciencia se desarrolla a partir de presupuestos compartidos por una comunidad científica, presentes en los canales habituales de enseñanza y difusión disciplinaria. La tarea normal, en este contexto, consiste en la resolución de problemas, la cual exige un permanente ajuste en la relación teoría-experiencia sin necesidad de discutir los fundamentos de la ciencia. Cuando se perciben anomalías y casos que no encajan se produce una crisis que provoca la discusión de los fundamentos, se descubren otros supuestos que permiten explicar las anomalías y ser adoptados por la comunidad científica al punto de proliferar alternativas y nuevos enfoques rivales. Ocurre, entonces, una revolución científica, el segundo modo de hacer ciencia. Así, el paso de uno a otro no es provocado por las inconsistencias lógicas, sino por un "desplazamiento de confianza" creado por problemas que no logra resolver o por la intervención de factores como las demandas sociales.

La realización subyacente que impulsa la producción teórica es, según Kuhn, el paradigma, respecto al cual propone una serie de definiciones de progresiva complejidad, mejor basadas en sus rasgos dinámicos (cómo funciona) que en definiciones esenciales (qué es). En primer lugar, afirma que se trata de una realidad histórica, de "realizaciones científicas universalmente reconocidas que, durante cierto tiempo, proporcionan modelos de problemas y soluciones a una comunidad científica" (2006, p. 13). Estas realizaciones están estrechamente relacionadas con la ciencia normal y comparten dos ventajas: la de convocar grupos de científicos en un tipo de ejercicio no basado en la competencia; y la incompletud respecto a la solución 
158

de problemas pendientes. Con referencia a esas realizaciones, Kuhn afirma que:

Su logro carecía suficientemente de precedentes como para haber podido atraer a un grupo duradero de partidarios, alejándolos de los aspectos de competencia de la actividad científica. Simultáneamente, eran lo bastante incompletas para dejar muchos problemas para ser resueltos por el redelimitado grupo de científicos. Voy a llamar, de ahora en adelante, a las realizaciones que comparten esas dos características, "paradigmas", término que se relaciona estrechamente con "ciencia normal". (2006, pp. 33-34)

De manera más detallada, especifica el paradigma, según el significado dominante, como el conjunto de compromisos y supuestos compartidos por un grupo científico; según el significado alternativo, asumido por el autor, se trata también de un ejemplo o caso de algo que hace de modelo para comprender otros casos de lo mismo. Su estudio concluye describiendo otro tipo de doble sentido según el cual debe ser entendido el concepto de paradigma:

Por una parte, significa toda la constelación de creencias, valores, técnicas, etc., que comparten los miembros de una comunidad dada. Por otra parte, denota una especie de elemento de tal constelación, las concretas soluciones de problemas que, empleadas como modelos o ejemplos, pueden remplazar reglas explícitas como base de la solución de los restantes problemas de la ciencia normal. (p. 269)

La ciencia normal es la que se basa en un paradigma; la ciencia revolucionaria es aquella que pasa de un paradigma a otro. Pero uno de los rasgos del paradigma es constituirse en fuente de coherencia al actuar como garante de las teorías a las que otorga credibilidad, debido a su cobijo en la ciencia normal y no - necesariamente- en razón del cumplimiento o no de las reglas, pues la ciencia normal no está determinada por reglas. 
La ciencia normal es una actividad altamente determinada, pero no necesita estar determinada enteramente por reglas. Esta es la razón por la cual, al comienzo de este ensayo, presenté paradigmas compartidos, más que reglas, suposiciones y puntos de vista compartidos, como fuente de coherencia para las tradiciones de la investigación normal. Las reglas, según sugiero, se derivan de los paradigmas; pero estos pueden dirigir la investigación, incluso sin reglas. (p. 79)

$[\ldots]$

La ciencia normal puede determinarse en parte por medio de la inspección directa de los paradigmas, proceso que frecuentemente resulta más sencillo con la ayuda de reglas y suposiciones, pero que no depende de la formulación de estas. En realidad, la existencia de un paradigma ni siquiera debe implicar la existencia de algún conjunto completo de reglas. (p. 82)

Ningún elemento es comunicable entre las teorías de un modo de hacer ciencia con respecto a las teorías del otro. Por tanto, una de las características que atribuye a los paradigmas - y que nosotros aplicamos a las teorías — es la inconmesurabilidad o imposibilidad de comparación entre las teorías enroladas en paradigmas distintos, pues obedecen a cambios tan drásticos y radicales que impiden toda posible comparación.

Díez y Moulines (1997, pp. 313-318) describen los siguientes elementos que constituyen el paradigma o matriz disciplinar de Kuhn (2006, pp. 279 y ss.): generalizaciones simbólicas, modelos, valores y ejemplares a los que las teorías particulares de la ciencia normal se adscriben. Veamos en qué consiste cada uno de esos componentes:

- Generalizaciones simbólicas: es el componente formalizable de la matriz disciplinar e incluye las leyes científicas en tanto formalismos abstractos vacíos de significado o aplicación 
empírica (los cálculos abstractos de la propuesta axiomática arriba revisada). Estas generalizaciones son incuestionables e irrefutables, y adquieren formas específicas conforme se aplican a la realidad; al mismo tiempo, son programáticas, preceden la investigación a modo de guía de manera que casi nunca entran en conflicto con la experiencia. Son las leyes específicas las que pueden ser contrastadas con la experiencia. Al ser irrefutables, cuando se las abandona, se produce una revolución científica.

- Modelos: son analogías heurísticas o compromisos ontológicos que construyen imágenes a partir de las cuales se pueden asimilar casos que requieren ser explicados. Los modelos producidos por un paradigma determinan qué puede ser aceptado como solución a un problema y condicionan la producción de ejemplares.

- Valores: es el conjunto de criterios axiológicos propios de una comunidad científica para evaluar su propia actividad: precisión, margen de error, fecundidad, coherencia, compatibilidad con otras teorías, entre los que cabe añadir la utilidad y la pertinencia social. Estos valores admiten jerarquías según aspectos exteriores a la actividad científica como los que se derivan del contexto social, económico, político o ideológico.

- Ejemplares: junto con las generalizaciones simbólicas, es el elemento más importante de un paradigma. Son ejemplos modélicos o casos que hacen de modelo: "son aplicaciones empíricas específicas del aparato formal que sirven de modelo o guía para el trabajo de resolución... o las partes de la realidad a las que se aplica el formalismo" (Díez y Moulines, 1997, p. 316). Así, el sistema solar es un ejemplar de la física newtoniana. Mediante los ejemplares, las situaciones nuevas se comprenden según otra anterior bien establecida: el sistema 
luna $x$ de Saturno puede ser entendido a partir de otro sistema tomado como modelo: Luna-Tierra. La ciencia normal produce exitosamente ejemplares por medio de los cuales los términos teóricos se cargan de contenido empírico. Los cambios científicos provocan modelos diferentes al punto de generar mundos inconmensurables, según nos posicionemos en uno u otro paradigma.

Cabe señalar que Kuhn no profundiza el término "teoría" por considerar que remite a estructuras mucho más limitadas en su naturaleza y alcance que los paradigmas. Así, da por sentado que varias teorías se articulan en torno a un paradigma, sin establecer con claridad el límite y las relaciones puntuales entre ambos instrumentos. En relación con otros aportes revisados en este libro, la propuesta de Kuhn cuestiona y con razón la perspectiva de Popper, según la cual la ciencia se transforma merced a su mismo empuje y dinámica interna y al calor del procedimiento lógico de falsación con la realidad; antes bien, son los aspectos histórico-sociales los que provocan las revoluciones científicas y que permiten, incluso, que una teoría perviva aun con datos en contra (Pozo, 2002, p. 18) o bien, sea abandonada por la falta de pertinencia con las expectativas sociales. Del mismo modo, en el mismo capítulo I, vimos cómo Morin asume el concepto de paradigma precisamente por su imprecisión y ductilidad que lo convierte en apto para explicar procesos de relación interteórica y entre conocimientos más amplios y abarcantes.

\section{Los programas de investigación de Lakatos}

Lakatos también conforma la revuelta historicista y su principal aporte consta en su obra La metodología de los programas de investigación, publicada en inglés, en 1968, con el título The methodology of scientific research programmes. Este autor afirma que la teoría fun- 
ciona como una red de miniteorías cuyos conflictos e inconsistencias respecto a la naturaleza o datos de observación pueden subsanarse modificando una parte de la red. Esa parte de la red es el programa de investigación, el concepto fundamental de su propuesta. Todo programa de investigación consta de dos componentes: el núcleo firme (ideas centrales) y el cinturón protector (ideas auxiliares) cuya misión es impedir que el núcleo pueda ser refutado empíricamente.

Ahora bien, la teoría de la gravitación de Newton, la teoría de la relatividad de Einstein, la mecánica cuántica, el marxismo, el freudianismo, son todos programas de investigación dotados cada uno de ellos de un cinturón protector flexible, de un núcleo firme característico pertinazmente defendido, y de una elaborada maquinaria para la solución de problemas. Todos ellos, en cualquier etapa de su desarrollo, tienen problemas no solucionados y anomalías no asimiladas. En este sentido todas las teorías nacen refutadas y mueren refutadas. (Lakatos, 1989, p. 9)

El núcleo vertebra y confiere continuidad a una teoría al mismo tiempo que determina dos tipos de reglas metodológicas: la heurística negativa (lo que se debe evitar) y la heurística positiva (lo que se debe asumir). La heurística negativa prohíbe aplicar la refutación al núcleo y evitar su derrumbe por medio de un cinturón protector de hipótesis auxiliares o complementarias que se pueden modificar. La heurística positiva establece los pasos para modificar la parte refutable del programa (el cinturón auxiliar y protector). Una teoría evoluciona según la aplicación de estos caminos heurísticos. Más arriba hemos visto cómo Morin asume este punto de vista (cfr. supra).

Pocos científicos teóricos implicados en un programa de investigación se ocupan excesivamente de las "refutaciones". Mantienen una política de investigación a largo plazo que anticipa esas refutaciones. Esta política de investigación, u orden de investigación, queda establecida, con mayor o menor detalle, en la heurística positiva del 
programa de investigación. La heurística negativa especifica el núcleo firme del programa que es "irrefutable" por decisión metodológica de sus defensores; la heurística positiva consiste de un conjunto, parcialmente estructurado, de sugerencias o pistas sobre cómo cambiar y desarrollar las "versiones refutables" del programa de investigación, sobre cómo modificar y complicar el cinturón protector "refutable".

La heurística positiva del programa impide que el científico se pierda en el océano de anomalías. La heurística positiva establece un programa que enumera una secuencia de modelos crecientemente complicados simuladores de la realidad: la atención del científico se concentra en la construcción de sus modelos según las instrucciones establecidas en la parte positiva de su programa. Ignora los contraejemplos reales, los "datos" disponibles. (1989, p. 55)

La falsación de una teoría se da por la aparición de una teoría mejor, por la irrupción de un programa de investigación progresivo con mayor capacidad para explicar e incorporar hechos nuevos frente a otras teorías o programas regresivos que explican lo ya conocido. La progresión - y no la revolución, como proponía Kuhn- puede ser de carácter teórico (progresión teórica), cuando establece predicciones nuevas, aunque no corroboradas y cuando una teoría se incluye en otra; o bien de carácter empírico, cuando corrobora alguna de las predicciones teóricas. Pero, en realidad, el potencial de progreso de un programa de investigación se relaciona con su capacidad de extender el potencial predictivo a nuevos dominios (Pozo, 2002, p. 21), configurar problemas y rendir predicciones.

Pero ¿cómo podemos distinguir un programa científico o progresivo de otro pseudocientífico o regresivo? [...] Pero todos los programas de investigación que admiro tienen una característica común. Todos ellos predicen hechos nuevos, hechos que previamente ni siquiera habían sido soñados o que incluso habían sido contradichos por programas previos o rivales. (Lakatos, 1989, p. 9) 
Lakatos asume a la vez que complejiza la idea de falsación de Popper - punto de vista que califica de falsacionismo ingenuo- relativizando sus alcances debido a que no necesariamente la falsación da de baja una teoría: también impulsa su reajuste y mejora. $\mathrm{Al}$ mismo tiempo, enriquece la falsación como un proceso producido no solo desde la empiría a la teoría, ya que ocurre en la confrontación entre teorías rivales cuando una teoría mejor sustituye a otra que, al ser superada, deja de ser vigente.

Pero entonces se desvanece el carácter claramente negativo del falsacionismo ingenuo; la crítica se hace más difícil pero también positiva, constructiva. Naturalmente, si la falsación depende de la aparición de teorías mejores, de la invención de teorías que anticipen hechos nuevos, entonces la falsación no es simplemente una relación entre una teoría y la base empírica, sino una relación múltiple entre teorías rivales, la "base empírica" original y el crecimiento empírico que tiene su origen en la confrontación. (1989, p. 40)

Lakatos rechaza la postura kuhniana de inconmensurabilidad entre las teorías cuando se transforman los paradigmas y adopta una perspectiva de continuidad que incluye el carácter acumulativo y sucesivo de las teorías. Sin embargo, tienen lugar cambios cualitativos ocasionales producidos por el cambio de un programa o de las ideas que componen su núcleo central. La caracterización de Morin ( cfr. supra) en torno a los elementos de la teoría se fundamenta claramente en la propuesta de Lakatos. El punto débil de la propuesta de Lakatos, en cambio, radica en la imprecisión del alcance o dimensión de los programas de investigación, cuestionamiento análogo al del paradigma de Kuhn. 


\section{Larry Laudan: la teoría, herramienta para la solución de problemas empíricos y conceptuales. Las tradiciones de investigación}

Laudan desarrolla un modelo de comprensión de la ciencia en su obra El progreso y sus problemas. Hacia una teoría del crecimiento cientifico ([1977] 1986) ${ }^{33}$, en la que describe, desglosa y complejiza la noción de "problema", el rol de la teoría respecto a estos (los problemas generan teorías y las teorías, problemas) y la manera en que las teorías se conectan e interactúan entre sí a la manera de tradiciones de investigación. Proporciona, así, una perspectiva distinta a la de Kuhn y Lakatos, que también se enfocan en la solución de problemas sin detenerse en sus implicaciones para construir un modelo muy dinámico y flexible que explica la ciencia y su progreso, a partir de la noción central de que "las teorías son un tipo de cosas que resuelven problemas".

Si los problemas son el punto central del pensamiento científico, las teorías son su resultado final. Las teorías son relevantes, son cognoscitivamente importantes, en la medida en que - y solo en la medida en que- proporcionan soluciones adecuadas a los problemas. Si los problemas constituyen las preguntas de la ciencia, las teorías constituyen las respuestas. La función de una teoría es resolver la ambigüedad, reducir la irregularidad a uniformidad, mostrar que lo que sucede es en cierto modo inteligible y predecible. (1986, p. 100)

Las credenciales de una teoría, o los criterios con que se las evalúa, no dependen de factores internos autorreferenciales como si

33 La obra de Laudan se divide en tres partes. En la primera, ofrece los criterios con los cuales clasifica diverso tipo de problemas; en la segunda, identifica los requisitos que permiten determinar "cuándo una teoría proporciona una solución aceptable a los problemas" (1986, p. 104), y en la tercera, aporta ejemplos de la historia de la ciencia que argumentan a favor de su tesis central. 
son verdaderas, debidamente corroboradas o bien confirmadas. Sus méritos radican en "si constituyen soluciones adecuadas a problemas relevantes". Su tesis central se expresa en la siguiente proposición:

Hay muchos objetivos inmanentes — no trascendentes - en cuyos términos podemos intentar una caracterización de la ciencia; podemos considerar que la ciencia se encamina hacia teorías bien comprobadas, teorías que predicen hechos nuevos, teorías que "salvan los fenómenos”, o teorías que tienen aplicaciones prácticas. Mi propuesta, más general que estas, es que el objetivo de la ciencia consiste en obtener teorías con una elevada efectividad en la resolución de problemas. Desde esa perspectiva, la ciencia progresa solo si las teorías sucesivas resuelven más problemas que sus predecesoras. (1986, p. 11)

Laudan, entonces, identifica minuciosamente las condiciones y requisitos para que un problema sea considerado como tal solo en relación con una teoría; y ofrece una tipología que articula y distingue dos tipos de problemas (1986, pp. 43 y ss. y 82 y ss.):

a. Problemas empiricos". Se refieren a los "problemas acerca del mundo" (aquellos que nacen de los datos de la realidad) en el sentido del dominio (el conjunto de objetos y hechos) de una ciencia dada. Los datos dependen de las teorías disponibles que les otorgan un marco de indagación para ser identificados y reconocidos como tales (las teorías nos dicen qué puede ser preguntable). Un hecho se convierte en problema cuando la teoría lo define como tal. La solución de estos problemas depende del estudio de los objetos del dominio y no tienen que ver con la explicación satisfactoria de un hecho. A estos problemas Laudan los denomina de primer orden. Pueden, a su vez, ser de tres tipos: a.1) problemas no resueltos; a.2)

34 El desarrollo in extenso de los problemas empíricos y su taxonomía tiene lugar en Laudan (1986, pp. 43 y ss.). 
problemas resueltos; a.3) problemas anómalos, aquellos no resueltos por una teoría, pero resueltos por una o más teorías alternativas. Estos últimos son más importantes que los problemas no resueltos para explicar el progreso de la ciencia. Así, uno de los rasgos del progreso científico "es transformar los problemas empíricos anómalos y no resueltos en problemas resueltos" (1986, p. 46). Así, es más importante solucionar los problemas empíricos antes que explicarlos (la ciencia tiene una carga muy fuerte sobre esto último).

b. Problemas conceptuales ${ }^{35}$. Se tratan de características de las teorías y no tienen existencia independiente fuera de ellas. Pueden, a su vez, de dos tipos: b.1) internos (inconsistencias y ambigüedades); y b.2) externos, aquellos que denotan conflictos del tipo inconsistencia o incompatibilidad lógica entre y respecto a otras teorías o marcos doctrinales. Configuran problemas a ser resueltos más determinantes que los empíricos y que las anomalías. Respecto a los problemas conceptuales externos, Laudan (p. 87) propone la siguiente taxonomía de dificultades que provocan problemas conceptuales: a) dificultades intracientíficas, referidas al marco de la práctica científica; b) dificultades normativas, que tienen que ver con el ámbito metodológico de una teoría. Ante una inconsistencia, las alternativas consisten en cambiar la teoría en razón de la metodología de otra teoría, o cambiar la metodología de una teoría en razón de los aportes de otra teoría; c) dificultades relativas a la visión del mundo, que denotan incompatibili-

35 El desarrollo extenso de los problemas conceptuales y su taxonomía tiene lugar en Laudan (1986, pp. 82 y ss.). 
dades con otros cuerpos de conocimientos no científicos o creencias $^{36}$. A estos problemas los denomina de orden superior.

La distinción entre problemas empíricos y conceptuales es clave, y la importancia de los problemas conceptuales es tal que "cualquier teoría acerca la naturaleza de la ciencia que no encuentre una función para los problemas conceptuales, pierde toda pretensión de ser una teoría acerca de cómo ha evolucionado realmente la ciencia" (Laudan, 1986, p. 100). Las teorías funcionan bien casi siempre sin un ajuste total entre sus elementos, según una lógica y pragmática muy flexibles y de soluciones aproximadas, en las que resultan irrelevantes atributos como la verdad o la falsedad, tal como lo demuestra la historia de la ciencia. Por lo tanto, las credenciales de una teoría hacen de la evaluación teórica un asunto comparativo, según el cual una teoría "debe vérselas con otras" (teorías rivales) en relación con la resolución de un problema. Esas credenciales dependen del saldo favorable en la solución de problemas empíricos, anomalías y problemas conceptuales, donde la teoría no responde desde sí, sino en relación con su capacidad de resolución respecto a otras teorías rivales. Así los supuestos del modelo de explicación del progreso científico, una categoría que no tiene nada que ver con el progreso ético o moral, son los siguientes:

(1) El problema —empírico o conceptual — resuelto es la unidad básica del progreso científico; y (2) el objetivo de la ciencia es ampliar al máximo la esfera de problemas empíricos resueltos, al tiempo que reducir al mínimo el ámbito de problemas anómalos y conceptuales. (1986, p. 100)

36 Respecto a esto último, es llamativa la taxonomía bipartita de las creencias entre científicas y no científicas, e incluir en estas últimas la metafísica, la lógica, la ética y la teología, lo cual revela que la línea demarcatoria está constituida por el modelo de las ciencias naturales donde la empiría juega un rol crucial. 
Respecto a la metateoría, Laudan concibe que la teoría está constituida por redes proposicionales de distinto registro y alcance (1986, pp. 105 y ss.) que funcionan según dos niveles de generalidad diferenciados. Así, las del primer tipo están constituidas por un conjunto de doctrinas relacionadas (hipótesis o axiomas o principios) con las cuales lleva a cabo predicciones experimentales y explicaciones detalladas de los fenómenos naturales. A este tipo de teorías, relacionadas directamente con su campo fenoménico y con sus especificaciones, las denomina microteorías. Las del segundo tipo están constituidas por un conjunto de doctrinas o supuestos mucho más generales y no tan directamente relacionables o corroborables con un ámbito empírico. De este tipo son las familias de teorías (ejemplo: las teorías de la evolución) u otras que pueden conectarse con una gama muy amplia de especificaciones, a pesar de la enorme diferencia entre sí (ejemplo: la teoría cuántica). A las del segundo tipo, Laudan las denomina tradiciones de investigación y las equipara con las macroteorías o las superteorías de Lakatos.

La tradición de investigación, entonces, se refiere al concepto amplio de teoría, tal como se describe en el segundo caso, consta de al menos los siguientes rasgos iniciales: un tipo de asociación entre teorías, supuestos compartidos y temporalidad larga (1986, pp. 113 y ss.):

- Conjunto de teorías específicas. Son aquellas teorías asociadas que concretan o ejemplifican las tradiciones de investigación, sus compromisos ontológicos y formas de proceder. Algunas de las teorías específicas serán contemporáneas; y otras, herederas temporales de teorías anteriores. Y no todas serán consistentes entre sí. La función de las teorías específicas "es explicar todos los problemas empíricos del dominio 'reduciéndolos’ a la ontología de la tradición de investigación” (p. 114). 
- Supuestos compartidos. Son aquellos elementos primeros que individualizan las tradiciones de investigación y distinguen una tradición de otra. Son de dos tipos: a) los compromisos metafísicos (conjunto de creencias acerca de qué tipos de entidades y procesos constituyen el dominio de la investigación); y b) las normas epistémicas y metodológicas (cómo debe investigarse el dominio, cuál es el conocimiento de fondo intocable, normas de verificación de hipótesis, cómo se recogen y analizan los datos). Ambos dan forma a la heurística (orientaciones para la investigación) y a la axiología (normas de evaluación). Toda tradición propone directrices de cómo modificar o transformar teorías. Estos supuestos funcionan unas veces como "síes" (alientan rutas) y otras como "noes" (limitan).

- Temporalidad larga. A diferencia de las teorías específicas, las tradiciones de investigación se caracterizan por una larga historia frente a la corta vida de muchas teorías.

La función total de las tradiciones de investigación es proporcionar "las herramientas decisivas que necesitamos para resolver problemas, tanto empíricos como conceptuales", y, además, otorgar el marco para identificar y expresar teóricamente esos problemas. Por lo tanto, una tradición de investigación se evalúa según su capacidad de resolución de problemas, y por su potencial para crear y generar problemas empíricos y conceptuales. Una tradición no es evaluada en términos de ser confirmada o refutada de verdadera o falsa, o de poseer o no consistencia ontológica o metodológica: "Una tradición de investigación puede tener un éxito enorme en la generación de teorías fructíferas y ser, sin embargo, deficiente en su ontología y metodología” (1986, p. 118). Las tradiciones de investigación son, en rigor, "criaturas históricas... creadas y articuladas en un medio intelectual concreto, colaboran en la producción de teorías específicas y — como todas las demás instancias históricas- crecen y de- 
clinan" (p. 133). Pero también se transforman con el tiempo debido a los siguientes factores: debido a cambios en alguna de sus teorías específicas subordinadas, o cambios en los elementos nucleares más básicos (contra Kuhn y Lakatos que afirman que ese núcleo básico es rígido y no puede cambiar).

Las tradiciones de investigación pueden coexistir una al lado de otra. Una tradición no necesariamente sustituye a otras, como sugiere Kuhn cuando afirma que el período de ciencia revolucionaria supera y sustituye al período de ciencia normal: así, la cohabitación entre teorías o una familia de estas es la regla, tal como lo demuestra la historia de la ciencia. Pero no solo pueden coexistir, también es posible que distintas tradiciones se integren entre sí de dos modos diferentes: cuando una tradición se injerta en otra, sin ninguna modificación importante en los supuestos de ninguna de ellas; o cuando su fusión demanda el rechazo de algunos elementos fundamentales incompatibles

Otros criterios de evaluación de las tradiciones de investigación se relacionan con dos ámbitos: el de la comparabilidad y el del contexto. La comparabilidad se despliega en dos modos de evaluación: a) adecuación de las últimas teorías de una tradición a la resolución de problemas en un momento dado (evaluación sincrónica); b) progresividad, para establecer si a lo largo del tiempo la tradición conservó, incrementó o perdió la capacidad de resolver problemas (evaluación diacrónica). La evaluación de las tradiciones de investigación tiene lugar, además, en dos contextos distintos: a) contexto de aceptación que ocurre cuando la comunidad o un grupo de científicos decide considerar como si fuese verdadera o dignas de crédito una tradición o un grupo de teorías, cuyo criterio óptimo debería ser su capacidad de resolución de problemas; $\mathrm{y} b$ ) contexto de utilización: algunas veces se escogen teorías o tradiciones de investigación no por la confianza o el crédito que se deposita en ellas, sino por ser una alternativa productiva respecto a 
las más aceptadas; porque hay buenas razones para trabajar con teorías poco aceptadas (Laudan, 1986, p. 149). Y este factor es una causa muy frecuente del progreso científico.

La noción de que una teoría soluciona problemas no es nueva ni original. Laudan reconoce que otros lo habían afirmado antes que él, incluido Popper (cfr. supra) y tanto Kuhn como Lakatos le conceden su lugar a la empresa de solución de problemas. Pero ninguno de ellos se había tomado en serio la afirmación sin ir más allá de la retórica. Laudan, de hecho, es el primero que elabora un modelo de comprensión del progreso científico a partir de la práctica concreta de la historia de dos ciencias: las ciencias naturales y la física, donde la relación entre el núcleo axiomático y la empiría ha sido siempre problemática. Describe cómo las teorías y las tradiciones de investigación se justifican a sí mismas por su capacidad de solucionar problemas, desglosando sus implicaciones epistémicas y metodológicas al punto de ser el primero y el único — afirma él mismo- que concede a los problemas conceptuales un rol clave en el progreso de científico, porque sin ellos resultaría imposible entenderlo.

Su reflexión surge en medio de la percepción generalizada de la filosofía de la ciencia que atribuye a los problemas empíricos el primado en la explicación del cambio científico y a los que se les atribuye la causa de la preferencia de una teoría por otra. Kuhn y Lakatos, por ejemplo, adhieren a esa tendencia (Laudan, 1986, p. 100) y Popper es otro ejemplo ya revisado de la primera importancia concedida a la empiría, capaz de falsar una teoría si esta no encaja con ella. Laudan propone, en cambio (coincidiendo con Lakatos, como hemos visto), que la empiría no necesariamente falsea una teoría; más bien induce a su mejora y la impulsa a favorecer un mejor ajuste entre sus elementos (p. 100). 
Laudan va mucho más allá y llega a afirmar que el progreso de la ciencia depende no solo de la solución de problemas empíricos, sino también de la adecuación del sistema normativo de la teoría respecto a la indagación de cierto tipo de problemas. Así, su propuesta contribuye a la toma de conciencia de que tanto los enfoques inductivos como el hipotético deductivo (del que Popper es un prominente representante), hoy considerado la práctica dominante en la ciencia, obedecen a momentos históricos distintos, en los que la reflexión debía, primero, dar cuenta de datos observables y al alcance de la mano (enfoque inductivo) y, más tarde, debido a los avances de la física que requerían dar cuenta de dominios no tan accesibles a la observación, resultaron más adecuados los enfoques hipotético-deductivos.

Por ello, el "reconocimiento de problemas conceptuales normativos es una fuerza de la evolución histórica de la ciencia mucho más potente de lo que han admitido algunos historiadores de la ciencia” (Laudan, 1986, p. 94). Igual de importantes son otros factores relacionados con doctrinas no científicas ligadas a la visión del mundo y a las controversias metafísicas, así como los conflictos ideológicos y morales que impulsan la ciencia en diversas direcciones. Estos no constituyen pseudoproblemas sino factores que tensionan la ciencia e inciden positivamente en la solución de problemas.

\section{Comentario e implicaciones}

Los aportes revisados en el capítulo II se refieren a los aspectos menos familiares y accesibles de la teoría de la teoría, los cuales, queramos o no, operan subyacentes en la práctica cotidiana de la ciencia y la enseñanza universitaria, especialmente respecto al carácter modélico de la teoría cada vez más presente en la economía, las ciencias de la vida y las ciencias técnicas. Acceder a las diversas opciones que 
permiten de una u otra manera comprender los elementos de las teorías y sus relaciones, así como la manera en que las teorías se articulan entre sí, es de mucha utilidad y pertinencia. Veamos por qué:

Las corrientes axiomáticas nos llaman la atención sobre el encadenamiento de proposiciones de progresivo grado de abstracción que constituyen las teorías (enunciados empíricos, generalizaciones empíricas, axiomas con sus respectivos términos) cuyas reglas de control obedecen a la lógica. No dudamos de que se trata de una aproximación relevante al hecho de que toda teoría no se reduce al conjunto de enunciados empíricos referidos al dominio de la realidad que buscan comprender, sino que incluye otros de carácter puramente lógico y axiomático, de un alto grado de abstracción y generalidad. Asimismo, es una propuesta que nos ofrece una primera definición de los elementos básicos de una teoría y de sus reglas del juego en el terreno de la lógica y del encadenamiento de proposiciones.

El análisis estructural de las teorías no está muy presente en la metateoría de las ciencias sociales y, a decir verdad, tampoco es frecuente y común observar su despliegue en ciencias como la biología, la física o la genética, no obstante existir descripciones teóricas como las aplicadas por Lorenzano (2002a), para la reconstrucción estructural de la bioquímica o para la teoría del gen (2002b); y por Casanueva (2002) para analizar redes teóricas sobre la hibridación mendeliana. A pesar de las búsquedas, no logramos identificar análisis similares aplicados a las ciencias sociales; no obstante, hemos reconocido elementos que resultan familiares para un tipo de sensibilidad epistémica ampliamente difundida en el análisis de la realidad sociocultural. Estos son los siguientes:

a. Toda teoría relaciona dos ámbitos: el contenido conceptual y el dominio de la realidad que se busca comprender según 
una relación entre ambos de aproximación y verosimilitud. Es decir, nos advierte de que lo real no es reductible a la teoría ni la teoría es una copia de lo real, pues se concibe, en el fondo, a partir de una lectura teórica. Se refuerza la idea de que toda teoría remite a un núcleo básico, paradigmático, que busca estabilidad y un cinturón protector que genera una dinámica defensiva de dicho núcleo.

b. La lectura estructural atribuye importancia a los aspectos pragmáticos constitutivos de la teoría y la comunidad de científicos es el más decisivo porque se constituye en una comunidad de sentido que sanciona y determina las preferencias y opciones teóricas más allá de las determinantes lógicas. Por ello, la ciencia no es un escenario autorregulado por sus propios códigos y procedimiento, pues depende para su desarrollo de los intereses sociales de los usuarios. Al mismo tiempo, refuerza la idea de que no existen razones esenciales para considerar la ciencia como una forma privilegiada y mejor de conocimiento: son los diversos usuarios que sancionan diversas formas de saberes según sus perspectivas e intereses.

c. Las teorías son realidades dinámicas y no las podemos entender solo a partir de los elementos que las constituyen en un momento dado de su evolución: es necesario, además, establecer su recorrido a través del tiempo, a fin de constatar la persistencia de los elementos estables y la transformación de los elementos accidentales.

d. Asimismo, toda teoría no se reduce a sus conceptos clave, sino a las redes de especificación y concreción que la refieren a diversos dominios de lo real y de aplicación cada vez más específicos. El concepto de teoría-red contiene ricas implicaciones para las ciencias sociales, pues nos ayudan a compren- 
der la necesidad de articular diversos niveles de especificidad en la explicación teórica.

e. Toda teoría no es un corpus autosuficiente y autorreferenciado definido por sus propios términos: implica relaciones y vínculos necesarios con otras teorías. En efecto, en antropología usamos términos prestados, dados y desarrollados no solo por fuera de las teorías referenciales. Antes bien, provienen de otros entornos disciplinares; y viceversa, constatamos que muchos de los conceptos anidados en la antropología se han difundido ampliamente hacia otros entornos como la política y el sentido común, y son asumidos, también, como dados.

La perspectiva semántica, sin duda alguna, es la que gana cada vez mayor importancia en la academia debido, entre otras razones, a la creciente necesidad de modelizar o correr modelos para ordenar y manejar datos cada vez más numerosos y diversos obtenidos y correlacionados mediante los recursos informáticos, por ejemplo, para explicar y predecir el cambio climático, los fenómenos astronómicos y las situaciones económicas. La enorme cantidad de datos requeridos para estos y otros dominios de la ciencia implica incluirlos en un modelo capaz de dar cuenta de ellos. Por lo tanto, las teorías no solo ofrecen explicaciones causales y externas a los fenómenos de cualquier tipo sino y sobre todo proveen de marcos interpretativos, porque ellas mismas constituyen una interpretación de la realidad, sin los cuales, los datos son significantes vacíos.

Para las ciencias sociales y, en general, las corrientes historicistas son muy útiles porque, a diferencia de la corriente axiomática, remarcan más allá de la lógica los aspectos pragmáticos e históricos que intervienen en el desarrollo científico, de tal modo que resulta inadmisible un tipo de análisis de las teorías que excluya las comunidades de sentido y el contexto histórico que las animan y vertebran entre sí. Al- 
gunos cuestionan que Laudan encierre la ciencia y la teoría en el marco estricto de la solución de problemas, pues no es una condición que explica por sí misma el progreso científico. No pocas veces la dinámica del conocimiento no va a la par de la solución de problemas y, sin embargo, es posible afirmar que el conocimiento progresa. Un crítico del concepto de progreso científico, tal como lo definen Laudan y Kuhn, es Alexander Bird (2007) que considera esta postura regresiva, ya que el progreso de la ciencia tiene que ver con la acumulación de conocimiento teórica y metodológicamente justificado ${ }^{37}$.

El aporte de Laudan es insustituible para comprender la epistemología del problema y potente para describir la dinámica viva así como el funcionamiento creativo de las teorías que rinden epistémicamente a pesar de los desajustes y los interrogantes pendientes. Así es como funciona la ciencia en realidad. Su enfoque centrado en la capacidad de la teoría para la solución de problemas nos recuerda al filósofo estadounidense Charles Sanders Peirce (1839-1914), padre del pragmatismo y la semiótica, para quien un sistema de teorías debería tomar en cuenta aquellas que de veras han solucionado problemas. El innegable aire de familia con la tradición de Peirce no es casual en Laudan y refleja una opción epistémica clara que se expresa, además, en su rol de presidente de la International Peirce Society en el 2009.

Consideramos que Laudan es muy importante, además, porque contribuye a tomar muy en cuenta el aspecto metodológico como una dimensión esencial e indisociable de la teoría y alerta sobre la imposibilidad de enajenar de esta los métodos y las técnicas que le dan vida y sentido, admitiendo, a la vez, una relación muy flexible y epistémicamente productiva entre los principios axiomáticos y las metodologías.

37 Para el análisis de los argumentos de Bird, también en contra de la corriente semántica, ver Islas Mondragón (2015). 
Los autores referidos en la última sección (Kuhn, Lakatos y Laudan) aportan elementos que vertebran una matriz descriptiva de las teorías, o de un conjunto de estas emparentadas según programas o tradiciones de investigación, tal como la que proponemos en la Tabla 9 que reinterpreta y añade algunos aspectos a los ya revisados. Los ejes descriptivos y los rasgos que los constituyen son útiles para desarrollar marcos teóricos que establecen las relaciones de continuidad o ruptura de las opciones conceptuales y metodológicas respecto a otras propuestas.

Tabla 9

Matriz descriptiva de teorías

\begin{tabular}{|l|l|}
\hline \multicolumn{1}{|c|}{ Ejes descriptivos } & \multicolumn{1}{c|}{ Componentes } \\
\hline Supuestos compartidos & $\begin{array}{l}\text { Compromisos ontológicos: cómo concibe la realidad y la historia; } \\
\text { la cultura, la sociedad y la persona. Cómo concibe la identidad } \\
\text { y la acción social. } \\
\text { Compromisos epistemológicos: cómo concibe el conocimiento. } \\
\text { Compromisos éticos y políticos: cómo concibe el proyecto de so- } \\
\text { ciedad y de convivencia. }\end{array}$ \\
\hline $\begin{array}{l}\text { Heurística } \\
\text { Normas epistémicas }\end{array}$ & $\begin{array}{l}\text { Rol del conocimiento científico. } \\
\text { Enfoque de la teoría: explicativo, estructural, interpretativo, } \\
\text { complejo. } \\
\text { Criterios de evaluación: lógica, significatividad, relevancia, capa- } \\
\text { cidad de resolución de problemas, potencial transformador... }\end{array}$ \\
\hline Normas metodológicas & $\begin{array}{l}\text { Procedimientos investigativos. } \\
\text { Técnicas connaturales. } \\
\text { Énfasis metodológicos. } \\
\text { Encadenamientos discursivos. }\end{array}$ \\
\hline $\begin{array}{l}\text { Áreas de aplicación y } \\
\text { solución de problemas } \\
\text { misma tradición }\end{array}$ & $\begin{array}{l}\text { Aplicaciones conceptuales: área de problemas teóricos. } \\
\text { Aplicaciones empíricas: área de resolución de problemas sociales, } \\
\text { educativos, etc. } \\
\text { Marco empírico: área de la realidad que le es más connatural. }\end{array}$ \\
\hline $\begin{array}{l}\text { Tradición de pensamiento en que se inserta la teoría. } \\
\text { Cercanías, continuidades y rupturas con otras teorías. }\end{array}$ \\
\hline
\end{tabular}

Elaboración de los autores. 


\section{Capítulo III LA TEORÍA: APROXIMACIONES PEDAGÓGICAS Y SOCIOCULTURALES}

\section{Introducción}

El presente capítulo selecciona tres autores muy puntuales no relacionados entre sí, que describen desde perspectivas y tradiciones de pensamiento muy distintas no la teoría en sí, en sus componentes y elementos que la constituyen, sino las características del pensamiento o conocimiento teórico considerado de manera más amplia y general. Se trata de Gilbert Ryle, Magoroh Maruyama y Kieran Egan, a quienes consideramos relevantes porque, a diferencia de los aportes de la epistemología y de la filosofía de la ciencia ya revisados, proporcionan una aproximación psicosocial y cultural con implicaciones para la gestión del conocimiento, para comprender la heterogeneidad de la producción teórica en la ciencia y las concepciones en torno al desarrollo del pensamiento en instituciones educativas.

Gilbert Ryle (1900-1976) fue profesor de filosofía metafísica de la Universidad de Oxford y miembro de la escuela Analítica. Sus puntos de vista y postura crítica en torno al "teorizar" se condensan en la obra El concepto de lo mental ([1949] 2005), en la que basamos nuestra sistematización. "Teorizar" es una capacidad ejecutoria aprendida en la que intervienen habilidades y desempeños puntuales transmitidos e incorporados comprensivamente mediante el "discurso didáctico". La "teoría” y el "teorizar" son comportamientos 
públicos y, por ello, observables que tienen lugar "fuera de los individuos" ("entre los individuos") y no, como se suele suponer, en algo como la mente, considerada un centro intraindividual que comanda operaciones intelectuales. Por ser una actividad intersubjetiva sujeta a reglas del juego, el teorizar, al igual que muchas otras actividades humanas, está sujeta al aprendizaje.

Magoroh Maruyama (1929), formado en Matemáticas (Universidad de California) y en Epistemología Cultural (Universidad de Lund), fue profesor visitante de ciencias administrativas en la Universidad del Sur de Illinois cuando escribió su artículo más conocido "Mindscapes and Science Theories" ("Paisajes mentales y teorías de la ciencia"), publicado por la revista Current Anthropology en octubre de 1980. En él, recoge investigaciones anteriores para afinar la caracterización, desde la antropología de la ciencia, de los diversos "patrones cognitivos/cogitativos/perceptivos" en cuyo marco las teorías científicas se producen, expresan y funcionan de distinta manera. Consideramos que su aproximación es útil por concebir los escenarios académicos como espacios heterogéneos donde, a pesar de que la teoría constituye su lenguaje común, esta se despliega de manera distinta según diferencias culturales marcadas por las disciplinas o las instituciones.

Kieran Egan (1942) es un filósofo de la educación contemporáneo $^{38}$ y la obra que sistematizaremos ha sido publicada primero en inglés en 1997 y su versión en español, en el año 2000, con el título Mentes educadas. Cultura, instrumentos cognitivos y formas de comprensión. La intencionalidad de su propuesta, a diferencia de to-

38 De origen irlandés, formado en Inglaterra y radicado posteriormente en Estados Unidos, donde se doctoró en Filosofía de la Educación en la Universidad de Cornell. Actualmente, labora en la Simon Fraser University de Canadá e integra la Academia Nacional de Educación de Estados Unidos. 
das las que serán revisadas en este capítulo, es pedagógica en todo el sentido de la palabra porque apunta al proyecto de cultivar la imaginación en el desarrollo intelectual de los niños, adolescentes y jóvenes mediante la inclusión en la educación formal de diversas formas de comprensión atesoradas a lo largo de la historia de la cultura. Su propuesta sigue de cerca la inspiración vygotskiana, según la cual el aprendizaje es un proceso social atado a la misma dinámica del lenguaje y son las mediaciones sociales las que lo hacen posible. Por otro lado, resignifica la idea de recapitulación de Spencer, de manera tal que el estudiante no recapitula los contenidos a lo largo del itinerario educativo, sino las formas de pensar propias de la historia de la cultura. La escuela es el escenario de ejercicio y cultivo de esas múltiples formas de comprensión que incluyen instrumentos intelectuales específicos. El lenguaje teórico es, apenas, uno de estos, entre otros.

\section{Gilbert Ryle: teorizar y teoría como actuaciones discursivas}

En El concepto de lo mental Ryle describe la teoría y el teorizar como expresiones del actuar inteligente observable únicamente a partir de los comportamientos públicos inteligentes y desde la metodología propia de la filosofía del lenguaje ordinario (Dennett, 2005, p. 18). A partir de cómo ambos términos se usan y aparecen en el lenguaje corriente es posible identificar exclusiones, asociaciones y parentescos con otros términos vinculados con la inteligencia, como el de "actuar inteligentemente", "poseer conocimiento", "actividad intelectual" y otros que refieren adjetivaciones y desempeños intelectuales asociados. Su aporte es vigente y reviste interés para nosotros porque, en su momento - y todavía hoy — contribuyó a cuestionar el intelectualismo cartesiano que, a pesar de todas las críticas, goza todavía de buena salud en la academia en aquellos no pocos casos en 
los que ampara la doctrina oficial que otorga primacía a las teorías y los conceptos y cuando su posesión se considera condición previa del pensar y el actuar inteligentes.

La presente sistematización de la propuesta de Ryle articula dos momentos: el primero de los cuales desarrolla su crítica a la leyenda intelectualista cartesiana, proponiendo que las acciones inteligentes son formas públicas de actuar que implican capacidades aprendidas y habilidades. La segunda desplegará las descripciones en torno al teorizar y la teoría, así como el correlato de sus formas discursivas.

\section{La práctica eficiente precede a la teoría}

El punto de partida de Ryle es desarmar el dualismo cartesiano y declara inviable la segmentación polarizada mente-cuerpo, ya sea porque se trata de un error categorial (pone en el mismo plano categorías que pertenecen a órdenes distintos de la existencia), ya porque el dualismo atribuye a la mente, sin querer y resultado de su propia inviabilidad, leyes análogas a las que rigen el mundo físico o porque hace de esta un fantasma en la máquina del cuerpo. A continuación de la crítica, desglosaremos la distinción entre "saber hacer" y "saber que..." desde la cual define la actuación inteligente y construye las bases de su edificio argumental.

\section{En contra del dualismo cartesiano y la leyenda intelectualista}

Comencemos por lo primero. Según Ryle (2005, pp. 25 y ss.), el dualismo cartesiano se funda en la doble composición de la persona humana constituida por un cuerpo y una mente, instancias opuestas e irreductibles entre sí, ambas en relación de oposición contrastiva y jerarquizada, deberíamos añadir. El cuerpo remite al espacio y sus procesos pueden ser observados y controlados por observa- 
dores externos y, al ser observable, la vida corporal es pública y sus funciones reductibles a leyes mecánicas o físicas. La mente no decurre en el espacio sino en el tiempo y sus funciones no están sujetas a leyes mecánicas o físicas. Al no ser observables por otros, son patentes y accesibles a la conciencia de cada individuo.

Así, la leyenda intelectualista forja la idea de individuos que viven dos tipos de existencia, "dos vidas", "dos mundos", a la manera de "historias paralelas" (la cara y cruz de una moneda), en relación de "oposición polar" (p. 27), signadas por dos tipos de acontecimientos: los del mundo físico y los del mundo mental. La mente "no es observable por otro y su desarrollo es privado. Solo yo puedo tener conocimiento directo de los estados y procesos de mi propia mente" (p. 25), al punto que, en cosas de la mente, somos como Robinson Crusoe (p. 27) ${ }^{39}$. La conciencia, la autoconciencia y la introspección permitirían al individuo acceder directamente a su mundo mental con mayor claridad y distinción que con las que es capaz de acceder al mundo físico pero con la imposibilidad de acceder al mundo interno de los otros ${ }^{40}$. El acceso mediante la actuación lingüística y verbal no es posible ya que estas interacciones están del lado de las leyes físicas y nada dicen de la mente.

La crítica de Ryle apunta contra la ilusión cartesiana de que las operaciones mentales son accesibles al individuo del mismo modo, pero con mayor claridad respecto a los acontecimientos físicos. Pero no puede obviar responder a la pregunta: ¿de qué manera construi-

39 Para Ryle el espacio es el campo común que conecta lo que sucede entre un cuerpo y otro; no es así para los hechos mentales que "acaecen en ámbitos aislados, las 'mentes', y no existe conexión causal directa entre lo que le sucede a una mente y lo que le pasa a otra..." (p. 27).

40 "La soledad absoluta es el destino inevitable del alma. Solo nuestros cuerpos se pueden encontrar" (p. 29). 
184

mos conceptos generales referidos a facultades y operaciones mentales de todos los individuos si no son observables por otros? La única respuesta posible de la leyenda intelectualista es postular la existencia de la mente, expresión de un lugar que corresponde a la "geografía lógica" en el que subyacen procedimientos y producciones mentales que anticipan las acciones. La mente sería ese centro de operaciones oculto e inaccesible que produce abstracciones, algo así como lo que entendía Popper, inspirado en Frege, al postular la existencia de un núcleo productor de operaciones mentales.

Dando un paso más, Ryle proporciona una metáfora para ilustrar el error que plantea la segmentación cuerpo-mente y consiste en el dogma del fantasma en la máquina (2005, pp. 29 y ss.), porque conduce a concebir a la persona como un fantasma inserto en la máquina, pero sujeto al fin y al cabo a procesos no mecánicos, según los cuales "las leyes de lo mental deben explicar las operaciones no espaciales de la mente como efecto de otras operaciones no espaciales" (p. 33). Parecería que las leyes causales abarcan también los procesos mentales, aunque de distinto tipo que las leyes físicas. Tal concepción da lugar a la hipótesis paramecánica (la mente también posee dinámicas del tipo "máquina”), conclusión contradictoria a la que no puede escapar el dualismo cartesiano cuyo desliz culmina en considerar que la mente es, análogamente, una máquina. En consecuencia, a pesar del contraste mente-cuerpo, el determinismo de las leyes físicas se cierne también sobre las leyes de la mente.

Las operaciones mentales tuvieron que ser descritas negando las características atribuidas a los cuerpos; no están en el espacio, no son movimientos, no son modificaciones de la materia, no son accesibles a la observación públicas. Las mentes no son trozos de un mecanismo de relojería. Son simplemente trozos de un no mecanismo [...] la mente humana no es meramente un fantasma 
enjaezado a una máquina, sino que es en sí misma una máquina espectral. (2005, p. 33)

Para Ryle no es posible concebir la persona constituida por dos realidades en oposición, los procesos físicos por un lado y los procesos mentales por otro, pues plantear esa segmentación obedece a un error categorial. La postulación de una "oposición polar entre ellas es sostener que ambos términos poseen el mismo tipo lógico”. Lo corporal y lo mental no son términos de una misma categoría. Ambos son distintos en el sentido de que no cabe entre ellos ni la absorción ni la exclusión, y aceptar que se tratan de categorías diferentes lleva a superar el dualismo mente-materia (p. 36) y a evitar la subsunción de lo mental en la materia (materialismo) y viceversa (idealismo). Ambos términos "ofrecen dos maneras distintas de existir; algo así como 'crecer' tiene sentidos diferentes en la 'marea está creciendo', 'las esperanzas están creciendo', y 'la edad promedio de mortalidad está creciendo"” (p. 36).

\section{Teorizar y teoría desde la distinción "saber hacer" y "saber que..."}

A continuación de la crítica del dualismo cartesiano, plantea la distinción clave entre dos maneras de conocer que no siempre van ni tienen por qué ir juntas: el "saber hacer" y el "saber que..." ${ }^{41}$, siendo lo primero la actuación de disposiciones (capacidades y habilidades) aprendidas del individuo para actuar inteligentemente; y lo segundo, el conocimiento consciente y puntual de normas, prin-

41 El capítulo II de su libro El concepto de lo mental lleva por título, precisamente, "Saber hacer y saber que...", y cuya traducción literal del inglés corresponde a "Saber cómo y saber qué". Pero en español, preferimos decir que "Juan sabe tocar piano" y no "Juan sabe cómo tocar el piano" (el giro inglés usual). Con respecto a los puntos suspensivos de "saber que..." se entiende que deben ser llenados por proposiciones. (Ver nota del traductor, en Ryle, 2005, p. 39). 
cipios y criterios. Con base en esta distinción, Ryle expresa de la siguiente manera la tesis central de su edificio argumental: “... el ejercicio práctico de la inteligencia no puede ser analizado en términos de una operación en serie que consiste en considerar prescripciones para luego ejecutarlas" (p. 54).

En efecto (y el ejemplo es nuestro), conocer la sintaxis y la gramática de una lengua indígena ("saber que...") no implica necesariamente hablarla ("saber hacer"). Asimismo, muchos — la mayoría- de quienes hablan fluidamente el kichwa ("saber hacer") no son conscientes de las normas gramaticales subyacentes en sus ilocuciones ("saber que...”). Seguramente sus interacciones verbales no fluyen según el esquema tal que los interlocutores previamente se dictan a sí mismos la regla gramatical para luego construir "en su cabeza” la oración y recién expresar a los participantes de la conversación el enunciado que quieren compartir. De hecho, hablamos e interactuamos verbalmente sin anticiparnos las reglas gramaticales sino, y simplemente, ejecutándolas, actuándolas. El correlato de la tesis fundamental para los términos "teoría" y "teorizar", que pretendemos profundizar descriptivamente, se expresa de la siguiente manera:

La práctica eficiente precede a la teoría [...] En consecuencia, es posible llevar a cabo inteligentemente ciertas operaciones sin que sea posible tener en cuenta las proposiciones que determinan cómo ejecutarlas. Algunas acciones inteligentes no están reguladas por el conocimiento previo de los principios que las rigen. (Ryle 2005, p. 44)

El distinguir entre dos sentidos diferentes del saber, en tanto "saber hacer" y "saber que...", deshabilita la posibilidad de una instancia que define las acciones inteligentes de operaciones internas anteriores del tipo "planear qué hacer". Por ello, no es admisible concebir algo así como la "mente" humana, cual si fuera un comando de operaciones intelectuales (el fantasma en la máquina) que dicta des- 
187

de las normas a cada paso de la actuación. Con esta distinción, Ryle da otro golpe que desbarata la "doctrina oficial" (de la ciencia) y de la persistente "leyenda intelectualista" que, en cambio, identifica el "saber hacer" con el "saber que...", sobre la base de que

toda actuación inteligente presupone la observancia de reglas o la aplicación de criterios. Se sigue de ello que toda operación considerada inteligente debe ser precedida por un reconocimiento intelectual de esas reglas o criterios, esto es, que el sujeto debe primero reconocer internamente ciertas proposiciones acerca de lo que debe hacer (a veces denominadas "máximas", "imperativos", o "proposiciones regulativas") para comportarse —-solo después- de conformidad con tales dictados. (2005, p. 43)

En realidad, la inteligencia es un comportamiento y un atributo de la actuación; solo el actuar es inteligente y se atribuye el adjetivo "inteligente" a una persona que actúa inteligentemente. La persona inteligente "sabe hacer" en tanto que aquella que "sabe" no necesariamente "sabe hacer"; no siempre se desempeña acorde con ese saber. La tesis de Ryle posibilita trasladar explícitamente la primacía del "saber hacer" al ámbito pedagógico, al definirla como capacidad aprendida desde la observación que conduce a la práctica o a partir la enseñanza, que consiste en asimilar ejecutorias y actuar reglas de juego, tal como sucede en los siguientes ejemplos proporcionados por el mismo Ryle:

Pero podría ser posible que un niño aprendiera a jugar al ajedrez sin oír hablar de reglas en ningún momento. Observando los movimientos hechos por otros jugadores y advirtiendo cuáles son permitidos y cuáles no, podría adquirir el arte de jugar correctamente sin llegar a ser capaz de exponer las prescripciones que definen "correcto" e "incorrecto". Las reglas de los juegos de frío-caliente y del escondite, y las reglas elementales de la gramática y de la lógica, se aprenden de esta manera. Aprendemos a hacer mediante la 
práctica, ayudados por la crítica y el ejemplo, aunque a menudo sin recibir lección alguna sobre la teoría. (2005, p. 55)

El "saber hacer" es una forma de acción compleja, accesible a partir de lo que se puede observar: el comportamiento manifiesto y observable, pero es necesario ir más allá de él no como quien busca causas ocultas, "sino aptitudes, habilidades, hábitos, propensiones e inclinaciones" (p. 59). Las acciones inteligentes son aptitudes complejas que requieren de un conjunto de habilidades. El aprendizaje del actuar inteligente convoca la distinción y la relación entre tres términos importantes: la aptitud (capacity), el hábito y la habilidad (ability) de tal forma que la aptitud para aplicar reglas es una disposición adquirida resultado de la práctica (p. 56). La aptitud resuelve los problemas pensando y corrigiendo el paso siguiente, a diferencia de la habilidad que es de orden mecánico, como quien usa "hábilmente" la calculadora para resolver una operación matemática.

La aptitud no es un hábito, ya que se cultiva por el adiestramiento, en tanto que el hábito es un condicionamiento producto de la rutina adquirida por la repetición. Aunque el hábito está presente en algunas habilidades, no es una aptitud, ya que esta última es modificable: "es de la esencia de la acción inteligente ser modificada por las que la preceden. El sujeto está siempre aprendiendo..." (Ryle, 2005, p. 56). La aptitud, en tanto capacidad modificable y modificadora, produce innovación pues supone la capacidad de torcer el rumbo y enriquecer las posibles respuestas ante nuevas situaciones (p. 61).

Las aptitudes inteligentes son complejas también en otro sentido, pues no implican disposiciones uniformes en todos los individuos ni el mismo grado de competencia ni de ejecutorias ni maneras de actuarlas. Así, las aptitudes inteligentes revisten "una amplia gama de actualizaciones más o menos disímiles" (p. 69) entre los individuos. Aunque todos conocen las mismas reglas del ajedrez, la performance 
de cada uno es distinta y cada quien las actualiza de diversa manera. Incluso quien observa jugar el ajedrez participa de la misma aptitud de manera diferente en tanto observador crítico porque ha asimilado las reglas, del mismo modo que aquel que sabe de armonía es capaz de apreciar, sin ejecutar, una sinfonía siguiendo la partitura.

Al tratarse de una forma de proceder, el aprender aptitudes requiere del adiestramiento y es producto del desempeño concreto. Por lo tanto, no equivale a adquirir información. Así, el aprendizaje no procede desde dentro hacia afuera (desde los principios que se actualizan de un centro de operaciones: la mente), sino de afuera hacia adentro, pro medio de su despliegue público ("Aprendo con la actividad del otro"), tal como sucede cuando aprendemos las leyes de la lógica o del juego del ajedrez hasta que se constituyen en una forma de pensar ejercitada y actuada vez por vez.

En este punto, Ryle ubica en su lugar a las operaciones intelectuales y el sentido exacto de lo que entiende por operaciones mentales. Tales operaciones no están en la mente ya que se actúan públicamente y, en rigor, la mente no es un lugar ni siguiera metafóricamente. Así, nuevamente en contra del dogma del fantasma en la máquina, sostiene que

al describir las operaciones mentales de una persona no estamos describiendo un segundo conjunto de operaciones espectrales. Describimos determinadas fases de nuestra vida, esto es, los modos en los que esa conducta se lleva a cabo [...] los actos que observamos son, en sí mismos, los que se están haciendo con inteligencia [...] El sujeto es activo, corporal y mentalmente, aunque no simultáneamente en dos "lugares" distintos o con dos "máquinas" diferentes [...] [El lugar de la mente] está en el tablero de ajedrez, en el púlpito, en el escritorio del estudioso, en el estrado del juez, en el asiento del conductor de camiones, en el estudio y en la cancha de fútbol. En estos lugares la gente trabaja y juega, torpe o inteligentemente. $(2005$, p. 65$)$ 
190

\section{La teoría y sus formas discursivas}

Para Ryle las actuaciones que solemos relacionar con la razón, el intelecto, el entendimiento — como "teorizar" — no tienen ningún rango de exclusividad respecto a otras que despliegan "reglas del juego", y sus aptitudes no están reservadas a una élite porque las actividades que consideramos intelectuales comparten las mismas características de todas las actividades inteligentes como el ser "intencionales, habilidosas, cuidadosas, voluntarias, etc., considero tales operaciones como meras ocupaciones transitorias, parecidas a ocupaciones tales como hacer nudos, seguir una canción o jugar a las escondidas" (2005, p. 301).

Pero sin atribuirles algún tipo de anterioridad causal, es posible describir conceptos y actividades que consideramos intelectuales no por su carácter sino en razón de sus objetivos y finalidades. Aquellas actividades que denominamos intelectuales no responden a una forma distinta de actuar y se expresa tanto y tan bien mediante el despliegue de una conversación espontánea como en su forma meditada y cuidadosa, aunque le atribuyamos el carácter de intelectual solo a la segunda. Ambas actuaciones están atravesadas por una diferencia de propósito y finalidad, pero su especificidad no está dada por provenir o no desde un lugar denominado intelecto. Simplemente, "la forma de hablar corriente no tiene por objeto presentar las teorías..." (2005, p. 304).

La tendencia errónea de ubicar algunas actividades más cerca que otras del ámbito intelectual, que conduce a distinguir entre actividades intelectuales y no intelectuales, se afinca en la práctica social de la enseñanza que cultivó ciertas aptitudes por medio del aprendizaje proporcionado por el discurso didáctico, la lectio, que requiere de espacios e interacciones de tipo escolar. Ha sido esta práctica la 
que creó la idea de que, en efecto, existen facultades intelectuales separadas del resto y entronizó la figura del intelectual como aquel que ha recibido tal tipo de enseñanza, pero ello no da pie a concebir que se trata de acciones que vienen de un ámbito exclusivo y diverso a otros, pues todos ellos comparten los principios que rigen cualquier forma de actuación (2005, p. 305).

Por lo tanto, aquello que define el lenguaje científico que solemos definir como "intelectual” en realidad remite a propósitos, contextos, formas institucionales, actores, roles y textualidades específicas. La distinción de Ryle entre "pensar" (la tarea) y "pensamiento" (resultado de la tarea) apunta a algo parecido y es clave para remover el error de describir el "pensar" en términos prestados de sus resultados. De hecho, términos como "juzgar”, “abstraer”, "deducir”, "predicar", etc. "no denotan actos del pensar" (p. 307), porque el pensar no es accesible a la observación, pero sí las acciones expresadas en producciones como artículos, conferencias, informes... allí y solo allí se despliegan las operaciones analíticas, críticas, propositivas, no en otro lugar. En esencia, las actividades denominadas "intelectuales" comparten el mismo rasgo de sujetarse a reglas, como cualquier otra actividad, como ocurre con el juego o el trabajo.

Luego de remover la ilusión de un centro de operación con dedicación exclusiva para aquellas actividades a las que atribuimos el carácter de "intelectuales", Ryle (pp. 307 y ss.) inserta la distinción entre "construir una teoría", la tarea (tratar de obtener y lograr una teoría; equivale a viajar), y "tener una teoría”, el resultado (poseerla; equivale a llegar a destino). "Tener una teoría” es análogo a tener un lápiz. No quiere decir que haré algo con la teoría, pero estoy listo a producir un enunciado o una aplicación, de la misma manera que estoy dispuesto a usar el lápiz cuando la necesidad lo requiera. "Tener una teoría” irradia capacidades y posibilidades insospechadas, 
como la de explicarla y aplicarla, la de convocar teorías para explicar y predecir hechos, la de crecer en el lenguaje que hace posible comunicar teorías. Todas estas capacidades van juntas.

Pero las teorías, lo mismo que los planes, no se construyen meramente con el objeto de poder describirlas. El fin principal que se persigue al ofrecer esos ejercicios didácticos [...] es prepararse para poder utilizar esas lecciones en fines didácticos ulteriores. Colón no realizó sus viajes para poder agregar algo a lo que se decía en las lecciones sobre temas geográficos. Poseer una teoría o plan no es meramente ser capaz de decir en qué consiste. Ser capaz de describir una teoría, de hecho, ser capaz de hacer una cosa, a saber, su exposición didáctica. El dominio de los teoremas de Euclides no reside meramente en la posibilidad de citarlos, sino también en la posibilidad de contestar a objeciones y de determinar con su ayuda la medida de los campos. (p. 308)

Aunque no sabemos cómo, las teorías se transforman en "versiones que no son puramente didácticas" (p. 308) y eso tiene que ver con las capacidades deductivas expresadas en forma de predicciones (anticipar hechos futuros) y "retrodicciones" (explicación retrospectiva de hechos pasados): ambos aspectos son constitutivos del discurso didáctico, del aprendizaje de las teorías. Rememorar una teoría consiste en un acto didáctico que actualiza no solo la teoría de un científico, sino lo que habría dicho y hecho hoy y aquí con esa teoría. Otra de las capacidades que detona el "poseer teorías" es la capacidad comunicativa de enseñarlas, de dominar el lenguaje que hace posible transmitirla, es decir, nos da acceso a las capacidades propias de cómo hablar científicamente.

¿Cómo se construyen las teorías? El primer paso es fijarse en la producción textual que explican y describen las teorías. Esas formulaciones en prosa no contienen ni los procedimientos ni las observaciones ni los instrumentos, al menos, no todos aquellos que los autores desplegaron en su construcción. El segundo aspecto a tomar 
en cuenta consiste en que, en la tarea de construir teorías, intervienen personas con un cierto nivel de educación.

Pero, al margen y por encima de ambos aspectos, "la tarea de construir la teoría consistió en abrir sendas donde no las había” y a veces el "tener" o "poseer una teoría" subsume e invisibiliza todo aquello que ocurre cuando se la construye, presentando a los autores en plena y permanente posesión de sus teorías, oscureciendo las dudas y los diálogos interiores. Así, la tarea de construir una teoría implica otras tareas no explícitas y que no aparecen en los géneros discursivos que la comunican. Casi siempre quedan al margen reportes como la autopreparación del autor para comunicarla (al fin y al cabo, es una senda para facilitar el camino) y también la tarea didáctica de preparar a otros estudiosos.

Así, en esa senda el andar es más suave y veloz cuanto más trajinada por el autor y por otros que lo siguen, sin que el caminante advierta el volumen de los desbroces ni las irregularidades aplanadas. Toda teoría implica restricciones formales que apuntan a lograr el mínimo esfuerzo y la máxima eficacia tanto de parte de quien la comunica como de quien intenta comprenderla. Por ello, la presentación final de una teoría no condensa todos los elementos que intervienen en su construcción. Así el lenguaje de ambas fases, la de construcción y la de posesión, será distinto en complejidad y estilos enunciativos, pero, por lo regular, y por razones expositivas, se suele presentar primero el núcleo proposicional (el resultado) del que se derivan deducciones. Este orden es dado por restricciones discursivas a la hora de exponer la teoría, lo cual no solo trastoca lo que en realidad ocurre, sino que induce a pensar que, en la construcción de las teorías, intervienen principios anteriores. Lo que comunica primero es lo último en la línea de producción de tareas y si aparece así no tiene nada que ver con lo que de verdad ocurre en la construcción de teorías, sino simplemente en su exposición. 
Nos parece que Ryle invita a considerar la teoría como una realidad eminentemente discursiva. Se actúa en lo textual poniendo en escena todo aquello que se suele hacer y es posible comunicar cuando se comunica una teoría. Aunque la descripción de las teorías acuda a un vocabulario abstracto para construir enunciados que se articulan orgánicamente en forma de premisas y conclusiones no significa que esas operaciones ocurran en otro lugar que no sea el texto o invoquen otras realidades que no sean actuaciones de producción textual. Reconocer otra posibilidad conlleva a admitir que existen instancias internas, operaciones privadas y centros del "sumar y restar" anteriores que han comandado la construcción (p. 316), invocando nuevamente el dogma del fantasma en la máquina. Los términos "inferir", "ideas", "juicios”, "pensamiento", "tener ideas abstractas" tienen sentido solo como realidades operadas y actuadas en las diversas formas de discurso científico, en la exposición concreta; no refieren correlatos de algo que ocurre en la mente, sino en el discurso. Siguiendo su metáfora, estos términos forman parte del destino del viaje, una vez poseída la teoría, no del viaje mismo ("construir una teoría"), aunque su encadenamiento discursivo induzca la errónea idea de secuencia causal. En realidad, son producciones, constituyen una posesión en tanto ejecutoria exitosa, no un proceso ${ }^{42}$.

[El teórico] puede dar lecciones, porque ha terminado de aprender. Puede utilizar su equipo, porque se encuentra equipado. Como la tarea

42 Para Ryle las actuaciones lógicas inferenciales que van de una premisa a una conclusión no son "procesos”: “Paso’ es una metáfora equívoca. Es también equívoca cuando se utiliza para describir el cambio que se produce cuando una persona entra en posesión de una verdad que ha estado negociando durante un lapso prolongado o breve" (p. 323). El tiempo que lleva pasar de una premisa a una conclusión no indica la duración de pasar de una acción a otra; refiere un nivel precario de ejecutoria de una actividad compleja que se desarrolla como un todo y ello porque el lenguaje científico traslada el sentido primario de los términos "concluir", "deducir" y "probar" como verbos de éxito en lugar de asumirlos como verbos de posesión (p. 324). 
195

de entrenarse en el manejo del arma ha terminado, puede utilizarla ahora sin dificultades. Sus "pensamientos" son lo que ha obtenido ahora; no son las tareas sin las cuales no podría tenerlos ahora”. (p. 319)

\section{Comentarios y repercusiones pedagógicas}

Ryle aporta a la epistemología su potencial crítico en contra de la leyenda intelectualista, haciendo del "teorizar" una plataforma de actuación y desempeño constituida por capacidades y habilidades específicas susceptibles de ser aprendidas. "Teorizar" es una forma de actuación inscrita en una capacidad más amplia y compleja; al mismo tiempo, es producto del aprendizaje que convierte a los individuos y los colectivas en aptos para convocar, identificar, insertar y producir conceptos y teorías a diversos niveles. Por ello, su aporte es preponderantemente pedagógico antes que epistemológico, y se conecta con un marco rico de referencias filosóficas, lingüísticas y antropológicas. $\mathrm{Al}$ incluir el "teorizar" entre los comportamientos complejos que siguen reglas del juego observables solo a partir de aquello que hacemos públicamente a través de las interacciones, Ryle evoca, de inicio, la perspectiva de las Investigaciones filosóficas de Ludwig Wittgenstein ([1945] 2008), para quien la categoría "reglas del juego" es central, desplegándola y especificándola en las reglas del juego del lenguaje, las cuales entretejen el nombrar con el actuar, explican la constitución de las formas de vida y mueven a las personas entre sí.

Además, se conecta con los presupuestos de la pragmática lingüística de Austin (su contemporáneo y crítico) ${ }^{43}$, tan bien expresados en el título de su obra más conocida: Cómo hacer cosas con palabras ([1962] 1982) porque, para Ryle, el "teorizar" y la producción teórica constan entre lo que es posible hacer por medio del decir y sus formas

43 Austin produjo, apenas un año después de publicado el libro de Ryle, una revisión crítica del mismo. Ver Austin, J. (1950). 
específicas de discurso. El pensamiento acaece de afuera hacia adentro porque es aprendido, y algunas actuaciones, como el diálogo interior (del individuo consigo mismo), mediante el cual aprendemos y entendemos en interlocución con nosotros mismos, reproducen prácticas comunicativas y discursivas intersubjetivas. A la producción teórica le corresponde una "producción discursiva" a partir de reglas del juego públicamente desplegadas y, por ello, solo observables tal como los individuos interactúan y se comunican entre sí, sin considerar relevante el indagar mecanismos subpersonales que remiten a posibles dinámicas cerebrales o algún tipo de estructura lógica profunda subyacente ${ }^{44}$. Ryle contribuye, así, a romper el halo de misterio en torno al "teorizar" y a superar el enclaustramiento intimista de la producción teórica - considerada un suceso producido en la mente de los científicospara ubicarla en la escena de la producción pública debido a que accedemos a ella por medio del lenguaje y la comunicación, pulsando formas específicas de actuación discursiva.

La teoría es una producción, además de aprendida, comunicada; se trata de una producción discursiva ligada a formas específicas y convencionales de discurso (el discurso teórico) que usa el lenguaje abstracto y comprende otras tantas formas enunciativas específicas: una de ellas es el discurso didáctico mediante al cual aprendemos y transmitimos la producción teórica.

Al colocar la teoría y la acción de teorizar en la escena pública, Ryle anticipa desarrollos posteriores como el de la antropología simbólica desarrollada en la obra La interpretación de las culturas, de

44 Según el mismo Dennett, la apuesta y las preguntas de Ryle se enfocan en "lo que las personas hacen, acerca de lo que denomino el nivel personal del pensamiento... no acerca de cómo el cerebro hace posible que las personas hagan lo que hacen; esas cuestiones de nivel subpersonal estaban completamente fuera del área de su interés" (2005, p. 16). 
Clifford Geertz ([1978] 1983), en la que remarca el carácter público de los símbolos; y el interaccionismo simbólico de Erving Goffman, en su obra Ritual de la interacción ([1967] 1970), según la cual los intercambios e interacciones simbólicas tienen lugar mediadas por un marco público (frame) que les otorga sentido. Así, accedemos al "teorizar" observando no dentro de las personas sino fuera de ellas, a partir de lo que despliegan entre sí en sus interacciones e intercambios cada vez que desempeñan las reglas del juego y los roles del "teorizar" en el marco de sentido que norman y anticipan las expectativas de los interactuantes.

La perspectiva de Ryle es sumamente útil para la docencia universitaria porque ancla la enseñanza y el aprendizaje en el cultivo y posesión de capacidades complejas de actuación y ejecutorias discursivas públicas como son, de hecho, la investigación, la resolución de problemas y la creatividad para enfocar y delimitar preguntas e indagaciones. Ryle nos recuerda que la universidad es el lugar en el que se aprende ciencia "haciendo ciencia", desde, en sus términos, un "saber hacer" en acto y no tanto o no solo desde los conceptos, cuestionando la norma común de anteponer su posesión como condición primera e indispensable. Asimismo, nos recuerda que, desde el punto de vista del aprendizaje, "comprender es una forma de saber hacer" y, por lo tanto, no constreñida a los límites actuales del individuo sino sujeta a desarrollo y adiestramiento: todos pueden aprender ciencia haciéndola. Solo basta aprender las "reglas del juego", los desempeños.

De esa manera, Ryle es un punto de apoyo para otorgar sentido pedagógico al aula universitaria porque desautoriza el patrón académico expresado en el eslogan "primero la teoría y luego la práctica”, a partir de actividades expositivas que apuntan a transmitir los conceptos para luego esperar que se actúe conforme a estos, haciendo de la práctica el paso siguiente de la secuencia. Más bien, 
Ryle anima a imaginar que la "teoría” y el "teorizar" no transportan cursos de acción; se incluyen en estos, son en sí mismos "cursos de acción". El docente enseña a "teorizar" en el sentido de generar capacidades y habilidades para actuar las reglas del juego discursivas propia de las "teorías", como parte del obrar inteligente de la comunidad académica.

Aplicar la secuencia teoría-acción ocurrió no pocas veces también en escenarios de desarrollo local a lo largo de los años 70 y 80 del siglo pasado, donde cambiar la situación equivalía a "concientizar" inclinando, casi siempre, la balanza del lado de la trasmisión ideológica a cargo de sujetos con acceso privilegiado a los conocimientos. A su vez, la capacitación se entendió como el mecanismo de trasvase de nuevos conceptos con la esperanza de que ellos generarían nuevas formas de actuar por la misma fuerza de las teorías y las nociones. Ambas prácticas son formas desafortunadas de entender la docencia universitaria y el desarrollo porque, según hemos visto, el "obrar inteligente" no procede de esa manera y nos invita a ejercer la docencia y el conocimiento local desde aquella actuación y ejercicio que conocemos como "hacer ciencia" o "actuar el desarrollo" entendidos como formas de "saber hacer", a partir de capacidades y habilidades aprendidas en escenarios públicos y cursos de acción colectiva observables y al alcance de todos.

\section{La producción de teorías cientificas y los paisajes mentales de Magoroh Maruyama}

Su propuesta — no exenta de críticas, como veremos despuésnos parece relevante porque considera la pluralidad de posibles ejercicios de las teorías científicas y enriquece el marco descriptivo sin referirse, como es usual en la antropología, al contraste de otros tipos de conocimiento con el conocimiento científico: es precisamente su 
mirada preponderantemente dirigida a identificar cómo las diferencias culturales afectan el ejercicio y la producción de las teorías de la ciencia, lo que convierte su aporte en un lugar relevante y obligado para nuestra indagación. La ciencia, así, y por extensión, las teorías, obedecen a patrones diferenciados que regulan la producción de marcos éticos, epistémicos y cosmológicos también diferenciados.

\section{Modelos de causalidad y paisajes mentales}

Mediante la relectura y reorganización de sus hallazgos etnográficos anteriores en torno a cómo se producen las teorías en las ciencias físicas, biológicas y sociales, principalmente, Maruyama forja la certeza de la existencia de diversos patrones de cognición, percepción, conceptualización, diseño, planificación y toma de decisiones en los que operan epistemologías de la investigación diferentes relacionadas, a su vez, con características de personalidad y orígenes culturales diversos. Esa base etnográfica

evidenció que cada cultura contenía todos los tipos epistemológicos individuales encontrados en otros, aunque la distribución porcentual de los tipos varió. De igual forma, se hizo evidente que la misma teoría podría ser defendida por motivos epistemológicos diferentes y que muchas teorías aparentemente diferentes u opuestas podrían derivar de un solo tipo epistemológico y, por consiguiente, tener las mismas fallas... (1980, p. 589)

El concepto de "paisaje mental" es la noción clave que le permite reorganizar el material para caracterizar la producción de distintos tipos de teorías científicas como producidos y recirculados bajo las lógicas particulares de cada marco. Así, las teorías científicas o el perfil de tratamiento teórico de los problemas científicos se pueden clasificar según los siguientes cuatro modelos causales que conforman tipos o subtipos, niveles de evolución sucesiva que admiten 


\section{0}

combinaciones e hibridaciones ${ }^{45}$. Estos modelos causales, o "metatipos causales en teorías de la ciencia", son subyacentes en la constitución de los paisajes mentales correspondientes.

1.- Modelos de causalidad no recíproca, en los que las relaciones causales pueden ser probabilísticas o deterministas, y en donde no existen bucles causales; las relaciones causales obedecen a la ley transitiva.

2.- Modelos de eventos independientes, en los que los estados más probables del universo o de un sistema aislado son estados de distribución aleatoria de eventos independientes, cada uno con su propia probabilidad; existen relaciones no independientes y estructuras no aleatorias, pero son menos probables tendiendo a estar en estados más aleatorios, desestructurados y homogéneos.

3.- Modelos homeostáticos ${ }^{46}$ de bucle causal, en los que las relaciones causales pueden ser probabilísticas o deterministas y pueden formar bucles; las estructuras y los patrones de heterogeneidad se mantienen por los bucles causales homeostáticos.

4.- Los modelos de bucle causal morfogenético, en los que los bucles causales probabilísticos o deterministas pueden aumentar la heterogeneidad, generar patrones de relaciones mutuamente beneficiosas entre los elementos heterogéneos y elevar el nivel de sofisticación del sistema. (Maruyama, 1980, pp. 589-590)

Cada uno de estos modelos y sus variantes tiene un papel específico en momentos históricos diferentes. Así, los modelos del tipo 4 son los más nuevos en las ciencias "y complementan o reemplazan

45 La metodología que subyace en la identificación de estos modelos parten de investigaciones individuales y redes de investigación a cuyos resultados se aplicaron modelos matemáticos y simulación por computadora.

46 El término homeostático (homeostasis) proviene de las ciencias biológicas y define el conjunto de fenómenos basados en mecanismos de autorregulación en función de mantener el equilibrio o procesar situaciones de reequilibrio. La noción de autorregulación fue revisada anteriormente en la epistemología de Edgar Morin. 
cada vez más a los modelos homeostáticos que se desarrollaron durante la Segunda Guerra Mundial con el uso de sistemas de retroalimentación de corrección de errores en dispositivos, tales como la artillería antiaérea conectada con el radar por computadora” (p. 590). Entre otros casos, Maruyama ejemplifica cómo funcionan las explicaciones teóricas en torno al caso de la evolución civilizatoria y describe cómo proveen horizontes explicativos distintos, según los modelos de causalidad al que se adscriben, tal como se observa en la Tabla 10.

Tabla 10

Las teorías sobre la evolución civilizatoria según los metatipos causales

\begin{tabular}{|c|c|c|c|}
\hline $\begin{array}{c}\text { Modelos } \\
\text { de causalidad } \\
\text { no recíproca }(1)\end{array}$ & $\begin{array}{c}\text { Modelos } \\
\text { de eventos } \\
\text { independientes (2) }\end{array}$ & $\begin{array}{l}\text { Modelos homeostáti- } \\
\text { cos de bucle causal ( } 3 \text { ) }\end{array}$ & $\begin{array}{c}\text { Modelos } \\
\text { de bucle causal } \\
\text { morfogenético (4) }\end{array}$ \\
\hline $\begin{array}{l}\text { Supervivencia } \\
\text { del más fuerte } \\
\text { (competitividad) }\end{array}$ & $\begin{array}{l}\text { Capacidad de } \\
\text { sobrevivir las } \\
\text { rupturas }\end{array}$ & $\begin{array}{l}\text { Interacción } \\
\text { entre individuos } \\
\text { enmarcada en } \\
\text { una configuración } \\
\text { estable. }\end{array}$ & $\begin{array}{l}\text { Relaciones mutua- } \\
\text { mente beneficiosas } \\
\text { entre miembros } \\
\text { heterogéneos. }\end{array}$ \\
\hline $\begin{array}{l}\text { Dirección } \\
\text { homogénea de } \\
\text { la civilización. } \\
\text { La diferencia } \\
\text { es entre más } \\
\text { y menos } \\
\text { avanzados. }\end{array}$ & $\begin{array}{l}\text { Heterogeneidad } \\
\text { evolutiva. } \\
\text { Dirección im- } \\
\text { predecible de los } \\
\text { cambios. }\end{array}$ & $\begin{array}{l}\text { Evolución resulta- } \\
\text { do de interacción } \\
\text { entre elementos } \\
\text { heterogéneos. }\end{array}$ & $\begin{array}{l}\text { Interacciones que ge- } \\
\text { neran heterogeneidad } \\
\text { beneficiosa continua. }\end{array}$ \\
\hline $\begin{array}{l}\text { Sociedad } \\
\text { compuesta de } \\
\text { líderes } \\
\text { y seguidores. }\end{array}$ & $\begin{array}{l}\text { Sociedad que } \\
\text { irrumpe y } \\
\text { sustituye la } \\
\text { anterior. } \\
\text { Liderazgo de } \\
\text { ruptura; de } \\
\text { instauración. } \\
\text { La evolución al } \\
\text { no ser predecible } \\
\text { es peligrosa. }\end{array}$ & $\begin{array}{l}\text { Sociedad: } \\
\text { configuración } \\
\text { estable y satis- } \\
\text { factoria de las } \\
\text { interacciones. } \\
\text { Cultura: forma } \\
\text { de ajuste a las } \\
\text { condiciones locales. }\end{array}$ & $\begin{array}{l}\text { Cambios en varias } \\
\text { direcciones: evolución } \\
\text { multidireccional en la } \\
\text { misma condición local. } \\
\text { Relaciones de posición } \\
\text { con base en caracterís- } \\
\text { ticas no comunes antes } \\
\text { que por condiciones } \\
\text { óptimas. }\end{array}$ \\
\hline
\end{tabular}


202

\begin{tabular}{|c|c|c|c|}
\hline $\begin{array}{c}\text { Modelos } \\
\text { de causalidad } \\
\text { no recíproca }(1)\end{array}$ & $\begin{array}{c}\text { Modelos } \\
\text { de eventos } \\
\text { independientes (2) }\end{array}$ & $\begin{array}{l}\text { Modelos homeostáti- } \\
\text { cos de bucle causal ( } 3 \text { ) }\end{array}$ & $\begin{array}{c}\text { Modelos } \\
\text { de bucle causal } \\
\text { morfogenético }(4)\end{array}$ \\
\hline $\begin{array}{l}\text { Cambios } \\
\text { rápidos y } \\
\text { acelerados. } \\
\text { El cambio defi- } \\
\text { nido por la velo- } \\
\text { cidad (invención } \\
\text { y factores exter- } \\
\text { nos) pero no por } \\
\text { la dirección. }\end{array}$ & $\begin{array}{l}\text { Cambios } \\
\text { aleatorios. } \\
\text { Cambios por } \\
\text { sustitución y } \\
\text { saltos: lo que } \\
\text { viene reemplaza } \\
\text { lo anterior. }\end{array}$ & $\begin{array}{l}\text { Cuando la } \\
\text { configuración } \\
\text { cambia, sur- } \\
\text { ge una nueva } \\
\text { configuración. } \\
\text { El cambio se debe } \\
\text { a influencias } \\
\text { externas o internas. }\end{array}$ & $\begin{array}{l}\text { Cambios continuos, } \\
\text { graduales o rápidos. } \\
\text { Puede haber saltos o } \\
\text { superación de umbral. } \\
\text { Desarrollo de nuevas } \\
\text { formas: paso de la } \\
\text { energía del petróleo a } \\
\text { la eólica, por ejemplo. }\end{array}$ \\
\hline
\end{tabular}

Elaboración de los autores a partir de Maruyama (1980, pp. 590-591). Los textos en cursiva son resaltados de los autores con fines didácticos.

Sobre la base de estos tipos causales construye tipos epistemológicos de rango mucho más amplio que denomina "paisajes mentales", vale decir, "una estructura de razonamiento, cognición, percepción, conceptualización, diseño, planificación y toma de decisiones que puede variar entre un individuo, profesión, cultura o grupo social a otro". Los paisajes mentales configuran la tipología y características de las teorías científicas producidas. En la Tabla 11 Maruyama describe los tipos de paisaje mental con sus respectivos componentes y relaciones entre componentes y procesos.

Tabla 11

Tipos de paisaje mental y sus características ${ }^{47}$

\begin{tabular}{|l|l|l|l|}
\hline $\begin{array}{c}\text { Tipo de paisaje mental } \\
\text { (por sus siglas en inglés) }\end{array}$ & Componentes & $\begin{array}{c}\text { Relación entre los } \\
\text { componentes }\end{array}$ & \multicolumn{1}{|c|}{ Proceso } \\
\hline H (Jerárquico) & Homogéneo & Jerárquico & Clasificación \\
\hline I (Independiente) & Heterogéneo & Individual & Aleatorio \\
\hline S (Homeostático) & Heterogéneo & Interactivo & Homeostático \\
\hline G (Morfogenético) & Heterogéneo & Interactivo & Morfogenético \\
\hline
\end{tabular}

Tomado de Maruyama (1980, p. 591).

47 Nuestra traducción. Las palabras en cursiva son resaltados de los autores, pues las siglas en inglés no coinciden con las del castellano. 
Maruyama describe los rasgos característicos de cada uno de los paisajes mentales (a los que también denomina fases mentales), según las siguientes variables: filosofía general, ética, política ambiental, toma de decisiones, valores, estética, arquitectura, actividad social, religión, causalidad, lógica, conocimiento, percepción y cosmología. Para fines de nuestra exposición, y por razones didácticas, seleccionamos las siguientes variables: filosofía general, ética, conocimiento y cosmología, cuya descripción nos permitimos transcribir en el Cuadro 2 (1980, pp. 592-594).

\section{CUADRO 2: ASPECTOS DESCRIPTIVOS DE LOS PAISAJES MENTALES: FILOSOFÍA GENERAL, ÉTICA, CONOCIMIENTO Y COSMOLOGÍA ${ }^{48}$}

\section{Filosofía general}

H: Subordinación de la parte al todo. Existe una mejor manera para todos los individuos. Los principios universales se aplican a todos. La sociedad consta de categorías, supercategorías y subcategorías, estructuras, superestructuras e infraestructuras.

I: La sociedad es simplemente un agregado de individuos que piensan y actúan de manera independiente. Solo los individuos son reales.

S: La sociedad consiste en individuos heterogéneos que interactúan para el beneficio mutuo. Las interacciones mantienen un patrón armonioso de heterogeneidad o en ciclos. Las interacciones no son jerárquicas.

G: Los individuos diferentes interactúan para beneficio mutuo. Las interacciones no jerárquicas generan nueva diversidad, nuevos patrones y nueva armonía, y buscan nuevas relaciones para beneficio mutuo.

Nuestra traducción. 


\section{La ética}

$\mathrm{H}$ : El más fuerte domina a los más débiles. La ganancia de un individuo es la pérdida del otro (suma cero). Las decisiones deben tomarse por número de votos (dominación por cantidad) o por consenso (suposición de la existencia de una mejor solución para todos). Lo que beneficia a un mayor número de personas es mejor que lo que beneficia a un menor número de personas. Lo que es bueno para la mayoría también es bueno para las minorías. Las minorías pueden ser sacrificadas o ignoradas. Las diferencias generan conflictos, mientras que la misma fomenta la paz; por lo tanto, todas las personas deben ser iguales o similares, y las personas que son diferentes deben ser descartadas. Los débiles, los enfermos, los pobres deben morir; la raza superior o la clase social debe sobrevivir y gobernar. Aquellos que no cumplen con el "estándar" son anormales o desviados, y deben ser castigados o eliminados.

I: Todo el mundo debe ser autosuficiente. Ser pobre es culpa de la persona, y cada quien debe hacer lo que le corresponde. Las obligaciones sociales deben reducirse o eliminarse, y debe hacerse énfasis en la privacidad y el aislamiento. Las interacciones son dañinas (suma negativa). Se debe velar por el interés propio (las tabulaciones estadísticas se encargarán del resto y legitimarán a la persona como democrático).

S: Los individuos diferentes se ayudan los unos a los otros, pues las diferencias son deseables, necesarias y beneficiosas. La igualdad genera competencia y conflicto, mientras que la diversidad permite el beneficio mutuo. Todas las partes pueden beneficiarse de la interacción (suma positiva). Existe armonía entre diversos individuos, y esta armonía debe mantenerse.

G: Los individuos que son diferentes deben ayudarse los unos a los otros. Las diferencias son deseables, necesarias y beneficiosas. La igualdad crea competencia y conflicto, mientras que la diversidad permite el beneficio mutuo. Todas las partes pueden beneficiarse de la interacción (suma positiva). Debe generarse una nueva diversidad, y se deben 
buscar relaciones mutuamente beneficiosas con nuevos elementos para generar nuevos patrones de armonía.

$[\ldots]$

\section{El conocimiento}

H: Solo existe una verdad. Si las personas están suficientemente educadas o informadas, entonces estarán de acuerdo. Hay una mejor manera para todas las personas. El conocimiento de las reglas generales es superior al conocimiento de los detalles. Los hechos indican los principios universales. La realidad objetiva existe independientemente del perceptor. Las diferencias en la percepción se deben al error y a la falta de objetividad. La medición cuantitativa resulta básica para el conocimiento. Lo que no se puede medir resulta irreal o inválido.

I: Cada quien debe buscar las partes específicas de la información que son necesarias para la actividad; es inútil buscar principios universales o aprender más allá de nuestro interés.

S: La visión binocular nos permite ver tridimensionalmente, no porque los dos ojos vean lados diferentes, sino porque la diferencia entre las dos imágenes permite al cerebro calcular la dimensión que es invisible para ambos ojos. Del mismo modo, las diferencias subjetivas entre varias personas permiten calcular las dimensiones que son invisibles para todos. Esto se conoce como "visión poliocular"... o "análisis subjetivo cruzado". Los objetivistas consideran las diferencias como errores y descartan como irreales las partes de un objeto en las que los ojos no están de acuerdo. Este procedimiento elimina todas las partes del objeto, excepto las partes planas perpendiculares. El resultado es mucho menos que una visión monocular y es una distorsión grave de la realidad. "Apegarse a las partes en las que estamos de acuerdo e ignorar aquellas en las que no estamos de acuerdo" es un principio objetivista ampliamente practicado que distorsiona la realidad de una manera que va mucho más allá que el principio poliocular y una simple visión monocular. 
G: Igual que $S$.

[...]

\section{La cosmología}

$\mathrm{H}$ : El universo es homogéneo en el tiempo y el espacio. Los procesos son repetibles con la misma probabilidad en diferentes momentos y en diferentes lugares si las condiciones son las mismas (probabilísticas o deterministas).

I: El estado más probable es la distribución aleatoria de los eventos independientes, cada uno con su propia probabilidad. Las estructuras son no aleatorias e improbables y, por lo tanto, tienden a decaer. El universo se descompone.

S: Hay armonía entre los elementos heterogéneos. La armonía se mantiene porque las interacciones mutuas corrigen la desarmonía. La decadencia se puede contrarrestar. El universo se mantiene a sí mismo.

G: Las interacciones generan más diversidad, nuevas combinaciones de relaciones mutuamente beneficiosas, nuevos patrones y un creciente nivel de sofisticación de los sistemas biológicos, sociales y algunos sistemas físicos. El universo crece.

Adaptado de Maruyama, 1980, pp. 592-594. Traducción del autor.

\section{Comentarios finales}

La propuesta de Maruyama ha ganado difusión y reconocimiento, pero también ha recibido críticas, muchas de ellas muy radicales, que el mismo autor consigna en los comentarios de lectura recogidos al final de su artículo (1980, pp. 600-607). De esos comentarios destacamos las siguientes objeciones: 
- Sobresimplifica la realidad y corre el riesgo de construir estereotipos sobre la producción teórica y las epistemologías.

- Se trata de una propuesta en la que el modelo es más importante que la lógica, al punto de forzar que ciertas realidades que no encajan sean incluidas a la fuerza en el modelo.

- La producción teórica es parte de la discursividad pública y de los intercambios relacionales. La noción de paisaje mental, en cambio, predetermina la producción teórica sobre estos intercambios e interacciones concretas y situadas.

- Los paisajes mentales están atravesados por una carga de valoración moral, según la cual nadie quisiera pertenecer al paisaje $\mathrm{H}$ o I y todos quisieran formar parte del paisaje G.

Maruyama ejemplifica históricamente momentos, espacios y producciones de pensamiento que se atienen a uno u otro paisaje mental, mostrando, además, las posibles hibridaciones y entrecruces. Pero también aplica la noción de paisajes mentales a la caracterización de formas de pensar de religiones y culturas de largo recorrido, dando la impresión de que, en realidad, los tipos de paisajes mentales admiten un rango de aplicación que van más allá de las teorías tal como se actúan en la ciencia, es decir, la noción de paisaje mental parece, en realidad, aplicable a todo tipo de pensamiento.

Según nuestro punto de vista, Maruyama proporciona un marco descriptivo valioso para identificar y entender el funcionamiento de esquemas diferenciados de pensamiento que modulan la producción teórica. Muestra, además, que la ciencia es una realidad heterogénea constituida por prácticas sociales diversificadas que producen teoría desde horizontes constituidos por implicaciones lógicas, sociológicas, epistémicas, cosmológicas, políticas, éticas y ambientales también diversas. La razón de esta diversidad no estriba tanto en la especificidad de los objetos de conocimiento que carac- 


\section{8}

terizan las ciencias, sino que obedecen a las culturas y pertenencias que soportan prácticas científicas distintas.

$\mathrm{Su}$ alcance incluye preguntas sobre los aspectos relacionados con el rol de la herencia y los procesos posnatales y psicológicos, por medio de los cuales los paisajes mentales se cristalizan en los individuos hasta constituir marcos de pensamiento difíciles de ser removidos o transformados, pero sin proporcionar avances sustantivos al respecto. Respecto a los ámbitos de aplicación, Maruyama refiere el potencial pedagógico de su propuesta basada en los paisajes mentales para la educación temprana de los niños, aunque solo menciona de paso tal posibilidad sin desarrollarla; en efecto, la identificación de diversos paisajes mentales haría posible replicar y cultivar sus respectivas formas de pensar y de concebir la realidad y, así, enriquecer el desarrollo de múltiples capacidades y enfoques.

Su noción de paisaje mental fue tomada en cuenta por el mismo Morín (ver supra) como posible alternativa a la noción de paradigma en la búsqueda de encontrar esquemas y modelos más amplios para explicar la articulación entre las teorías, aunque se definió por este último, como vimos, en razón de su flexibilidad e indeterminación. Asimismo, en su artículo, encontramos un cierto parentesco y aire de familiaridad con la producción impulsada por la etnografía de la ciencia en torno a las actividades y procedimientos de los científicos, especialmente la de Latour y Woolgar (1979) basada en la etnografía del laboratorio; y la posterior de Knorr-Cetina (1999) sobre las culturas epistémicas en la ciencia y cómo ellas caracterizan la producción de conocimiento. Es necesario aclarar que el artículo de Maruyama no tiene los alcances de Latour y de Cetina, quienes evidencian que la ciencia es una palestra social constituida por fuerzas sociales en pugna que la tensionan en múltiples sentidos, como describe Martínez (2002) en su estudio sobre ciencia y feminismo. 
En realidad, los paisajes mentales aparecen como entidades idealizadas que cobran vida independiente al margen de los colectivos científicos concretos, de sus atributos de clase, género e intereses y de las prácticas que les dan vida y soporte real. Por ello, dan la impresión de que los paisajes mentales son esquemas previos a los que los científicos parecen adscribirse de manera pasiva, cual si se tratara de guiones preestablecidos con la capacidad de condicionar per se la producción teórica.

No obstante, creemos sin estar del todo seguros - y a partir de la trayectoria de asesor corporativo que marcó su biografía profesional ${ }^{49}$ - que su investigación coincidió, a la vez que se inscribió en la emergencia de marcos analíticos marcados por categorías como capital intelectual, inteligencia organizacional y gestión del conocimiento como claves del desarrollo empresarial y de la teoría organizacional, a fin de garantizar una producción flexible y atenta a los cambios del mercado y la sensibilidad de los usuarios, temas que coparon la escena desde fines de los años 80 hasta el presente. La adaptación a tales desafíos requeriría de la capacidad para identificar en las organizaciones paisajes mentales y culturas cognitivas, a fin de potenciar aquellas más abiertas y dispuestas a generar innovaciones en un marco de incertidumbre y de cambios constantes en las exigencias de los consumidores ${ }^{50}$.

49 Gracias a un perfil multifacético que combina las matemáticas, la antropología, la neurociencia y la psicología, Maruyama se desempeñó como consultor en alcaldías, compañías, corporaciones internacionales e instituciones públicas como la NASA, el Departamento de Comercio de Estados Unidos, Volvo, Michelin y la Federal Motors de Indonesia, entre otras.

50 Esa tendencia a caracterizar las modalidades y flujos del conocimiento en las empresas y corporaciones se refleja en aportes como los de Annie Brooking (1997) sobre el capital intelectual de las empresas; Gerrit Broekstra (1998) sobre la discursividad en la organización; e Ikujiro Nonaka e Hirotaka Takeuchi (1999) sobre las organizaciones creadoras de conocimiento, a partir de la dinámica innovadora de las compañías japonesas. 
Fue entonces que las instituciones públicas y la misma universidad comenzaron a mirarse y evaluarse a sí mismas en el espejo de las grandes corporaciones. Los temas en torno a cómo se producen, recirculan y se asumen las innovaciones y las instancias generadoras de conocimientos pertinentes y prácticas flexibles para enfrentar los retos de escenarios cambiantes constituyeron preocupaciones emergentes desde los 80 hacia el presente, también en las instituciones de educación superior. Aunque, valga decirlo, la comprensión de los factores que inciden en la producción diferenciada de teorías, según las diversas culturas académicas presentes en las instituciones de educación superior, constituye una línea de investigación con vida propia cultivada independientemente por la sociología de la ciencia y el conocimiento, al margen de la ola corporativa empresarial.

\section{Kieran Egan y la teoría como instrumento de conocimiento de la forma de comprensión filosófica}

La propuesta de Egan se inscribe en el diseño de una alternativa para un mejor manejo de la educación - y en el marco de la educación formal - en general, a la vez que fundamenta e impulsa un proyecto pedagógico que parte del siguiente principio: la humanidad ha creado formas de comprensión diferenciadas dotadas de instrumentos cognitivos específicos que se constituyen en mediaciones mediadoras de carácter simbólico basadas en el lenguaje y la capacidad mimética corporal. La educación debe garantizar el acceso y cultivo a todas las formas de comprensión y sus respectivos instrumentos intelectuales que hacen posible producir y compartir conocimientos. Así, los individuos replican en su ciclo de vida las transiciones y particularidades de las formas de comprensión producidas por la historia de la cultura.

La comprensión es una categoría polisémica que ha sido actuada de diversa manera a lo largo del desarrollo cultural occidental, 
generando tipos de comprensión que componen las capas que constituyen la compleja mente moderna. Esas formas son las siguientes: la comprensión mítica, la comprensión romántica, la comprensión filosófica, la comprensión irónica y la comprensión somática. Los instrumentos cognitivos de cada una constituyen la psique de los niños de afuera hacia adentro, es decir, modelan desde los intercambios sociales las capacidades de los individuos. La teoría es, entre otros, el instrumento intelectual y simbólico de un tipo de lenguaje propio de una forma de comprensión específica e históricamente situada: la comprensión filosófica.

La sistematización que ofrecemos a continuación consta de tres partes: la primera dará cuenta de los fundamentos pedagógicos y filosóficos de su proyecto; la segunda describirá las formas de comprensión y sus respectivos instrumentos cognitivos, desplegando con mayor detalle la forma de pensamiento filosófico y su correspondiente instrumento de conocimiento: la teoría, que constituye el centro de nuestro interés. La tercera y última parte ofrece algunas conclusiones e implicaciones pedagógicas en torno al cultivo del pensamiento teórico.

\section{La historia de la cultura y las bases pedagógicas para el cultivo de la imaginación}

Egan inicia dando cuenta del conflicto imposible de resolver entre tres herencias mutuamente incompatibles que se disputan el primado a la hora de articular el currículo sin resolver sus desafíos (2000, pp. 26 y ss.): la herencia durkheimiana, la herencia platónica y la herencia roussoniana, cuya brevísima caracterización es como sigue:

a. La herencia durkheimiana, que busca la socialización, esto es, la incorporación de los niños en los valores de su comunidad (acento ético) para salvaguardar la homogeneidad social. Hoy, 
la socialización se traduce en la necesidad de que los niños y jóvenes entiendan la sociedad en que viven y vislumbren su rol y lugar en ella; pero también se hace patente en las fuerzas que buscan homogeneizar el sujeto para garantizar su adaptabilidad, adecuación y conformidad con las expectativas sociales.

b. La herencia platónica (La República), que enfatiza los contenidos y el cultivo de la mente (la mente se convierte en aquello que aprende), por medio del manejo de contenidos ilustrados y formas de discusión sofisticadas (la academia) para acceder a una visión privilegiada de la realidad y discernir en medio de ella. Hoy se traduce en garantizar el acceso a la información y en el reconocimiento de la autoridad del experto para conectar el sujeto con las grandes discusiones y conversaciones que trascienden su ámbito inmediato.

c. La herencia roussoniana, que enfatiza los métodos (los métodos no son medios sino objetivos), a fin de adecuar el aprendizaje al ritmo, modalidades e intereses de los niños como ejes de la educación centrada en el individuo y sus intereses. Hoy se traduce en modular los contenidos de acuerdo a la situación individual y las condiciones evolutivas del sujeto y en proporcionar un marco de experiencias que motiven el aprendizaje. Los contenidos obedecen a los intereses temáticos que el sujeto configura a medida que indaga e investiga (aprendizaje por descubrimiento). No es importante lo que el estudiante sabe, sino lo que es capaz de hacer con lo que sabe. El enseñante no es autoridad sino un facilitador y motivador, un forjador de los entornos de aprendizaje.

Egan postula que es imposible impulsar las tres herencias a la vez; el intento de compatibilizarlas a toda costa es, en realidad, la causa de numerosos e irresolubles problemas en la educación. Por ejemplo, acceder a una visión privilegiada para la interpretación de 
situaciones y problemas (Platón) que coloca al individuo sobre los que carecen de dichas herramientas es incompatible con el modelo de educación que busca la adecuación e incorporación del individuo a la sociedad (Durkheim); de la misma manera que la propuesta de Rousseau (y la de Dewey) es incompatible con la de Platón porque en este último el sujeto debe acceder a conocimientos sofisticados independientemente de sus intereses, de tal manera que el desarrollo del conocimiento se impone sobre las condiciones psicológicas. Si en Rousseau y Dewey el desarrollo impulsa el conocimiento, en Platón el conocimiento impulsa el desarrollo. Finalmente, la herencia roussoniana es incompatible con la durkheimiana debido a que apunta a mantener a los niños (la niñez es en él una categoría compleja e idealizada) alejados de los valores sociales que están contaminados e interrumpen el libre desenvolvimiento de capacidades y de la individualidad. Por ello, la educación debe proteger cuanto sea posible al niño, retrasando cuanto sea posible su socialización para garantizar su libertad y creatividad.

Hoy, de hecho, ninguna práctica pedagógica se limita a ninguna de las tres herencias, y lo usual es intentar equilibrios y compromisos que, sin embargo, no logran subsanar las incompatibilidades de fondo. En este punto, Egan propone dejar a un lado estas herencias poderosas que se han fortalecido a lo largo del tiempo y plantea, más bien, asumir como categoría principal los "tipos de comprensión”. Solo así será posible integrar sin contradicciones los elementos clave de cada herencia porque, en efecto, cuando los niños y adolescentes acceden a esos tipos de comprensión y a sus respectivos instrumentos intelectuales en función de entender el mundo acaban socializándose. Así se trascienden los contenidos, se asegura la socialización y se proporcionan formas (métodos, itinerarios, no contenidos) de comprensión. La categoría "tipos de comprensión”, entendida esta última como un término polisémico, reemplaza la de 
"conocimiento", casi siempre impuesta en primer lugar, dando lugar a unos currículos más ricos, enlazados con muy diversas formas de comprensión, que suponen a su vez pistas de socialización, porque esos tipos y formas están enlazadas con desarrollos específicos e históricos de la cultura (2000, pp. 44-48).

Sobre la base de esta nueva categoría, Egan construye el andamiaje para una nueva teoría pedagógica basada en dos referentes conceptuales (pp. 48-56): el concepto evolucionista de recapitulación del inglés Herbert Spencer (1820-1903); y la perspectiva cultural del aprendizaje del soviético Lev Vygotsky (1896-1934). Ambos autores comparten el mismo sustrato basado en la noción fundamental de que "el niño sigue el camino de la cultura", aunque desde esquemas de pensamiento muy distintos. La teoría evolucionista de la recapitulación, cuyas implicaciones pedagógicas apoyó, por un momento, también John Dewey (1859-1952), supone la posibilidad de organizar y ordenar lógicamente el currículo replicando en los niños, y según su evolución psicológica, los contenidos y conocimientos de cada una de las fases del proceso de desarrollo (evolución) de la cultura, de tal manera que

Si el género humano ha dominado sus diversos tipos de conocimiento siguiendo un orden, en cada niño aparecerá una aptitud para adquirir estos tipos de conocimiento en el mismo orden. La educación debería ser una repetición en pequeño de la civilización. (Spencer, 1861, p. 76, citado en Egan, 2000, p. 49)

La idea de recapitulación fue desechada primero en razón de la urgencia de la sociedad industrial que demandaba acortar el camino del conocimiento y colocar a los niños en las necesidades del presente. Dewey llegó a desecharla por considerar que llevaría a una imitación innecesaria e irrelevante del pasado (Egan, 2000, p. 51) sobre el principio de que el progreso — punto de llegada - impone y sobrepone su saber sin necesidad de volver a andar el camino anterior. 
El segundo puntal del andamiaje teórico de Egan es el aporte de Lev Vygotsky ([1962] 1995), según la cual el aprendizaje es un proceso social que requiere de mediaciones simbólicas mediadoras, como los instrumentos intelectuales concebidos como realidades simbólicas del lenguaje de complejidad creciente como, por ejemplo, el lenguaje oral, la narración mítica, la teoría, la ironía... concebidas como funciones sociales externas simbólicas en el sentido de procesos interpsíquicos que operan desde la sociedad y la cultura hacia los individuos. El aporte de Vygotsky es solidario con la importancia de los tipos de comprensión transportados por instrumentos intelectuales que se constituyen de afuera hacia adentro en funciones psicológicas del individuo respecto a los contenidos.

Según Vygotsky, comprendemos el mundo mediante el empleo de unos instrumentos intelectuales mediadores que, a su vez, influyen profundamente en el tipo de comprensión que obtenemos. Por lo tanto, nuestro desarrollo intelectual no se puede entender adecuadamente en función del conocimiento que acumulamos o en función de unas etapas psicológicas como las de Piaget, sino que exige una comprensión del papel desempeñado por los instrumentos intelectuales disponibles en la sociedad en la que crece una persona. (Egan, 2000, p. 51)

Gracias a ello es posible entender la educación como el proceso de "interiorización de maneras históricamente determinadas y culturalmente organizadas de actuar sobre la información, la naturaleza social de las personas acaba siendo también su naturaleza psicológica" (Luria, 1979, p. 45, citado en Egan, 2000, p. 52). Vygotsky ofrece la oportunidad de reinterpretar y reposicionar la noción de recapitulación no en el sentido de recuperar contenidos y conocimientos de cada una de las etapas de la historia de la cultura, sino desde el desarrollo del lenguaje y sus correspondientes formas o tipos de comprensión regladas por instrumentos intelectuales. 
Ello deriva en un giro no menor que implica pasar de lo que comprendían nuestros antepasados a entender cómo comprendían nuestros antepasados: “... la mejor manera de concebir la educación es considerar que los individuos adquieren cada uno de estos tipos de comprensión en la mayor medida posible y siguiendo el mismo orden en que se desarrollaron históricamente" (Egan, 2000, p. 17). Esta postura que reinterpreta la recapitulación cultural distancia la propuesta de Egan de la Piaget, según la cual la comprensión y el conocimiento, en cambio, siguen la dirección opuesta — de adentro hacia fuera - que va del desarrollo del niño a los conocimientos. De esa manera, Egan afirma lo siguiente:

Mi propuesta es que la mejor manera de comprender la educación es verla como un proceso en el que el individuo recapitula los tipos de comprensión desarrollados durante la historia de la cultura. Este punto de vista implica que si estudiamos cómo se produjo históricamente esta transición podremos aprender algo que tenga un valor práctico para la educación; además, también podríamos comprender por qué esta transición es tan problemática para muchos niños y por qué hay muchos niños más que solo la realizan de una manera superficial. Si encontramos que en nuestra historia cultural la transición entre el conocimiento "preescolástico" y "escolástico" [...] ha sido problemática, las dificultades de los estudiantes no nos sorprenderán tanto; y si analizamos cómo se ha producido este desarrollo histórico podremos crear un currículo y unos métodos de enseñanza que apoyen este desarrollo en los estudiantes de hoy mejor que las formas actuales de enseñanza. (2000, p. 110)

\section{Formas de comprensión e instrumentos intelectuales. \\ La teoría: instrumento de conocimiento de la comprensión filosófica}

El concepto nuclear de tipos de comprensión es un concepto polisémico, vale decir, su significado varía y significa cosas dis- 
tintas según el contexto histórico y cultural concreto en el que se sitúa y el instrumento intelectual que despliega. De esa manera, comprender por medio del relato mítico no es lo mismo que comprender por medio de descripciones y enumeraciones de los viajeros o mediante conceptos y supuestos teóricos. Egan plantea que la historia de Occidente ha desarrollado cinco formas de comprensión a lo largo de su recorrido cultural: la comprensión mítica, la comprensión romántica, la comprensión filosófica, la comprensión irónica y la comprensión somática. De cada una de ellas identifica la etapa correspondiente de su desarrollo histórico cultural, establece su correspondencia con la etapa evolutiva del individuo, a la vez que describe el tipo de desarrollo del lenguaje que le corresponde, así como sus instrumentos intelectuales, formas discursivas y la redefinición de la realidad que cada una proyecta y genera.

La relación entre las formas de comprensión que se suceden unas a otras es acumulativa; es decir, la subsiguiente se apoya a la vez que recupera los instrumentos intelectuales de la anterior y sus formas discursivas, constituyéndose en su condición de posibilidad, pero con riesgos de pérdidas y rupturas. En la mente de los usuarios, sin embargo, no constituyen apartados inconexos y funcionan como un todo; $y$, antes que mentalidades independientes, constituyen perspectivas diferentes de la realidad. La Tabla 12 caracteriza los cinco tipos de comprensión identificados por Egan, sus instrumentos intelectuales y formas discursivas, así como la etapa histórico-cultural y la fase evolutiva del individuo que corresponde a cada una de ellas. 
Tabla 12

Tipos de comprensión e instrumentos intelectuales según Egan

\begin{tabular}{|c|c|c|}
\hline $\begin{array}{c}\text { Tipo de } \\
\text { comprensión }\end{array}$ & $\begin{array}{l}\text { Instrumentos intelectuales; } \\
\text { aspectos del lenguaje y formas } \\
\text { discursivas }\end{array}$ & $\begin{array}{c}\text { Etapa histórico cultural } \\
\text { y fase evolutiva }\end{array}$ \\
\hline Mítica & $\begin{array}{l}\text { Lenguaje oral } \\
\text { Narración y relato. Mito: expre- } \\
\text { sión de la mente poética. Metáfo- } \\
\text { ra y dualismo. } \\
\text { Comprensión totalizante }\end{array}$ & $\begin{array}{l}\text { Culturas orales no alfabetizadas. } \\
\text { Niños de } 8-9 \text { años. Despliegue del } \\
\text { aprendizaje deliberado. }\end{array}$ \\
\hline Romántica & $\begin{array}{l}\text { Lenguaje basado en la escritura } \\
\text { alfabética } \\
\text { Descripción, enumeración, clasi- } \\
\text { ficación, definición, heterogenei- } \\
\text { dad del espacio temporal. }\end{array}$ & $\begin{array}{l}\text { Sintaxis reflexiva de la Grecia } \\
\text { clásica. } \\
\text { Ejemplo más temprano: Historia, } \\
\text { de Heródoto (siglo V a C.). } \\
\text { Adolescentes de } 10 \text { a } 15 \text { años. }\end{array}$ \\
\hline Filosófica & $\begin{array}{l}\text { Lenguaje teórico. Lenguaje de la } \\
\text { ciencia } \\
\text { Recopilación de información } \\
\text { articulada con suposiciones e } \\
\text { hipótesis. } \\
\text { Integra el detalle y la generalidad. }\end{array}$ & $\begin{array}{l}\text { Nace en la Grecia clásica: Platón y } \\
\text { Aristóteles. } \\
\text { Ejemplo: Historia de Tucídides } \\
\text { (Grecia clásica). Busca: una teoría } \\
\text { de la historia. } \\
\text { Impulsada por la imprenta, la } \\
\text { ciencia e instituciones académicas. } \\
\text { Fase evolutiva: } 15 \text { años en adelante. }\end{array}$ \\
\hline Irónica & $\begin{array}{l}\text { Ironía: duda epistémica radical. } \\
\text { Conciencia de los límites del } \\
\text { lenguaje. } \\
\text { Densificación-complejidad del } \\
\text { vocabulario. } \\
\text { Tensiona teoría y narrativa; } \\
\text { teoría-imaginación artística. } \\
\text { Separación lo que se dice-lo que } \\
\text { se quiere decir. }\end{array}$ & $\begin{array}{l}\text { También nace en Grecia: Heráclito } \\
\text { y Sócrates. } \\
\text { Se expresa en el modernismo y el } \\
\text { posmodernismo. Kierkegaard y } \\
\text { Nietzsche. } \\
\text { Edad adulta }\end{array}$ \\
\hline Somática & $\begin{array}{l}\text { Lenguaje comunicativo prelin- } \\
\text { güístico intencionado: Mimesis } \\
\text { corporal } \\
\text { Supone conciencia individual } \\
\text { corporal y conciencia colectiva. } \\
\text { Tipos: juegos, gestos, movimien- } \\
\text { tos kinéticos intencionados. }\end{array}$ & $\begin{array}{l}\text { Etapa prelingüística de la } \\
\text { comprensión. } \\
\text { La capa cultural mimética se } \\
\text { fusiona con todas las formas de } \\
\text { comprensión. } \\
\text { Constituye la ironía del tipo de } \\
\text { comprensión irónica. }\end{array}$ \\
\hline
\end{tabular}

Elaboración de los autores a partir de Egan (2000, pp. 57-234). 
A continuación, describimos brevemente cada una de ellas, deteniéndonos con mayor detalle en la forma de comprensión filosófica que es aquella que despliega el conocimiento teórico como instrumento intelectual.

\section{LA COMPRENSIÓN MÍTICA}

Es propia de las culturas orales cuyo referente en Occidente son los mitos griegos. Evolutivamente, corresponde a la edad de entre 2 a 8 - 9 años, momento de repliegue de las disposiciones genéticas y despliegue del aprendizaje deliberado. Conforma el sustrato de todas las formas de conocimiento posteriores que retoman y proyectan de manera distinta muchos de sus elementos del lenguaje y la comprensión del mundo. Su instrumento intelectual está constituido por el lenguaje verbal, tal como se expresa en los relatos y narraciones míticas, expresiones de la mente poética.

El mito es una forma de relato (forma discursiva de estructura narrativa episódica) que conecta los elementos de la realidad, según los siguientes recursos de asociación entre contenidos:

a. Dualidad, que actúa y ordena las diferencias en oposiciones binarias, orientadas a comprender para actuar.

b. Fantasía, mediación que trasciende la experiencia y lo inmediato para reordenar el entorno, haciendo posible el control conceptual del mundo. La fantasía desmiente el dogma de la expansión progresiva del entorno que va de lo concreto a lo abstracto. El conocimiento recorre el camino inverso que va de lo abstracto a lo concreto y de lo lejano a lo próximo.

c. Abstracción, proceso según el cual el lenguaje va de lo abstracto a lo concreto; de lo general a lo particular. Lo abstracto consiste también en aquello no necesariamente consciente 


\section{0}

o formulable pero que está presente y organiza la realidad. Desmiente el mito del pensamiento concreto de los niños.

d. Metáfora, recurso del lenguaje poético mediante el cual se explica una cosa por medio de otra y constituye una forma de imaginación sofisticada de conexión entre realidades.

e. Imágenes que apelan a la memoria sensorial y a la simulación de escenarios. Supone una conexión del conocimiento con la sensorialidad (incorporación del conocimiento).

La forma de comprensión mítica es imaginativa y pragmática a la vez porque genera conocimiento para actuar en el mundo y un tipo de realidad basada en el carácter prototípico de los personajes y de las acciones. Es una forma de comprensión integradora porque capta el mundo como totalidad dada y conocida. El mito propone una realidad vivida cuyo vínculo con el sujeto es la intensidad emotiva (memoria) vinculante: en el relato todo lo que tiene significado cognitivo tiene significado afectivo. Lo sagrado es el valor más importante del mundo, que es una categoría afectiva antes que cognitiva.

\section{LA COMPRENSIÓN ROMÁNTICA}

Hace referencia a la conciencia reflexiva sobre el lenguaje propia de la Grecia clásica, y supone que la escritura genera recursos sígnicos y simbólicos que constituyen y dan forma desde sí mismos a nuevas maneras de pensar y proyectar el mundo. El ejemplo prototípico más temprano es la Historia de Heródoto (siglo V a. C.), cuyo rasgo particular es la colección de hechos maravillosos y exóticos ubicados en los límites del mundo. Esa etapa cultural responde, en los individuos, a la fase evolutiva que va de la preadolescencia a la adolescencia. La forma del lenguaje que soporta la comprensión romántica es la escritura alfabética que abre la posibilidad de producir registros detallados y memorias. 
Las estructuras discursivas e instrumentos intelectuales que median la asociación entre contenidos son, por ejemplo, la descripción, la enumeración, la clasificación, la definición y el análisis que constituirán el sustrato de la forma de comprensión filosófica basada en el acopio de información compleja en cantidad y cualidad. Esos recursos hacen posible tejer formas discursivas investigativas y exploratorias mediante la combinatoria de materiales heterogéneos distantes en el tiempo y en el espacio (a diferencia del tiempo y el espacio homogéneos del mito) como las descripciones etnográficas, la referencia indirecta y directa a testimonios, las enumeraciones y colecciones (el impulso adolescente por coleccionar elementos de una clase pero de variada procedencia en el tiempo y el espacio obedece al desarrollo de esta forma de comprensión).

El mundo se vive desde los detalles y el impulso del conocimiento apunta a lo remoto, lo exótico, lo extremo (para los adolescentes la reseña de récords es importante), lo sublime y los contextos. El personaje arquetípico es el héroe como autodidacta excéntrico. El tipo de comprensión romántica propone la realidad como entidad autónoma, fuera del alcance en primera instancia pero abierta al conocimiento, de tal forma que conocer es la mayor aventura y la actitud heroica más importante, a diferencia del mito que integra el mundo en una totalidad accesible y al alcance de la mano y de la acción. A la lógica del descubrimiento y la exploración le corresponde un aprendizaje por excitación e intensidad que invita a "probar los límites".

La forma de comprensión romántica proporciona una forma de abstracción basada en la descontextualización del detalle para referirlo y clasificarlo taxonómicamente según clases de similares $\mathrm{u}$ opuestos. A la vez, promete el acceso a los límites de la realidad y extremos de la experiencia, según un movimiento que va de afuera hacia adentro, de los límites al contexto inmediato. En los adoles- 
centes esta forma de comprensión es importante porque otorga los elementos que le permiten salvaguardar la identidad en medio de un mundo por conocer y de límites difusos. El valor sigue siendo la conexión afectiva con el mundo, pero también el sentimiento heroico de probar y tentar cognitivamente los límites del mundo.

\section{LA COMPRENSIÓN FILOSÓFICA Y LA TEORÍA}

Es el tipo de comprensión en el que se inscribe la teoría y, por lo tanto, el centro de nuestra atención. Nace también en la Grecia clásica y toma forma con el pensamiento de Platón y Aristóteles, dos de los exponentes de obligada referencia porque dan nombre y forma a lo que hoy reconocemos como pensamiento teórico. El producto narrativo prototípico y temprano es la Historia de Tucídides constituida en su ejemplo porque, a diferencia de Heródoto, no busca lo maravilloso, sino identificar los principios subyacentes que determinan los hechos; es decir, su objetivo no es acumular detalles, sino construir una teoría de la historia y establecer el o los principios que la mueven. Esta forma de comprensión corresponde a la fase evolutiva que va desde la adolescencia a los 20 años y la edad adulta. Históricamente, se consolida con la imprenta en la Ilustración, y hoy en la ciencia, práctica establecida e institucionalmente normada de indiscutible impacto en la vida social. La comprensión filosófica supone y es consecuencia de la alfabetización y requiere de una clase particular de formas comunicativas muy pautadas, así como de comunidades e instituciones que las sostienen y les otorgan credibilidad.

Toma forma en el pensamiento teórico sistemático y en sus instrumentos intelectuales, entre ellos las suposiciones e hipótesis. El pensamiento teórico se caracteriza por, al menos, los siguientes rasgos: a) generalización trazada por el enlace de los elementos de la realidad agrupados conceptualmente por nexos causales; b) provee 


\section{3}

una visión que trasciende los actores (el héroe romántico individual) a los agentes sociales que explica la historia a partir de causas y efectos; c) abierto a las anomalías y, por ello, flexible y dinámico; d) capaz de dotar de certidumbre ideológica que alimenta la identidad.

El pensamiento teórico se autopropone como visión privilegiada de la realidad y vía exclusiva hacia la verdad. Apunta a identificar lo recurrente, las reglas, leyes y principios generales subyacentes en la realidad, así como sus redes causales o conexiones basadas en los conceptos. Por lo tanto, despliega una reducción discursiva del mundo que genera un ciclo según el cual lo particular se subsume en lo general y lo general se enriquece o modifica con lo particular. El pensamiento teórico genera, así, esquemas que se transforman ante nuevas explicaciones que deben incluir y dar cuenta de las anomalías que surgen.

La comprensión teórica se basa en el primado de la comprensión escéptica sobre la tradición y, por lo tanto, es desestabilizante. El valor es de carácter epistémico (aquello que hay que comprender por medio de la teoría) y se expresa la verdad, que toma forma mediante términos teóricos. Lo abstracto, las teorías, adquiere realidad en el lenguaje que genera un mundo paralelo habitado por ideas. La verdad, al mismo tiempo, implica apego a un discurso formal atravesado por el lenguaje abstracto, sofisticado y que demanda la recopilación de información abundante y a conexiones de tipo argumental. El discurso filosófico apela a la prosa que articula corpus teóricos, así como preguntas y proposiciones metodológicas y empíricas. Ejemplo de la producción literaria propia de la comprensión filosófica son los tratados, los artículos científicos, los diccionarios y enciclopedias, cuya credibilidad está asociada a la pertenencia y respaldo de comunidades e instituciones académicas. La figura prototípica de la comprensión filosófica es el erudito, el científico que indaga y cuestiona, lo cual supone, si no totalmente, al menos el sacrificio de gran parte del sustrato poético y mítico. 


\section{4}

\section{LA COMPRENSIÓN IRÓNICA Y LA COMPRENSIÓN SOMÁTICA}

Son los dos últimos tipos de comprensión que desarrolla Egan, de tal modo que la comprensión irónica trasciende y deconstruye la comprensión filosófica; la comprensión somática, a su vez, ironiza y relativiza la comprensión irónica y toda forma de comprensión basada en el lenguaje verbal o escrito. La comprensión irónica también nació en Grecia y se desarrolló de la mano de pensadores como Heráclito y Sócrates, y se expresó en el modernismo y el posmodernismo; dos de las figuras más prominentes fueron Kierkegaard y Nietzsche. La ironía es el instrumento intelectual central y es una manera de pensamiento basado en la duda epistémica radical y en la conciencia de los límites del lenguaje. Supone la alfabetización, y un desarrollo tal de la escritura dotada de un altísimo grado de densificación y complejidad del vocabulario.

La ironía despliega un discurso de desconstrucción de lo aparentemente sólido y de refutación de sí mismo y de las narraciones canónicas. El pensamiento irónico supone la separación entre lo que se dice y lo que se quiere decir, articulando y tensionando entre sí la teoría y la narrativa, la teoría y la imaginación artística. Así, la realidad es reflejo del lenguaje y la reflexión sobre la realidad lleva siempre a la reflexión sobre el lenguaje; al mismo tiempo, hay una discrepancia insalvable entre afirmación y realidad. El personaje prototípico es el irónico, que se complace en deconstruir el orden, para crear el caos y romper los esquemas generales. Para el irónico el conocimiento es ilusorio y el mundo es contingente; por lo tanto, es inútil buscar certezas. Lo importante es pensar para ser radicalmente libre de los esquemas generales, por medio de la superación de la metafísica, de las cosmovisiones y las visiones finalistas de la historia y el cosmos. El mundo es el resultado de un conjunto de perspectivas diversas expresadas en narrativas. Para el irónico el valor no es epis- 


\section{5}

témico (la verdad), sino político (el consenso), porque es necesario convivir en medio de las perspectivas diversas.

La comprensión somática — para cuya descripción Egan se remite a la descripción de Merlin Donald (Origins of the Modern Mind) - corresponde a la etapa prelingüística que se anticipa y se fusiona con todos los tipos de comprensión. El instrumento intelectual es la mimesis corporal, acto simbólico comunicativo no lingüístico que se expresa, por ejemplo, en el juego, los gestos y los movimientos kinéticos intencionados. En tanto intencionado, es decir, dotado de una finalidad comunicativa, supera la imitación (forma de reproducción literal del referente) y la emulación (reproducción menos literal del referente).

Las características de la representación mimética son la intencionalidad, la generatividad (capacidad articulatoria de gestos), la comunicación (carácter público de la mimesis), la referencia a un significado (sígnica y simbólica) y la inclusión de una gama ilimitada de objetos. El punto de partida de la forma de comprensión mimética es la experiencia del cuerpo, experiencia singular por individual e intransferible, y se despliega más allá del lenguaje porque no es expresable en términos lingüísticos. De esa manera, la mímesis ironiza todos los tipos de comprensión basados en el lenguaje pues supone que existe un núcleo más allá de la posibilidad del lenguaje y fuera de su alcance, tal como es la experiencia del cuerpo. Al mismo tiempo, la experiencia corporal, en tanto individual e intransferible, constituye un nosotros corporal empático; más allá, más profundo y más amplio que el consenso propio de los usuarios del lenguaje.

\section{Implicaciones pedagógicas}

El proyecto pedagógico de Egan responde al contexto de las sociedades multiculturales contemporáneas, especialmente aquellas 


\section{6}

situadas en el mundo desarrollado que, al reconocerse como tributarias de la tradición intelectual de Occidente, ven en ella un repositorio de recursos de múltiples posibilidades para el cultivo de la imaginación a partir de los usos culturales del lenguaje. Entre los puntos a favor destacamos la distinción de múltiples formas de comprensión a las que les corresponden otras tantas formas de comunicación y que son propias de la tradición occidental, solo en apariencia monolítica. De esa manera, hace de la comprensión una práctica polisémica abierta a muchas maneras de concebir el desarrollo de la imaginación y del pensamiento, enlazando estos dos términos que no siempre logramos emparejar. Se debe valorar también el rol que Egan atribuye a la comprensión somática, constituyéndose en el metapunto de vista desde el cual redimensionar el alcance de los tipos de comprensión basados en el lenguaje.

Aunque construida en Estados Unidos, la propuesta de Egan tiene algo que decir y ofrecer a las experiencias educativas de los países emergentes como los nuestros, por varias razones. La primera consiste en que ofrece la posibilidad de identificar y remover el positivismo que persiste, sin ser nombrado, en la tradición educativa de cuño liberal que alimenta todavía gran parte del currículo, generando una cultura educativa aferrada a los contenidos propios de la ciencia y refractaria al cultivo de otras formas de pensar que remiten, por ejemplo, a la filosofía y a la religión ${ }^{51}$, para mencionarlos con los mismos rótulos del lenguaje positivista. Esta pesada herencia, que ancla la escuela al progresismo de fines del siglo XIX e inicios del XX, promueve el abandono y la superación de otros tipos de comprensión porque detienen el pro-

51 En nuestros contextos, el término religión alude directamente a las instituciones religiosas, como la Iglesia católica y las iglesias protestantes. No obstante, el sentido positivista del término religión es mucho más complejo y entraña los tipos de comprensión más elementales propios de las sociedades clasificadas como salvajes. El pensamiento mítico, por ejemplo, entra en esta categoría. 
greso y estorban el acceso urgente a los conocimientos y destrezas necesarias, además, para que los individuos puedan ejercer sus derechos como ciudadanos y contribuir al desarrollo de su nación.

La segunda razón, de alguna manera continua a la primera, consiste en la ventana crítica que proporciona Egan para valorar hoy las propuestas y programas de desarrollo del pensamiento de los años 90 cuyo objetivo era lograr operadores simbólicos capaces de lidiar con gran cantidad de información, propuestas que en su momento fueron consideradas como alternativa para las reformas educativas, al menos en Ecuador. Sin desmerecer su valor y el rol que jugaron, ni desconocer su apertura a la diversidad respecto a las formas de comprensión tal como propone, por ejemplo, la teoría de las inteligencias múltiples de Gardner, existe el peligro de que los programas de desarrollo del pensamiento tiendan a totalizar el currículo anclados en las operaciones e instrumentos intelectuales (nociones, conceptos, teorías, argumentos, subargumentos y sus respectivas formas proposicionales) que - ahora sabemos- son propios del pensamiento filosófico, con el peligro de dejar a un lado el cultivo de otros instrumentos y mediaciones simbólicas sobre las cuales se construye la posibilidad de interacción entre varios tipos de comprensión. El propósito de tales programas se vería más enriquecido con la siempre difícil apertura a la diversidad de tipos de comprensión, a partir de las cuales establecer un orden lógico y una secuencia pedagógica del currículo.

No obstante, el límite de Egan radica en la perspectiva multicultural que la alimenta, que inevitablemente apunta a subalternizar las diferencias epistémicas, trasladándolas al pasado para recuperarlas en el marco del ejercicio hegemónico del pensamiento científico en función de otras formas consideradas contemporáneas. América Latina, en cambio, es un continente que se debate entre la multiculturalidad y la interculturalidad, y en el que la pluralidad de los tipos 


\section{8}

de comprensión no son el resultado de la recapitulación del pasado de Occidente, instancia esta última ni de lejos la única tradición que ofrece posibilidades de diversidad de tipos de comprensión; ni en América Latina ni en Estados Unidos ni en Europa.

La interculturalidad latinoamericana — desde la perspectiva del Sur - asume que la pluralidad de tipos de comprensión son contemporáneos, están presentes entre nosotros y son recursos comunicativos y de pensamiento vivos ejercidos aquí y ahora por los pueblos y nacionalidades indígenas, por los afroamericanos y otros colectivos que disputan la contemporaneidad a otros tipos de pensamiento. Por lo tanto, no funcionan como capas previas que hacen posible otras subsiguientes. La oralidad (que incluye el pensamiento mítico), la conversación, las formas de deliberación colectiva, y otras que contemplan por supuesto el despliegue de formas letradas de pensamiento y comunicación, son posibilidades para ejercer en el presente la toma de decisiones respecto al futuro de su existencia colectiva diferenciada en medio de los cambios y de las amenazas.

El silenciamiento de estos tipos de comprensión no es producto de fallas y tareas pendientes de la recapitulación cultural, sino de la tarea hegemónica de ocultamiento y subalterización en torno a ellos, a fin de neutralizar su potencial de disputar y remover el presente civilizatorio. Esos tipos de comprensión son realidades simultáneas y constituyen destrezas colectivas atesoradas para discernir, deliberar y decidir. Pero la intervención de las relaciones de poder entre los tipos de comprensión propiciadas por el multiculturalismo y el eurocentrismo, en las que se inserta casi siempre el ejercicio del pensamiento teórico, se desplegará detalladamente a lo largo del próximo capítulo. 


\section{Capítulo IV TEORÍAS DE LA EMANCIPACIÓN Y PRÁCTICA TEÓRICA. DEBATES CONTEMPORÁNEOS}

\section{Sobre la necesidad de una teoría emancipatoria}

La primera pregunta que debemos hacernos es si hay necesidad o no de una teoría de la emancipación en los discursos contemporáneos. ¿Es necesaria una nueva teoría de la emancipación? ¿Acaso los distintos desarrollos del marxismo no nos habían ya proporcionado una sólida teoría de la emancipación? ¿Acaso la teoría crítica de Max Horkheimer no había afinado la propuesta marxista? (1937). En definitiva, ¿por qué es necesaria una teoría de la emancipación hoy? ¿Por qué sentimos que es insuficiente hoy una teoría emancipatoria como la formulada en el siglo pasado? ¿Qué ha cambiado?

Probablemente se trata de un cambio en el paradigma interpretativo del conjunto de las ciencias en general (Kuhn, 1962) y de las ciencias sociales, en particular. Ese cambio - proponemos- tiene que ver con la instalación del horizonte de la diversidad y la crítica a los metarrelatos o teorías totalizantes. ¿Qué quiere decir esto? Que por mucho tiempo la manera de hacer teoría se basó en una serie de supuestos heredados de la concepción moderna del mundo; a partir de ella se instaló un horizonte de seguridad en grandes "verdades" esenciales. A partir de la década del 70 del siglo pasado, ese 
horizonte comenzó a fraccionarse debido a la instalación de debates posmodernos y poscoloniales (Garcés, 2009).

La posmodernidad se ha manifestado de distintas maneras y en distintos ámbitos. Se podría decir que, en lo fundamental, cuestionó varios de los pilares en los que se sustentaba y se sustenta el pensamiento moderno: binarismo excluyente, metarrelatos fundacionales (cristianismo, marxismo, liberalismo), negación de diversidad, entronización de un solo sujeto de emancipación, etc. (Lyotard, 1990; Vattimo, 2000).52 Sin embargo, estas críticas llevaron a un relativismo absoluto que diluyó todo compromiso emancipatorio. Ello, además de constituirse en una crítica eurocéntrica al pensamiento eurocéntrico de la modernidad (Jameson, 1984; Garcés, 2009), asunto sobre el que volveremos en breve.

La teoría poscolonial, por su parte, estableció una poderosa crítica al modelo eurocéntrico y colonial de conocimiento, es decir, puso en duda la validez universal de un conocimiento que en realidad ha sido construido desde y para una espacialidad concreta: el mundo europeo, del cual derivan todas o la mayoría de las ciencias sociales (Wallerstein, 1996). En este sentido, se trata de un conocimiento provincial con pretensiones de universalidad (Chakrabarty, 2001). El planteamiento según el cual lo post- no se trata de un asunto temporal, sino de una condición que cruza el espectro de las

52 Esta suerte de esquematización de la modernidad hace referencia a la dimensión emancipatoria que habría tenido y que, según Dussel (2000), constituye su cara oculta ya que niega el rol victimario que tuvo sobre las poblaciones de América desde el momento de la conquista. Esta mirada, sin embargo, no debe llevar a negar la diversidad de formas que esta ha asumido a lo largo de la historia. Así, a manera de ejemplos podemos decir que para Habermas la modernidad se trata de un proyecto inacabado (1998); Appadurai la piensa en términos de desbordamiento (1996), y para Santos se trata de un proyecto amplio y contradictorio que se ha movido permanentemente entre emancipación y regulación (1995). 


\section{1}

prácticas sociales (Hulme, 1996; Garcés, 2009), ha permitido a la teoría poscolonial ayudarnos a mirar el lugar que ocupa la diversidad subalternizada en las poscolonias (Rivera y Barragán, 1997).

Un paréntesis explicativo: el término subalternidad, de uso recurrente en la teoría poscolonial, pretende responder a una concepción mucho más amplia y productiva que la reducida concepción de proletariado instalada por el marxismo. Subalternidad busca dar cuenta de una situación de dominación en términos no solo de clase sino de género, generación, casta, raza, etnia, etc. (Guha, 1997a; $1997 b$ ). Se trata de una posición en la escala de poder que, sin embargo, no es estática sino relacional y relativa (Coronil, 2000): relacional en el sentido de que no se ocupa de manera definitiva y esencial la posición de dominador o dominado, sino en el marco de las relaciones que configuran tal cualidad. Y por ello mismo se trata de una posición también relativa.

\section{La crítica moderno-colonial}

En el contexto latinoamericano estos dos horizontes críticos, tanto a la modernidad como a la colonialidad, han confluido en uno solo: el de las teorías de la modernidad-colonialidad llevadas adelante, entre otros, por Mignolo (2005), Escobar (2007), Walsh (2005, 2007). ¿En qué consiste esto? En no separar los dos ámbitos; es decir, hacer visible que la modernidad es inseparable de la colonialidad; la modernidad se inauguró con la conquista de América (Dussel, 2000) y, por lo tanto, se vuelve inseparable de una construcción moderno-colonial.

Uno de los elementos claves de esta postura decolonial es la crítica al eurocentrismo, a aquella construcción histórica según la cual Europa se habría convertido en el centro de la historia mundial 


\section{2}

gracias a sus cualidades intrínsecas. Uno de los aportes fundamentales de Dussel será justamente exponer el hecho que, antes de 1492, lo que existía en el mundo eran sistemas interregionales en los que la Europa central, que después — hacia el siglo XVIII — se volverá hegemónica, no era otra cosa que el lugar más periférico del sistema regional más importante del momento (1998). Se ha dado, entonces, una construcción eurocéntrica del conocimiento que niega la colonialidad como elemento constitutivo e indisociable de las sociedades. Y se ha universalizado ideológicamente una mirada provinciana, parroquialista de la modernidad: la europea. De tal manera que el eurocentrismo es la pretensión de universalidad del conocimiento europeo, gracias a privilegios epistémicos y ontológicos (CastroGómez, 2019). Esta pretensión de universalidad (más precisamente universalismo) vino acompañada de la imposición de lo europeo como algo universal que debe ser adoptado por todos.

Gracias al eurocentrismo, la colonialidad no funcionó únicamente en el nivel institucional (el de la Colonia histórica), sino también a nivel epistémico, de modo que podemos hablar de una colonialidad epistémica. Desde esta perspectiva los desarrollos teóricos de la academia del norte se han desplegado desde la condición blanca, macha, rica; es el lugar desde donde se pretende haber producido verdadero conocimiento y teoría. Bajo el discurso de neutralidad, la academia ha pretendido que la teorización no tiene vínculos con la condición económica, sexual, racial, etc. Como veremos, el lugar desde donde se siente, se piensa, se habla, se escribe es parte fundamental de lo sentido, pensado, hablado, escrito. Sin embargo, debe ser claro que cuando hablamos de lugar no nos referimos a un lugar físico, sino social, cultural, político, como veremos en breve.

Por otro lado, el riesgo de depositar toda la cualidad teorizadora en el lugar del teorizador es que, en nombre de un pretendido 
universalismo eurocéntrico, se busque plantear una teoría "otra", es decir, una teoría que en su radicalidad considere estar ubicada en el fuera de la modernidad, tal como de alguna manera puede ser planteada por actores subalternizados del tipo indígenas, mujeres, afros, etc. Se trata de una posición que hace alusión a lo que Spivak (1997) llama esencialismo estratégico, es decir, un esencialismo de tipo político que permite a los subalternos posicionarse ante el poder.

El planteamiento de Castro-Gómez (2019) y de Mary Louise Pratt (2010) en este sentido es claro: ellos plantean que, antes que pretender ubicarse por fuera de la modernidad, se trata de atravesarla, no de rodearla o negarla. En efecto, Pratt propone: "Para los estudiosos modernos de la neocolonia, la descolonización exige que no pasemos alrededor sino a través de los discursos de la metrópoli y su producción de sujetos" (p. 421). Es decir, "El camino hacia la descolonización y la toma de conciencia no pasa alrededor sino a través de los códigos de la modernidad" ( $\mathrm{p}, 418)$.

Castro-Gómez (2019), por su parte, se pregunta en qué podría consistir un proyecto no antimoderno sino transmoderno. Se trataría del modo en que el proceso mundial de modernización económica, política y cultural puede ser asimilado dialécticamente desde las distintas culturas subalternizadas por la colonización europea.

Significa atravesar la modernidad pero desde "otro lugar", precisamente desde aquellos que fueron "negados" por la modernización hegemónica euronorteamericana (posicionada como "centro" de la modernidad). En términos de Marx, la transmodernidad sería entonces la "negación de la negación", es decir, la asimilación creativa y emancipadora de la modernidad realizada desde historias locales. Se trata de una modernidad vivida desde la exterioridad relativa que niega su forma occidentalista y eurocentrada. Una modernidad, en últimas, descolonizada. Pero tal descolonización no remite, como 


\section{4}

decíamos, a un proyecto antimoderno, sino a un proceso crítico y emancipatorio frente a las instituciones desarrolladas por la modernidad misma (p. 85).

En este sentido, un proyecto transmoderno no significa el retorno a valores premodernos o precoloniales. Se trata de una asunción de doble cara:

de un lado, la modernidad eurocentrada es reinterpretada desde las historias locales negadas por la colonización; pero del otro lado, y al mismo tiempo, la propia cultura subalterna, modificada ya indefectiblemente por los procesos de modernización, debe ser reinterpretada críticamente (pp. 85-86).

Desde otro lugar reflexivo, el teórico indio Homi Bhabha plantea su crítica tanto al pensamiento dicotómico y al binarismo esencialista de la teoría moderna como al teleologismo de la izquierda clásica marxista. Para él, "No hay una verdad política o social simple que aprender, porque no hay una representación unitaria de una agencia política, ninguna jerarquía fija de valores y efectos políticos" (2002, p. 48). Por ello, apuesta por la defensa de la hibridez y el posicionamiento antiesencialista que ofrece el espacio inter-medio:

Quiero tomar posición sobre los márgenes móviles del desplazamiento cultural [...] y preguntar cuál podría ser la función de una perspectiva teórica comprometida, una vez que se toma como punto de partida paradigmático la hibridez cultural e histórica del mundo poscolonial. (p. 41)

Bhabha plantea la necesidad de explorar un Tercer Espacio como posibilidad de "eludir la política de la polaridad y emerger como los otros de nosotros mismos" (p. 59). De manera que es en el inter, en el espacio in-between que se puede lograr el sentido de la lucha cultural poscolonial (p. 59). 


\section{5}

\section{¿Quién teoriza, sobre qué y para qué?}

Lo dicho no niega que sea importante la corporeidad de quienes teorizan. La teoría no se produce en el aire sino a partir de sujetos corporizados concretos, situados territorialmente en espacios concretos con relaciones concretas. Los proclamadores de la modernidad divulgaron la ilusión de que el conocimiento es desincorporado y deslocalizado y, por lo tanto, neutral, incontaminado por las marcas sociales, raciales, coloniales, sexuales (Garcés, 2009).

Por el contrario, la teoría crítica contemporánea se esmera en plantear el lugar de enunciación desde el cual se teoriza porque, en definitiva, toda teoría funciona como un sistema de representación. En el caso de las humanidades y las ciencias sociales, hay un fuerte énfasis de representar al subalterno (Bhabha, 2002; Kozlarek, 2017).

El intelectual que representa al subalterno puede hablar por él como si fuera su apoderado o puede representarse al estilo de quien ejecuta una obra de teatro, es decir, poniéndose en escena, ex-poniéndose ante los demás, es decir, poniéndose en evidencia ante los demás. Dice Spivak que eso es lo que tiene que hacer el intelectual, exponerse ante los demás en lugar de pretender representar al subalterno (1998). De manera que el investigador y el intelectual generalmente buscan representar al otro, al subalterno, en términos de su apoderado, en términos de alguien que puede hablar en lugar del otro (vertreten). Spivak plantea que la tarea del intelectual es en realidad re-presentarse a sí mismo (darstellen), volver a presentarse ante los demás, en cuanto al lugar privilegiado que ocupa en los palacios del saber de la academia. Darstellen hace referencia justamente a la necesidad de ponerse en escena, de realizar una actuación intencional (pp. 181-183).

En esta perspectiva la pregunta importante es si aquel que representa al subalterno o pretende representarlo puede teorizar en su 


\section{6}

nombre. En las últimas décadas muchos subalternos han accedido a niveles superiores de estudios y no quieren ser representados por otros, sobre todo cuando esos otros provienen del mundo clasificatorio colonial. Ellos plantean ser la voz autorizada para hablar de sí mismos y de sus pueblos como una forma de superar el colonialismo epistémico, arrogándose la condición de condensar en sí toda la subalternidad de su grupo. En esta perspectiva, más importante que la teoría en sí misma sería quién la enuncia. Ello daría legitimidad a la teoría y tendría que ver con la incorporación de la teoría, es decir, con la capitalidad de teorizar desde la carne, la historia, la piel, la dominación.

En tal contexto debemos preguntarnos quiénes son los subalternos de carne y hueso que pueden desarrollar una reflexión teórica emancipadora. Como decíamos, todos aquellos que sufren la dominación por su condición de clase, género, raza, “anormalidad”, etc. De manera más específica podríamos decir que se condensan en los llamados nuevos movimientos sociales (Santos, 2001). En efecto, el tema del conocimiento es clave en ellos debido al contexto de producción cultural en el capitalismo posindustrial, aspecto que forma parte del orden que es necesario transformar (Juncosa, 2006, p. 85). Sin querer hacer un elenco exhaustivo, podemos aludir a los movimientos feminista, indígena, globalización alternativa, Sin Tierra, entre otros.

Por la complejidad que significa intentar lograr una perspectiva unificadora de los movimientos sociales con respecto a los aportes teóricos nos referiremos solo al movimiento feminista. En este movimiento el conocimiento, en general, y la producción teórica, de manera específica, son aspectos fundamentales. ¿Por qué? La tesis fundamental es que el conocimiento hace posible la transformación social de las relaciones de género y la construcción de sí mismas (p. 172), lo que implica una nueva manera de conocer a partir de las mujeres. 


\section{7}

En función de lo dicho, el feminismo despliega su ejercicio teórico en dos direcciones: 1 . una crítica hacia las estructuras y condicionamientos antropo y androcéntricos del ejercicio científico y epistémico; 2. una dirección propositiva de construcción de una epistemología feminista de la teoría que haga posible la transformación de las relaciones sociales en su conjunto (pp. 172-176).

\section{Lenguaje y teoría}

Una mirada menos pretenciosa del valor de la teoría de acuerdo al sujeto o lugar de enunciación tiene que ver con la enunciación misma, es decir, con el lenguaje en el que y desde el cual se teoriza. ¿Cómo se habla y se escribe de teoría? Ello depende de para quién y con quién se escribe. ¿Para los expertos? ¿Para los lectores del mundo académico? ¿Para los subalternos? La teorización sobre los subalternos se hace en un lenguaje que los subalternos no escuchan. La teórica Spivak ya citada (1998) se preguntaba si pueden hablar los subalternos; Silvia Rivera (2003, p. 56) decía que los subalternos no pueden ser escuchados por las élites dominantes. En el contexto de este capítulo podríamos decir que los académicos no pueden hablar el lenguaje del subalterno. Si uno escribe o habla para los subalternos, ¿puede escribir o hablar en su lenguaje?

"En su lenguaje" puede significar varias cosas. La más "radical" es teorizar desde una lengua minorizada, como suelen ser las lenguas indígenas. Por ejemplo, es legítimo preguntarse cómo teorizar a partir del yuyay 'pensar' y del yachay 'saber' kichwa, con la carga de racismo lingüístico heredado desde la Colonia (Garcés, 2009). Ya desde la segunda mitad del siglo XVI e inicios del XVII, se debatía si el kichwa era una lengua que servía para expresar ideas abstractas y espirituales, tal como hoy se debate si es una lengua que permite expresar los conocimientos de la modernidad $(2005,2009)$. 


\section{8}

En los debates contemporáneos sobre comunidad, comunitariedad, comunalidad, etc. (Liceaga 2013, Carrera y Solórzano 2019, Martínez 2016), podría ser útil pensar, por ejemplo, desde el minkanakuy kichwa como una forma de posibilitar un proyecto comunitario social. Minkana hace referencia a 'encargar, encomendar', mientras el sufijo -naku es un indicador de reciprocidad. De manera que minkanakuy expresa el encargarse mutuamente, el ponerse mutuamente en manos del otro/a. He aquí un ejemplo de la riqueza teórica que es posible trabajar desde/en/a partir de las lenguas minorizadas y subalternizadas por el dominio colonial. Y no solo desde una perspectiva de intercambio lingüístico, también en la propia lengua tenemos el problema de las diferencias entre el lenguaje popular-cotidiano y el lenguaje académico. Es legítimo preguntarse si se puede teorizar en el lenguaje de albañiles, montubios o vendedoras de mercado.

\section{¿Es posible interculturalizar la teoría?}

Esto nos lleva a la posibilidad de interculturalizar la teoría. Es decir, no solo incorporar lo diverso en las teorizaciones, sino que la misma teoría esté imbuida de la diversidad, que podamos asumir distintos horizontes teóricos en sus mecanismos de formulación, en sus lenguajes, en sus niveles; en definitiva, jes posible interculturalizar la teoría? Boaventura de Sousa Santos propone comprender de manera más compleja la relación entre ignorancia y conocimiento como base de posibilidad de una interculturalización de la teoría a partir de la traducción.

Dice Santos que todo acto de conocimiento se mueve en un eje que va de "A" (ignorancia) a "B" (conocimiento). En la modernidad se habrían constituido dos formas de conocimiento: el conocimiento-regulación y el conocimiento-emancipación. En el co- 


\section{9}

nocimiento-regulación el punto de ignorancia se denomina "caos", mientras el punto de saber sería "orden"; por contrapartida, en el conocimiento-emancipación el punto de ignorancia se denomina "colonialismo" y el punto de saber se designa "solidaridad".

A pesar de que estas dos formas de conocimiento están inscritas en la matriz de la modernidad eurocéntrica, la verdad reside en que el conocimiento-regulación llegó a dominar por completo el conocimiento-emancipación. Esto se debió al modo bajo el que la ciencia moderna se convirtió en conocimiento hegemónico y se institucionalizó como tal. Al dejar de lado la crítica epistemológica de la ciencia moderna, la teoría crítica, a pesar de pretender ser una forma de conocimiento-emancipación, acabó por convertirse en conocimiento-regulación. (2000, pp. 30-31)

De ahí que lo necesario hoy en día no es una nueva teoría con pretensiones de criticidad o abarcadora de todas las luchas sociales, sino una teoría de la traducción. Santos propone que no habiendo un principio único posible de transformación social, no habiendo agentes históricos de transformación únicos, no habiendo una forma única de dominación, lo que se necesita en la contemporaneidad de las luchas sociales no es tanto una teoría común, sino una teoría de la traducción que haga mutuamente inteligibles las luchas.

Nuestra posición puede resumirse del siguiente modo. En primer lugar, no hay un principio único de transformación social, e, incluso aquellos que continúan creyendo en un futuro socialista, lo ven como un futuro posible, en concurrencia con otros futuros alternativos. No hay agentes históricos únicos ni una forma única de dominación. Son múltiples las caras de la dominación y de la opresión, y muchas de ellas fueron irresponsablemente olvidadas por la teoría crítica moderna $[\ldots$.$] . En la ausencia de un principio único, no es posible reunir$ todas las resistencias y agencias bajo el amparo de una gran teoría común. Más que de una teoría común, lo que necesitamos es una 


\section{0}

teoría de traducción que haga mutuamente inteligibles las luchas y permita a los actores colectivos "conversar" sobre las opresiones a las que se resisten y las aspiraciones que los animan. (p. 28)

Así,

El conocimiento-emancipación no aspira a una gran teoría; aspira, eso sí, a una teoría de la traducción que sirva de soporte epistemológico a las prácticas emancipadoras, todas ellas finitas e incompletas y, por ello mismo, sólo sustentables cuando se organizan en red. (p. 32)

Lo dicho por Santos empata con la propuesta de Castro-Gómez (2007): hoy necesitamos, hacia dentro de la academia, de transdisciplinariedad (Garcés, 2018), y hacia fuera, de transculturalización del conocimiento. ${ }^{53}$ ¿Cómo pensar la transculturalización del conocimiento en la confrontación de conocimientos legitimados por el poder y el conocimiento cotidiano? (2019).

\section{Teorizar sobre / desde / con los no humanos}

Pero, además, el debate contemporáneo se posiciona críticamente ante el antropocentrismo que caracterizó por mucho tiempo a la modernidad. Esto ha llevado a cuestionar la clásica separación entre naturaleza y cultura (2019).

La sistematización de lo considerado "naturaleza", en términos científicos, es un proyecto nuevo que se fraguó en el siglo XVIII en el marco de los viajes realizados por científicos europeos a distintas partes del mundo (Pratt, 2010).

El conocimiento moderno estableció la distinción entre ciencias de la naturaleza y ciencias de la cultura (Eco, 1985): se considera

53 Hay varios estudios y paradigmas de pensamiento pluri, inter o transdisciplinario. Véase al apartado 4 del capítulo II. 


\section{1}

que las primeras interpretan datos, hacen interpretaciones de "primer grado"; las segundas serían interpretaciones de interpretaciones o interpretaciones de "segundo grado". La ciencia natural consistiría en interpretación de datos, trabaja con datos independientes de su observación. Las ciencias de la cultura o ciencias humanas, por el contrario, trabajan con interpretaciones de una práctica anterior, su objeto de estudio es un hecho ya interpretado.

Cuando la sociología estudia las funciones sociales, la antropología los sistemas de parentesco, la lingüística las reglas sintácticas, esas disciplinas explican el modo en que los seres humanos de determinado grupo actúan de conformidad con hábitos que son resultado de una interpretación de la realidad, aun cuando los sujetos no sean capaces de dar razón de ellos mediante interpretaciones posteriores (verbales, por ejemplo) rigurosamente organizadas (p. 263).

Lo dicho tiene relación con los debates antropológicos de las últimas décadas en las que varios autores afirman la diversidad no solo en términos culturales sino ontológicos. Es lo que se ha llamado "el giro ontológico". En términos generales, este "pretende disolver las certezas que forjó la modernidad sobre la naturaleza al juzgarlas reduccionistas, etnocéntricas, anticuadas y, hasta cierto punto, ingenuas" (Ruiz y Del Cairo, 2016, pp. 194-195). Y es que en el llamado pensamiento occidental se ha instalado la idea de "naturaleza" vinculada a miradas antropocéntricas y racionalistas; ambas permitían asumirla como un objeto a ser dominado a fin de satisfacer las necesidades humanas (2016).

La epistemología moderna ha separado el mundo de las cosas del mundo de los hombres y se ha olvidado de rastrear la agencia de los no humanos, las transformaciones que producen en los humanos (Latour, 2001). 


\section{2}

El antropólogo Philippe Descola (2012) examina la manera en que las distintas sociedades se relacionan con lo natural, problematizando así la clásica división entre naturaleza y cultura que heredó la modernidad. En sus investigaciones las distintas concepciones de lo natural conllevan distintos modos de relacionamiento con lo no humano. Una naturaleza vista como objeto, o como "exterioridad" (Santos, 2003), implica un tipo de acción sobre ella, diferente del caso en que los seres que habitan tal naturaleza son vistos como pares espirituales.

De manera complementaria, Viveiros de Castro propone, desde el perspectivismo, tomar en serio la diferente manera en que los pueblos indígenas establecen o no la distinción clásica entre naturaleza y cultura. En muchos de dichos pueblos "o mundo é habitado por diferentes espécies de sujeitos ou pessoas, humanas e não-humanas, que o apreendem segundo pontos de vista distintos" (2004, p. 225).

Como señalan Ruiz y Del Cairo:

El perspectivismo amerindio puede ser sucintamente definido como una ontología en la que el mundo es aprehendido desde diferentes puntos de vista por diferentes clases de seres — cada uno de ellos provisto de conciencia y cultura-, quienes, a su vez, se perciben a sí mismos como humanos al tiempo que definen a otros seres como no-humanos. Hace énfasis en la noción de punto de vista, esto es, un conjunto de disposiciones perceptuales y afectivas que se encuentran arraigadas o incorporadas en cada sujeto. (p. 196)

Finalmente, el antropólogo colombiano Arturo Escobar desarrolla su crítica a la manera en que se concibe la relación naturalezacultura en Occidente desde la noción colonialidad de la naturaleza (2011). Esta está marcada por las visiones mecanicistas de Occidente sobre la naturaleza. Las principales características de la colonialidad de la naturaleza son las siguientes: a) clasificación en jerarquías que 
ubica a los no-modernos, los primitivos y la naturaleza en el fondo de la escala clasificatoria; b) visiones esencialistas de naturaleza; c) subordinación del cuerpo y la naturaleza a la mente; d) visión de los productos de la tierra como subordinados al mercado impulsado por los humanos; e) ubicación de ciertas naturalezas fuera del mundo masculino eurocéntrico; f) subalternización de otras articulaciones de biología e historia a los regímenes modernos (p. 51).

Desde este posicionamiento establece el valor de lo que llama "ontologías relacionales". Se trata de ontologías

en las cuales los mundos biofísicos, humanos y supernaturales no se consideran como entidades separadas, sino que se establecen vínculos de continuidad entre estos. Es decir, en muchas sociedades no-occidentales o no-modernas, no existe la división entre naturaleza y cultura como la conocemos y, mucho menos, entre individuo y comunidad, de hecho, no existe el "individuo" sino personas en continua relación con todo el mundo humano y no-humano, y a lo largo de los tiempos. (2014, pp. 58-59)

Esta mirada propone con fuerza, entonces, el principio de relacionalidad, según el cual "todas las cosas del mundo están hechas de entidades que no pre-existen a las relaciones que las constituyen" ( $\mathrm{p}$. 58 , subrayado en el texto).

Enfatiza este autor que las ontologías no hacen alusión a simples formas representativas, sino que crean verdaderos mundos. Así, en una ontología en la que la montaña es un ser inerte, un objeto sin vida, es fácil derivar prácticas extractivistas; en una ontología en la que la montaña es un ser sintiente se seguirán prácticas de relacionamiento con ella. Lo propio puede decirse de la intersubjetividad tojolabal en la que "la milpa se pone triste" y la tierra es considerada "Nuestra Madre"; por tanto, no puede ser comercializada (Lenkersdorf, 1999, pp. 106-119). 


\section{4}

Entonces la pregunta es si es posible teorizar desde y con lo no humano. En el mundo andino pacha expresa la indisolubilidad de tiempo y espacio y pachamama da cuenta de la indisolubilidad de los seres que habitan la pacha. ¿Es posible pensar-conocer-teorizar desdecon los demás seres con los que compartimos el espacio y el tiempo?

El momento que nos ha tocado vivir, a propósito de la pandemia producida por el coronavirus, parece que nos obliga a ello. La modernidad nos había adoctrinado con la idea de que el ser humano es el centro de todo y dentro de su pensamiento se erigió la idea del valor del individuo: un sujeto dueño de su destino y de su historia. Ello nos puso a unos humanos por encima de otros humanos y no humanos, vivos y no vivos. La crisis de la covid-19 nos muestra cómo un no humano no vivo nos sometió y transformó radicalmente el mundo y las prácticas de nosotros los seres humanos y ello nos está obligando a saber, no solo si es posible pensar desde y con lo no humano, sino a hacerlo.

\section{El giro decolonial de los estudios culturales latinoamericanos y la práctica teórica}

En este apartado final retomaremos algunas afirmaciones surgidas a lo largo del libro en el marco de una reflexión disciplinaria definida por la epistemología o la filosofía de la ciencia, a fin de resignificarlas o debatirlas situándolas a la luz de lo que denominamos giro decolonial de los estudios culturales latinoamericanos, proyecto que apunta también a maneras otras de producir ciencia y trabajar con la teoría. La primera parte insiste en reiterar desde esta postura los interrogantes fundantes del pensamiento teórico; es decir, los desde dónde y para qué. Como veremos, las respuestas se agrupan en torno a la opción de pensar para vivir y son provocadas por las lecturas de Aimé Césaire ([1950] 2006), Luis Maldonado-Torres (2006) y Catherine Walsh (2013). 
La segunda parte despliega algunas características concretas de la práctica teórica desplegada en el escenario de una lucha hegemónica que disputa el marco de referencia epistémico a las imposiciones y composiciones del capitalismo tardío neoliberal y a los esquemas que, más allá del capitalismo, ahondan la crisis civilizatoria porque son insostenibles y hostiles a las trayectorias colectivas de vida. Para este apartado nos basaremos en la obra de Stuart Hall (2010) que ha contribuido a entender los estudios culturales latinoamericanos como un proyecto político que demanda nuevas formas y horizontes de práctica teórica.

\section{Del "pensar para conocer" al "pensar para vivir". La experiencia colonial como certeza colectiva del pensar}

Según Maldonado-Torres, Aimé Césaire plantea, en su "Discurso sobre el colonialismo" ([1950] 2006), una nueva ruta epistémica que consiste "en plantear que la razón es intersubjetiva y dialógica de antemano, y que la esclavitud y la colonización... representan su violación más extrema" (Maldonado-Torres, 2006, p. 187). Esa postura es fundante para el giro decolonial de los estudios culturales y traza su agenda crítica contra toda forma de pensamiento teórico, basado en el ocultamiento de la colonialidad, ya sea porque se encapsula en la certeza solipsista del sujeto o en la confianza que otorgan los automatismos metodológicos que eluden pensar desde las experiencias colectivas de sufrimiento y amenazas a la vida.

Maldonado-Torres (2006, 173 ss.), en su comentario al "Discurso sobre el colonialismo” de Aimé Césaire ([1950], 2006), cuestiona el patrón epistémico moderno colonial y señala el límite del proyecto crítico cartesiano que busca alcanzar 'claridad y distinción' a partir de la certeza que otorga el "yo pienso, luego existo". En efecto, Descartes impulsó un modelo epistémico basado en la duda metódica del sujeto, duda confinada en los márgenes de su intimidad 


\section{6}

solipsista y traducida en interrogantes a ser develados para pensar más allá de toda autoridad y doctrina, pero sin vinculación alguna con la experiencia del otro colonizado. Esa es la causa del fracaso del proyecto crítico de la empresa cartesiana que obliga a comparecer en el tribunal de la razón, fracaso extensivo también a la empresa crítica husserliana afincada en la autoevidencia de la intuición fenomenológica y, aunque parte de la experiencia del otro, de todas maneras se trata de una intuición instaurada en la subjetividad. La imposibilidad de ambos itinerarios se debe a que

mientras Descartes y Husserl intentan establecer o reformular las bases del proyecto histórico europeo a partir de la centralidad del sujeto y del valor epistemológico de la "claridad" y la "distinción" (o intuición fenomenológica en el caso de Husserl), Césaire busca introducir un nuevo tipo de razón crítica que descansa en la "claridad" que el sujeto colonizado tiene de la perversidad del proyecto civilizatorio europeo. (2006, p. 185)

Desde la lectura de la experiencia histórica de la colonialidad, el "tribunal de la razón" no radica en la subjetividad, sino en el otro colonizado que el pensamiento eurocentrado se niega y resiste a ver: los “condenados de la tierra", los damné, aquellos que son privados de ejercer un don, a quienes se les niega ofrecer lo que tienen (p. 186). Esta negación a reconocer el verdadero carácter de la civilización europea — su carácter colonial — será, a la postre, la causa del fracaso de intentos posteriores similares, incluido los de la razón posmoderna:

El "hombre europeo" se ha mantenido ciego ante la realidad del colonizado. Y por eso no ha logrado conocer más sobre sí mismo. Pero el "esclavo" ha conocido la perversidad y la inconsistencia del "amo" por siglos. Señala Césaire que los esclavos saben que los amos "mienten" (a sí mismos y a ellos) y que, al estar desapercibidos o al negarse a confrontar su mentira, son "débiles". Los esclavos y los colonizados aparecen como una fuente epistémica necesaria para 
que Europa pudiera adquirir "claridad" y "distinción" con respecto a su propia identidad y a la naturaleza de su proyecto histórico. En esto, señala Césaire en un gesto de crítica interna, los europeos traicionaron a Descartes. La mentira, más que la "claridad" y la "distinción" eran aspectos centrales del proyecto europeo [...] En vez de un proceso de duda metódica, los condenados pasaron por un proceso de sufrimiento metódico basado en la supuesta falta de humanidad de los mismos. (p. 186)

La expresión máxima del pensamiento anclado en la subjetividad individual es el proyecto cartesiano, al cual nos hemos referido en varios de los capítulos anteriores y al que uno de los autores revisados, Gilbert Ryle, cuestiona por razones diversas a la postura del giro decolonial de los estudios culturales y, como vimos, derroca su intelectualismo y el dualismo mente-cuerpo (ver capítulo III) para defender su posición de la teoría como resultado de una actividad, no de algo llamado mente. Pero Maldonado-Torres incluye otros intentos fallidos de trascender la razón moderna, como la fenomenología de Husserl y sus discípulos. De ellos, hemos mencionado, en la “Introducción”, a Levinas (2004) y a Gadamer (1983), y vale situar aquellas afirmaciones con relación al giro decolonial.

Rescatábamos de Levinas su crítica a la ciencia y al pensamiento teórico (al que considera una forma de conciencia, la conciencia teórica) porque se despliega según los mecanismos de las ciencias naturales, los cuales resultan limitados para comprender otras regiones del ser. Su crítica al pensamiento teórico, en este tramo, es ontológica, no histórica, y parte de la diversidad de las regiones del ser que no pueden ser atendidas a partir de la teoría naturalista que permea la ciencia. Pero Levinas incluye una nueva categoría en la que se muestra el ser de manera privilegiada: lo vivido, cuyo acceso no es total para la conciencia teórica. Así, "el modo de la conciencia o de la representación a través del cual entramos en contacto con el ser es 


\section{8}

un acto con una estructura determinada; es... la intuición” (2004, p. 93). La intuición posee el objeto, en tanto que la intención significativa (comprender mediante símbolos y significados) tiende a él... (p. 93 y ss.). Respecto a Gadamer, mencionábamos que la certeza fenomenológica no proviene del método sino de la autoconciencia que revelan puntos de apertura al otro (1983, pp. 37-39). La certeza es la confianza que surge de la inmediatez del propio cuerpo. Tanto Levinas como Gadamer, si bien plantean formas de conciencia individual abiertas a lo vivido, al otro desde la propia corporalidad que plantean horizontes al pensamiento más allá de los límites de la ciencia y del método, esos elementos no pasan de la experiencia subjetiva y no dejan de ser formas de conciencia individual de la experiencia vivida de la propia corporalidad que no remiten a experiencias históricas colectivas vividas por cuerpos colonizados, por los cuerpos de los esclavos y los cuerpos de las mujeres.

El giro decolonial de los estudios culturales latinoamericanos, a partir de Césaire, propone dos grandes horizontes para la práctica teórica: el horizonte crítico que identifica las formas en que la colonialidad com-pone las relaciones entre las personas, la economía, las subjetividades, la relación con la naturaleza, con el género, etc., a la vez que im-pone sus patrones; y el horizonte de disputar, reconocer y plantear nuevas formas, o formas otras de vivir juntos, decolonizantes (porque la colonialidad lo abraza todo). Como afirma Walsh,

son estos momentos complejos de hoy que provocan movimientos de teorización y reflexión, movimientos no lineales sino serpentinos, no anclados en la búsqueda o proyecto de una nueva teoría crítica o de cambio social, sino en la construcción de caminos — de estar, ser, pensar, mirar, escuchar, sentir y vivir con sentido u horizonte des(s)colonial. (2013, p.16)

Por lo tanto, el giro decolonial propone un horizonte de pensamiento marcado por lo existencial y enmarcado en un proyecto 
político que impulsa el pensar y actuar de múltiples maneras desde la opción por las existencias colectivas diferenciadas. Ese horizonte es distinto al metodológico, que conduce el pensamiento según ciertas reglas del juego de carácter lógico y procedimental; es también diverso al horizonte ontológico subjetivo, que revisamos en Levinas y Gadamer, que consiste en adecuar las formas de pensar con las distintas regiones del ser y de la subjetividad.

Desde el horizonte existencial podemos imaginar un tipo de relación distinta de la teoría con los elementos propios de la investigación en el contexto de la ciencia, como el objeto de conocimiento, el método y las técnicas. Lo usual, en la práctica tradicional de la ciencia, consiste en que la teoría preceda la metodología y esta última asume el rol de mediación entre la teoría y la identificación de técnicas, a la vez que de esclarecimiento de las implicaciones y compromisos de la teoría para con la investigación. La teoría propone un marco de trabajo investigativo (framework) que la metodología se encarga de identificar reflexivamente en función del objeto de conocimiento propuesto. Por lo tanto, la secuencia de la ciencia tradicional ordena los elementos de la investigación de la siguiente manera: objeto de conocimiento - teoría - metodología - técnicas de investigación.

Ejercer la práctica teórica desde opciones existenciales que en su diferencia confrontan la colonialidad provoca incluir nuevos elementos de la secuencia y desplazar otros para relacionarlos de distinta manera. En primer lugar, el objeto de conocimiento es desplazado a un lugar secundario y su lugar primario es sustituido por la opción existencial, pues reivindicar una existencia colectiva diferenciada se convierte en el elemento fundante de la secuencia. Este desplazamiento no es un hecho menor y evidencia dos trayectorias muy distintas para el pensamiento teórico: la de pensar para conocer y la de pensar para existir (o pensar para vivir). Así, el dinamismo de la 


\section{0}

práctica teorética se sustrae de la fuerza de gravedad de los intereses de conocimiento absorbidos por las agendas cognitivas del tipo tradiciones de investigación (Imre Lakatos) o programas de investigación (Harry Laudan) que revisamos en el capítulo III.

En segundo lugar, la opción existencial primera confiere a la metodología una mayor densidad y la ubica en un lugar intermedio entre la opción existencial y la teoría, y entre la teoría y las técnicas, porque su rol consiste tanto en clarificar las implicaciones de la opción existencial para el teorizar y el investigar, así como orientar las decisiones teóricas y las técnicas de investigación, de tal forma que no solo constituyan logros cognitivos sino prácticas transformadoras que produzcan por sí mismas reafirmaciones de las existencias colectivas. La nueva secuencia, entonces, se despliega de la siguiente manera: opción existencial - metodología - teoría - metodología - técnicas de investigación.

Finalmente, la perspectiva existencial confiere un nuevo sentido a la metodología y la integra en las pedagogías decoloniales, aquellas formas de pensar, aprendizajes, conocimientos y estrategias atesoradas por los colectivos mediante los cuales pudieron sobrevivir:

Pedagogías entendidas como las metodologías producidas en los contextos de lucha, marginación, resistencia y lo que Adolfo Albán ha llamado "re-existencia"; pedagogías como prácticas insurgentes que agrietan la modernidad colonialidad y hacen posible maneras muy otras de ser, estar, pensar, saber, sentir, existir y vivir-con. (Walsh, 2013, p. 12)

\section{"La teoría nunca será suficiente". Stuart Hall y la práctica teórica como proyecto político}

La posición del jamaiquino Stuart Hall (1932-2014) es muy importante porque tal vez se trate de la reflexión más consistente sobre la teoría desde los estudios culturales entendidos como proyecto 
político. Rastreamos algunos rasgos del teorizar en tres de sus ensayos que constan en la extensa recopilación de su producción titulada Sin garantías (2010) ${ }^{54}$, y enumeramos puntualmente aquellos que nos permiten dialogar y debatir con algunas afirmaciones de los capítulos anteriores.

Hall inscribe la práctica teórica como forma de intervención en el campo de la cultura donde tienen lugar batallas antihegemónicas de larga duración, esto es, en el horizonte de transformaciones profundas e históricas, más allá de la coyuntura. Sus aportes son una sólida invitación a ejercer el pensamiento de manera tal que permita

entender lo que está sucediendo y, especialmente, proporcionar maneras de pensamiento, estrategias de sobrevivencia, y recursos para la resistencia a todos lo que son ahora excluidos en términos económicos, políticos y culturales, de algo que podría llamarse acceso a la cultural nacional. $(2010,28)$

Ubica el teorizar como una faz del trabajo del intelectual orgánico de inspiración gramsciana que disputa sentidos en el terreno de la cultura, campo de batalla de una lucha ideológica por la hegemonía y contra la dominación. En este campo de disputas, por un lado, la práctica teórica es una intervención que hace visibles factores estructurales hegemónicos no evidentes; por otro, alimenta entendimientos para la toma de decisiones y de acción frente a tales estructuras.

La producción teórica de alguna manera está inserta en la producción de lo popular, es una "traducción del conocimiento en la práctica de la cultura" y transcurre de forma tal que "ni el conoci-

54 Estos ensayos son los siguientes: "El surgimiento de los estudios culturales y la crisis de las humanidades" ([1990] 2010, pp. 17-28); "Estudios culturales: dos paradigmas" ([1980] 2010, pp. 29-50) y "Estudios culturales y sus legados teóricos" ([1992], pp. 51-72). 


\section{2}

miento ni la práctica [van] por separado" (Hall, 2010, p. 24). Por ello, el intelectual orgánico interviene en la cultura para convertir lo dado - el sentido común- de inconsciente en consciente al explicitar sus formas de operar al mismo tiempo que traduce ese conocimiento en prácticas que generan un nuevo sentido común, es decir, un conocimiento apropiado y asumido por lo popular, por la cultura popular, en un ciclo abierto de complejidad progresiva ( $\mathrm{p}$. 44). En otro lugar, Hall se refiere al sentido común (en el contexto de su crítica al posmodernismo) de otra manera, pero con relación a que la teoría para volverse popular debe atravesar y negociar los códigos "de las masas populares", para poder conformar posibilidades de transformación y de confrontación contra las fuerzas dominantes, aunque siempre en tensión con el sentido común y con una cierta inadecuación que empuje los cambios hacia adelante:

Para que algo se vuelva popular se necesita una lucha. Esto nunca es un proceso simple, como Gramsci nos lo recordaba. No es algo que simplemente suceda. Y esto significa que siempre debe haber una distancia entre la conciencia práctica inmediata, o el sentido común de la gente ordinaria, y aquello en que es posible que se convierta. (p. 84)

La práctica teórica así entendida se ejerce en medio de un necesario "forcejeo" —en palabras de Hall (pp. 59 ss.) — que nace de la tensión entre teoría y la práctica con algunas consecuencias que marcan las siguientes señas de identidad del teorizar según el proyecto político de los estudios culturales:

a. Los avances teóricos sin compromisos respecto a proyectos políticos no sirven. El trabajo teórico exquisito o estar en las avanzadas teóricas no salvan de la insignificancia a la hora de responder a las crisis. La pregunta crucial es si tales hallazgos teóricos metodológicos contribuyen a ganar batallas y pueden 


\section{3}

ser insertados "en una comprensión del proyecto histórico/ político más amplio que ahora confronta a la humanidad" (p. 27). La formación de conceptos y el poder de la abstracción no tienen primacía en tanto impliquen eludir la tensión entre lo teórico y lo político. "Las ganancias teóricas nunca serán suficientes" (p. 59).

b. La conexión de la práctica teórica con las emergencias sociales no disminuye el compromiso por la "la ineludible seriedad del trabajo intelectual" que impulsa "a saber más que los intelectuales tradicionales", porque se trata de trabajar en el contexto de una disputa, de una confrontación que nos exige al máximo (p. 63). En esta disputa "no puntúa” la militancia del intelectual que no se inscribe en el trabajo teórico y conceptual.

c. Las teorías que nos generan tensión son mejores que aquellas que nos ayudan a hablar cómodamente: "la única teoría que vale la pena tener es aquella con la que uno tiene que luchar, no aquella de la que uno habla con una fluidez profunda” (p. 54).

d. La práctica teórica debe tener tanta conexión con las emergencias sociales que debe ser capaz de interrumpir su camino para atender las interrupciones que patean la puerta del pensamiento para tensionar y sacudir la teoría y torcer su curso normal. Algunas emergencias sociales causan interrupciones que provocan transformaciones teóricas (p. 59) como, por ejemplo, el feminismo.

e. La práctica teórica está tensionada también por la comunicación de conocimientos, en sí misma una función intelectual distinta a lo que hoy conocemos como difusión de la ciencia, pues el intelectual orgánico "no se puede absolver de la responsabilidad de la transmisión de esas ideas, ese conocimiento, a través de la función intelectual, a quienes no pertenecen profesionalmente a la clase intelectual" (p. 56). 


\section{4}

Este primer esbozo de solo algunos rasgos de la práctica teórica, según la entiende Hall, da pie para retomar algunas posturas revisadas en el libro. Por de pronto, Hall propone la práctica teórica como algo distinto a la teoría de la práctica de Pierre Bordieu (1977) y su relectura hace posible impulsar el trabajo intelectual para "movilizar todo lo que podemos encontrar en términos de recursos intelectuales para entender qué es que sigue haciendo las vidas que vivimos, y las sociedades en que vivimos, profundamente antihumanas" (Hall, 1992, p. 17, citado en Walsh, 2013, p. 17).

Asimismo, si bien Hall se reconoce muy cercano a la escuela del pensamiento crítico de Frankfurt, revisado en el capítulo I, su crítica descentra la figura del intelectual para hacer de la teoría una suerte de traducción en categorías populares al servicio de y en dependencia respecto a las formaciones sociales en las que inscribe su trabajo intelectual. El intelectual, entonces, será un traductor que no podrá absolverse de la tarea de comunicación, lo cual constituye una novedad respecto a la teoría crítica de Frankfurt, que corre el riesgo de encapsularse en la academia y alimenta el peligro de "dar pensando", sin apuntar a la constitución de lo popular como marco de intervención y de negociación semiótica y de sentidos.

La práctica teórica de Hall obliga, por último, a repensar la noción de sentido común que revisamos en el capítulo II y que trasluce el punto de vista de la filosofía de la ciencia, según la cual la teoría sucede en un plano distinto y separado y, si, en todo caso, existen similitudes y conexiones, estas serán de carácter formal. Para Hall, en cambio, la conexión entre teoría y sentido común es mucho más rica y ambos conforman dimensiones distintas de un mismo ciclo, según el cual el sentido común es la apropiación de la teoría por los movimientos o formaciones sociales. No existe práctica teórica sin la modelación del sentido común pues se trata de conocimientos asu- 


\section{5}

midos en las prácticas sociales y que generan nuevas aproximaciones desde esas mismas prácticas.

Tal opción cambia la noción de productividad o ganancia teórica más allá de cualquier narrativa del progreso o de cualquier posición que defina el avance de la ciencia en términos de progreso conceptual, como afirmaba Laudan en el capítulo III, parar quien las credenciales de la teoría consisten en exhibir la mayor lista posible de solución de problemas mejor si son conceptuales antes que los empíricos. Para Hall la práctica teórica cierra algunos problemas, pero más que ganancias teóricas abre nuevos interrogantes y problemas. La ganancia no consiste en la capacidad de "nombrar algo nuevo que no podía decir antes... [sino] sumergirnos en nuevos problemas, nuevos forcejeos" (2010, p. 67). Esas ganancias no otorgan garantías ni seguridades y no ocurren según la lógica problema-solución (como afirma Laudan), sino según un ciclo que va "de problemática en problemática... se gana terreno, pero siempre inestable" (p. 67). 

Appadurai, A. (1996). La modernidad desbordada. Dimensiones culturales de la globalización. Montevideo, Buenos Aires: Trilce y Fondo de Cultura Económica.

Austin, J. (1950). Intelligent Behaviour. A Critical Review of The Concept of Mind. En Times Literary Supplement. Reeditado en Wood, O. y Pitcher, G. (Eds.). (1970). Ryle. A Collection of Critical Essays (pp. 45-51). Nueva York: Anchor Books.

(1982). Cómo hacer cosas con palabras. Barcelona: Paidós.

Berger, P. y Luckmann, T. (2003). La construcción social de la realidad. Buenos Aires: Amorrortu.

Bhabha, H. (2002). El lugar de la cultura. Buenos Aires: Manantial.

Bird, A. (2007). What Is Scientific Progress? Nous, 41(1), pp. 64-89.

Bisquera, R. (1988). Métodos de investigación educativa. Guía práctica. Barcelona: CEAC.

Broekstra, G. (1998). An organization is a conversation. En Grant, D., Keenoy, T. y Oswick, C. (Eds.). Discourse and organization (pp. 152-176). Londres: Sage Publications.

Brooking, A. (1997). El capital intelectual. El principal activo de las empresas del tercer milenio. Barcelona: Paidós.

Bunge, M. (1985). Teoría y realidad. Barcelona: Ariel. (1999). Las ciencias sociales en discusión. Una perspectiva filosófica. Buenos Aires: Sudamericana.

Carrera, P. y Solórzano, F. (Comps.). (2019). La universidad-comuna. Centralidad de la acción comunitaria en la gestión y prácticas universitarias. Quito: Abya-Yala, UPS.

Casanueva, M. (2002). La red teórica de la hibridación mendeliana. En Díez, J. A. y Lorenzano, P. (Eds.). Desarrollos actuales de la metateoría estructuralista. Problemas y discusiones (pp. 231 y ss.). Buenos Aires: Universidad Autónoma de Zacatecas, Universidad Nacional de Quilmes, Universitat Rovira y Virgili.

Castro-Gómez, S. (2007). Decolonizar la universidad. La hybris del punto cero y el diálogo de saberes. En Castro-Gómez, S. y Grosfoguel, R. (Eds.). 


\section{8}

El giro decolonial. Reflexiones para una diversidad epistémica más allá del capitalismo global (pp. 79-91). Bogotá: Siglo del Hombre, Universidad Central, IESCO, Instituto Pensar. (2019). El tonto y los canallas. Notas para un republicanismo transmoderno. Bogotá: Universidad Javeriana.

Césaire, A. (2006). Discurso sobre el colonialismo. Barcelona: Akal.

Chakrabarty, D. (2001). Postcolonialismo y el artificio de la historia: ¿quién habla de los pasados "indios"? En Mignolo, W. (Comp.). Capitalismo y geopolítica del conocimiento. El eurocentrismo y la filosofia de la liberación en el debate intelectual contemporáneo (pp. 133-170). Buenos Aires: Signo.

Chalmers, A. (1987). ¿Qué es esa cosa llamada ciencia? Madrid: Siglo XXI.

Cornford, F. M. (2007). La teoría platónica del conocimiento. Barcelona: Paidós.

Coronil, F. (2000). Listening to the Subaltern: Postcolonial Studies and the Neocolonial Poetics of Subaltern States. En Chrisman, L. y Parry, B. (Eds.). Postcolonial Theory and Criticism (pp. 37-55). Cambridge: The English Association.

Dalla Chiara, M. L. y Toraldo di Francia, G. (2001). Confines. Introducción a la filosofía de la ciencia. Barcelona: Crítica.

Datri, E. y Córdoba, G. (2004). Introducción a la problemática epistemológica. Una perspectiva didáctica de las tensiones en la filosofía de la ciencia. Rosario: Homo Sapiens.

Dennett, D. C. (2005). Reintroduciendo El concepto de lo mental. En Ryle, G. (2005). El concepto de lo mental (pp. 11-23). Barcelona: Paidós.

Descola, P. (2012). Más allá de naturaleza y cultura. Buenos Aires: Amorrortu.

Díaz, E. (Ed.). (1998). Metodología de las ciencias sociales. Buenos Aires: Biblos.

Diez de la Cortina Montemayor, E. (s/f). Semblanza filosófica. http://cibernous. com/autores/popper2/teoria/biografia.html

Díez, J. A. y Lorenzano, P. (2002). La concepción estructuralista en el contexto de la filosofía de la ciencia del siglo XX. En Díez, J. A. y Lorenzano, P. (Eds.). Desarrollos actuales de la metateoría estructuralista. Problemas y discusiones (pp. 13 y ss.). Buenos Aires: Universidad Autónoma de Zacatecas, Universidad Nacional de Quilmes, Universitat Rovira y Virgili.

Díez, J. A. y Lorenzano, P. (Eds.). (2002). Desarrollos actuales de la metateoría estructuralista. Problemas y discusiones. Buenos Aires: Universidad Autónoma de Zacatecas, Universidad Nacional de Quilmes, Universitat Rovira y Virgili.

Díez, J. A. y Moulines, C. U. (1997). Fundamentos de filosofía de la ciencia. Barcelona: Ariel Filosofía.

Donald, M. (1991). Origins of the modern mind. Cambridge: Harvard University Press. 
Dussel, E. (2000a). Ética de la liberación en la edad de la globalización y de la exclusión (3. ${ }^{\mathrm{a}}$ ed.). Madrid: Trotta.

(2000b). Europa, modernidad y eurocentrismo. En Lander, E. (Comp.). La colonialidad del saber: eurocentrismo y ciencias sociales. Perspectivas latinoamericanas (pp. 41-53). Buenos Aires: Clacso.

Eco, U. (1985). Signos, peces y botones. Apuntes sobre semiótica, filosofía y ciencias humanas. En De los espejos y otros ensayos. Barcelona: Lumen.

Egan, K. (2000). Mentes educadas. Cultura, instrumentos cognitivos y formas de comprensión. Barcelona: Paidós.

Escobar, A. (2007). Mundos y conocimientos de otro modo. El programa de investigación de modernidad / colonialidad latinoamericano. En Saavedra, J. L. (Comp.). Educación superior, interculturalidady descolonización (pp. 11-54). La Paz: PIEB, CEUB.

(2011). Epistemologías de la naturaleza y colonialidad de la naturaleza. Variedades de realismo y constructivismo. En por Montenegro, L. (Ed). Cultura y naturaleza. Aproximaciones a propósito del bicentenario de la independencia de Colombia (pp. 50-72). Bogotá: Jardín Botánico de Bogotá José Celestino Mutis.

(2014). Sentipensar con la tierra. Nuevas lecturas sobre desarrollo, territorio $y$ diferencia. Medellín: Unaula.

Espejo, R. (2008). Peirce, la abducción y la investigación científica. Revista Observaciones Filosóficas 6. https://www.observacionesfilosoficas.net/peircelaabduccion.html

Estany, A. (2001). La fascinación por el saber. Introducción a la teoría del conocimiento. Madrid: Crítica.

Fernández, M. E. y Barbosa, S. R. (1996). Tendencias sociales y politicas contemporáneas. Perspectivas y debates (3. $\left.{ }^{\mathrm{a}} \mathrm{ed}.\right)$. Buenos Aires: Docencia.

Ferrater Mora, J. (2009). Diccionario de filosofia (Tomos I-IV). Barcelona: Ariel.

Feyerabend, P. K. (1989). Limites de la ciencia. Explicación, reducción y empirismo. Barcelona: Paidós.

Foucault, M. (2005). Arqueología del saber. México: Siglo XXI.

Gadamer, H.-G. (1993). Elogio de la teoría. Discursos y artículos. Barcelona: Península.

Garcés, F. (2005). De la voz al papel. La escritura quechua del Periódico Conosur Nawpaqman. La Paz: Plural, Cenda. (2009). ¿Colonialidad o interculturalidad? Representaciones de la lengua y el conocimiento quechuas. La Paz: PIEB, UASB-Q. 


\section{0}

(2018). Interdisciplinariedad y pensamiento complejo. En Mulier Sapiens 5(9), pp. 6-21.

(2019). ¡Y qué saben ellos! (Re)flexionando relaciones epistémicas entre cultura, escritura y naturaleza desde el ámbito andino. En Garcés, F. y Bravo, R. (Coords.). Interculturalidad. Problemáticas y perspectivas diversas (pp. 75-121). Quito: Abya-Yala, UPS.

Geertz, C. (1983). La interpretación de las culturas. Madrid: Gedisa.

(2004). Conocimiento local. Ensayos sobre la interpretación de las culturas. Barcelona: Paidós.

Génova, G. (1997). Charles S. Peirce: la lógica del descubrimiento. Cuadernos de Anuario Filosófico 45. Pamplona: Universidad de Navarra.

Gianella, A. (2003). Introducción a la metodología de la ciencia (6. ${ }^{a}$ ed.). La Plata: Universidad Nacional de La Plata.

Gibbons, M., Limoges, C., Nowotny, H., Schwarzman, S., Scott, P. y Trow, M. (1997). La nueva producción del conocimiento. La dinámica de la ciencia y la investigación en las sociedades contemporáneas. Barcelona: Pomares-Corredor.

Goffman, E. (1970). Ritual de la interacción. Buenos Aires: Biblioteca de Ciencias Sociales.

Gordon, L. R. (2013). Decadencia disciplinaria. Pensamiento vivo en tiempos dificiles. Quito: Abya-Yala.

Guha, R. (1997a). Sobre algunos aspectos de la historiografía colonial de la India. En Rivera, S. y Barragán, R. (Comps.). Debates post coloniales. Una introducción a los estudios de la subalternidad (pp. 25-32). La Paz: Historias, Sephis, Aruwiyiri.

(1997b). Prefacio a los estudios de la subalternidad. Escritos sobre la historia y la sociedad surasiática. En Rivera, S. y Barragán, R. (Comps.). Debates post coloniales. Una introducción a los estudios de la subalternidad (pp. 23-24). La Paz: Historias, Sephis, Aruwiyiri.

Habermas, J. (1984). Teoría de la acción comunicativa: complementos y estudios previos. Madrid: Cátedra.

(1986a). Ciencia y técnica como ideología. Madrid: Tecnos.

(1986b). Conocimiento e interés. Madrid: Taurus.

(1996a). La lógica de las ciencias sociales (3. ${ }^{\mathrm{a}} \mathrm{ed}$.). Madrid: Tecnos.

(1996b). Apéndice a una controversia (1963). Teoría analítica de la ciencia y dialéctica. En La lógica de las ciencias sociales (pp. 22-37), (3. $\left.{ }^{\mathrm{a}} \mathrm{ed}.\right)$. Madrid: Tecnos. 
(1996c). Un fragmento (1977): Objetivismo en las ciencias sociales. En La lógica de las ciencias sociales (pp. 453-506), (3. a ed.). Madrid: Tecnos. (1998). Modernidad: un proyecto incompleto. Punto de Vista, 21, 1-9.

Hall, S. (2010). Sin garantías. Trayectorias y problemáticas en estudios culturales. En Restrepo, E. Walsh, C. y Vich, V. (Eds.). Quito: UASB, Envión, Universidad Javeriana - Instituto Pensar.

Hempel, C. G. (2005). La explicación científica. Estudios sobre la filosofía de la ciencia. Barcelona: Paidós.

Hirschberger, J. (1961). Breve historia de la filosofia. Barcelona: Herder.

Hollis, M. (1998). Filosofía de las ciencias sociales. Barcelona: Ariel Sociología.

Horkheimer, M. (1998). Teoría tradicional y teoría crítica. En Teoría crítica (pp. 223-271). Buenos Aires: Amorrortu. (2003). Teoría crítica. Buenos Aires: Amorrortu.

Hulme, P. (1996). La teoría poscolonial y la representación de la cultura en las Américas. En Casa de las Américas XXXVI(202), pp. 3-8.

Ibarra, A. (2002). Estructuralismo y representación científica. En Díez, J. A. y Lorenzano, P. (Eds.). Desarrollos actuales de la metateoría estructuralista. Problemas y discusiones (pp. 117 y ss.). Buenos Aires: Universidad Autónoma de Zacatecas, Universidad Nacional de Quilmes, Universitat Rovira y Virgili.

Ibarra, A. y Mormann, T. (2000). Variedades de la representación en la ciencia y la filosofia. Barcelona: Ariel.

Islas Mondragón, D. (2015). El progreso de la ciencia como resolución de problemas: una defensa de las posturas funcionalistas - internalistas. Valenciana, 8(15), pp. 129-155.

Jameson, F. (1991). El posmodernismo o la lógica cultural del capitalismo avanzado. Barcelona: Paidós.

Jonas, H. (1995). El principio de responsabilidad. Ensayo de una ética para la civilización tecnológica. Barcelona: Herder.

Juncosa Blasco, J. E. (2006). Teorías del conocimiento en experiencias universitarias con movimientos sociales. Un aporte para la carrera de Antropología Aplicada de la Universidad Politécnica Salesiana. (Tesis de maestría inédita en Desarrollo de la Inteligencia y Educación). Universidad Técnica Particular de Loja, Pontificia Universidad Católica del Ecuador. Ibarra. (2013). Epistemología del riesgo y trama de la vida en tres autores de la modernidad crítica: Jonas, Beck y Giddens. Universitas Revista de Ciencias Sociales y Humanas 19, 237-261. 


\section{2}

(2014). Buen Vivir, relacionalidad y disciplina desde el pensamiento de Lewis Gordon y Martin Nakata. Pistas epistémicas decoloniales para la educación superior. Alteridad. Revista de Educación 9(1), 19-34.

Knorr-Cetina, K. (1999). Epistemic cultures: How the Science make Knowledge, Cambridge: Harvard University Press.

Kozlarek, O. (2017). Los retos para una teoría social crítica. Hacia una "crítica poscolonial reconstructiva”. En Sociológica 32(92), pp. 41-68.

Kuhn, T. S. (2006). La estructura de las revoluciones científicas. México: Fondo de Cultura Económica.

Lakatos, I. (1989). La metodología de los programas de investigación científica. Madrid: Alianza.

Lander, E. (1994). La ciencia y la tecnología como asuntos políticos. Límites de la democracia en la sociedad tecnológica. Caracas: Universidad Central de Venezuela.

Laso, S. I. (2004). La importancia de la teoría crítica en las ciencias sociales. Espacio Abierto, 13(3), pp. 435-455.

Latour, B. (2001). La esperanza de Pandora. Ensayos sobre la realidad de los estudios de la ciencia. Barcelona: Gedisa.

Latour, B. y Woolgar, S. (1979). Laboratory Life. The construction of Scientific Facts. Thousand Oaks: Sage Publications.

Laudan, L. (1986). El progreso y sus problemas. Hacia una teoría del crecimiento cientifico. Barcelona: Encuentros.

Lenkersdorf, C. (1999). Los hombres verdaderos. Voces y testimonios tojolabales (2a ed.). México: Siglo XXI.

Levinas, E. (2004). La teoría fenomenológica de la intuición. Salamanca: Sígueme.

Liceaga, G. (2013). El concepto de comunidad en las ciencias sociales latinoamericanas: apuntes para su comprensión. Cuadernos americanos, 145, 57-85.

Lorenzano, C. (2002a). Una reconstrucción estructural de la bioquímica. En Díez, José A. y Lorenzano, P. (Eds.). Desarrollos actuales de la metateoría estructuralista. Problemas y discusiones (pp. 209 y ss.). Buenos Aires: Universidad Autónoma de Zacatecas, Universidad Nacional de Quilmes, Universitat Rovira y Virgili. (2002b). La teoría del gen y la red teórica de la genética. En Díez, J. A. y Lorenzano, P. (Eds.). Desarrollos actuales de la metateoría estructuralista. Problemas y discusiones (pp. 263 y ss.). Buenos Aires: Universidad Autónoma de Zacatecas, Universidad Nacional de Quilmes, Universitat Rovira y Virgili. 
Luria, A. R. (1976). Cognitive development: Its cultural and social foundations. Cambridge: Harvard University Press.

(1979). The making of mind: A personal account of Soviet psychology. Cambridge: Harvard University Press.

Lynch, M. P. (2005). La importancia de la verdad para una cultura pública decente. Barcelona: Paidós.

Lyotard, J. F. (1990). La condición posmoderna. Informe sobre el saber. México: REI.

MacIntyre, A. (2001). Tras la virtud. Barcelona: Ed. Crítica.

Maldonado-Torres, N. (2006). Aimé Césaire y la crisis del hombre europeo. En Césaire, A. Discurso sobre el colonialismo (pp. 173-196). Barcelona: Akal,

Mancuso, H. R. (2001). Metodología de la investigación en ciencias sociales. Lineamientos teóricos y prácticos de semioepistemología. Buenos Aires: Paidós.

Martínez, J. (2015). Conocimiento y comunalidad. En Bajo el volcán, 15(23), 99-112.

Martínez, L. A. (2002). ¿Introducir a las mujeres en la producción científica o lograr la democracia cognitiva? En Vega, S., Cuvi, M. y Martínez, A. Género y ciencia. Los claroscuros de la investigación cientifica en el Ecuador (pp. 13 y ss.). Quito: Abya-Yala.

Maruyama, M. (1980). Mindscapes and Science Theories. Current Anthropologist, 21(5), pp. 589-608.

Mignolo, W. (2005). El pensamiento des-colonial, desprendimiento y apertura: un manifiesto. https://edisciplinas.usp.br/pluginfile.php/146654/mod_resource/content/1/Walter\%20Mignolo\%20-\%20El\%20pensamiento $\% 20$ descolonial $\% 20-\% 20$ desprendimiento $\% 20 y \% 20$ apertura.pdf

Models in Science. Stanford Encyclopedia of Philosophy. (First published Mon Feb 27, 2006; substantive revision Tue Feb 4, 2020). https://plato.stanford. edu/entries/models-science

Morin, E. (1981). El Método I: La naturaleza de la naturaleza. Madrid: Cátedra. (1983). El Método II: La vida de la vida. Madrid: Cátedra. (1988). El Método III: El conocimiento del conocimiento. Madrid: Cátedra. (1992). El Método IV: Las ideas. Su hábitat, su vida, sus costumbres, su organización. Madrid: Cátedra.

(2001). La mente bien ordenada. Barcelona: Seix Barral. (2007). La emergencia del sentido a partir del no-sentido. Convergencia, Revista de Ciencias Sociales 44, 155 y ss.

Moulines, U. (2002). ¿Dónde se agazapa la pragmática en la representación estructural de las teorías? En Díez, J. A. y Lorenzano, P. (Eds.). Desarrollos 


\section{4}

actuales de la metateoría estructuralista. Problemas y discusiones (pp. 99 y ss.). Buenos Aires: Universidad Autónoma de Zacatecas, Universidad Nacional de Quilmes, Universitat Rovira y Virgili.

Muñoz, B. (2005). Modelos culturales. Teorías sociopolíticas de la cultura. Barcelona: Anthropos.

Nagel, E. (1991). La estructura de la ciencia. Barcelona: Paidós.

Nonaka, I. y Takeuchi, H. (1999). La organización creadora de conocimiento. Cómo las compañias japonesas crean la dinámica de la innovación. México: Oxford University Press.

Palladino, E. (2002). La teoría y la práctica. Buenos Aires: Espacio.

Pardo, R. H. (1998). La problemática del método en ciencias naturales y sociales. En Díaz, E. (Ed.). Metodología de las ciencias sociales. Buenos Aires: Biblos.

Peirce, C. S. (1988). El hombre, un signo. (El pragmatismo de Peirce). Barcelona: Crítica.

(1902). Teoría. En Dictionary of Philosophy and Psychology. Nueva York: MacMillan. [Traducción al castellano Rivera Sánchez, M., 2007]. https://www.unav.es/gep/TeoriaPeirceLaddFranklin.html (1903). Cómo teorizar. Traducción castellana de Sara Barrena (2003). https://www.unav.es/gep/ComoTeorizar.html (1904). Qué es el pragmatismo. Traducción castellana de Norman Ahumada (2004). https://www.unav.es/gep/WhatPragmatismIs.html

Pérez Ransanz, A. R. (2000). La concepción semántica de las teorías y el debate sobre el realismo científico. En Ibarra, A. y Mormann, T. (Eds.). Variedades de la representación en la ciencia y la filosofía (pp. 109 y ss.). Barcelona: Ariel.

Popper, K. R. (1973a). La miseria del historicismo. Madrid: Alianza.

(1973b). Lógica de la investigación científica. Madrid: Tecnos.

(1973c). La lógica de las ciencias sociales. En Adorno, T. W. et al. La disputa del positivismo en la sociología alemana (pp. 101-120). Barcelona: Grijalbo. (1994). Post Scriptum a La lógica de la investigación cientifica. Volumen II: El universo abierto. Un argumento a favor del indeterminismo (2. ${ }^{\mathrm{a}} \mathrm{ed}$.). Madrid: Tecnos.

(1995). La responsabilidad de vivir. Escritos sobre política, historia y conocimiento, Barcelona: Paidós.

(1998). En busca de un mundo mejor. Barcelona: Paidós.

(2001). Epistemología sin sujeto cognoscente. En Estany, A. La fascinación por el saber. Introducción a la teoría del conocimiento (pp. 125 y ss.). Madrid: Crítica. 
(2002). Sociedad abierta, universo abierto. Conversación con Franz Kreuzer. Madrid: Tecnos.

(2005). El mito del marco común. En defensa de la ciencia y la racionalidad. Barcelona: Paidós.

(2006). La sociedad abierta y sus enemigos. Barcelona: Paidós.

Pozo, J. I. (2002). Teorías cognitivas del aprendizaje (7. ${ }^{\text {e }}$ d.). Madrid: Morata.

Pratt, M. L. (2010). Ojos imperiales. Literatura de viajes y transculturación. México: Fondo de Cultura Económica.

Quesada, D. (1998). Saber, opinión y ciencia. Barcelona: Ariel Filosofía.

Ribes, D. (1989). Pluralismo teórico y límites de la ciencia. En Feyerabend, P. K. Limites de la ciencia (pp. 9-37). Barcelona: Paidós.

Rivera, S. (1997). Lógica y lenguaje. En Díaz, E. (Ed). Metodología de las ciencias sociales (pp. 31-64). Buenos Aires: Biblos. (2003). Mirando el pasado para caminar por el presente y el futuro (qhip nayr uñtasis sarnaqapxañani). En Oprimidos pero no vencidos (Prefacio a la 4. a ed. en castellano), (pp. 17-72). La Paz: Aruwiyiri, Yachaywasi.

Rivera, S. y Barragán, R. (Comps.). (1997). Debates post coloniales. Una introducción a los estudios de la subalternidad. La Paz: Historias, Sephis, Aruwiyiri.

Ruiz, D. y Del Cairo, C. (2016). Los debates del giro ontológico en torno al naturalismo moderno. Revista Estudios Sociales 55, pp. 193-204. http:// dx.doi.org/10.7440/res55.2016.13

Ryle, G. (2005). El concepto de lo mental. Barcelona: Paidós.

Santos, Boaventura de S. (2000). Crítica de la razón indolente. Bilbao: Desclée de Brouwer.

(1995). De la mano de Alicia. Lo social y lo político en la postmodernidad. Bogotá: Siglo del Hombre y Uniandes.

Sneed, J. D. (1979). The Logical Structure of Mathematical Physics (2. ${ }^{\text {ed. }}$.). Dordrecht: Reidel.

Spencer, H. (1861). Education: Intellectual, moral and physical. Londres: G. Manwaring.

Spivak, G. (1997). Estudios de la subalternidad: deconstruyendo la historiografía. En Rivera. S. y Barragán, R. (Comps.). Debates post coloniales. Una introducción a los estudios de la subalternidad (pp. 247-278). La Paz: Historias, Sephis, Aruwiyiri. (1998). ¿Puede hablar el subalterno? Orbis Tertius 3 (Número especial), p. 6.

T. S. Kuhn. (2006). La Estructura de las Revoluciones Cientificas. México: Fondo de Cultura Económica.

Ureña, E. M. (1998). La teoría crítica de la sociedad de Habermas. Madrid: Tecnos. 


\section{6}

Van Fraassen, B. C. (1996). La imagen científica. México: Paidós.

Vattimo, G. (2000). Posmoderno. ¿Una sociedad transparente? En Arditi, B. (Ed.). El reverso de la diferencia. Identidad y politica (pp. 15-22). Caracas: Nueva Sociedad.

Viveiros de Castro, E. (2004). Perspectivismo e multinaturalismo na América indígena. O que nos faz pensar 18, pp. 225-254.

Vygotsky, L. (1962). Thought and language. Cambridge: MIT Press. [Traducción al castellano Pensamiento y lenguaje. Barcelona, Paidós, 1995].

Wallerstein, I. (2004). Capitalismo histórico y movimientos antisistémicos. Un análisis del sistema mundo. Barcelona: Akal. (Coord.). (2006). Abrir las ciencias sociales. Informe de la Comisión Gulbenkian para la reestructuración de las ciencias sociales (9a ed.). México: Siglo XXI.

Walsh, C. (2005). Introducción: (Re)pensamiento crítico y (de)colonialidad. En Walsh, C. (Ed.). Pensamiento crítico y matriz (de)colonial. Reflexiones latinoamericanas (pp. 13-35). Quito: UASB, Abya-Yala. (2007a). ¿Es posible unas ciencias sociales/culturales otras? Reflexiones en torno a epistemologías decoloniales. Nómadas 26, pp. 102-113.

(2007b). Interculturalidad y colonialidad del poder: un pensamiento y posicionamiento otro desde la diferencia colonial. En Saavedra, J. L. (Comp.). Educación superior, interculturalidad y descolonización (pp. 175-213). La Paz: PIEB, CEUB.

(2013). Pedagogías decoloniales. Prácticas insurgentes de resistir, (re)existir $y$ (re)vivir. Quito: Abya-Yala.

Wellmer, A. (1966). Metodología como teoría del conocimiento. La ciencia en Karl Popper (Tesis doctoral). Universidad de Fráncfort, Fráncfort.

Wittgenstein, L. (2008). Investigaciones filosóficas. Barcelona: Crítica.

Zamora Bonilla, J. (2001). Guía bibliográfica conceptual de historia y filosofia de la ciencia. Madrid: Sociedad de Lógica, Metodología y Filosofía de la Ciencia en España.

Zima, Pierre V. (1973). Theodor W. Adorno, Walter Benjamin, Erich Fromm, Max Horkheimer, Herbert Marcuse. La escuela de Frankfurt. Barcelona: Galba. 
La teoría integra el sentido común académico y se ejerce en la cátedra universitaria casi siempre sin reparar en su condición de realidad abstracta sujeta a continuas discusiones y transformaciones. Para dar cuenta de su carácter problemático y problematizable, los autores afrontan dos preguntas: ¿qué es una teoría?, ¿en qué consiste teorizar? En la búsqueda de respuestas, recorren, con rigor y detalle, los aportes más significativos provenientes tanto de la filosofía de la ciencia y la epistemología como de los estudios culturales y el diálogo de saberes.

La trayectoria lograda ratifica que la teoría se despliega de modos diversos atravesada por la permanente tensión entre pensar para conocer y pensar para vivir en colectivo; tiene vida más allá de la lógica investigativa y se constituye en práctica teórica cuando se inserta en proyectos políticos. Redactada para contribuir a la docencia universitaria, la obra apunta a fomentar puntos de encuentro y conversación entre docentes, investigadores y estudiantes de todas las áreas del conocimiento ofreciéndoles la posibilidad de nombrar sus propias praxis teóricas situándolas en medio de otras posibles.
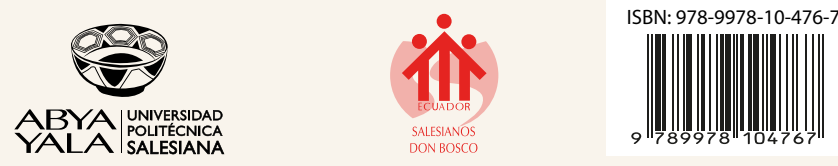